DECLASSIFIED

\title{
HANFORD LABORATORIES MONTHLY ACTIVITIES REPORT APRIL, 1963
}

MAY 15, 1963

HANFORD ATOMIC PRODUCTS OPERATION RICHLAND, WASHINGTON 


\section{LEGAL NOTICE}

This report was prepared as an account of Government sponsored work. Neither the United States, nor the Commission, nor any person acting on behalf of the Commission:

A. Makes any warranty or representation, expressed or implied, with respect to the accuracy, com. pleteness, or usefulness of the information contained in this report, or that the use of any information, apparatus, method, or process disclosed in this report may not infringe privately owned rights; or

B. Assumes any liabilities with respect to the use of, or for damages resulting from the use of any information, apparafus, method, or process disclosed in this report.

As used in the above, "person acting on behalf of the Commission" includes any employee or contractor of the Commission, or employee of such contractor, to the extent that such employee or contractor of the Commission, or employee of such contractor prepares, disseminates, or provides access to, any information pursuant to his employment or contract with the Commission, or his employment with such contractor. 


\section{DECLASSIFIED}

$\mathrm{HW}-77397$

This document consists of 206 pages. Copy No. of copies. Series

HANFORD LABORATORIES

MONTHLY ACTIVITIES REPORT

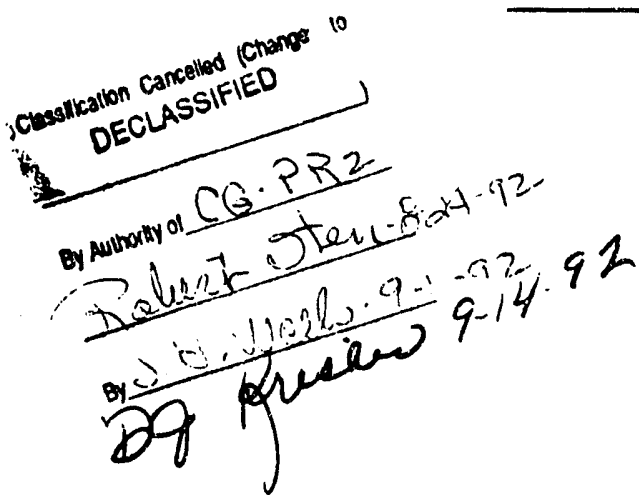

APRIL 1963

Compiled by

Section Managers

May 15, 1963

\section{HANFORD ATOMIC PRODUCTS OPERATION RICHLAND, WASHINGTON}

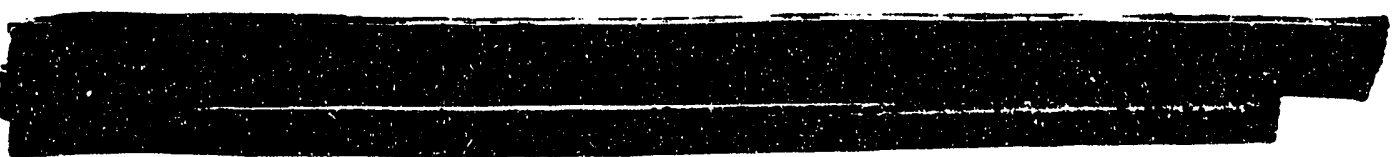

PRELIMINARY REPORT

This report was prepared only for use within General Electric Company in the course of work under Atomic Energy Commission Contract $A T(45-1)-1350$. Any views or opinions expressed in the report are those of the author only.

\begin{tabular}{l|l|l|l|l}
\hline Route To: & P. R. No. & Location & Route Date & Signature and Date \\
\hline & & & & \\
\hline & & & & \\
\hline
\end{tabular}




\section{DISTRIBUTION}

Copy Number

$\begin{aligned} 1 & \text { W. E. Johnson } \\ 2 & \text { H. M. Parker } \\ 3 & \text { F. W. Albaugh } \\ 4 & \text { C. A. Bennett } \\ 5 & \text { F. E. Crever, GEAPD } \\ 6 & \text { I. H. Dearnley } \\ 7 & \text { W. E. Foust } \\ 8 & \text { P. F. Gast } \\ 9 & \text { A. R. Keene } \\ 10 & \text { H. A. Kornberg } \\ 11 & \text { R. S. Paul } \\ 12 & \text { W. H. Reas } \\ 13 & \text { W. D. Richmond } \\ 14 & \text { W. Sale } \\ 15 & \text { H. P. Shaw - W. S. Frank } \\ 16 & \text { W. K. Woods } \\ 17-20 & \text { Atomic Energy Commission, Richland Operations Office } \\ & \text { Attn: J. E. Travis } \\ 21-23 & \text { F. P. Baranowski, Director, Division of Production } \\ 24 & \text { Washington 25, D. C. } \\ 25 & \text { Savannah River Operations Office, Aiken, South Carolina } \\ 26 & \text { 300 Files } \\ & \text { Record Center }\end{aligned}$




\section{TABLE OF CONTENTS}

Force Report and Personnel Status Changes . . . . . . iv

General Summary

Manager, H. M. Parker . . . . . . v through xxix

Reactor and Fuels Laboratory

Manager, F. W. Albaugh . . . . . A-1 through A-65

Physics and Instruments Laboratory

Manager, R. S. Paul . . . . . . B-1 through B-35

Chemical Lahoratory

Manager, W. H. Reas . . . . . C -1 through C-23

Biology Laboratory

Manager, H. A. Kornberg . . . . . D-1 through D-12

Applied Mathematics Operation

Manager, C. A. Bennett . . . . . E-1 through E-5

Programming Operation

Manager, W. K. Woods . . . . . F-1 through F-6

Radiation Protection Operation

Manager, A. R. Keene . . . . . G-1 through G-10

Finance and Administration Operation

Manager, W. Sale . . . . H-1 through H-13

Test Reactor and Auxiliaries Operation

Manager, W. D. Richmond . . . . I-1 through I-7

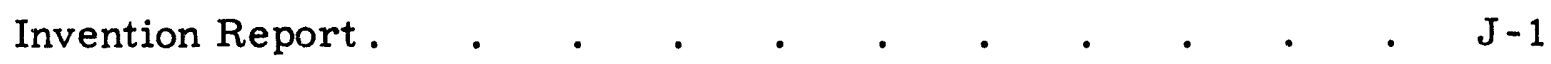




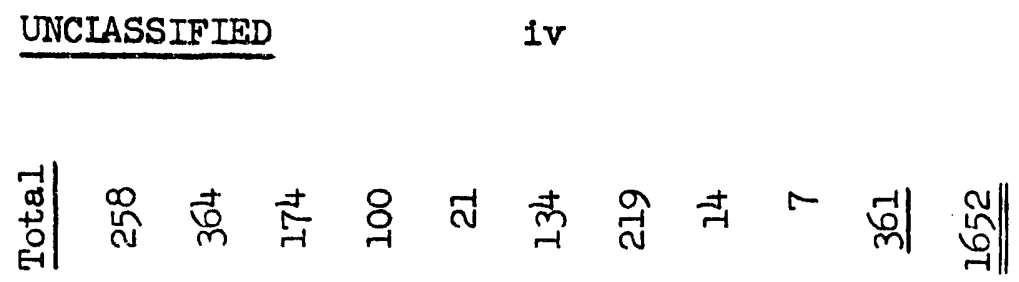

HW-77397

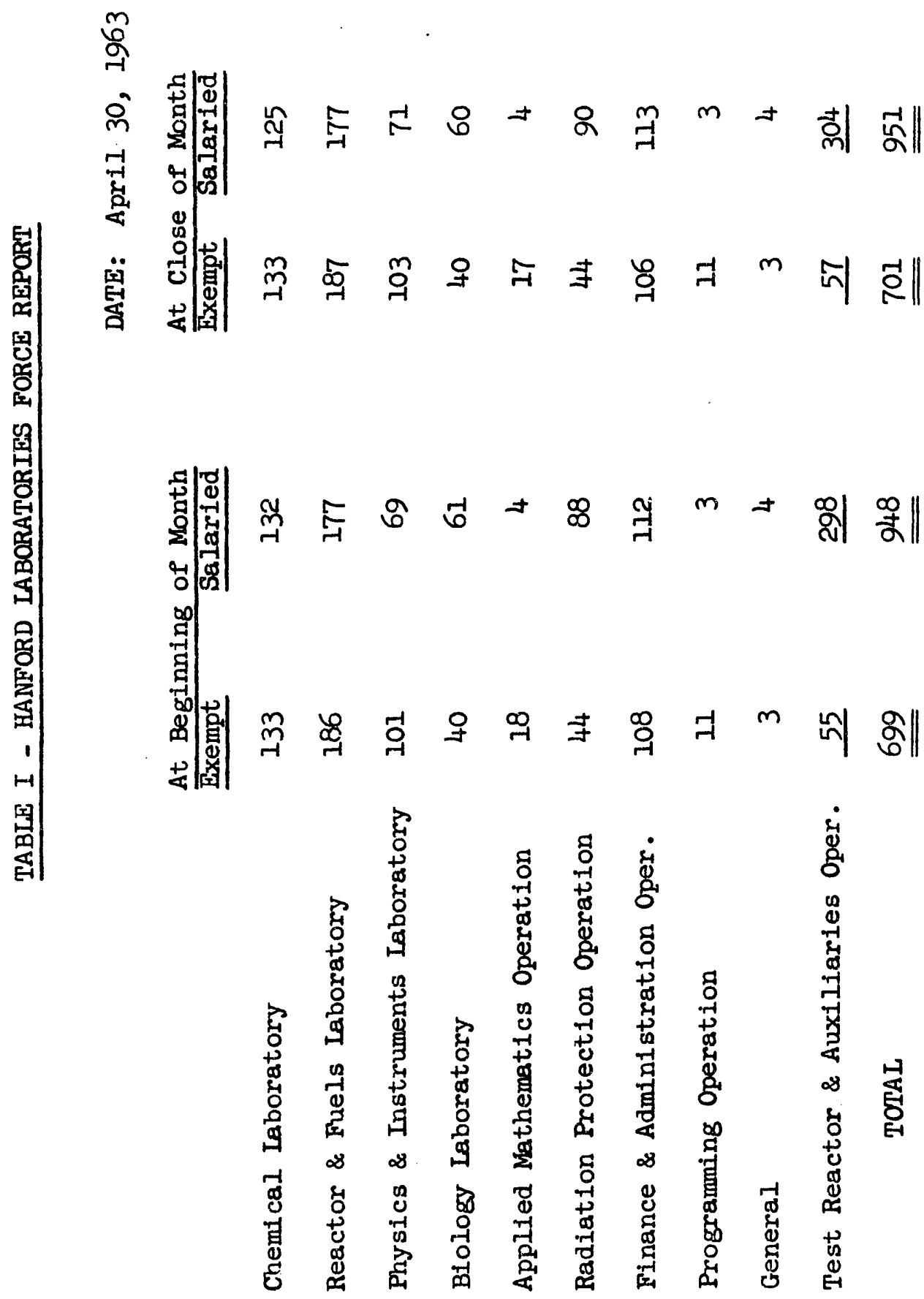

UNCLASS IFIED 


\section{BUDGET AND COST SUMMARY}

April operating costs totaled $\$ 2,553,000$, an increase of $\$ 73,000$ over the previous month; fiscal year-to-date costs are $\$ 23,709,000$ or $77 \%$ of the $\$ 30,857,000$ control budget. Hanford Laboratories' research and development costs for April compared with last month and the control budget are shown below:

(Dollars in thousands)

HL Programs 02 Program 03 Program 04 Program 05 Program 06 Program 08 Program

NRD Sponsored IPD Sponsored CPD Sponsored FPD Sponsored Total

\begin{tabular}{rr}
\hline $\begin{array}{c}\text { Current } \\
\text { Month }\end{array}$ \\
\hline \\
\\
$\$ \quad 87$ \\
27 \\
1012 \\
128 \\
254 \\
21 \\
\hline 1529 \\
186 \\
70 \\
96
\end{tabular}

$\$ 1881$ $\cos \mathrm{T}$

$\begin{array}{cc}\begin{array}{c}\text { Previous } \\ \text { Month }\end{array} & \begin{array}{c}\text { FY } \\ \text { To Date }\end{array} \text { Budget } \\ \text { Spent }\end{array}$

\begin{tabular}{|c|c|c|c|}
\hline $\begin{array}{r}\$ \quad 70 \\
24 \\
1026 \\
132 \\
241 \\
16 \\
\end{array}$ & $\begin{array}{rr}\$ \quad 745 \\
& 118 \\
9 & 768 \\
1 & 064 \\
2567 \\
\\
& 57 \\
\end{array}$ & $\begin{array}{r}\$ 1069 \\
175 \\
12718 \\
1353 \\
3154 \\
\\
97\end{array}$ & $\begin{array}{l}70 \\
67 \\
77 \\
79 \\
81 \\
59\end{array}$ \\
\hline $\begin{array}{r}1509 \\
180 \\
59 \\
111 \\
--\end{array}$ & $\begin{array}{r}14319 \\
903 \\
766 \\
1167 \\
493\end{array}$ & $\begin{array}{r}18566 \\
1270 \\
932 \\
1421 \\
493\end{array}$ & $\begin{array}{r}77 \\
71 \\
82 \\
82 \\
100\end{array}$ \\
\hline$\$ 1859$ & $\$ 17648$ & $\$ 22682$ & $78 \%$ \\
\hline
\end{tabular}

RESEARCH AND DEVELOPMENT

\section{Reactor and Fuels}

The effects of several hundred ppm phosphorus impurity in uranium on the uranium structure, clad to core bonds, braze to core bonds, and fabrication have been experimentally studied. No detrimental effects have been observed to date.

Volume increase resulting from grain boundary tearing in uranium under irradiation is being studied in Hanford I\&E fuel elements. Test elements irradiated to $1000 \mathrm{Mwd} /$ ton with a maximum fuel temperature of $400 \mathrm{C}$ have shown no visual changes; irradiation is being continued. 


\section{DECLASSIFIED}

vi

HW -77397

Fluted, single-tube $\mathrm{N}$-Reactor fuel elements designed to accommodate substantial swelling of uranium are now in their third cycle of irradiation in the ETR. An N inner-size fluted element has sustained a $3 \%$ volume increase without difficulty and is being further irradiated.

Clad thinning is being studied in a series of Zircaloy-2 clad uranium rods being irradiated in $\mathrm{NaK}$ capsules. Nine capsules have been discharged at $1100 \mathrm{Mwd} /$ ton for examination to determine irradiation goals for the remaining capsules.

Design studies of shaped end caps for $\mathrm{N}-$ Reactor fuel element closures indicate that a major reduction in stress levels can be obtained with properly contoured end caps.

The exposed braze layer of a self-brazed closure has withstood 100 days of exposure in a high temperature test loop without apparent attack. Two lots of elements with self-brazed closures for an N-Reactor production test are in the final stages of preparation.

Further development of the hot-headed closure has virtually eliminated the previously existing joint crevice; the immersion copper plating procedure has been improved; and the four ring projection weld cap has produced sound welds with bonded interfacial areas.

Damage to $\mathrm{N}$-Reactor process tubes by wear of fuel element supports after five simulated charging operations (with intervening autoclaving between each charging operation) has scratched tubes to a maximum depth of 1.7 mils. Average wear for the last scratching cycle was 0.3 mil. Wear occurred only after deliberately starting the scratching process.

Multiproduct fuel element development is proceeding with the fabrication of 21 experimental lithiurn-aluminum target cores jacketed in aluminum. Eleven of these are being directly canned in Zircaloy -4 and the remaining 10 will be anodized before Zircaloy -4 canning. 
Test fabrication of $\mathrm{N}$-Reactor fuel element supports continued; substantial amounts of this work will be transferred to NRD in the near future.

A high temperature induction furnace is being operated at temperatures in excess of $3000 \mathrm{C}$ using a newly designed magnetic flux concentrator.

A Zircaloy-z clad heater rod assembly exposed to simulated $\mathrm{N}$-Reactor coolant at a heat flux of $280,000 \mathrm{Btu} /(\mathrm{hr})\left(\mathrm{ft}^{2}\right)$ for 143 days showed extensive corrosion and oxide scale formation in crevices.

The first instances of significant crud deposition on Zircaloy-clad fuel elements operating in high $\mathrm{pH}$ water were noted in recent KER tests 1 and 2. These depositions may be related to off-standard water quality or recently cleaned loops.

No effect of heat treatment on the corrosion of Zircaloy-2 exposed to $360 \mathrm{C}, \mathrm{pH} 10$ ( $\mathrm{LiOH})$ deoxygenated water was observed after 2 weeks of exposure. However, it was noted that the pretransition hydrogen pickup fraction was higher for beta than alpha heat treated samples.

Testing of $\mathrm{NH}_{4} \mathrm{OH}$ as a substitute for $\mathrm{LiOH}$ for $\mathrm{pH}$ control in $\mathrm{N}$-Reactor continued. In out-of-reactor tests, corrosion rates of $\mathrm{N}$-Reactor coolant system structural materials were no greater in $\mathrm{NH}_{4} \mathrm{OH}$ treated water than in LiOH treated water at $\mathrm{pH} 10$.

Studies to evaluate fretting tendencies of $\mathrm{N}$-Reactor fuel elements continued; different spring supports and external vibration frequencies were used.

Evaluation of the Hays dissolved oxygen analyzer with influent streams containing dissolved oxygen and hydrazine demonstrated that the analyzer can measure oxygen concentration accurately when hydrazine is present. This instrument will be used on $\mathrm{N}$-Reactor water.

A newly developed decontamination procedure, the use of alkaline permanganate followed by sulfamic acid, was recommended for decontariination of an ETR loop and performed well. 
To quicken rupture, stress rupture tests on $\mathrm{N}$-Reactor process tube sections have recently been conducted at temperatures up to $400 \mathrm{C}$. The Larson-Miller parameter was then used to estimate time to rupture at lower temperatures for the same stress level. By this means, a rupture time of 20 years may be predicted for $30 \%$ cold-worked $\mathrm{N}$-Reactor tubing at $300 \mathrm{C}$ and a hoop stress of $48,000 \mathrm{psi}$. Operating $\mathrm{N}$-Reactor loop stress is only about 12,000 psi.

The effects of high flow rates of water on aluminum have been simulated by spinning aluminum discs in water at velocities up to $72 \mathrm{fps}$. Substantial erosion-corrosion attack is achieved at the outer perimeter of discs in $95 \mathrm{C}, 300$-Area water. Definite changes in the type of attack are observed on introduction of dichromate.

Monitoring of graphite in KW-Reactor from December 1962 to April 1963 disclosed the very low average burnout rate of $1.5 \%$ per 1000 operating days at positions $n$ the reactor normally associated with peak burnout rates.

Prelimina $y$ information has been obtained from analog and digital computer programs which shows the expected gas composition for a reactor traverse as a function of entry composition. The calculated values of initial water content for burnout rates of 2, 3, and 4\% per 1000 operating days were, respectively, $0.47,0.71$, and $0.94 \mathrm{~mm}$.

Capsule $\mathrm{H}-5-2$ of the $\mathrm{N}-$ Reactor graphite long term irradiation series was iemoved from the GETR after 5 cycles of irradiation. Cumulative exposure, estimated at $5 \times 10^{21}$ nvt ( $\left.E>0.18 \mathrm{Mev}\right)$, has been obtained on some of the samples. Sample H-4-3 was installed in the reactor and sample H-6-2 continues to operate satisfactorily.

Flow tests to determine the effect of a broken spline lodged in a $\mathrm{K}$-Reactor outlet nozzle were performed. Tests indicated that the use of the perforated plate to cover the collection channel leading to the nozzle elbow would decrease the pressure drop across the nozzle if a broken spline becomes lodged over the outlet channel. 
Empirical correlations which describe much of the boiling burnout experiments on the $\mathrm{N}$-Reactor fuel element obtained in the Heat Transfer Laboratory have been formulated. The accuracy of these correlations is generally $\pm 10 \%$ over the range of conditions considered.

Improvement of the MAC computer code for solving shielding attenuation problems has begun. This will correct minor discrepancies and ultimately simplify input-output so that the code may be more widely used.

Design and fabrication of the PRTR second generation mechanical shim rod continued. A new first-generation PRTR shim rod has been operated in the environmental test facility for 11 days. Coasting of the single control element has been observed during testing.

Corrosion coupons placed in the secondary side of the main steam generator ( $\mathrm{HX}-1)$ of PRTR in June 1961 have been periodically examined since their installation. There are no indications of cracks or local corrosion on AISI 304 SS specimens. Carbon steel coupons corrode initially in a relatively rapid manner, but subsequent corrosion is minor. Pitting up to 8 mils deep has been observed on carbon steel.

The first $\mathrm{UO}_{2}-\mathrm{PuO}_{2}$ fuel cluster containing recycled PRTR plutonilim was completed and another is in process.

Conditions were determined for producing uniform physical mixtures of $\mathrm{UO}_{2}-\mathrm{PuO}_{2}$ in fuel rods by bottle loading. Good linear correlation was found between a gamma scan of a $\mathrm{UO}_{2}-\mathrm{PuO}_{2}$ fuel rod and known plutonium concentrations in the rod.

Specifications were written for off-site fabrication of the top and bottom end brackets of the PRTR 19-rod clusters.

Destructive examination of a concentric tubular PRTR $f$ lel element after $1360 \mathrm{Mwd} /$ ton $_{U}$ indicated that internal gas pressure should cause no problem on exposure to design exposure level. 
Destructive examination of two vibrationally compacted $\mathrm{UO}_{2}-\mathrm{PuO}_{2}$, PRTR Mark I elements that failed during operation revealed brittle Zircaloy-2 fracture and loss of a small plug of Zircaloy-2 in each case. The failures seem associated with cladding faults rather than with fuel cladding interactions, plutonium segregation, or local overheating of the cladding.

Routine examination of PRTR test element 1082 (hot swaged $\mathrm{UO}_{2}$ ) in the FEEF disclosed a severe longitudinal scratch on an outer fuel rod. The element will be refurbished by removing the outer wire wrap, replacing the scratched rod, and installing circumferential wire bands. Inspection and ring gaging of fuel elements in the PRTR basin indicates 10 to $20 \%$ of the elements need some type of maintenance. Bent pins and white corrosion spots are the most common difficulties.

Work started on installaticr of ndditional vibrational compaction facilities for fabrication of EBWR int. Performance of the double can container assembly being developed for impaction of $\mathrm{UO}_{2}-2.5 \mathrm{wt} \% \mathrm{PuO}_{2}$ for EBWR was improved by inserting a mild steel oxygen getter between the inner and outer cans. Test capsules containing high-energy-rate impacted $\mathrm{UO}_{2}-\mathrm{PuO}_{2}$ were prepared for irradiation at power generations prototypic of EBWR fuel rods. Two capsules containing the first high-energy-rate impacted $\mathrm{UO}_{2}-\mathrm{PuO}_{2}$ were successfully irradiated in the MTR to $\sim 1000$ $\mathrm{Mwd} /$ ton $_{\text {fuel }}$ at surface heat fluxes $\sim 900,000 \mathrm{Btu} /(\mathrm{hr})\left(\mathrm{ft}^{2}\right)$.

Continued out-of-reactor tests (47 days at PRTR coblant conditions) of a ring-contact end fixture on a PRTR Mark I fuel element caused no wear or fretting corrosion.

Essentially no grain growth was observed in magnetic force resistance welds on bexyllium supplied by France and Oak Ridge.

High density ( $>99 \% \mathrm{TD}$ ) $\mathrm{UO}_{2}-25 \mathrm{wt} \% \mathrm{PuO}_{2}$ was produced by arc-melting pressed pellets under 1 atm of argon. 
High-energy-rate impaction techniques were used to impact specimens of PuN, PuN-W cermet, and $\mathrm{PuO}_{2}$. This is the first time it has been possible to produce high density PuN without Pu metal inclusions.

Approximately $60 \%$ loss of material occurred during heating of PuN50 vol\% AlN pellets in flowing helium for 12 hours at $1700 \mathrm{C} . \mathrm{PuO}_{2}-50$ vol\% AIN pellets lost about 25\% of their mass after heating in helium for 8 hours at $1600 \mathrm{C}$.

Seleciive loss of plutonium from molten UC-2 wt\% PuC was observed. The electrical resistivity of 37.2 at. \% C, arc-cast PuC abruptly decreases at temperatures of 500 to $550 \mathrm{C}$.

Four test capsules containing various geometrical combinations of 1/2-inch diameter single and polycrystalline $\mathrm{UO}_{2}$ pellets were discharged after irradiation to $\sim 1000 \mathrm{Mwd} /$ ton $_{\text {fuel }}$ at surface heat fluxes of $\sim 800,000$ $\mathrm{Btu} /(\mathrm{hr})\left(\mathrm{ft}^{2}\right)$.

Single crystal $\mathrm{UO}_{2}$ was found to be significantly more transparent than polycrystalline $\mathrm{UO}_{2}$ in the infrared at wavelengths greater than $1.0 \mu$.

$\mathrm{UO}_{2}$ single crystal spheres and $30 \mathrm{~kg}$ of high-energy-rate impacted $\mathrm{UO}_{2}$ were prepared and characterized for shipment to Euratom.

Uranium metal shot and phosphorous were reacted to produce uranium plıosphide. Preliminary data indicate a melting point of $1900 \pm 50 \mathrm{C}$.

Dense aluminum nitride, AlN, was formed by high-energy-rate impaction. Four-inch diameter, solid cermet discs approximately 1 inch thick were fabricated for use as mechanical property sainples. A $\mathrm{UO}_{2}{ }^{-}$ tungsten cermet with only a very small amount of the metal phase was formed by impaction of tungsten coated $\mathrm{UO}_{2}$ particles. A technique for the encapsulation of cermets simultaneously with the impaction of the cermet was developed. Six cermet fuel specimens, two Mo-UO 2 and two Mo-UN cermets clad in Mo, and one $\mathrm{W}-\mathrm{UO}_{2}$ and one $\mathrm{W}-\mathrm{Un}$ cermet clad in W, were fabricated for irradiation at NRTS.

\section{DECLASSIFIED}

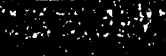




\section{DECLASSIFIED}

Stactint

xii

$\mathrm{HW}-73397$

Work continued on four different plutonium fuels for special test purposes. Over 100 fuel rods were made involving extrusion, coextrusion, and pelletizing fabrication processes.

An 800 psi tensile loaded graphite creep sample was installed ir ETR and is operating successfully.

The low exposure irradiation testing at 320 and $540 \mathrm{C}$ of graphite containing boron carbide showed damage greatly exceeding that expected for unboronated graphite, an effect undoubtedly arising from irradi un effects of the $n$, alpha reaction on boron.

The irradiation induced decomposition of carbon monoxide was studied at $550 \mathrm{C}$ and under pressures ranging from 1 to $18 \mathrm{~atm}$. The overall stoichiometry was $5 \mathrm{CO} \rightarrow 2 \mathrm{CO}_{2}+$ solids which are believed to be carbon suboxides.

Electron microscopic examination of graphite, made from natural flake filler and coal tar pitch binder, before and after irradiation disclosed a structure not observed in coke graphite.

For the first time in Hanford tests, aluminum coupons exposed at high temperature conditions ( $\mathrm{H}-1$ Loop at $290 \mathrm{C}, \mathrm{pH} 7.9$ ) for 45 days showed about $50 \%$ lower in-reactor corrosion rates than the out-of-reactor control pieces, probably due to the deposited crud film. The corrosion rates of the out-of-reactor samples appeared to be velocity-dependent and were high (1-3 mils/month) as would be expected in water at this $\mathrm{pH}$.

An increase in the $\Delta \mathrm{T}$ of deionized water, from 8 to $61 \mathrm{C}$, as it circulates through an out-of-reactor nonisothermal loop has increased aluminum corrosion up to a factor of 2 . The maximum effect was observed with upstream samples; downstream samples in the specimen holder were little affected by the temperature drop across the system.

Oxidation studies of Hastelloy-C in $1000 \mathrm{C}$ air and $25 \mathrm{~mm} \mathrm{O}_{2}$ indicate the rate of weight gain is initially pressure dependent but becomes independent of oxygen pressure after about 10 hours. 
Pipe sections in the as-received, strained, and ruptured conditions were heated to $2100 \mathrm{~F}$ with an alternating current through the pipe length to determine the effects of strained conditions on temperature uniformity. Initial test resuits indicate that temperatures were uniform in all three conditions. Pipe resistance to the flow of electrical current may prove to be a quick, simple, and relatively inexpensive way to heat pipe for high temperature burst test work.

Fracture studies of notched Zircaloy-2 specimens containing $23 \%$ cold work and tested in low bending showed that a transition from ductile to brittle fracture occurs at $-80 \mathrm{C}$. Electron microscopy of fracture surfaces has revealed a distinctive crystalline feature below $-80 \mathrm{C}$ which may be associated with the transition.

In a series of tests to determine the stress dependency of creep on Zircaloy-2 during irradiation, 2000 hours have been accumulated in a test at 20,000 psi stress and $350 \mathrm{C}$ on $20 \%$ cold-worked Zircaloy-2. The creep rate at 1700 hours was determined to be $1.8 \times 10^{-6} \mathrm{in.} / \mathrm{in} . / \mathrm{hr}$, less than the out-of-reactor rate but slightly more than the rate during reactor outage. The latter difference in rates during reactor operation and shutdown does not agree with previous observations. Further tests will be made to determine if this is due to stress dependency.

Thin foils of iron have been successfully deformed on the Instron testing machine and subsequently thinned and examined by electron trans mission microscopy. A foil deformed $5 \%$ was observed to have many dis location tangles but no indication of pile-ups, an important observation in view of the emphasis placed on dislocation pile-ups in many of the older theories of yielding in iron.

Welds of the superalloy candidates for use in the model ATR high temperature gas loop are being subjected to stress rupture tests at $1800 \mathrm{~F}$. Joints of Hastelloy X and Haynes alloy 25 welded to themselves and to each 
other are being tested. Thus far, the strengths of the welded specimens have been higher than those of the base metals as given in the published literature.

Experiments were made to determine the effect of helium on the high temperature heat transfer properties of insulations. At $2000 \mathrm{~F}$ the thermal conductivity through a cross-section of Fiberfrax in 1 atm of helium was $600 \%$ greater than through Fiberfrax evacuated to 28 inches mercury.

A single crystal rod of molybdenum with a [111] rod axis has been grown by seeding in the electron beam zone-refining apparatus. Growth of the seeded rod began at a (111) face cut on the seed crystal. The success of the seeding technique makes available any desired crystal orientation for future experiments.

An annealing chamber for low temperature isochronal and isothermal annealing treatments has been assembled and tested. This device will faciliitate the study of low temperature recovery in the range -190 to $0 \mathrm{C}$. It has been found possible with this device to control temperatures within $1 \mathrm{C}$ and maintain constant temperatures over extended periods of time.

Quenching treatments have been carried out on 0.003 -inch diameter nickel wire. Quenching rates of $>5000 \mathrm{C} / \mathrm{sec}$ have been attained. The quenched nickel is expected to contain a high concentration of single vacancies or simple vacancy complexes.

Foils of molybdenum containing $<10 \mathrm{ppm}$ carbon and $100 \mathrm{ppm}$ carhon which had been irradiated to $10^{18}$ and $10^{19}$ nvt (fast) have been strained $1-2 \%$. Foils irradiated to $10^{19}$ nvt became severely cracked; dislocation motions were confined to channels. Samples which had been irradiated to $10^{18}$ nvt exhibited considerable ductility and did not crack after $2-3 \%$ strain.

Three coextruded Zircaloy-2-clad Th-U fuel elements are now being irradiation tested in the ETR. 
Two thorium specimens irradiated to burnups of 0.18 and 0.92 at. $\%$ at $<300 \mathrm{C}$ successfully completed the 100 -hour vacuum anneal at $750 \mathrm{C}$. No visual evidence of damage was observed. The samples are now being processed for metallography, hardness, and density.

Thorium-uranium tensile specimens irradiated from 0.5 to 1.5 at. $\%$ burnup at $<300 \mathrm{C}$ were recovered from $\mathrm{NaK}$ capsules and their densities determined. No change in density occurred. Room temperature tensile tests will be conducted and the broken ends processed for hardness, density, and metallography.

The uranium-uranium interface in a dual enriched uranium rod could no longer be detected after annealing at $950 \mathrm{C}$ for 100 hours. This is in sharp contrast to the pronounced interface that existed after all lower temperature annealing treatments and suggests that oxides have either decomposed or gone into solution.

A total of 24 inches of high purity rhenium single crystals has been obtained. Orientations ar jing determined. Single crystals have been successfully grown from polycrystalline rods by zone melting.

Final Fast Supercritical Pressure Power Reactor core dimensions were established for the two moderator region core chosen last month. Slight plutonium enrichment is being incorporated in the flux trap absorber zones to flatten power peaking during life. Initial burnup calculations show a reactivity gain of $0.3 \% \frac{\Delta \mathrm{k}}{\mathrm{k}}$ in the initial 3 years of core life.

A dome seal is being evaluated for possible use by AECL. In initial tests slower heat-up rates during thermal cycle testing of the dome seal has reduced previously observed dome deformation.

The experiments undertaken to determine the two phase (steamwater) pressure drop in standard commercial piping and fittings were concluded. Data were obtained at pressures of 800,1200 , and 1600 psia, and flow rates of $1.0,2.0,3.0$, and $4.0 \times 10^{6} \mathrm{lb} / \mathrm{hr} / \mathrm{ft}^{2}$, and steam 


\section{DECLASSIFIED}

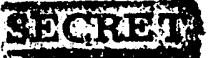

xvi

HW -77397

qualities up to $25 \%$ by weight were considered. Preliminary examination of the data has indicated that the two phase pressure drop in the various fittings considered were in many cases significantly lower than the values predicted by the Martinelli-Nelson two phase pressure drop correlation.

Experiments were started under the AEC/AECL Cooperative Program to define the boiling burnout heat flux for a 19-rod cluster fuel element cooled by steam-water mixtures (fog cooling). The boiling burnout heat fluxes obtained in the intital seven experiments were inconsistent with earlier data and exhibited erratic trends. This behavior was attributed in part to possible coolant flow instability in the inlet piping to the test section.

\section{Physics and Instruments}

In support of $\mathrm{N}$-Reactor, an exponential pile measurement was made of the strength of a spline in a water filled cross coolant tube. The strength was about one-fifteenth that of a horizontal control rod in the same position.

Preparations were ander way for measuring absolute $\mathbf{k}_{\infty}$ values for KVNS fuel pieces in zirconium process tubing in support of the retubing of K-Reactors.

Portions of the $\mathrm{N}$-Reactor instrumentation system are being tested in conjunction with other interested HAPO groups. Main emphas is to date has been on the slow gamma scan instrumentation.

$\mathrm{N}$-Reactor simulation studies are continuing with a single-node, six delayed group investigation of reactivity, inlet water, and fuel metal temperature, power rate of change and other reactor parameters. Pressurizer and injection pump simulation studies are complete.

In the Critical Mass Laboratory, experiments were performed with plutonium-nitrate solutions in an 11.5-inch diameter water reflected sphere. Experiments were to study the relationship between critical concentration and the nitrate content. The lowest plutonium concentration which would go critical was $86 \mathrm{~g} / 1$ in a $0.2 \mathrm{M}$ solution. 
In conjunction with the above experiments, measurements were made to determine the lifetime of neutrons in the plutonium nitrate solution and to estimate $k_{\text {eff }}$ for cases where the sphere was partially filled. The lifetime was $19 \mu \mathrm{sec}$. The effective neutron multiplication constant of the solution was determined as a function of the amount of solution in the sphere. When the sphere contained about $60 \%$ of the critical volume, the effective multiplication constant was 0.94 . This work is of interest in evaluating whether pulsed neutron techniques can be used to determine the safety of in-plant processing equipment.

Measurements of the inelastic scattering of slow neutrons from light water at $95 \mathrm{C}$ continued during the month. Measurements have been made for eight different values of neutron energy changes. This work is needed to determine the effect of water on shifting the neutron energy spectrum in reactors.

Development continued on an apparatus to measure slow neutron inelastic scattering by time-of-flight techniques.

Measurements were made of total cross section for neutrons of 3 to $15 \mathrm{Mev}$ for samples of 14 elements. These included the first Hanford measurements on manganese, selenium, and tellurium.

Studies were carried out in the PCTR using a 19-rod cluster of $\mathrm{Pu}-\mathrm{Al}$ in a 6.5-inch graphite lattice. This is the tightest lattice spacing used to date in a program designed to study the effect of the neutron spectrum on the reactor physics properties of $\mathrm{Pu}-\mathrm{Al}$ fuel containing $20.6 \% \mathrm{Pu}^{240}$.

Startup experiments in the Plutonium Recycle Critical Facilities continued during the month with power level calibrations, and measurements of neutron flux distributions, moderator level coefficients, and control and safety rod worths. The safety rod system was worth about one-half the value required by the Process Specifications. Relocation of the safety rods closer to the center of the reactor corrected this deficiency. 


\section{DECLASSFIED}

A new series of approach-to-critical experiments was begun using 0.5 -inch diameter $\mathrm{Pu}-\mathrm{Al}$ fuel rods in light water lattices. The rods contain $2 \mathrm{wt} \%$ plutonium containing $16 \% \mathrm{Pu}^{240}$. This is a higher $\mathrm{Pu}^{240}$ content than previously used and is closer to the kind of isotopic content which might be used in power reactors. The lattice spacing being used in the first experiment in the series is 0.66 inch center-to-center. The rods are arranged in a hexagonal pattern. This is about as tight a lattice as is feasible.

Preliminary results on measurements of the spectrum in the ARMF have been received. These results are needed to interpret experiments previously performed in which $\mathrm{Pu}-\mathrm{Al}$ fuel capsules were irradiated in the MTR and subsequently measured in the ARMF.

Comparisons were made of the calculated flux in the PRTR, 19-rod cluster, natural uranium fuel element using three transport theory codes, $I_{2}$, double $S_{2}$, and $P_{3}$. While the resulting calculated thermal utilization factors agreed within $0.3 \%$ of each other, the $\mathrm{I}_{2}$ and double $\mathrm{S}_{2}$ gave a more reasonable flux distribution in the central rod.

The one-dimensional, multienergy group transport theory code is being used to calculate the flux spectrum in plutonium-fueled rods. The effects of the $\mathrm{Pu}^{239}-0.3 \mathrm{ev}$, and the $\mathrm{Pu}^{240}-1$ ev resonances are being determined. Several successful cases were run during the month.

The ALTHAEA-MELEAGER code is being changed so that effective resonance integrals show the effect of all isotopes rather than being restricted to indicating the self-shielding effects as was done previously. The CALX program will now perform endpoint searches in time, and will stop properly when the reactivity falls below a certain value. Work continued on other code development work.

A substantial part of the comparison study of $\mathrm{UO}_{2}, \mathrm{PuO}_{2}$, and $\mathrm{PuN}$ as fuels for small, compact, fast reactors is complete. The plutonium fuels give marked decreases in core volume and weights with the PuN fueled core being the lightest and smallest of the three. 
Some results on temperature coefficient studies on Phoenix fuel reactors have been obtained. The average temperature coefficients over a 68 to $500 \mathrm{~F}$ temperature range are all very strongly negative $\left(\sim 2.0 \times 10^{-4}\right.$ $\left.\Delta \mathrm{K} /{ }^{\circ} \mathrm{F}\right)$, but are not a strong function of $\mathrm{Pu}^{240}$ content neglecting Doppler broadening. This effect is being treated separately.

The Project Proposal for design funds for the HTLTR has been forwarded to the Atomic Energy Commission for approval. (This was approved by the RLOO-AEC on May 3, 1963). A draft of the design criteria for the HTLTR has been reviewed and comments have been made for incorporation in the final design criteria.

Development of regenerating neutron flux detectors is continuing with the postirradiation analysis of plutonium, uranium, and cobalt samples recently irradiated in KE facility. Preliminary values of the cadmium ratio and the spectral parameter, $r$, have been obtained from reactivity measurements of the cobalt sample. Mass spectrometer analys is of the other samples are planned for the near future.

Development of microwave methods of in-reactor monitoring of neutron flux has been reactivated. First attempts will be made to correlate flux level with microwave attenuation.

Efforts to extend operation of the multiparameter eddy current tester to four parameters are meeting with considerable difficulty. To date, four parameter separation appears technically feasible; however, continued development effort will be required to make its application practical.

Medical hypodermic needles are being used with success for ultrasonic field strength measurements. The small needle bore allows measurements to be taken at extremely confined points within the sonic field, and have provided for the first time measurements of wave front shape and direction. 
A potentially serious problem associated with the cracking of zirconium process tube Vanstone flanges has been eliminated. The flange cracks, which formed at the tube ends as the ends were flared, were initiated by small surface scratches on the inside tube surface. A process which removes the scratches by a dry honing, controlled grit blasting has virtually eliminated the problem.

The first results were received from the survey-by-urinalysis program in Alaska. They indicated that high body burdens of $\mathrm{Cs}^{137}$ exist in other parts of the state than those visited last summer. Whole body counting will be done at some of these new places this coming summer. Preparations for the summer's work have begun.

The measurement of the specific power of $\mathrm{Pm}^{147}$ by calorimetry was completed.

Radiological physics work continued on: $\mathrm{P}^{32}$ counting, shadow shield calibration, $\mathrm{X}$-ray counting, precision long counter calibration, tissue-equivalent chamber energy sensitivity measuremeit, neutron spectrometry, and investigation of radiation induced thermal conductivity change in graphite.

Analys is of Hanford atmospheric diffusion data for a ground level release over a wide range of atmospheric stabilities has resulted in a relation between the lateral growth of a plume and the time of travel from the source, where the product of the mean wind speed and the standard deviation of the wind directions over the time of the emission is a parameter. This product, determined from wind velocity measurements near the source point, is directly related to the width of the plume and applies for travel times up to 30 minutes from the source. 


\section{Chemistry}

In-reactor studies show that low radionuclide production and release to the effluent can be maintained providing the zeta potential of the process water is held constant by varying the rate of alum addition.

The $\mathrm{Ni}^{65}$ concentration of reactor effluent water may be a useful measure of the corrosion rate of aluminum fuel element jackets.

Trilauryl amine extraction of neptunium and plutonium from fulllevel Purex waste resulted in recoveries of abcut 98 and $87 \%$, respectively. Gelatinous solids in the plant waste did not interfere with the extraction chemistry or operations.

In related studies, the presence of up to $1 \%$ of trilauryl amine in the Purex solvent does not impair uranium and plutonium extraction nor fission product decontamination.

Nuclear magnetic resonance measurements indicate that the mechanism of extraction of cesium into a BAMBP-D2EHPA solvent involves the extraction of BAMBP-solvated cesium ions by D2EHPA.

Two chemical paths leading to the degradation of CSREX solvent are found; temperature and the concentrations of nitrite and nitric acid are the important parameters.

Engineering studies led to an improved definition of process flowsheet and operating conditions which result in better overall recoveries for strontium, cesium, and rare earths from Purex waste solutions.

T'he solids component of simulated, formaldehyde-treated, Purex waste slurries is found to contain significant fractions $(11-85 \%)$ of the radioisotopes of interest to waste management and fission product recovery programs. Leaching studies are in progress.

A zeolite bed loaded with about 7000 curies of $\mathrm{Sr}^{90}$, hot air dried, and subsequently sealed is being monitored to determine the extent of 


\section{DECLASSIFIED}

Stomitis

xxii

HW -77397

pressure build-up as a result of the radiolytic decomposition of residual wat - or of temperature effects. Preliminary evidence thus far indicates elaborate drying equipment may not be necessary for plant application.

Studies indicate that potential fuel cycle cost savings of 0.1 to 0.25 mills/kwh are possible for the specific reactor case investigated by employing close-coupled or captive plant fuel reprocessing, vice conventional fuel reprocessing services.

The pot calcination of full-level Purex waste containing high concentrations of sodium nitrate results in significant volatilization of fission product cesium, the bulk of which is subsequently trapped in the off-gas condenser.

The passage of steam-stripped, Purex tank farm condensate through a thin bed of a strong base anion exchange resin resulted in an effluent having a fission product ruthenium concentration below its $\mathrm{MPC}_{\mathrm{w}}$ value through 9800 column volumes.

A polyethylene glycol chromatographic column was found to retain tritium from both tritiated water and ammonia present in reactor condensate samples.

\section{Biology}

Quachrome Glucosate appears to be neither more nor less toxic to fish than dichromate when administered at relatively high concentrations for brief periods of time.

There seems to be a suggestion that the increase in the fish disease, columnaris, with increased temperature, is due to decreased resistance of the fish rather than increased virulence of the microorganism. This is a tentative conclusion based on incomplete evidence.

The radiotoxicity of $\mathrm{I}^{131}$ in the thyroid is being compared with the effects following $X$-irradiation of the thyroid region in young sheep. This experiment should help clarify limits for $\mathrm{I}^{131}$ in human beings which is currently based (by the FRC) on response of children to X-irradiation of the thymus. 
$\mathrm{Te}^{132}-\mathrm{I}^{132}$ was fed to lactating ewes to cietermine distribution of these two isokars. Unlike iodine, only a small fraction of the Te was transferred to milk. Tissues showing the highest concentrations of Te were the thyroid and kidney.

The GI absorption of $\mathrm{Pm}^{147}$ was found to be $0.05 \%$ (the ICRP shows a figure of $0.01 \%$ ).

The presence of large quantities of $\mathrm{Pu}$ administered to rats along with $\mathrm{Np}$ seems to enhance the fecal excretion of $\mathrm{Np}$, both in the presence of DTPA and in its absence. No explanation is offered for this phenomenon.

In research done more than a year ago, we reported that TTHA, which can be administered orally for $\mathrm{Pu}$ removal, is not as effective as DTPA. However, we have recently tested a new TTHA preparation which seems to be of greater purity than that previously available. Preliminary results indicate that it is considerably more effective than D'TPA when given orally. In fact, this TTHA appears as effective when given orally as DTPA when given intraperitoneally.

In a dog that died 3 years after a single exposure to $\mathrm{Pu}^{239} \mathrm{O}_{2}, 1.4 \mu \mathrm{c}$ was found in the total body, of which $50 \%$ was in the lung and $42 \%$ in the pulmonary lumph nodes.

The effect of $\mathrm{I}^{127}$ on the thyroid deposition of $\mathrm{I}^{131}$ when both, as vapors, are administered to dogs was again tested. Large concentrations of $\mathrm{I}^{127}$ actually increased the body deposition of $\mathrm{I}^{131}$ despite the isotopic dilution. However, isotopic dilution decreased the thyroid deposition by a factor of two. These results are less favorable than those obtained in rat experiments and do not support the suggested use of generators to release stable iodine to the atmosphere in the event of a reactor release of radioiodine.

Rats are being exposed to pitchblende uranium ore dust to obtain lung burdens of 2 to $3 \mathrm{mg}$. This early work is to determine uranium daughters which remain in the lung.

\section{DECLASSIFIED}




\section{DECLASSIFIED}

Radiation diarrhea, previously prevented through exteriorizing the bile duct, is now being prevented (in rats) by the perfusion into the small intestine of a bile salt sequestrant. Rats so treated outlive, slightly, control rats and do not develop diarrhea.

Cells in pea root meristemic tissue show decreased frequency of division when exposed to $\mathrm{Cs} / \mathrm{K}$ ratio in excess of unity. (Earlier work showed toxicity to be visibly apparent when the root environment contained $\mathrm{Cs} / \mathrm{K}$ in excess of unity.)

\section{Programming}

In the production of $\mathrm{Cm}^{244}$ it is very important to keep the plutonium, which is being burned, separate from the new $\mathrm{Pu}^{239}$ being formed; otherwise, the new plutonium serves as a continuing source of $\mathrm{Pu}^{241}$ and hence of $\mathrm{Cm}^{242}$ which contaminates the product. The purity of the $\mathrm{Cm}^{244}$ is also increased by operating at high specific power (so that less $\mathrm{Pu}^{241}$ is allowed to decay) and, of course, by extended irradiation (so that $\mathrm{Cm}^{242}$ can decay as the formation of $\mathrm{Cm}^{244}$ continues). Finally, the $\mathrm{Cm}^{244}$ purity is improved by hardening the neutron spectrum, either by increasing the moderator temperature or by adjusting the reactor lattice, to enhance resonance absorption of neutrons in $\mathrm{Pu}^{242}$.

Computer codes have been revised to permit calculation of the production of fission product strontium, cerium, technetium, and promethium. The isotopic composition of these fission product elements is a function of exposure. A major effect, of course, is the saturation concentration of isotopes with short half lives. Another important factor in some cases is the difference in yield from fission of $U^{235}$ compared with fission of plutonium isotopes which predominate in highly exposed fuel.

TECHNICAL AND OTHER SERVICES

Ten plutonium incidents occurred during the month which required special bioassay sampling of the personnel involved to determine if internal deposition had occurred. In one of these cases, excision was used to remove 
plutonium remaining in a wound. Pending bioassay results for the persons involved in these incidents, the total number of confirmed plutonium deposition cases at Hanford remains at 316, of which 229 are currently employed.

An IPD maintenance man received a whole body exposure of $5 \mathrm{r}$ gamma on April 17, 1963, while removing a gunbarrel from the rear face of the 105-B Reactor. The reactor was shut down to discharge a ruptured fuel element. During the operation, the gunbarrel fell free, exposing the employee to a high dose rate. Inspection of the gunbarrel under water indicated the presence of at least a portion of the ruptured fuel element in the end of the gunbarrel.

A criticality false alarm light appeared on the panelboard in the Patrol room in the 3706 Building on April 6, 1963. The light indicated a criticality false alarm had occurred in the 306 Building. Consequently, Patrol initiated the crash alarm system. Investigation revealed that the signal light was caused by a short in the telephone system in the 306 Building when telephone men working in the building accidentally crossed terminals. The alarm did not signal in the 306 Building and, therefore, no personnel evacuated the building.

A power cutage occurred in the 308 Building April 8, 1963, as the result of work being performed on some distribution transformers. Because of this momentary ventilation failure, the ventilation and differential pressure alarm sounded. All personnel evacuated the building and reentry was accomplished using standard radiation monitor procedures. The emergency power functioned effectively, thus preventing a possible loss of contamination control.

Functional relationships between rail size characteristics have been obtained which aid in determining optimum conditions for improvement of $\mathrm{K}$-Reactor fuel elements that failed to meet specifications. In addition, previous work on rail height specification is being extended to include consideration of the distribution of minimum annuli under different conditions of fuel element ellipticity.

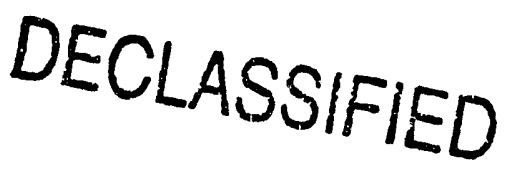


Extensive data from sample exchanges associated with plutonium metal assay have been reviewed to determine the major sources of variation and any significant changes or trends during a 5-year period. A similar review was made of the monthly analytical bias corrections obtained from an analyses of standard solutions.

The computer program which simulates chemical reactions between $\mathrm{N}$-Reactor stack gases is now in routine operation. Much valuable information about the zirconium-graphite compatibility problem is being obtained.

Recent tests on metallic shapes shear-spun from bla: $s$ provided by the previously reported computer program demonstrate that the rather severe dimensional and radiographical specifications can be met and that the finished product is superior to that fabricated by more conventional methods.

The new IRA-II for the processing of radiochemical data is now in routine use. Discussions are being held to see if this system can be extended to other analytical laboratory data.

SUPPORTING FUNCTIONS

April output for PRTR was $545 \mathrm{Mwd}$ for an experimental time efficiency of $49 \%$ and a plant efficiency of $31.3 \%$. There were two operating periods during the month, both of which were terminated manually; one was a scheduled shutdown for fuel transfers, and the other was due to "leaker" indication of fuel element 5174.

Fuel exposure history at month-end was:

Maximum $\mathrm{UO}_{2}$ exposure/element Average $\mathrm{UO}_{2}$ exposure/element Maximum $\mathrm{Pu}-\mathrm{Al}$ exposure/element Average $\mathrm{Pu}-\mathrm{Al}$ exposure/element Maximum Moxtyl expusure/element Average Moxtyl exposure/element
$3166 \mathrm{Mwd} /$ ton $_{\mathrm{U}}$ $2162 \mathrm{Mwd} /$ ton $_{\mathrm{U}}$

81. $5 \mathrm{Mwd}$

63. $3 \mathrm{Mwd}$

$55.6 \mathrm{Mwd}\left(\sim 1112 \mathrm{Mwd} /\right.$ ton $\left._{\mathrm{U}}\right)$

32. $2 \mathrm{Mwd}\left(\sim 644 \mathrm{Mwd} /\right.$ ton $_{U}$ ) 
A total of 270 hours was charged to repair work. The majority, 248 hours, was required for steam bellows repairs. Process tube 1455 was replaced.

Twelve days of critical testing and 8 days of subcritical testing in the Plutonium Recycle Critical Facility were realized. Reactor kinetic studies of EBWR cores were performed. The PRCF Design Scope for Light Water Conversion, HW-76941, was approved and issued.

Installation of shielding, revised pressure relief systems, emergency depressurization valve, and inlet shut off valve was completed in the Fuel Element Rupture Test Facility (Project CAH-867). Fuel Element Rupture Test Facility Discharge Method, HW-77117, was issued.

The gas loop in the Gas-Cooled Loop Facility (Project CAH-822) was operated at $1400 \mathrm{~F}$ during acceptance tests and performed fully within expectations. The gas-bearing blower was operated continuously for 30 hours at $150 \mathrm{psig}, 450 \mathrm{~F}$ and $6000 \mathrm{rpm}$. The two blowers at the vendor's plant are scheduled for delivery in May.

Technical Shops' total productive time for the month was 27,033 hours. Distribution of time was as follows:

$\begin{array}{lccc} & \text { Man-Hours } & & \text { \% of Total } \\ \text { N-Reactor Department } & & & \\ \text { Irradiation Processing Department } & 4043 & & 10.59 \\ \text { Chemical Processing Department } & 354 & & 1.96 \\ \text { Hanford Laboratories } & 19772 & & 73.14 \\ \text { Construction Engineering and Utilities } & \frac{--}{27033} & & 100.00 \%\end{array}$

Total productive time for Laboratory Maintenance Operation was 17,400 hours of 19,200 hours potentially available. Of the total productive time realized, $87.5 \%$ wac expended in support of HL components and $12.5 \%$ was used in providing service to other HAPO components. 


\section{DECLASSFIED}

Manpower utilization for April is summarized as follows:

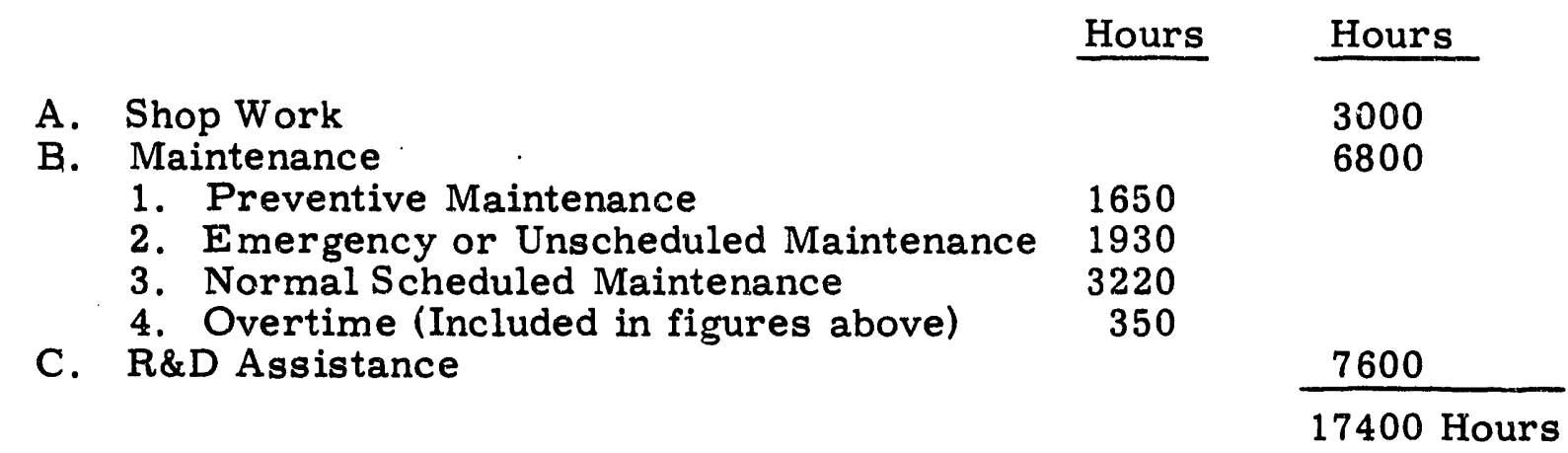

Heavy water physical inventory at the end of April indicated a PRTR loss of 1594 pounds valued at $\$ 22,013$. Scrap generated during the month amounted to 2645 pounds $(\$ 4391)$. On April 17, 1963, 16, 556 pounds of heavy water scrap valued at $\$ 207,961$ were shipped to SROO-AEC.

Effective March 1, 1963, the unit cost for long-term (loop) irradiations was increased from $\$ 15$ to $\$ 25$ by the Idaho Operations Office, AEC. This change will increase costs $\$ 331,000$ this fiscal year and will cause the current financial plan to be exceeded by $\$ 325,000$. The Richland Operations Office has been advised by IOO that a financial plan revision, reflecting current IU funding requirements, will be prepared in the near future.

Activity in the area of visitor presentations is summarized below:

\begin{tabular}{lcc} 
& \multicolumn{2}{c}{ Number of Visitors } \\
\cline { 2 - 3 } Visitors Center & $\frac{\text { In April }}{1822}$ & Since 6-13-62 \\
Plant Tours & 555 & 41,847 \\
& 5 & --
\end{tabular}

The composition of HAPO professional recruiting activity this month follows:

$\mathrm{Ph} . \mathrm{D}$. BS / MS (Direct Placement) BS / MS (Program)

\begin{tabular}{|c|c|c|}
\hline & $\begin{array}{c}\text { Offers } \\
\text { Extendec }\end{array}$ & $\begin{array}{r}\mathrm{Acc} \\
\mathrm{Re}\end{array}$ \\
\hline
\end{tabular}

15

$--\quad 17$ $--\quad 59$
6
0

8 35
Open Offers at Rejections

4 Month-End 
SECRET

xxix

KW -77397

Seven technical graduates were placed on permanent assignment. Six additions to the program were made; its current strength is 40 .

Authorized funds for eight active projects total $\$ 6,260,500$. The total estimated cost of these projects is $\$ 7,595,000$ of which $\$ 571,000$ had been spent through March 31, 1963.

HM Parker:JEB:dph

DECLASSIFIED

SECRET 


\section{DECLASSIFIED}

$A-1$

REACTOR AND FUELS LABORATORY MONTHLY REPORT

APRIL 1963

\section{TECHNICAL ACTIVITIES}

\section{A. FISSIONABLE MATERIALS - O2 PROGRAM}

1. Metallic Fuel Development

Phosphorus Impurity in Uranium. Investigation was continued on the effects of phosphorus impurity on uranium structure, fabricability and properties, and fuel element quality. Metallographic examination of derby metal contalning $430 \mathrm{ppm}$ phosphorus had indicated the formation of a eutectic between a phosphorus compound, presumed to be UP, and uranium. The eutectic composition is estimated to be at 1000-1500 ppm P. Microprobe analysis of this metal NLO and MCW confirmed the identity of the compound as UP ( 11.52 w/ P P). Sections of this metal were heated 4 hours at 900,950 , 1000 , and $1050 \mathrm{C}$ and water quenched. Examination showed a slight growth of the compound, but no indication of solubility of the phosphorus even at the highest temperature. Additional melting point determinations on ingot stock containing 135 and $280 \mathrm{ppm} P$ continue to show a depression in melting point of approximately $10 \mathrm{C}$ compared to nonphosphorus containing metal.

Preparation of small dingots (about 5 pounds) with intended phosphorus levels of 1000,1500 , and 2000 ppm was requested from MCW. This metal has been received but not analyzed for phosphorus content.

Examination was made of NIE fuel containing $170 \mathrm{ppm} P$ in the ascoextruded, beta heat treated, and braze heat affected conditions. No detrimental effects on uranium structure, clad to core bonds, or braze to core bonds were observed. Tensile tests are in progress, comparing the properties of this metal with that of standard NIE fuel.

The NIE and NOE ingots ( 135 and $280 \mathrm{ppm} \mathrm{P)} \mathrm{examined} \mathrm{the} \mathrm{previous}$ month were given primary extrusion at HAPO, and the NIE billet has been coextruded. Examination of the coextrusion and sections of the primary extrusion are in progress. No detrimental effects of the phosphorus impurity on the fabrication of fuel have been observed to date.

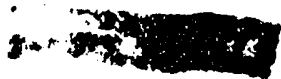


MrR Irradiation of I\&E Fuel Elements. Recent irradiations of thickwalled uranium tubes by SRL have resulted in volume increases considerably in excess of those that would be predicted solely from fission gas swelling. Examinations have shown that extensive grain boundary tearing has occurred in the uranium resulting in large numbers of irregularly shaped voids. Four Hanford I\&E fuel elements are being irradiated in the GEH-4 loop facility in the MTR to invesiigate the possible occurrence of large volume increases at intermediate temperatures. The elements were returner to the reactor loop at the beginning of the last cycle. The maximum metal fuel temperature is now approximately $400 \mathrm{C}$ and accumulated exposure is approximately $1000 \mathrm{MWD} / \mathrm{T}$.

Fluted Fuel Eloment Irradiations. Two fluted single-tube N-reactor size fuel elements have completed two cycles of irradiation ( 400 $\mathrm{MWD} / \mathrm{T}$ ). No appreciable volume change could be measured at the end of the second cycle. The elements are now undergoing their third cycle of irradiation in the ETR $M-3$ loop. One $N-1$ nner size fluted element which is being irradiated in the P-7 loop of the ETR has undergone a volume increase of approximately three percent after an exposure of $1200 \mathrm{MWD} / \mathrm{T}$ (5 cycles).

Examination of $N$-Fuel Components. The post-irradiation examination of a third " $N$ " outer fuel element component (NOE) irradiated at prototypic conditions in KER has been started. Two spot-welded supports were observed to be completely missing, having been torn loose at the welds during post-irradiation handing and shipping. The exposed crevice region between the support tab and the clad surface was free of any white oxide or crud formation. The tubular element was sectioned to expose the inner surfaces at the areas of contact with the inner tube (NIE) supports to observe possible evidence of fretting corrosion. Superficial examination and surface replication indicated no fretting occurred. In other respects, the "N" fuel element continues to show satisfactory irradiation performance and behavior.

Cladding Deformation Studies. Thirty-six NaK capsules containing a total of 94 Zircaloy-2 clad uranium rods are being irradiated in F-reactor to provide data on the effects of cladding thickness uniformity, temperature, and exposure on the strain capabilities of Zircaloy-2 fuel cladding. Nine of these capsules were discharged at an exposure of $1100 \mathrm{MWD} / \mathrm{T}$. The fuel samples in these capsules will be examined for clad performance and the Information obtained will be used to help establish discharge exposures for the remaining 27 capsules. The latest temperature and power data for the capsules still under Irradiation indicate that temperatures are remaining very close to those desired.

\section{Hixing}

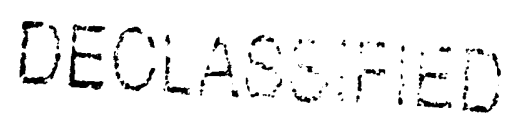


Analysis of Fuel Element End Caps. The difference in themal expansions between fuel and end cap material in metallic fuel elements is a potential cause of fuel element fallures. Numerous case studies of a numerical method of stress analysis for shaped end closures with thickened or reinforced cladding near the cap have been run. General case studies have been mun for thickness to radil ratios from 0.01 to 0.10 with transitions of linear and parabolic thickening. These studies indicate that a major reduction in stress levels can be obtained with transition regions. An end cap section with uniform bending stress intensity can be obtained with a linear thickening of cladding when appropriate lengthto-height ratios are selected. In the case of linear thickening the selection of the correct ratio is critical. If parabolic thickening is used the selection of maximum height-to-length ratio is not as critical and the lowering of the maximum stress intensity is almost as great as in the linear case. An added benefit of lower stresses near the end cap also occurs. Besides the general study, a specific design study for an $\mathrm{N}$-inner fuel element was made. The particular example of a machined end cap with a transition length. of 235 mils was selected. Reductions in bending stress of a factor of six were obtained with this design. The transition zone de a 300 angle with the outer cladding and a $36^{\circ}$ angle with the inner cladding.

Self-Brazed Closure Development. Two lots of elements for an in-reactor production test are in the final stages of preparation. The test pieces have been fabricated and tested; it remains to autoclave them. The high-temperature test loop elements including one with the bare braze annulus have passed the 100-day exposure period without any apparent attack. Thus it appears that the eutectic Cu-NI-Zr braze layer is sufficiently resistant to corrosion at operating temperature to make it satisfy the criterion that the secondary closure should resist corrosion well enough to permit full-term irradiation in case the primary closure should develop a leak.

Hot Headed Closure Studies. Improvements in hot heading techniques and relocation of the projection rings have virtually eliminated the undesirable joint crevice which previously existed on both the OD and ID of the element. Recent welded joints show crevice variation from zero to 0.004 inch.

End cap copper immersion plating procedures have been modified and as a result the projection weld quality has improved. 
A redesign of the retaining collars which are used to support the $O D$ of the element during welding has significantly increased the usable life of the ceramics. Measurenents of welded elements have shown that the diameter of the element decreases in the joint region under the retaining ring as a result of the welding operation. This dimensional change can be overcone by grinding a sultable taper on the ID of the retaining rirag,

Metallographic examination of recent hot headed closures using a cap with four ring projections indicates that the projections are sound and that the interface areas between the projection welds over the Zircaloy clad and the interface areas between the projection welds over the urantum are bonded. There appears to be some evicence that a small amount of uranium near the zircaloy-copper-uranium interface had reached the melting temperature.

Closure and Jolning. Corrosion tests have continued on the Zircaloy2-beryllium brazing alloys with variable beryllium, uranium and gases. These tests are conducted in $360 \mathrm{C}$ water. After more than 90 hours the $1 \mathrm{w} / 0$ uranium-Zircaloy-2 alloy has about the same light reflectance reading as zircaloy and only a slightly higher weight gain. The higher uranium alloys have been failing at a very rapid rate, but those of $I \mathrm{w} / O U$ and below appear the same as Zircaloy-2. When beryllium is varied in the Zircaloy-2, the corrosion coupons show a linear graying with increasing berylilum content up to $5 \mathrm{w} / \circ \mathrm{Be}$. There is little difference in welght gain of the specimens up to 300 hours, but the light reflectance shows a large variation th time and beryllium content. When both uranium and beryllium are varied, uranium (250 ppm) with beryllium causes the corrosion rate to increase rapidly and the light reflectance to increase witn increasing beryllium content. The coupous with the lowest uranium (250 ppm) and highest berylilum (5 w/o) content turned chalk white. The effect of gaseous contamination $\left(2000 \mathrm{ppm} \mathrm{O}_{2}\right.$ ) was more pronounced in Be- $\mathrm{zr}-2$ alloys tnan in $\mathrm{Zr}-2$.

The coupons were extremely brittle and turned white after only 50 hours in $360 \mathrm{C}$ water. Thereafter the light reflectance measurements stabilized and the weight continued to increase. These tests are continuing and will be expanded to include carbon additions to the $\mathrm{Zr}$-Be series.

Closure Soundness Tests for Target Elements. An extremely sensitive test for minute leaks in the closures of aluminum clad target elements has been developed. While the principle is not new, its

\section{DECLASSIFIED}

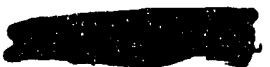


successfui application has called for some modification of standard equipment, as well as the use of unusual techniques.

The procedure involves filling the annulus in the canned element with helium before welding the closure. The pieces are then tested in a modified mass-spectrograph leak detector.

The modification consists of an added evacuable chamber which may be isolated from, or opened up to, the mass-spectrograph test unit. In effect the unit now consists of three separate chambers, each capable of isolation from the others, and capable of separate evacuation: (a) the high vacuum section including forepump, diffusion pump, cold trap, pressure gage and mass-spectrograph tube (Vee-tube) connected by an infinitely adjustable throttle valve to (b) the manifold section including roughing pump, and intermediate pressure gage together with connecting plumbing, in turn, connected through a manual valve to (c) the added section consisting of matching pieces of Pyrex pipe fitted to a suitably gasketed base and so chosen as to form a sealed chamber. A separate pump and valve evacuates this chamber.

The plece to be tested is put into one chamber and evacuated to about $1000 \mu \mathrm{Hg}$. This chamber becomes loaded with He proportional to the size of the leak and the time left under vacuum. With the throttle valve closed and the manifold section evacuated to the limit, the valve between sections $B$ and $C$ is cracked slightly until the manifold pressure reaches some arbitrarily predetermined value $(\mathrm{e} . \mathrm{g} .500 \mu \mathrm{Hg})$. Then the throttle valve is cracked until some predetermined pressure is maintained in the vee-tube chamber, while the helium content is monitored. A very tiny leak may give a dubious response the first time, but a repeat sample from chamber " $c$ " will show a much stronger response if there is a real leak. Two interfering conditions are:

(1) Leak so large that He charge is lost before test is applied. However, a leak of this size can be seen visually, or in case of doubt, the specimen can be recharged by evacuating and backfilling with helium.

(2) Background of He in the air around test unit. In this case a test for background must be mun before each trial test.
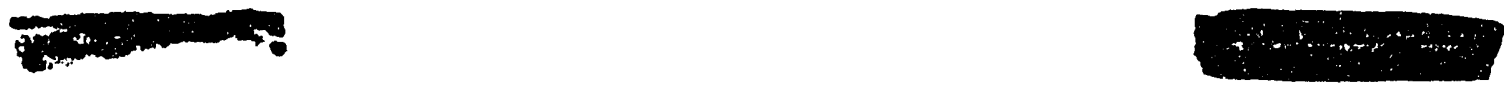
Fuel Component Development. Laboratory tests to study possible damage to $\mathbb{N}$-reactor process tubes by charging $\mathrm{N}$-fuel elements are proceeding. A series of tests are being conducted to determine to what extent the reactor process tube is damaged by the repeated corrosion of the bare Zircaloy-2 that is exposed by scratching by the fuel element supports. The test cycle consists of passing steel support shoes forty times over a single path on the process tube, then autoclaving the tube in $400 \mathrm{C}$, 1500 psi steam for 14 days to give the corrosion product buildup on the bare zircaloy-2 equivalent to that expected to form in-reactor between the charge and discharge of the fuel elements.

After the fourth autoclave cycle, as in the previous cycle, a total of 50 passes with four different shoes were made with no signs of scratching the autoclave film. Steel was deposited on the autoclave film from the shoes. Again it was necessary to intentionally initiate the scratching of the process tube in order to continue with the original purpose of the cyclic scratching autoclaving test. Five series of 40 passes, with autoclaving between each series, have now been completed on the same region of the process tube section. The scratch depth now varies from 0.0006 to 0.0017 inch. The average depth over the entire length of the tube increased from 0.0009 to 0.0012 inch during the last scratching cycle.

Fabrication of Fuel Fouling Probe Stock. A long life constant power

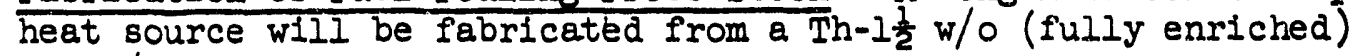
U-1 w/o $\mathrm{Zr}$ alloy for the purpose of studying the variation in heat transfer with film buildup on a Zircaloy-2 surface during irradiation. The primary arc melting of this material has been completed along with an identical ingot made up with normal uranium. The normal ingot will be used as pllot material for developing suitable fabrication procedures.

Past electrode preparation procedures would require that the 3.8 in. diameter $x$ 12-in. long ingot be sawed into longitudinal quarter sections turned slightly, and welded end to end to form the second melt electrode. Extrusion of the primary ingot to 2-in. diameter will be attempted with this material in an effort to eliminate the somewhat costly yuartering and welding steps previously used.

Fuel Fouling Detector. Ten 3-inch long Zircaloy-2 clad uranium rods have been prepared for use in testing mechanical thermocouple seal designs for possible use in the fuel fouling detector. All pieces have brazed end caps and have been beta heat treated. Four 


\section{DECLASSIFIED}

$A-7$

pieces have been fitted with a special end cap to be use: with $a$ compression seal now under development. The compression seai or these test pieces will receive extensive thermal cycle testirs to determine its suitability for in-reactor use.

Iithium-Aluminum Target Element. Twenty-one experimental ilihilusal uminum target s.lugs have been canned in aluminum in 6 iellum atmosphere. Both helium leak check and X-ray indicate that the welds are sound. Eleven of these elements are being canned in Zircaloy 4 directly and the remaining ten are being given an anodizing treatment prior to canning in Zircaloy-4.

Considerable difficulty was encountered in developing techniques for the welding of the aluminum cans. The process presently in use consists of welding the end caps to the aluminum can using the electron-beam process. One of the two caps has a 0.040 inch hole which allows for back filling with helium. This hole is sealed by resistance welding a 0.040 inch thick sijminum disk to the end cup. The pressure exerted during wif.dilis exiruidis a part of the disk into the hole which provides a mechanical seal in addition to the resistance weld.

Support Fabrication. During the period from April 1 through 22, there were 22,000 steel shoes and 34,000 inner supports fabricated. The addition of these quantities brings the total test fabrication numbers to:

$\begin{array}{lr}\text { Steel Shoes } & 50,000 \\ \text { Outer Supports } & 21,000 \\ \text { Inner Supports } & 77,000 \\ \text { Total Parts } & 149,000\end{array}$

Process yield has been increased by about $30 \%$ during the test fabrication. Support fabrication will now be transferred to NRD.

Facilities and Equipment. A high temperature induction furnace has operated at temperatures in excess of $3000 \mathrm{C}$. This furnace uses a magnetic flux concentrator which collects the RF induced magnetic flux and concentrates it on a very small area. Zircaloy-2 is melted in less than two seconds, a $200 \mathrm{gm}$ molybdenum ring was partially melted in two minutes. This unit has been used to make zirconium carbide for alloying additives to corrosion coupons and w1ll be used for brazing studies. With no maximum upper temperature limit and such rapid heating rate, the applications

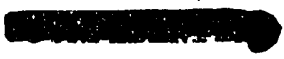


are almost limitless. The major problem is how to contain the molten material. To date graphite and tungsten have been used, but both react with all molten metals at these temperatures.

Fuel Element Rupture Device. A two-week test of the fuel element mupture device at simulated PRTR mupture loop conditions except for irradiation is in progress in the out-of-reactor TF-7 loop at 1706-KE. The test is being run to determine the effect of high pressure, high temperature water on graphite impregnated piston seals and to determine the characteristics of the system when the cutter is operated.

Nine explosively formed Zircaloy-2 basket tubes were recelved from Aerojet-General and inspected for acceptance. None of the tubes currently meet the warp specification. Six of the tubes will be annealed and returned for reforming. The remaining three tubes are axially split to such an extent that reforming is not feasible.

New ETR Shipping Cask. A new "pot type" shipping cask has been delivered for the shipment of irradiated fuels from the National Reactor Testing Station to Hanford. This new cask was designed to meet both the Interstate Commerce Regulations and the proposed $A E C$ regulations detailing safety requirements for such shipments. The cask has an internal cavi.ty of 7 inches ID by 48 inches long with a minimum of 13 inches of lead shielding.

Nickel Plating on Uranium. A satisfactory plating rack for supporting two-inch sections of regular I \& $E$ fuel cores was fabricated. A system for changing contact points during plating eliminated unplated areas at contact points as demonstrated by two-hour boiling water corrosion tests. Problems with gas pitting are being rectified by bath purification. The bath tested was $200 \mathrm{gr} / 1 \mathrm{NiSO}_{4} 6 \mathrm{H}_{2} \mathrm{O}, 45 \mathrm{gr} / 1$ sodium citrate and $5 \mathrm{gr} / \mathrm{I} \mathrm{NH}_{4} \mathrm{Cl}$.

2. Corrosion and Water Quality Studies

Effect of Velocity on the Corrosion of Aluminum - Rotating Disk Method. The effect of high flow rates on aluminum corrosion is being investigated by rotating four-inch diameter X-8001 aluminum disks in 300 Area tap and reactor process waters at temperatures up to $95 \mathrm{C}$ at linear flow rates up to $72 \mathrm{fps}$. 
Observations reported previously indicated considerable differences in the type of accelerated attack in tap and reactor prosess wits $r$. Since one difference in water quality was the dichromate in the process water, a mun was made in which $1.8 \mathrm{ppm} \mathrm{Na}_{2} \mathrm{Cr}_{2} \mathrm{O}_{7} \cdot \mathrm{H}_{2} \mathrm{O}$ was added in 300 Area tap water. After 72 hours, the attack on the rotating disk was similar to groove pitting observed or fivel element cladding. Since the type of attack was morlified by dichromate additions to tap water, the need for a study of the role of dichromate on groove attack is strongly indicated.

Effect of Heat Treatment on the Corrosion and Hydriding of Zircaloy-2. The effect of heat treatment on the corrosion and hydriding of Zircaloy-2 exposed to $360 \mathrm{C}, \mathrm{pH}-10$ (LiOH) deoxygenated water is presently being investigated. Samples cut from Zircaloy-2 sheet stock were heat treated at varicus temperatures ranging from $750 \mathrm{C}$ to $1010 \mathrm{C}$ for 10 minutes followed by slow cooling. At various intervals of time, duplicate samples of each heat treatment condition will be removed from the test for corrosion and hydriding measurements.

Welghings following an initial two-week exposure in $360 \mathrm{C} \mathrm{pH}-10$ deoxygenated water have shown no significant effect of heat treatment on the corrosion weight gains.

Evaluation of $\mathrm{NH}_{4} \mathrm{OH}$ to Adjust $\mathrm{pH}$ in NPR. Recent analysis of NPR operating conditions indicate that nucleate boiling will occur on the fuel elements. Nucleate boiling could result in the concentration of lithium hydroxide at vices on the $\mathrm{Zr}-2$ fuel element jackets, as, for example, under the fuel element supports. Severe corrosion of the $\mathrm{Zr}-2$ would then result. The substitution of a volatile additive such as ammonia for LiOH to control the $\mathrm{pH}$ would preclude the positbility of obtaining high alkali concentrations in the areas of nucleate boiling. As yet there is insufficlent knowledge about the effect of ammonium hydroxide on corrosion rates of the NPR primary system components.

a. Ex-reactor Corrosion Tests with $\mathrm{NH}_{4} \mathrm{OH}$ Inhibited Water. Tests were mun in the TF-5 Loop to determine the corrosion rates of A2l2 carbon steel, a low manganese carbon steel, sensitized 304 stainless steel, and Zircaloy-2 in $\mathrm{NH}_{4} \mathrm{OH}$ inhibited water. Specimens were exposed for periods up to 3000 hours in $290 \mathrm{C}$ deionized water with $\mathrm{pH}$ controlled at 10.0 using a by-pass flow through an ion exchange bed regenerated with ammoni m nydroxide. 
After formation of an initial protective oxide film, the corrosion of the carbon steels and the $\mathrm{Zr}-\mathrm{2}$ was essentially zero. The emount of corrosion to form the protective oxide on the carbon steel was $0.12 \mathrm{mil}$, and on the $\mathrm{zr}-2$ was 15-25 $\mathrm{mg} / \mathrm{dm}^{2}$. After forming an initial protective $\mathrm{film}$, the corrosion of the stainless steel proceeded at a low rate estimated at $0.01 \mathrm{mil} / \mathrm{yr}$. In ex-reactor tests, use of ammonium hydroxide for $\mathrm{pH}$ control resulted in corrosion rates as low, if not lower, than with lithium hydroxide. The corrosion rates were lower than normally reported for water adjusted with amonium hydroxide, perhaps because the $\mathrm{pH}$ employed in this test was higher than used in other reported tests.

b. Ex-reactor Testing of Thermocouple Elements. Another important variable in the evaluation of $\mathrm{NH}_{4} \mathrm{OH}$ as a conditioning a ent is its crudding characteristics. This is extreinely import.aut because the bulldup of crud on fuel elenent surfaces can lead to fouling severe enough to prodice fuel ruptures. To properly evaluate this varikble duritor an in-reactor test, it is necessary to employ a trarmocouple element.

A stainless steel clad, $\mathrm{Zr}-2$ jacketed thermocouple elpment has been designed for this purpose. Six prototypi eal elements were fabricated and tested in high temperature, bigh pressure ex-reactor loops. The thermocycling test: were performed in the TF-7 loop and the dynamic testing in the TF-9 loop. At the end of the testing period all six thermncouple elements were in excellent condition. Examination revealed no defects which could lead to muptures. The only ulfiurence between the elements tested and the elements to be used in-reactor is the fuel. The test elements are filled with natural uranium oxide, the in-reactor elements with enriched uranium oxide.

The elements to be used in-reactor are being fabricated and will be ready for the in-reactor test in the next month.

c. $\mathrm{NH}_{4} \mathrm{OH}$ Testing in $\mathrm{KER}-1$. On April $3 \mathrm{NH}_{4} \mathrm{OH}$ injection into the KER-I loop was initiated. This test is the first of a series of in-reactor tests to determine feasibility of using $\mathrm{NH}_{4} \mathrm{OH}$. Prior to $\mathrm{NH}_{4} \mathrm{OH}$ injection, the KRR-I LOOp was operated at high temperature and normal coolant quality - with IiOH to condition the coolant to $\mathrm{pH}$ 10. The transition from $\mathrm{LiOH}$ 
operation to $\mathrm{NH}_{4} \mathrm{OH}$ was achieved by simultaneously terminat: IiOH injection and injtiating $\mathrm{NH}_{4} \mathrm{OH}$ injection. During the transition period, approximately 25 hours, no operating difficulties were experienced and $\mathrm{pH}$ control was maintained between 9.9 and 10.1. Operation with $\mathrm{NH}_{4} \mathrm{OH}$ wiIl continue until the next scheduled shutdown in mid-May.

Water quality during the test has been very good and no crud problems have been experienced during equilibrium operation. Water quality is monitored during the test by frequent sampling and a continuous automatic analyzer monitoring amonia. Results to date indicate approximately $50 \%$ of the injected $\mathrm{NH}_{4} \mathrm{OH}$ is decomposing. During an earlier test conducted in the ex-reactor portion of the KER-I LOOD, It. was observed that the measured ammonia concentration was low and appeared to be independent of the injected concentration. The loss was attributed to a combination of thermal decomposition and adsorption in the piping walls. During the in-reactor test the difference in concentration: cetween the amonia injected (18-20 ppm) and the measured ammonia concentration was 8-12 ppm.

A program to identify the decomposition products has been initiated. Analyses for selected oxidization products of ancilia have yielded negative results. To date there is not enough information on gas samples to determine if $\mathrm{NH}_{4} \mathrm{OH}$ is breaking down into its elemental gases.

IPR Water Quality Instrumentation Studies. Evaluation for NPR operation of the Hays continuous dissolved oxygen analyzer with influent streams containing dissolved oxygen and hydrazine was completed. These tests demonstrated that the analyzer can measure the oxygen concentration accurately with hydrazine present when the instrument is properly calibrated. Although calibration of the instrument is more complicated when hydrazine is present, a technique was developed to permit precise calibration. 
A continuous colorimetric procedure for measuring trace concentrations of calcium in water is being investigated. The estimated sensitivity of this procedure is in the 5-10 ppb concentration range. This procedure is being developed as an alternate to hardness analysis for detecting raw water in-leakage in the NPR secondary coolant.

Hydrazine Injection to Control Oxygen. During low temperature operation at NPR the oxygen concentration in the primary system will be kept at an acceptable level by the injection of hydrazine. The effectiveness of this procedure was tested during low temperature operation of KER-I Loop in March. Hydrazine was added to the loop by feed-and-bleed with the normal $\mathrm{LHOH}$ solution used to maintain the $\mathrm{pH}$. During hydrazine injection the axygen concentration remained below $500 \mathrm{ppb}$ and the peroxide concentration below $100 \mathrm{ppb}$.

The water quality during the test was very good and no crud bursts were experienced. To facilitate certain loop repairs, hydrazine injection was terminated approximately 8 hours before the loop resumed high-temperature operation. At this time a slight crud burst was experienced; however, the burst was much smaller and cleared up faster than those experienced during the low temperature operations of the previous two months. No corrosion measurements were made during this period.

NPR Corrosion Studies. The fuel elements discharged from KFR-2 (stialnless-steel loop) on March 26 were examined for crud. The autoclaved Zircaloy-clad NIE-I fuel elements had elther no crud or a slight brown crud film with the shiny black $\mathrm{ZrO}_{2}$ visible beneath it. The unautoclaved Zircaloy sleeves surrounding these fuel elements were covered by a fairly heavy, unfform, dark-brown crud deposit. These elements had been exposed since November 27 at $\mathrm{pH} 10 \mathrm{IIOH}$ with an outlet temperature varying between. 175 and $230 \mathrm{c}$. During the test some amonium citrate cleaning solution had inadvertently been introduced into the loop, resulting in reduced pH $(6.5$ minimum $)$ and poor water quality for about 1 day. This experience may be contrasted to similar fuel elements discharged on March 3 from KaR-I (carbon-steel loop). With these a similar darkbrown crud deposit was found with the same intensity on both the autoclaved fuel elements and the unautoclaved sleeves. The KGR-l test was also at $\mathrm{pH} 10 \mathrm{~L} \mathrm{HOH}$ but operation followed loop modification, cleaning, and down time. These two instances are the only ones of significant crud deposition in any of tne KER loops during operation at high $\mathrm{pH}$. 
An electrically heated sample clad in Zircaloy-2 was discharged from TF-3 after exposure for 146 days in $\mathrm{pH} 10 \mathrm{L1OH}, 315 \mathrm{C}$ ialk water temperature at a heat flux of $380,000 \mathrm{Btu} / \mathrm{hr}-\mathrm{ft}^{2}$, which produced surface boiling. Heavy corrosion of the zirconium (white oxide formation with an estimated 3 mils maximum penetration) had occurred in two spots in the region of heat transfer where crevice was formed by a stainless sleeve used to hold a theimocongie. Two self-supports of the type used on NPR fuel elements were welded to the surface of the specimen. The specimen will be sectioned to see whether similar corrosion occurred in the crevices inder the supports.

Severe fretting was found on an experimental NPR fuel element exposed one week in the TF-7 Loop. The loop was operating with $\mathrm{pH} 10$ (LiOH) water at $530 \mathrm{~F}$. External vibrations at 54 cycles/sec with an $1.8 \mathrm{mil}$ amplitude were impressed on the test section. Postoperation examination revealed one buggy spring support completely ietached from the inner fuel element and numerous penetrations into the outer element where the inner element supports contacted the outer element. The maximum penetration was $18 \mathrm{mils}$. These elements are of an older design and probably will not be used in NPR.

The tests were repeated on the NPR fuel element design presently planned for NPR Irradiation. After three weeks exposure with induced vibration, no fretting occurred. This fuel element design has a higher spring constant than the elements which exhibited the severe fretting corrosion. The tests will be repeated under different vibration conditions to determine fretting tendencies.

Fretting corrosion between the outer fuel element supports and the process tube has not been observed with either type of fuel element.

Oxalate Precipitation and Film Deposition. An irhibited, complexed solution of oxalic acid, ammonium citrate, and ferric sulfate was found to be a satisfactory reagent for removing adherent oxide filns and contamination. Average decontamination factors of 16 for CS and SS were obtained with this solution when preceded by an alkaline permanganate pretreatment. As a single step carbon steel decontaminant, an average decontamination factor of 16 also was obtalned. Only a light trace of film was formed on carbon steel after 23 hours at $70 \mathrm{C}$. The corrosion rates of various materials (carbon steel, 410 stainless steel, brass, Zircaloy-2, 300 series stainless steel, Inconel, and Monel) were uniformly low ( $0.01 \mathrm{mil} / 6 \mathrm{hrs})$ with the exception of carbon steel which were $0.26 \mathrm{mil} / 6 \mathrm{hrs}$, and 410 stainless steel which were $0.16 \mathrm{mil} / 6 \mathrm{hrs}$. Further dynamic testing has been scheduled with this solution.

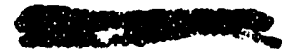

UNCLASSIFIED 
Decortamination Scanrirg. An improved proprietary solution containing $\mathrm{KMnO}_{4}$ and recommerded as a single step stainless steel decontaminant resulted in $\mathrm{MrO}_{2}$ precipitation after 4 hours of refluxing at $100 \mathrm{C}$. Decontamination data were not obtained since the precipitation was observed.

Decontamination of M-3-G-7 Loop, ETR, Idaho Falls. The M-3-G-7 Loop was successiuily ue contawinated using the glkaline permanganate pretreatmert rollowea ny an inhibited silfamic anid treatment. An overall decontamination factor of about 18 to 2.0 was obtained.

Dynamic Corrosion Rates at Elevated Temperatures. Corrosion testing Or several zirconium alloys. 304 stainless steel, and A2l2 carbon ste $\in I$ is continuing ir $700 \mathrm{~F}, \mathrm{pH} 10$ ( $\mathrm{LHOH}$ ), delonized water. After 2100 hours, the carbor steel. which had an initial penetration of $0.07 \mathrm{mil}$, was corroding at a rate of 0.20 ? $\mathrm{mil} /$ year. The stainless ste $\in$ l had an irttial penetration of $0.005 \mathrm{mil}$ and was sorroding at a rate of 0.04 mil/year.

Low $\mathrm{pH}(6.6$ Quachrom Gluccsate (PT-524). Coupon samples and K4N test elements have ascumul gt.ed 11 weeks exposure in SP-2, SP-x, and $S P-y$. Control facility SP $-x$ was inadvertently discharged by $K E$ processing; and the $K 4 \mathbb{N} \in$ lements were lost. However, diligent underwater search located the roupon holders that were in this facility.

3. Gas Atmosphere Stlidies

Resistance Measuremert Capsule. Following preliminary laboratory testing, a sapsule designed to measure the electrizal resistance of zirsonium oxide films was charged in KE reactor March 27, 1963. The atmosphere within the capsule at reactor startur was clean dry helium at $300 \mathrm{C}$. A decrease in resistance was observed at reactor startup. A further progressive decrease ir. oxide film resistance was measured durirg continued exposure to the dry helium. When $r \in$ sistarice measurererts dropped to 100 ohms, a small amount of water vapor was added to the gas inlet stream. The water vapor $r \in g \in n \in r a t e d$ the resistart oxide filre and the resistance measurements increased to 20,000 chms. Samples were again blanketed with dry helium and progressive decreases in resistance readings were observed unt1l the reastor sintdown, and the resistance again increased.

Graphite Birnout Monitoring. Smell graphite monitors discharged from channe.1 1880 at $K W$ Reactor showed very low burnolit rates. The test covered the period from December 11,1962 to April 4, 1963. The 
maximum rates were about $1.5 \%$ per 1000 operating days at distancs of 50 and 90 inches into the graphite stack. Low start-up i'requencie: and low oxygen concentrations, less than $0.0 .1 \%$ at equilibrium, we re important factors in reducing the measured burnout rates from $6 \%$ per 1000 operating days in the previous monitoring period.

Grap hite-Zirconium Compatibility in the N Reactor. Angivg ind digital computer programs are being used to study the N-Reactor gas atmosphere system. The analog calculations show that an initial gas composition of $0.5 \mathrm{~m} \mathrm{H}_{2} \mathrm{O}$, and 0.076 of $\mathrm{CO}, \mathrm{CO}_{2}$ and $\mathrm{H}_{3}$ if circulated through the reactor six times will lose enbugh waier to lead to possible zirconium hydriding conditions.

Results obtained from the digital calculations yield the following values for the partial pressure of water vapor entering the N-Reacts: stack when the flow rate is $400 \mathrm{cfm}$ and the partiai pressures of $\mathrm{Co}, \mathrm{CO}_{2}$ and $\mathrm{H}_{2}$ are all $0.076 \mathrm{~mm}$ : minimum water, $0.325 \mathrm{~mm}$; maximum water, ${ }^{2} 0.47 \mathrm{~mm}$. The maximim water value is based on a burnout limit of $2 \%$ per 1000 operating days (KOD) in the hottest grapinite in the stack, which is in the uncooled filler block and midway between two process tubes. For a 3\%/KOD limit the maximum water concentration is $0.71 \mathrm{~mm}$, and for $4 \% / \mathrm{KOD}$ the maximum water concentration is $0.94 \mathrm{~mm}$. A sumary of the water values in terms of dew point is given below:

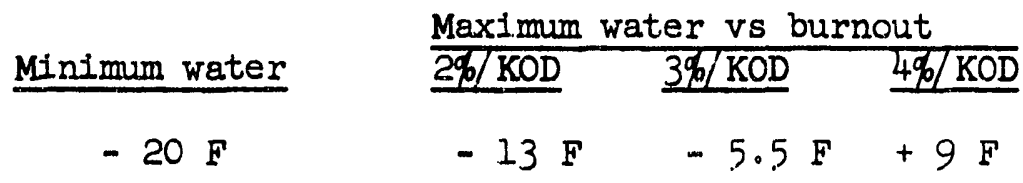

These results were based on the temperatures estimated in HW-64930 in 1960. Recent information indicates that the temperatures may be somewhat lower than originally salculated. The computer program is flexible enough so that temperature and other changes cail be included, and these will be studied in the next month or two.

It should be emphasized that the above calculations are obtained from a computational program embodying a particular model and using the best available data for the program parameters. The validity of the results depends upon how well the model represents the actual system and how good the data are. Until the calculations are checked experimentally for given conditions, the results should be considered as highly tentative. At this time the principal value of the program is to indicate the sensitiveness of computed compositions on the system parameters. 
4. Process Tube Development

Stress Rupture Testing of Reactor Presslire Tubes. An improved estimate has been made of the 20 -year rupture stress at $300 \mathrm{C}$ for $30 \%$ cold drawn and $35 \%$ tube reduced NPR process tubing. Stressmpture tests were conducted at $400 \mathrm{C}$ for both tube types at a stress of $42,000 \mathrm{psi}$. Time to mpture for the drawn tube was $86 \frac{1}{2}$ hours and for the tube reduced material 112 hours. Using the Larson-Miller parameter to estimate the corresponding rupture time at $300 \mathrm{C}$, the results indicate 526,000 and 695,000 hours, respectively. No claims are made at the moment for the validity of the LarsonMilier extrapolations.

5. Thermal Hydraulic studies

Present Reactor Studies. Flow tests were performed to determine the effect of a broken spline lodged in a " $K$ " reactor outlet nozzle. Standard " $K$ " outlet nozzles with and without the perforated plate covering the collectlon channel leading to the nozzle elbow were considered. The support charge consisted of (from front to rear) three 8-in. x 3/16-in. wall 16-hole perfs, either 8-in. tubulars, and two 8-in. x 3/16-in. wall 16-hole perfs. The results of these tests are summarized as follows:

\section{Type of Test}

(1) Nozzle with no perforated plate, no spline

(2) Same as (1) but with spline over collection chanr.e.

(3) Same as (1) but 1 ir. of spline extending into outlet opening

(4) Nozzle with perforated plate no spline

(5) Same as (4) but with spline over collection channel

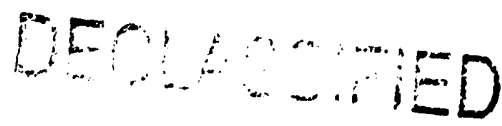

$\Delta \mathrm{P}, \mathrm{ps} 1$ at $10 \mathrm{C}$

(End Active

Section-Rear Heade.
Flowrate Bpm

55

55

55

56

55

32

55
$44 \cdot 3$

36
38 


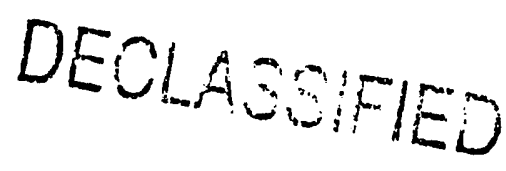

A $\cdots \cdot 17$

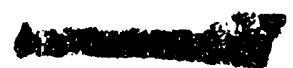

HW- 77397

These results indicate that the use of the perforated plate in the "K" outlet nozzle to sover the collection channel would decrease the pressure drop across the nozzle in the event of a broken spline becoming lodged over the outlet channel.

Flow tests were also performed on " $\mathrm{K}$ " and " $\mathrm{C}$ " reactor rear nozz.es to determine the pressure existing in the nozzle with the rtar connectors removed. A standard " $C$ " reactor rear nozzle with an $0.845 \mathrm{in.} \mathrm{nozzle} \mathrm{connector} \mathrm{adapter} \mathrm{and} \mathrm{a} \mathrm{"} K$ " nozzle with an 0.870 adapter were considered. At a tube flow of $50 \mathrm{gpm}$ of water at $20 \mathrm{C}$ to $27 \mathrm{C}$, the pressure in the rear nozzle was found to be 20 osiz: and 15.5 psig respecti vely for the " $C$ " and " $K$ " assemblies us ed in the tests.

II Reactor Studies. For the establishment and study of NPR boiling burnout limitations, it is desirable to express the burnout heat clux data obtained by the Heat Transfer Laboratory in the form of moirical correlations. A study was made of all correiations appearing in literature, and it was found that none would adequately describe the experimental information. Therefore, equations are being developed to fit these data. An empirical correlation which describes the relationship between the burnout heat flux, enthalpy and flowrate with an accuracy of $10 \%$ has been developed for the annular flow channels. Work on extending these correlations to other pressures and conditions is in progress.

\section{Shielding Studies}

The MAC computer code is being used to evaluate the shielding properties of Barytes concrete. These calculations will be compared with experimental data obtained when the Barytes shield blocks are taken Irom $105 \mathrm{DR}$. This work is still in progress.

In a test mu with the sample problem given in the MAC reference, HW-73381, it was apparent that the gamma dose at the inner shield regions erising from sources in the outer shield regions was not correct (This problem was first observed by Mr. U. Danali, EURATOM, Italy). A few minor modifications were made to the gamma subroutine at the suggestion of the MAC code author, E. G. Peterson. These modifications are currently being evaluated. 
Obtsining cross-sections for MAC input is complicated because of the 1 ta ge variety of elements in concrete and the fine group structure used by MAC. Steps are being taken to simplify input by calculating a cross-section listing, in proper MAC input format, for all elements of interest in MAC calculations. BARNS and the RBU Library are being used to supply the cross-sections. This cross-section listing will be published for general distribution and should make MAC more attractive for use outside $\mathrm{HL}$.

A master routine for BARNS is being prepared which will produce elastic, inelastic and capture cross-sections ready for MAC input.

BARNS in its present form will calculate group cross-sections from the point cross-sections, given in the RBU Library, for pure isotopes. Shielding calculations require cross-secti ons of naturally occurring elements; hence, combining of isotopic cross-sections is required. The above additions plus changes in output format for BARNS are being debugged.

A preliminary shielding program was prepared and reviewed. The final proposed program summary is now in preparation. Use of the shield plug assembly on top of the NPR in evaluating the primary shielding of the NPR during startup tests is being investigated. The facility was inspected and initial liaison has been established with the NPR staff. The feasibility of conducting concrete radiation damage studies is also being investigated.

7. Graphite Studies

N-Reactor Graphite Irradiations. The second second-generation capsule, $\mathrm{H}-5-2$, in the series of irradiations of $\mathrm{N} \cdots \mathrm{Reactor}$ graphite was removed from the GETR on April 3 after successfully completing 5 cycles ( 111.7 effective days) of irradiation. The maximum cumulative sample exposure is estimated to be $5 \times 10^{21} \mathrm{nvt}, \mathbf{E}>0.18$ Mev. All 9 thermocouples operated properly for the entire irradiation perlod.

Visual observation of the capsule in the hot cell disclosed that the stainless steel tube which protects the bottom end of the capsule was gone, apparently pulled off in some unknown manner by a vertical tensile force. Despite the loss of this protective cap, no unusual wear due to greater vibration was observed. 
The H-5-2 capsule was disassembled and all samples and flux monitors were recovered and appear to be in excellent condition. The amount of carbon deposit on the inside can walls was less than usual.

On April 3 the first third-generation capsule, $\mathrm{H}-4-3$, of the series was installed in the GETR. Installation and initial operation were entirely satisfactory, with sample temperatures matching those of previous capsules. The attempt to raise the temperature at sample position five was only partially successful. An increase of only $15 \mathrm{C}$ was obtained instead of the $50 \mathrm{C}$ expected.

The third second-generation capsule, H-6-2, in the series continues to operate satisfactorily. Number 5 thermocouple which failed early in the irradiation is still open.

\section{NEAFDNS - 03 PROGRAM}

- search and development in the field of plutonium metallurgy continued $\therefore:$ support of the Hanford 234-5 Building Operations and weapons deveiopment programs of the University of California Lawrence Radiation Laboratory (Project Whitney). Details of these activities are reported separately via distribution lists appropriate to weapons development work. 


\section{REACTOR DEVELOPMEATT - O4 PROGRAM}

\section{Plutonium Recycle Program}

Fuels Development

PRTR Fuel Element Development. The first UO2-PuO2 fuel cluster containing recycled FRTR Iutonium was completed and another is in process. A total of four swage-compacted clusters were fabricated.

Power Loading Studies. Conditions were determined for producing a unfiorm physical mixture of UO2-PuOs in a fuel rod by bottle loading. The bottled materlal mist be preblended for at least 30 minutes to achieve good unfformity. Additional tests are planned to determine the optimum blending time and to obtain statistical data on the uniformity of loadings produced by this method.

Nondestructive Test for Plutonium Segregation. Good linear correlation was found between a gama scan of a UO2-PuO2 fuel rod and the known plutonium concentrations in the rod. The rod contained UO2$\mathrm{PuO}_{2}$ pellets of various plutonium concentrations in the range from 0.1 to $1.0 \%$. Another rod is being made to permit calibration from 1.0 to $10.0 \%$ plutonium.

Cladding Integrity Studies. A review is being made or the fuel rod leak detection system to determine if an alternate method would be advantageous. The sensitivity of the vacuum leak detection method will be compared with that of the ANI pressure method.

Fnd Bracket Procurement. Specifications were written for off-site fabrication of the top and bottom end brackets of the PRIR 19-rod clusters. Purchase of these standardized items off-site will result in more efficient use of PFPP fanllities for fuel development work.

Examination of PRTR Nested Thbular Fuel Element. Destructive examination of the first Mark-II (concentric tubular) PRTR fuel element yielded needed information on internal pressure buildup caused by release of sorbed and fission product gases. The element (1501) was successfully irradiated to an exposure of $1360 \mathrm{MWD} / \mathbb{T}_{U}$. Measurements indicate that less than $10 \%$ of the fission gases and less than $50 \%$ of the sorbed gases were released during irradiation.

Predictions of the exposure at which the intermal cladding would fail by collapse were based on an assumed release of $25 \%$ of the fission gases and $75 \%$ of the sorbed gases. Information from the test element 
indicates that the calculated internal pressures are very conservative and that exposures more than twice those predicted $\left(25,000 \mathrm{MWD} / \mathrm{T}_{\mathrm{JJ}}\right)$ could be attained without cladding collapse.

Gross variations in fuel thickness, revealed during destructive examination of the outer component of the irradiated FRrg tubidisi fuel element, reflect fabrication difficulties. Tie largest viris.tion was measured 38 inches below the top end cap where the thickness ratio of diametrally opposed fuel sections was 1.55.

Post-1rradiation Examination of PRTR Fuel Element3. A ritraticnis? compacted UO2-Puक2, PRTR Mark-I element (5113) that failed during operation in the PRIR after an average exposure of $370 \mathrm{MND} / \mathrm{T}$ exLibited a brittle fracture, a precipitated second phase (possib?.e zirconium hydride) along the fracture suriacs, cracks in the ciadisio in the vicinity of the fracture, and minor fuel washout. Transvewa: cross-sections confirmed uniform distribution of the $\mathrm{P}_{10} \mathrm{O}_{2}$ enrichment and limited in-reactor sintering of the $\mathrm{UO}_{2}-\mathrm{PuO}_{2}$ cors. An unident:fied second phase was observed in the UO2-PuO2 core material only hit the vicinity of the failure (the material was sampled for analysis).

No detectable quantity of fuel particles was released intc the PRTR primary coolant following a cladding fallure of a vibrationally compacted $\mathrm{UO}_{2}-\mathrm{PuO}_{2}$, Mark-I element (5174) after an average exposure of $106 \mathrm{MW} / \mathrm{T}$. The reactor was shut down on $4 / 14 / 63,2.5$ hours after a steady increase in primary coolant activity indicatad a leaky fuel element. Primary coolant samples taken during oje.-iion and at the time of an activity burst during shutdown contained very little I-131 and I-132 activity. The gross activity was caused by xenon and krypton.

Examination of element 5174 revealed a 1/8-inch diameter hole through the zircaloy cladding in the top weld area of a rad in the 12-rod ring. The hole extends from the center of tine weld fusion band into the nonmelted fortion of the heat-affected zone. Due to the length of the end plus, the defect is not located over fuel material. The fracture surface of the base metal surrounding the hole appears brittle, and there is visual evidence of localized corrosion. Destructive examination is proceeding.

Routine examination of fuel element 1082 (hot swaged $\mathrm{UO}_{2}$ ) in the FEFF revealed a longltudinal scratch surrounded by discolored cladding on an outer rod about six feet below the top of the element. The outer wire wrap is worn approximately one-third of the way through at a point four inches below the top end fixture of the element. A large $1 / 2 \times 3 / 8$ inch) piece of hydrous aluminum oxide, apparently 
orlginating in the storage basin, was found wedged under the outer wire wrap in the vicinity of the element midpoint. This element will be refurbished by replacing the scratched rod and removing the outer wire wrap and installing wire bands.

Fuel "Refurbishing". Fuel element inspection and ring gaging in the PRIR basin indicates 10 to $20 \%$ of the fuel elements need some type of malenance. Bent pins and white corrosion spots are the most common difficulties.

PRIR Fuel Element Testing. A study is under way to assess the advantages of using the PRIR Rupture Loop as a research tool for testing fuel elements. Elements tested would Include types which it wou'd not be advisable to evaluate in a normal process channel; e.g., PuOz-UO2 elements with gross segregation of PuO2 or elements that have developed defects in service. The loop will be avallable for use approximately July 1963.

EBWR Plutonfum Fuel Elements. Work has started on the installation of additional vibrational compaction facilities in the PFPP. A prototype vibrational compaction facility was set up in the 325 Bullding to permit process development concurrent with project activities in the PFPP.

The order for 5000 pounds of fused $\mathrm{UO}_{2}$ for the BBWR load was altered to have the material crushed and screened to size, eliminating approximately one month of effort at HAPO.

Impaction of EBWR Fuel Material. Performance of the double can Impaction container assembly being developed for impaction of UO2$2.5 \mathrm{w} / 0$ PuO for EBWR was improved by inserting a strip of mild steel foil between the inner and outer cans. The steel acts as a getter of oxygen while the can is being heated to $1200 \mathrm{C}$, and thus prevents oxidation of the porous stalriless steel filter welded to the inside surface of the can $11 d$.

Irradiation Testing Program for EBWR Prototypic Fuel Rods. Highenergy-rate Impacted UO2-2.5 w/O PuOC was crushed and sized for vibrational compaction into capsules of EBWR fuel rod diameter. Two capsules containing impacted $\mathrm{UO}_{2}-\mathrm{PuO}_{2}$ and two containing a physical mixture of $\mathrm{UO}_{2}$ and $\mathrm{PuO}_{2}$ are to be included in an initial irradiation test. Bulk density of the encapsulated fuel will be 82 to $88 \%$ TD. The oxide fuel in each capsule will be blended before loadine, rather than incrementally loaded. Capsules will be irradiated at maximum BBWR conditions; $1 . e$. , a heat flux of 500,000 $\mathrm{Btu} / \mathrm{hr}-\mathrm{ft}^{2}$ and a rod power of $16.3 \mathrm{kw} / \mathrm{ft}$. The investigation will

UNCLASSIF IISD 
continue with 32 additional capsules and other prototypic f'uel rod irradiations.

Irradiation of High-Energy-Rate Impacted UO2-PuO2. Two 9/16-inch diameter capsules containing high-energy-rate impacted $\mathrm{UO}_{2}-\mathrm{PuO}_{2}$ were successfully irradiated in the MIR at suriace heat, fillues greater than $900,000 \mathrm{Btu} / \mathrm{hr}-\mathrm{ft} \mathrm{t}^{2}$. They were dischared attor reart: an exposure of approximately $1000 \mathrm{MWD} / \mathrm{T}$ fuel. Two similar capsules w1ll remain in the MTR to exposures of approximately $5000 \mathrm{MWD} / \mathrm{T}$ fuel.

Irradiation Performance of $\mathrm{MgO}-\mathrm{PuO}$ and $\mathrm{ZrO2-P102}$ Fuels. A hizh resolution autoradiograph of a $\frac{1}{2}$-inch diameter Mg-13.5 w/O PuO specimen, irradiated to approximately $10^{20}$ f'issions/cc at $\leq 1600 \mathrm{C}$ centerline temperature, illustrates self'-shielding effect.s. Not 100 . able fission product migration is not expected at this operating temperature, but the autoradiograph reveals a higher concertration of fission products near the periphery of the fuel. Also, the fission product distribution is not symmetrical, illustrating the greater power generation on the side nearer the center cf the MTR.

Fretting Corrosion Studies. Eddy current coils are to be used in fabrication of an element for PRTR impact (fretting) corrosion evaluation in the FDH-1 Loop. These colls will continuously monitor the relative position of the 12 outer rods of a 19-rod cluster with respect to the vertical test section. Vibrational compaction of a prototype fuel rod containing the eddy current coll produced spalling of the quartz coll base. Spalling was eliminated by surrounding the coll with -325 mesh $\mathrm{ZrO}_{2}$ powder before vibration.

Fuel Element Design Studies. A PRTR Mark-I fuel element having continuous ring contact surfaces on the end fixtures was tested 47 days at PRTR coolant conditions in the TF-7 facility. Only superficial wear occurred and only on the bottom ring even though the process tube was severely vibrated throughout the test.

Fuel Element "Rejuvenation". Three, one-foot-long rejuvenation f'uel rods were fabricated with $1 / 8$-inch ID stainless steel tubes down the center or the rods. One rod from the irradiated rejuvenation fuel element (GEH-4-81, now being returned from the MIR) will be combined with these three new rods to make a four-rod cluster test element for second cycle irradiation in the MIR.

Fast Reactor-Thermal Reautor Interchange Element. A fuel element was designed for proposed irradiation in both the PRTR and in a fast reactor. A design for a modiried PRTR process tube with inserts, 
required to accormodate the square array of fuel rods, was submitted to the Nuclear Safety Studies component for coment.'

Beryllium Joining. Initial metallographic examination of magnetic force resistance welds on beryllium supplied by France and oak Ridge was completed. This examination indicated welding conditions are obtainable that will limit recrystallization grain size to dimensions equal to, or only slightly larger than, the original grains in the French material. In the Oak Ridge material grain size in the weld area is either equal to, or smaller than that of the parent metal.

\section{Corrosion and Water Quality Studies}

Dissolution of Plutonium Ceramic Cores. The eighth test using irradiated MgO-PuO2 fuel rod sections in tne IRP was completed. Eighteen hours at $300 \mathrm{C}$ was required to dissolve the core of the element. The filter activity increase from the element was small, from $2.27 \mathrm{r} / \mathrm{hr}$ to $3.07 \mathrm{r} / \mathrm{hr}$. A $1.7 \mathrm{M}$ sulfamic acid solution with inhibitors was used for the dissolution step. The filter activity dropped to $2.06 \mathrm{r} / \mathrm{hr}$ during the pressurization of the chemical solutions in the loop and ald not change during an additional 45 minutes of recirculation at $40 \mathrm{C}$. The APOX solution was used for one hour at $105 \mathrm{C}$ and then $I M$ sulfamic solution was used. Reduction of the filter reading to $1.66 \mathrm{r} / \mathrm{hr}$ occurred during pressurization and did not change after $4 \frac{1}{2}$ hours at $70 \mathrm{c}$.

Facilities for Measuring Impact Corrosion of Zircaloy. A magnedash autoclave has been installed in the 314 loop and will be operating as soon as the loop is operating.

The second autoclave which is scheduled for installation in the PRTR is available and will be installed when the design change is approved. Installation of the unit during the month of April appears doubtful because of the large amount of maintenance work scheduled for the PRIR.

Impact Corrosion of Zirconium. A test in TF-2 facility was concluded to evaluate the use of a circumferential bumper spring support as a means of preventing impact corrosion of zirconium tubes with vertically suspended fuel assemblies, such as those in PRTR. A thin flat 302 stainless steel spring was affixed over the three support projections. After six weeks of operation at $300 \mathrm{C}, \mathrm{pH} 10$ LiOE, no sign of impact or fretting corrosion was noticed on either the Zircaloy-2 tube against which this test assembly was free to vibraie or on the steel spring. By comparison, similar tests without 
the spring resulted in several mils penetration in a shorter period of time. Although the increase in support area and reduction in amplitude of vibration undoubtedly acted to reduce the attack, the principal effect of the spring was probably to absorb the energy of impact.

PRIR Primary Coolant Zirconium Concentration. The program to routinely monitor the zirconium concentration in the PRTR primary coolant was continued. Bmission spectrographic techniques were used to obtain the analytical data. Recent results indicatie thres distinct points:

1. In general, the zirconium concentration was low, that is, in the 0-1 ppb range considered normal for this system.

2. Relatively high concentrations (2.5-10.0 ppb) were encountered for two days during and after replacement of several tube-to-nozzle gaskets. Resurfacing the tube flange faces might have introduced zirconium immediately prior to these measurements.

3. During the eight-day continuous operating period from $3 / 27-4 / 3 / 63$, the zirconium concentration increased markedly indicating a sustained high release rate of zircontum.

A continuous colorimetric procedure for measuring trace concentrations of zirconium in water was investigated. The procedure developed can detect concentrations as low as 1-2 ppb if the zirconium is present in Ionic form. Hydrolysis of the zirconium in aqueous solutions causes low results, however, and further tests have been discontinued temporarily pending development of a sultable procedure for converting all zirconium present to the ionic form.

Corrosion Rates and Deuterium Absorption of Zirconium Alloys in D2O. Samples of alpha annealed Zircaloy-2, Zircaloy-4 and crystal bar zirconium are being exposed at $275 \mathrm{C}$ and $360 \mathrm{C}$ in pure recirculated $\mathrm{pH}-10 \mathrm{D} 2 \mathrm{O}$ (99+ purity). The data after 28 days at $275 \mathrm{C}$ indicate no change in corrosion rate compared with $\mathrm{H}_{2} \mathrm{O}$ data. However, weight gains in $360 \mathrm{C} \mathrm{D} 2 \mathrm{O}$ are about $30 \%$ greater than previous runs in $360 \mathrm{C}$ $\mathrm{H}_{2} \mathrm{O}$. This is probably due to a brownish unidentified deposit found on the $360 \mathrm{C}$ samples. Initial deuterium absorption rates are higher in $275 \mathrm{C} \mathrm{pH}-10 \mathrm{D}_{2} \mathrm{O}$ than previous data in $300 \mathrm{C} \mathrm{pH}-10 \mathrm{H}_{2} \mathrm{O}$, while deuterium rates in $360 \mathrm{C} \mathrm{D} \mathrm{D}_{2} \mathrm{O}$ are lower than comparable $360 \mathrm{C} \mathrm{pH}-10 \mathrm{H}_{2} \mathrm{O}$ results. The hydrogen pickup resuits, particularly at $275 \mathrm{C}$, should 
be regarded as preliminary because of analytical uncertainties associated with the very low levels of hydrogen.

Steam Generatior Corrosion Coupors. Corrosion coupons placed in the secondary side of the main steam generator (BX-1) in June 1961, have been periodically examined and some replaced since their installation. The carbon and stalnless steel coupons are suspended on a vertical holder which placed some coupons in the steam phase and some in the water phese suring normal operation. All coupons are submerged during shuickiwn. The exposure perlod of samples reported on here was $2 y 5$ days (withdrawn in February 1963).

No cracks, pits or other local1zed corrosion of the 304 stainless steel coupons were noted during examination at 10X. The coupons displayed a light deposited film which was not removed because the coupons were returned to test. Previous experience has shown that the uniform corrosion of stainless steel in this system is extremely small.

The carbon steel coupons were welghed, examined, and two were stripped of corrosion product and deposited film. Minor pits were seen, especially in crevices, with one of the deeper pits measuring elght mils. A metal welght loss measurement corresponded to a uniform penetration of $1.4 \mathrm{mils}$. Two coupons carried over from the previous exposure period of 222 days showed only a minor change in welght and appearance. All coupons, except the two which were stripped, have been returned to test.

Reactor Components Development

Destructive Examination of Thube 0720. The eighth tube discharged from the PRIR under the PRTR pressure tube survelllance program was numbered 0720. The reason 0720 was discharged was that a $\mathrm{MgO}-\mathrm{PuO} 2$ fuel element muptured and it was consldered necessary to learn if this rupture caused hydriding of the tube. The results of the examination indicated that the rupture did cause localized hydriding of this tube and, therefore, tube 0720 had been compromised by the fuel element rupture.

Destructive Examination of Thab 5683. The ninth tube discharged from the PRTR under the PRTR pressure tube survelliance program was numbered 5683. The reason 5683 was discharged was that one PRIR operating month had passed since discharge of the eighth tube. This onerating month criteria for tube discharge rate was imposed by the Gelleral Electric Technological Hazards Counc1l. Thabe 5683 suffered $O D$ scratches during discharge. These scratches were observed and 
photographed while the tube was under water in the PRTR basin. In-reactor inspection of tube 5683 revealed several marks which had been caused by fuel wire wraps and by upper and lower fuel supports. Depth measurements of these marks varied from less than one mil to eight mils. The calculated fast neutron exposure of this tube was $4.8 \times 10^{19}$ minimum and $4.25 \times 10^{20}$ nvt maximum. In-reactor measurement of the ID was 3.252 inches. Pre-exposure inspection reports indicate that the ID was between 3.245 and 3.255 inches so there was good agreement beiween final inspection and in-reactor measurements.

Pre-exposure Inspection reports show that the 5683 had an unetched spot on the ID 13 feet from the flange and three scratches on the OD at one, six, and 16 feet from the flange, respectively.

The pre-exposure and in-reactor information on tube 5683 indicates that this tube would not have been considered a hazard. Sections of this tube are now ready for burst testing.

Pressure Tube Monitoring. Twenty-one process tubes were examined the latter part of this month. All of the tubes examined were located in the three center rows (1400, 1500 and 1600) of the PRTR. This inspection provided a fair sampling of fringe, charged with mixed oxide elements, and central, charged with UO2 elements, zone tubes. From this inspection, it is clearly evident that the wide pad or repadded and circumferentially bonded elements produce less fretting corrosion. Except for an 8- to 12-mil deep fretting mark, produced by the wire wrap on a single fuel rod, the fretting corrosion, in general, was not severe. There were, however, many new fretted areas assoclated with the spiral bundle wire wraps of the $\mathrm{UO}_{2}$ elements in those tubes which operated with $\mathrm{UO}_{2}$ elements for any period of time.

Fifteen of the tubes were also measured for ID's and eccentricity of the gas annulus. Although the data analysis is not yet complete, a preliminary check Indicates that all channels are within specifications.

Second Generation Mechanical Shim Rod for PRIR. Detailed design of the driving head including the assembly drawings, parts lists, and heat sinks is $95 \%$ complete.

Fabrication of the components for the first driving head is estimated 85\% complete. Fabrication of the components for the second driving head is estimated $40 \%$ complete. Orders have been placed for the rotary limit switches for both assemblies and the selsyn position 
Indication equipment for the second assembly.

Detalled design of the lower shim rod assembly, which includes the control rods, lead screws, guide extrusion, and shielding, is estimated $35 \%$ complete.

First Generation Mechanical Shim Rod Test. The new first generation PRIR shim rod has been installed in the kinvironment Test Facility and exposed to prototypical conditions (except for nuclear radiation) for 11 days. The shim rod has been operated brlefly each day. The only difficulty encountered to date has been the tendency of the single rod drive to coast downward. On at least one occasion the rod moved from full up to full down in about three hours. The tendency for the rod to coast has decreased with increased exposure to the operating environment, as was observed during initial shim rod tests.

EDEL-I Renovation. High temperature shakedown tests have been completed on the 100p. The system rupture disc flanges overheated as the result of convection currents in the stagnant line leading to the flanges, and it was necessary to provide cooling by wrapping the connecting pipe with copper tubing to pass cooling water. The disc remains within design temperature with this modification. The loop is eady ior extended operation.

Fretting Corrosion Investigation. Design is essentially complete on the pit piping to provide a prototypical PRTR pressure tube test assembly for the fretting corrosion investigation. Component parts such as the pressure tube, jumpers, and nozzle are belng gathered for installation. Testing will begin as soon as an instrumented fuel element is completed by the Advanced Fuels Development Operation.

A small autoclave was installed in EDL-I to be used as a fretting corrosion standard. Small Zircaloy-2 samples are installed inside tine autoclave with one being impinged on the other periodically by an external electromagnetic pulsing unit. Similar units will be installed on the PRTR primary lcop and in the Coolant Systems Development loop used for fretting corrosion tests. The results in these three units will be compared to determine if there is any effect from varying water chemistry in the three systems.

PRTR Rupture Loop Components. Discussions were held with Gray Tool Company on leakage and out-ci-round conditions experienced in testing of the stainless steel Grayloc connector for the PRTR Rupture Loop. It was determined that there was an error in the connector design. For improved reliability, Gray Tool Company will incorporate 
(a) a spherical nut seat and (b) a center relief groove in the clamps in replacement components. The spherical nut seat will reduce bending stresses in the clamp bolts and the center reliet groove is reported to yield more uniform clamping pressures around the hub.

PRTR Pressure Tube Seals. Design is $80 \%$ complete on a 3-station pressure tube seal test assembly to be installed on EDEL-I. Cap, nozzle, and bottom seals can all be tested at once on the three units.

Shroud Tube Replacement Mockup. Work is in progress to complete the shroud tube replacement mockup pit, which will be used to develop PRTR calandria shroud tube removal and replacement tools.

Hazards Analysis

PRTR Fuel Element Rupture Test Facility. Process Specirications for the operation of the PRTR Fuel Element Rupture Test Facility have been drafted and are being circulated for comment.

Plutonium Recycle Critical Facility. A hazards analysis of the Plutonium Recycle Critical Facility with light-water moderator and mixed-oxide fuel elements (fabricated for the EBWR loading) has been completed. It was found that operation under proposed limits would not lead to a nuclear accident in which fuel melting would occur. It was concluded that the severity of the credible accidents in PRCF critical experiments for the EBWR loading would be less than the maximum credible accident described in the original safeguards analysis.

Additional three-group diffusion theory calculations were completed for EBWR loadings to be investigated in the PRCF. An error in resonance self-shielding parameters which occurred because of an ambiguity in the GAM-I program description was discovered and corrected. This resulted in an over-estimate of the resonance absorption and, hence, critical mass for the loadings studied. There still appears to be some discrepancy between resonance integrals generated by GAM and measured values. However, parameters derived for excursion calculations on the analog computer are only slightly affected and it will not be necesisary to repeat the transient analysis. A summary of these calculations is presented in HW-69168 SUP2, "Plutonium Recycle Critical Facility Final Safeguards Analysis" 
2. Plutonium Ceramic Fuels Research

Preparation of High Density U02-2.5 w/O PuO2 Materials. High density ( $99 \%$ ID) U02-2.5 w/O PuO2 material was produced by arc melting pressed pellets under one atmosphere of argon. Pellets were first pressed without binder to a density of $5.89 \mathrm{~g} / \mathrm{cm}^{-3}$. After arc melting the material was massive in form, with a density of $10.99 \mathrm{~g} / \mathrm{cm}^{-3}$. Material loss was about $60 \%$ during melting, due to arc-blow of the powder released from the green pellet, presumably caused by incorrect arc distance from the tungsten electrode to copper hearth.

Impaction of Plutonlum-Containing Materlals. H1gh-energy-rate impaction technlques were used to impact specimens of PuN, a $50 \mathrm{v} / 0 \mathrm{PuN}-\mathrm{W}$ cermet, and $\mathrm{PuO}_{2}$. Complete containment of the plutonfum within the impaction assembly was realized in each case. The PuN was densified to $13.66 \mathrm{~g} / \mathrm{cm}^{-3}$ (95.9\% TD). Previous densification attempts by sintering and arc melting always resulted in the formation of Pu metal Inclusions due to thermal decomposition of the PuN. Microhardness of the impacted PuN was $460 \mathrm{kE} / \mathrm{mm}^{-2}$.

Dispersions of PuN and PuOz in AlN. PuN-50 v/O AlN pellets were heated in flowing He for 12 hours at $1700 \mathrm{C}$. Approximately $60 \%$ of the pellet mass volatilized leaving small gold-colored globules. $\mathrm{PuO}_{2}-50 \mathrm{v} / \mathrm{O}$ AlN pellets were sintered in flowing He for 8 hours at $1600 \mathrm{C}$. The sintered pellets were deformed and appeared to have lost about $25 \%$ of their mass.

Plutonium Cermets. Two mixtures of $\mathrm{PuO}_{2}$ and $\mathrm{Mo}, 28.6 \mathrm{v} / \mathrm{O}$ Mo and $50 \mathrm{v} / \mathrm{OMO}$, were pelletized and sintered in flowing He. The sintered densities were $91.9-92.5 \% \mathrm{TD}$ and $95.6-96.1 \% \mathrm{TD}$, respectively. Metallographic examinations showed the presence of the lamellar $\mathrm{PuO}_{1} .70$ eutectoid structure in each case. The PuO $2-x$ and Mo were uniformly distributed, but the continuous phase was PuO2-x. Phases identified by $\mathrm{x}$-ray diffraction were $\mathrm{PuO}_{2}, \mathrm{alpha}_{-} \mathrm{Pu}_{2} \mathrm{O}_{3}$, and $\mathrm{Mo}$.

$\mathrm{PuO}_{2-50} \mathrm{v} / \mathrm{OW}$ pellets were sintered in flowing He. Sintered densities ranged from 75.8 to $93 \%$ TD. The lamellar PuO .70 eutectoid structure was clearly visible in photomicrographs. The tungsten was uniformly distributed in a continuous $\mathrm{PLiO}_{2-\mathrm{x}}$ phase. X-ray diffraction showed the presence of $\mathrm{PuO}_{2}$, alpham $\mathrm{Pu}_{2} \mathrm{O}_{3}, \mathrm{~W}$, and $\mathrm{WO}_{3}$.

Instability of Molten (U, Pu) C. Preliminary data show that plutonium is lost selectively from molten UC-2 w/o PuC. Two buttons of this composition were held molten for $1,2,4$, and 8 minutes. The first button was made by turgsten arc melting from stoichiometric

UNCLASSIFIED 
UC $(4.8 \mathrm{w} / 0 \mathrm{C})$ and the second from slightly hyperstoichlometric UC $(5.2 \mathrm{w} / \mathrm{o} \mathrm{C})$.

Electrical Resistivity of PuC. The electrical resistivity of a 37.2 a/o C arc-cast PuC sample at $500 \mathrm{C}$ was $222 \mu \Omega$-cm. Heatine the sample to $520 \mathrm{C}$ caused the resistivity to abruptly decrease to $215 \mu \Omega-\mathrm{cm}$, and then slowly return to its original value in about 120 hours. A s1milar behavior was observed at $537 \mathrm{C}$.

3. Ceranic (Uranium) Fuel Research

U02 Performance Limits. Thermal expansion characteristics of $\mathrm{UO}_{2}$ may Impose an operating limit on $\mathrm{UO}_{2}$ fueled elements. Mathematical analyses indicate that the maximum permissille heat rating of $\mathrm{UO}_{2}$ fuel elements is sharply def'ined by fuel diameter and fuel bulk. density. It is considered possible to increase the neat flux limit by properly programing reactor startup to suitably modify the fuel structure during the early stages of irradiation.

Irradiation of Single Crystal UO2. Four test capsules containing various geometrical combinations of $\frac{1}{2}$-inch diameter sintered $\mathrm{UO}_{2}$ pellets and single crystal UO2 pellets were discharged after successful irradiation during one ETR cycle (approximately $1000 \mathrm{MW} / \mathrm{T}_{\text {fuel }}$ ) at a surface heat flux of approximately $800,000 \mathrm{Btu} / \mathrm{hr}-\mathrm{ft}^{2}$. Four similar capsules will be discharged after five ETR cycles.

Examination of these capsules will provide a direct comparison or the thermal conductivity of large grain and small grain $\mathrm{NO}_{2}$.

Optical Properties of UO2. Optical absorption data show that single crystal UO is significantly more transparent than polycrystalline UO2 in the infrared at wavelengths greater than $1.0 \mathrm{\mu}$. There is considerable transmission through single cyrstal specimens even in the visible wavelengths. Specimens less than $0.007 \mathrm{~cm}$ thick appear red in transmitted light.

Basic Materials for Research. $\mathrm{UO}_{2}$ single crystal spheres frrom 50 to $3000 \mathrm{mgs}$ in weight were prepared and characterized for shipment to Euratom for distribution to sites in Germany, and France. In addition, $30 \mathrm{kilograms}$ of high-energy-rate impacted vo2 were prepared, characterized, and packaged for shipment to Euratom for irradiation studies in $\mathrm{BR}-3$.

Preparation of Uranium Phosphide. A solid-solid reaction of stoichiometric amounts of uranium metal shot and phosphorous was used to produce UP. The reactants were sealed under an inert gas in a 
quartz tube within a stainless steel reaction tube and placed in a furnace for reaction. Preliminary data indicate a melting point of $1900+50 \mathrm{C}$ with no apparent reaction with the tungsten ribbon filament. A fraction of the material, probably UO2 inclusions, melted near $2700 \mathrm{C}$, suggesting some oxygen contamination during reaction. X-ray diffractometer and chemical analyses are now in progress.

Uranium Monosulfide. The melting poirt of uranium monosulfide (US 0.98 ) decreased $50 \mathrm{C}$ during irradiation to approximately $1.5 \times 1010$ fissions $/ \mathrm{cm}^{3}$. A $0.09 \%$ dilation of the US lattice and a $95 \%$ increase in hardness were measured previously.

Electron Microscopy of US. Uranium monosulfide was examined by reflection electron microscopy during controlled electron beam heating. Pronounced thermal etching occurred on the US and between grains, but individual particles of a second phase material remsined unchanged at temperatures to $1450 \mathrm{C}$. This behavior supports earlier suggestions, based on metallographic examinations, that the second phase may be UO2.

Alumirum Nitride. Because of its refractory properties, resistance to Iiquid metal corrosion, and low cross-section, aluminum nitride (AIN) is of interest for nuclear applications. Aluminum nitride ( -325 mesh powder with 5 w/o silicon carblle present as a solid solution) was heated to $800 \mathrm{C}$ in an evacuated container and high-energy-rate impacted at $188,000 \mathrm{psi}$ to form a compact disk. The density of this AlN was $2.3 \mathrm{~g} / \mathrm{cm}^{-3}$ (70\% ID) by Hg displacement; $2.93 \mathrm{~g} / \mathrm{cm}^{-3}$ (90\% TD) by $\mathrm{H}_{2} \mathrm{O}$ displacement; and $3.22 \mathrm{~g} / \mathrm{cm}^{-3}$ ( $99 \%$ TD) by He displacement. Measurements by Hg porosimetry ind1cated some $30 \%$ open porosity in the range from 10 to 0.06 microns.

Two corrosion samples of AlN, including one cracked open to expose a large surface area, were inmersed for 96 hours in $300 \mathrm{C}$ water. Based upon weight gains of both samples, conversion to $\mathrm{Al}_{2} \mathrm{O}_{3}$ with liberation of $\mathrm{NH}_{3}$ was complete.

U02 Cermets. Four-inch diameter, solld cermet discs approximately one inch thick were fabricated by high-energy-rate impaction. The large size of the cermets allows the machining of specimens of standard size for testing of mechanical properties. Cermets fabricated in this size include $\mathrm{UO}_{2}-35 \mathrm{v} / \mathrm{O} \mathrm{Nb}$, UO- $-35 \mathrm{v} / 0 \mathrm{MO}, \mathrm{UO}_{2}-35 \mathrm{v} / \mathrm{O}$ $\mathrm{Cr}, \mathrm{UO}_{2}-3 j \mathrm{v} / 0$ stainless steel, and $\mathrm{UO}_{2}-50 \mathrm{v} / \mathrm{O}$. 
Cermet Encapsulation. A technique f'or the encapsulation of cermets simultaneously with the jigh-energy-rate forming of the cermet was developed. The cermet powder was loaded in the impaction can and surrounded by a layer of metal powder containing no ceramic. The encapsulating metal was the same as that used for the matrix of the cermet. However, a metal different than that of the matrix could be used.

Irradiation Testing of Cermet Fuels. Six refractory metal clad cermet fuel capsules were fabricated for irradiation in the ETR. These capsules, which include two $\mathrm{Mo}^{-\mathrm{UO}_{2}}$ and two Mo-UN cermets clad in Mo, and one W-UO2 and one W-UN eermet clad in W, will be irradiated for relatively long times at cladding tenperatures greater than $2000 \mathrm{C}$.

\section{Basic Swelling Program}

Irradiation Program. Two controlled temperature general swellin; capsules reached their goal exposures and were discharged. One of the capsules operated at a constant temperature except for a 200-degree drop during a reactor outage that will have no bearing on the results. The second capsule cycled into the beta phase when control difficulties were encountered. This may well influence the observations.

A capsule containing specimens of high purity uranium, uranium with iron and silicon, and uranium with iron and aluminum is about $90 \%$ complete. Six additional capsules are in various phases of construction. These will contain high purity uranium, $U+\mathrm{Fe}$ and $\mathrm{SI}$, and $\mathrm{U}+\mathrm{Fe}$ and $\mathrm{Al}$ with vario's metaliurgical conditions represented.

Supporting Studies. Optlcal metallography is complete on a zeries of nonirradiated control specimens of Zircaloy-2 clad dual enriched uranium that had been annealed at $650,700,800$ and $950 \mathrm{C}$ for 100 hours. The penetration of uranium into the Zircaloy-2 was very nearly the same for the nonirradiated cortrol specimens as it was for irradiated samples given equivalent annealing treatments. There was essentially no metallographic evidence that zirconium had penetrated into the uranium. There were distinct differences between irradiated and nonirradiated specimens in the various compound layers that formed. Part of this variation is attributed to differences in cooling rate of the furnaces employed which may allow high temperature phases to transform on cooling. The major factor, however, that accounts for the differences is the swelling: that occurred in the irradiated uranium. The interdiffusion that 
occurred had a pronounced influence on pore formation in the uranium adjacent to the clad. This was the case for all temperatures studied. More study is required to fully understand. the significance and implication of this observation on fuel behavior.

The uranium-uranium interface was also examined in the control specimens. Surprisingly, a distinct challge in the appearance of this interface was observed. This interface could be seen in as-received samples as an irregular black line which at higher magniflcation looked as though it were actually a row of overlapping small pits. After annealing at $800 \mathrm{C}$ for 100 hours, this line is less distinct than after lower temperature anneals and after annealing at $950 \mathrm{C}$ for 100 hours, it has completely disappeared. Th1s line was thought to be due to the presence of small oxide particles that etched preferentially during metallographic preparation. The disappearance of the line, therefore, would indicate that the oxides were dissolved at $800 \mathrm{C}$ and above. This is somewhat surprising in that oxygen solubility is comonly belleved to be quite low in uranium. Additional specimens are beling annealed to learn more about the conditions urider which this Iine at the uranium-uranium interface disappears.

The stock of high purity uranium that has been used in this program has been exhausted and a second extrusion has been fabricated and evaluated. High purity dingot uranium was electron beam remelted. The resulting ingot was cleaned, triple-beta quenched, and then extruded at about a 16 to 1 reduction in cross-sectional area.

Chemical analyses were conducted ( $C, N$ and $H$ have yet to be reported) and extensive metallographic study performed on specimens representing each step of the fabrication. There were but very slight differences between the new material and the previously used uranium. It will hence be used as the source of specimens for high purity uranium for future irradiations.

Restrained Irradiations. The influence of restraint on the swelling of uranium is being investigated. Zircaloy-2 clad uranium rods with selected uranium temperatures, cladding thicknesses, and exposure are being irradiated in NaK-filled, temperature monitored capsules. Recent irradiations of $\mathrm{U}-2 \mathrm{w} / \mathrm{O} \mathrm{Zr}$ fuel, clad in Zircaloy-2, have shown that swelling is much worse in this alloy fuel than in unalloyed uranium irradiated under identical conditions. The purpose $0_{i}$ additional irradiations of Zircaloy-2 clad U-2 w/O $\mathrm{Zr}$ fuel in NaK capsules, now under way, is to f'urther investigate the swelling behavior and mechanisms in this alloy. One capsule has been aischarged 
at an exposure of $1100 \mathrm{MWD} / \mathrm{T}$. Evaluation of the behavior of the three fuel samples in this capsule will be used as a guide in determining the discharge exposure of the remaining capsules. The volume average fuel temperature of these samples was approximately $475 \mathrm{C}$.

Thorium. Two thorium specinens (B-2 and S-3) irradiated to 0.13 and $0.92 \mathrm{a} / 0$, respectively, have been annegled at $750 \mathrm{C}$ for 100 hours and are now being reprocessed for hardness, density, and metallography. No change in the external shape or appearance occurred during the anneal.

Thorium-Uranium. Four thorium-uranium tersile specimens (1.0, 4.0 and $5.4 \mathrm{w} / \mathrm{O} U$ ) were recovered from their respective noninstrumented, NaK-filled capsules and their densities determined. No change in the original density was observed. The specimens are now being tensile tested at room tenperature. The broken ends will then be processed for metallography and hardness.

\section{Irradiation Damage to Reactor Metals}

Alloy Selection. Procurement of materials to be used as test specimens for the Irradiation Effects on Reactor Structural Materials Program is continuing. Orders have now been placed for A-286, AISI 304, AISI 348, AM 355, and Zircaloy-2 alloys, thus completing this phase of the procurement. Witnessing of the fabrication of these alloys should begin the first week in May 1963.

Inconel 600 and Inconel X-750 alloy bar, plate, and sheet stock were hot rolled at the Huntington Alloy Product Division facllities on April 17 and 18, 1963. These alloys were hot rolled at $2200 \mathrm{~F}$ and a complete fabrication history recorded.

Tensile specimens of R-27, R-235, Hastelloy $N$, Inconel 625, Inconel 718, and TD Nickel were discharged from the ETR hot water loop facility and brought to the Hanfcrd Laboratories Radiometallurgy facility. These specimens were irradiated for one cycle to three different exposure levels at $280 \mathrm{C}$. Control specimens have also been received and will be examined to compare mechanical properties.

Oxidation resistance of various nickel base alloys is being compared by exposing heated specimens to flowing $\mathrm{CO}_{2}$ and observing changes in weight and microstructure. Two such tests were completed this month on Inconel 625 and TD Nickel exposed to $\mathrm{CO}_{2}$ at $1800 \mathrm{~F}$. 
In-Reactor Measurements of Mechanical Properties. The first test of a series to determine the stress dependency of zircaloy-2 during irradiation has now accumulated an excess of 2000 hours of test time. The $20 \%$ cold worked zircaloy -2 is being maintained at $350 \mathrm{C}$ with an applied creep stress of $20,000 \mathrm{ps} 1$. The creep rate at 1700 hours was determined to be $1.8 \times 10^{-6} \mathrm{in} / \mathrm{in} / \mathrm{hr}$. This rate is lower than the ex-reactor rate by an order of magnitude. The rate during the last reastor outage was so slow that it was difficult to measure accurately, but it appears to be slightly less than the rate during reactor operation. Creep rates during all reactor outages have been nearly equal to reactor operating creep rates for the stress and temperature conditions of this test. Opposite observations have been made for all previously reported tests at 250,310 and $350 \mathrm{C}$ where the applied stress was $30,000 \mathrm{psi}$. In these tests, reactor outage creep rates exceeded reactor operating creep rates. Additional tests will be made to determine if the observations made to date are the results of stress dependency.

Four ex-reactor $350 \mathrm{C}, 20,000$ ps1 Z1rcaloy-2 creep tests are in progress. For two of the tests the material is the same as that used in the in-reactor tests. The first of these tests has accumulated 1900 hours of which the first 100 hours yielded no usable data due to a stuck dial gage. The rest of the curve has the same tjpical shape as other ex-reactor curves. For the second test, increasing creep rates as a function of time are being observed. This is not characteristic of the material and loss of test control is suspected. The creep rates obtained in the latter portions of the first test are similar to those obtained on a second set of two tests. Zircaloy-2 specimens for these tests were obtained from material which was processed in the same manner as the original program material.

During the past month, another capsule was charged into the reactor with the anticipation of running a test at $310 \mathrm{C}$ and $35,000 \mathrm{psi}$. However, before reactor startup a leak was discovered in the reactor facilities and the test capsule had to be discharged. The creep capsule suffered only slight contamination and will be recharged at a later date.

Tensile testing of unirradiated Karma and Trophet A heating wires has been completed. Kanthal and 406 stainless steel wire have yet to be tested along with the irradiated counterparts of all four materials. 
Irradiation Effects in Structural Materials. The purpose of this program is to investigate the comoined effects of irradiation and reactor environment on the mechanical properties of structural materials. Special attention will be given to the determination of mechanical property changes produced in metals by irradiation at elevated temperatures.

During the month, 122 specimens were tested, 72 of which were irradiated notch tensile specimens of 21 rcaloy-2 and the remainder unirradiated control specimens. The control specimens included 24 tensile specimens of AISI 348 and AM-350 stainless steel and 10 tensile and 16 bend test specimens of Zircaloy-2.

A shipment of 294 specimens irradiated in the G-7, hot water loop was received during the month. This shipment contained tensile, notched tensile, and bend test specimens of zircaloy-2; AISI 304, 348,410 , and AM-350 stainless steels; and a variety of nickel base alloys. Neutron exposures for these specimens ranged from 1019 to $1021 \mathrm{nvt}(<1 \mathrm{Mev})$. Testing schedules for these specimens were established.

Twelve capsules containing stainless steel and nickel alloy samples have been sent to the EIR for Irradiation in the $3 \times 3, G-6$ position. Capsule design permits specimen surface temperatures to be that of the bulk reactor water $(\sim 120 \mathrm{~F})$. Since the G-6 position is adjacent to the G-7, hot water 100p, data obtained from these irradiations will separate the effect of irradiation temperature from the over-all efrects of reactor environment on metallurgical properties. The capsules will be charged at the end of cycle 54 for accumulation of neutron exposures ranging from $10^{19}$ to $10^{21}$ nvt.,

Two cryogenic apparatus for use with the Instron tensile instrument were developed. With the first a tensile test can be condusted in. a constant-temperature bath. With tile second the temperature can be continuously varied ietween 77 and $250 \mathrm{~K}$. Automatic temperature control is provided by a Brown recorder-controller; an electropneumatic converter; and an automatic, air operated, flow control valve. Iiquid nitrogen is vaporized, and streams of the vapor are directed on the specimen at a controlled rate by means of a perforated copper coil. The coil is especially designed to compensate for thermal gradients due to heat conduction from the grips and loading fixtures.

Tensile tests of transverse Zircaloy-2 specimens containing 0,10 , 20 , and $40 \%$ cold work were conducted at $-75 \mathrm{C}$ and $-196 \mathrm{C}$ using the constant-temperature bath apparatus. Tensile tests below room 
temperature serve a two-fold purpose - to determine the temperate at which ( $\left.1 \bar{L}^{\overline{2}} \mathrm{l}\right)$ and ( $11 \overline{2} 2$ ) twinning contribute to plastic deformation and to obtain strength values for use in fracture investigations.

Strains were measured with a Baldwin, separable-type extensometer, which was affixed to the test specimen and immersed in the bath. Prior to testing, the extensometer was calibrated over its entire extension range by a Boeckler screw and micrometer which was at equilibrium with the bath temperature. No decrement in Iinearity or accuracy of the inicroformer was observed for the two bath temperatures employed.

The $0.2 \%$ offset yield strength and the ultimate strength of Zircaloy-2 are about $80 \%$ higher at $-196 \mathrm{C}$ than at room temperature. The change in strength with temperature decreases with increase in temperature. Furthermore, the effect of cold work on strength varies with temperature. The difference in yield strength between annealed and $10 \%$ cold worked Zircaloy-2 increases with decrease in temperature. Greater amounts of cola work cause a marked, continuous increase in strengtin at room temperature; impart little edditional strength at $-75 \mathrm{C}$; and show a reversal in strength at $-196 \mathrm{c}$, where a maximum in strength occurs at $20 \%$ cold work.

The ductility of zircaloy-2 varles nearly in a linear manner with temperature below room temperature. Whereas the unfform strain of annealed, transverse specimens increases from 12 to $18 \%$ from 20 to $-196 \mathrm{c}$, the total strain decreases from 35 to $18 \%$ and the reduction in area is greatly reduced. Both uniform and total strain of cold worked specimens increase slightly with decrease in temperature. There is essentially no change in these properties with cold work greater than $10 \%$ at each of the temperatures of testing.

A test arrangement for inductively heating tensile specimens for testing at temperatures to $4000 \mathrm{~F}$ is being developed. Preliminary tests show that desired temperatures can be achieved with less than $5 \mathrm{kw}$ power input by employing tantalum susceptors. Current concentrators to attain higher temperatures with lower power consumption are being examined. An improved radiant lanp furnace has been designed and is being fabricated for high temperature testing in a variety of gaseous atmospheres.

Fracture studies of notched Zircaloy-2 specimens containing $23 \%$ cold work and tested in slow bending showed that a transition from ductile to brittle fracture occurs at $-80 \mathrm{C}$. The fractured surfaces of the specimens were examined by electron microscopy during the 
month. The microfractographs of specimens which failed by crack propagation transverse to the rolling direction had in general a ductile appearance both above and below the transition temperature. At temperatures below the transition, however, flat regions broken. by a network of striations were observed to be scattered throughout the structure. Crystallographic patterns having hexagonal symmetry ware also observed. These features appear to be related to the fracture mode and might account for the low fracture strength below -80 c. Sections tinrough the fracture trace of the broken bend-test specimens are being prepared for metallographic examination. Such examination will reveal tine modes of deformation that operate at temperatures above and below the ductile-brittle transition temperature.

Available information shows the impact transition temperature in Zircaloy-2 to be as much $0.5300 \mathrm{C}$ higher than the slow notch bend transition temperature. Charpy impact specimens are being prepared to attempt to find an explanation for so large a shift in transition temperature with strain rate. In addition to the cold worked material studied to date, slow notch bend specimens of annealed Zircaloy-2 are being prepared to determine the effects of cold work and anisotropy on the fracture behavior of Zircaloy-2.

Damage Mechanisms. The object1ve of this program is to establish the nature of the interaction between defects present prior to irradiation and those produced during irradiation, with emphasis on the role played by interstitial impurities. The investigation is presently concerned with high purity iron and its low carbon and nitrogen alloys.

Two alloys of Fe-T1 were prepared, one from Ferrovac "E", the other from Materials Research Corporation zone-refined iron, to investigate the effectiveness of $\mathrm{TI}$ in tying up interstitial impurities in iron. The amount of T1 added in each alloy was 4.5 times the interstitial content, an amount shown by previous investigators to be sufficient to remove the yield point in iron. The samples were prepared by co-melting the iron and titanium in a berylia crucible using induction heating and a graphite susceptor. The samples will be evaluated by tensile testing, electron transmission microscopy, and optical microscopy.

Thin foils of iron have been successfully deformed on the Instron testing machine and subsequently thinned and examined by electron transmission microscopy. The direct deformation of these foils was accomplished by gluing the ends of the foil to tabs winich in turn were held in the grips of the Instron machine. The use of an 
epoxy resin adhesive was found to be entirely satisfactory for this purpose. The method is superior to previous deformation methods using GE adhesive or Duco cement to hold a foil sample on a larger tensile specimen because it permits a direct measurement of the tensile properties of the foll material and deformations to fracture can be obtained where only a few percent strain was previously obtained.

Observations of an unirradiated foll of Johnson-Matthey Iron deformed $5 \%$ by the method described above show many dislocation tangles and no evidence of pile-ups. This observation is important in that many of the older theorles of yielding in iron were based on a mechanism of dislocation pile-up at grain boundaries. In addition, it was observed that the dislocation tangles were more numerous around the grain boundaries leading to the conclusion that the grain boundaries were sources of dislocations. Dislocation loops typical of plastically deformed materlal were also observed.

Zircaloy Corrosion and Hydriding. Hydrogen piakup results for several irradiated $z r-2$ coupons from quadrants 46,48 and 82 were obtained during the report period providing additional information on the variation of pickup of corrosion product hydrogen with work history. These coupons were rot analyzed for hydrogen previously because they were duplicates of analyzed coupons from quadrants 45,47 and 81 , both with regard to material and irradiation exposure history.

The fractional pickup of theoretical ccrrosion hydrogen for the annealed coupons was found to be consistent? y less than one-third of that found previously, while the pickup for $10 \%$ cold worked material remained approximately unchanged. At $20 \%$ cold work the values were up to $60 \%$ lower than the earlier results, and at $40 \%$ cold work tine pickup ranged to $40 \%$ lower than indicated eariler. Thus, these recent analyses do not show a tendercy for reduced hydrogen pickup at the level of $1.0 \%$ cold work so mich as a general trend of increased piciup witin increasing levels of cold work.

The only known difference between the histories of the sets of samples analyzed previously and those receritly aralyzed is a matter of about four months of additional auto-irradiation prior to analysis. To determine whether additional time and irradiation might have a measurable effect on hydrogen contert, samples of coupons from quadrants 45,47 and 81 were analyzed again for hydrogen content. Results were closely comparable with the previous 
data. Thus, the differences in hydrogen results are apparently real and independent of time and post-discharge auto-irradiation. The basic cause of the reduced hydrogen pickup shown by material in quadrants 46,48 and 82 remairs unexplained.

The overall averages of hydrogen fractional plckup results from more than 30 determinations performed to date on 18 irradiated coupons at each level of cold work show the following variation: $15,11,17$ and 20\% hydrogen pickup at 0,10,20 and 40\% cold work, respectively.

Oxidation of Superalloys. Oxidation tests on Hastelloy X, a nickel base superalloy, have been completed. Comparison of all welght gain versus time curves shows that surface preparation and $\mathrm{O}_{2}$ pressure have little effect on the oxidation kinetics.

Oxidation testing of Hastelloy $C$, a nickel base superalloy, has begun. Initial tests are on as-received (degreased) specimens. Two tests have been completed - one at $1000 \mathrm{C}$, one atmosphere laboratory air, and another at $1000 \mathrm{C}, 25 \mathrm{~m} \mathrm{O} \mathrm{O}_{2}$. Weight gain for Hastelloy C appears to be strongly pressure dependent. Welght gain in one atmosphere air is approximately twice that in $25 \mathrm{~mm} \mathrm{O}_{2}$ after 600 minutes of oxidation. The difference in welght gain thereafter remains approximately constant for the tests.

Lower oxygen pressure causes a rapid decrease in the initial oxidation rate, followed by an increase in oxidation rate after some time. In a test now in progress at $3 \mathrm{~mm} \mathrm{O}_{2}$ and $1000 \mathrm{C}$, the oxidation rate levels off rapidly and a slight weight loss is experlenced for a short period of time. Thereafter, the weight begins to increase normally. Since Hasteiloy C contains relatively high percentages of Mo and $W$, the welght losses may be caused by volatilization of Mo and $W$ oxides. Depletion of $W$ and Mo, or buildup of $\mathrm{N} 1$ and $\mathrm{Cr}$ oxides could hinder the process after some time. Subsequent metallographic observations of oxide and underlyine metal should clarlfy the mechanism.

Irradiation Damage to Inconel. A replica was made of the broken end of the Inconel helium gas loop pressure tube. The break appears to be intergranular with no visible shear lip. Metallographic samples were cut and are being processed from this portion of the pressure tube that had remained in the reactor because it had broken in half during removal. Replicas were taken from several sections of the Inconel tube that was originally removed from the reactor. These replicas will be used for electron microscopic examination of the precipitate at the grain boundaries. 
Irradiation Damage to Stainless Steel. Metallographic examination was started on the 347 SS pressure tube from the ETR-P7 10op. Samples were cut from the in-core and out-of-core sections of the tube; these will be examined before proceeding with mechanical tests.

Gas Loop Development. The design test for bending, thermal and

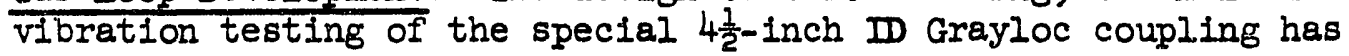
been prepared and forwarded to Equipment Laboratory and Testing, IPD, for coment and approval.

Welds of the superalloy candidates for use in the model ATR high temperature gas loop are being subjected to stress mupture tests at $1800 \mathrm{~F}$. Jolnts of Hastelloy $\mathrm{X}$ and Haynes Alloy 25 welded to themselves and to each other are belng tested. Inltial weld samples exhibited stress rupture strengths comparable to those strengths normal for the base metals. Half of the six samples tested ruptured in the weld while the other three ruptured in the base metals. Elongation for the samples ranged from about one to $16 \%$ with the two samples of Haynes Alloy 25 welded to itself, exhibiting the least elongation of about one and $4 \%$.

Radiation Damage and Dosimetry Studies. Detalled analyses have been made of neutron spectra in the N-Reactor latt1ce. These analyses were undertaken to determine spectral shifts and intensity gradients in the lattice which could produce differences in the rate of damage production in the structural materiale, and to provide a more accurate basis to convert test data to $\mathrm{N}$-Reactor conditions.

Analyses were made with a two-dimensional transport-theory code (2DXY). Elghteen energy groups were used, with 16 of these groups above $0.18 \mathrm{Mev}$. Spetial increments of $\frac{1}{2}$-inch were used in $x$ and $y$ axes.

Displacements in graphite were calculated using the de Halas model ${ }^{1}$ which considers hard shell as well as Rutherford scatterling. The gross production rate of vacancies - considering no concurrent thermal annealing - was found to vary by a factor of 1.9 across the $\mathrm{N}$-Reactor lattice. Since this rate is greatest in regions of low temperature where the damaging flux is highest and annealing is at a minimum, the net vacancy production will vary across the lattice by greater than the factor of 1.9 .

The graphite damage-production rate in the N-Reactor lattice will be compared with production rates $n$ facllities where the N-Reactor graphites are undergoing irradiation testing to determine if the

I R. E. Nightingale (ed.), Nuclear Graphite, Ch. 7. 
factors which have been used previously to correlate test data with reactor operation must be revised. Displacement production in the zirconium was calculated and it was found that the ratio in the process tube to that in the tubes used to cool alternate filler blocks is 1.6 , and the ratio to that of the fuel clad of the inner tube is 0.82 .

6. Gas-Cooled Reactor Studies

EGCR Graphlte Irradiations. The sixth capsule, H-3-6, in the series of Irradiations of EGCR graphite was installed without difficulty in the GBIR on April 3, 1963, and has been operating well.

The design modifications to lower temperatures at positions five and $s 1 x$ and which were made on the basis of computer analysis were very successful, achleving almost exactly the calculated temperatures. Thus, samples exposed to the most intense flux will be operating at about 450 to $500 \mathrm{C}$, considerably accelerating the production of data in this temperature range.

In-Reactor Creep. GHH-13-93 was installed in the F-6 position of the EIR on 3/15/63, and has operated for the last half of cycle 53. It appears to be working satisfactorily. It will bo removed at the end of cycle 54. GEH-13-94 is belng constructed and should be shipped during the next two-week period. GEH-13-94 will be installed for cycle 55 .

Boronated-Graphite Irradiations. Irradiatjon of two additional capsules (numbered 5A and $6 A$ ) has been coupleted. Length changes are shown in Table I. Sample GT-7 is not yet measurable due to high radioactivity ( $>5 R$ at $1 \mathrm{ft}$ ). 
Length Change of $B_{4} C$ Graphite as a Result of Irradiation

\begin{tabular}{|c|c|c|c|c|c|}
\hline Capsule & $\begin{array}{l}\text { Temp., } \\
{ }^{\circ} \mathrm{C} \\
\end{array}$ & Sample & Wt.\% B & Type & $\begin{array}{l}\text { Length Change, } \\
\text { of } \Delta \mathrm{L} / \mathrm{L}_{0}\end{array}$ \\
\hline $\begin{array}{l}5 A \\
5 A \\
5 A \\
5 A\end{array}$ & $\begin{array}{l}540 \\
540 \\
540 \\
540\end{array}$ & $\begin{array}{l}\text { JT-7 } \\
\text { JT-11 } \\
166-34 \\
\text { EM-1 }\end{array}$ & $\begin{array}{l}7 \\
7 \\
0 \\
5\end{array}$ & $\begin{array}{l}-- \\
\text { Gray } \\
-- \\
\text { Gray }\end{array}$ & $\begin{array}{c}-- \\
-0.081 \\
-0.041 \\
-0.169\end{array}$ \\
\hline $\begin{array}{l}5 \mathrm{~A} \\
5 \mathrm{~A} \\
5 \mathrm{~A} \\
6 \mathrm{~A}\end{array}$ & $\begin{array}{l}540 \\
540 \\
540 \\
320\end{array}$ & $\begin{array}{l}\text { DT-5 } \\
\text { ET-3 } \\
\text { DL-5 } \\
\text { ㅍL-17 }\end{array}$ & $\begin{array}{l}5 \\
5 \\
5 \\
5\end{array}$ & $\begin{array}{l}\text { Black } \\
\text { Gray } \\
\text { Black } \\
\text { Gray }\end{array}$ & $\begin{array}{l}-0.072 \\
-0.112 \\
-0.092 \\
-0.112\end{array}$ \\
\hline $\begin{array}{l}6 A \\
6 A \\
6 A \\
6 A\end{array}$ & $\begin{array}{l}320 \\
320 \\
320 \\
320\end{array}$ & $\begin{array}{l}166-6 \\
\mathrm{~L}-6 \\
\mathrm{HL}-16 \\
\mathrm{HT}-8\end{array}$ & $\begin{array}{l}0 \\
5 \\
7 \\
7\end{array}$ & $\begin{array}{l}-- \\
-- \\
\text { Black } \\
\text { Black }\end{array}$ & $\begin{array}{r}0.000 \\
-0.095 \\
-0.041 \\
+0.020\end{array}$ \\
\hline $\begin{array}{l}6 A \\
6 A\end{array}$ & $\begin{array}{l}320 \\
320\end{array}$ & $\begin{array}{l}\pi-9 \\
J T-5\end{array}$ & $\begin{array}{l}7 \\
7\end{array}$ & $\begin{array}{l}\text { Gray } \\
\text { Gray }\end{array}$ & $\begin{array}{l}-0.064 \\
-0.095\end{array}$ \\
\hline
\end{tabular}

The results show again, as in previous experiments, that the gray material contracts more rapidly than the black. The gray material contains the $\mathrm{B}_{4} \mathrm{C}$ more intimately than does the black, and it appears that fission recoll damage is responsible for the difference, i.e., the distance travelled by reaction products in graphite is larger in the case of fission in gray material. Althoush exposures are not known quantitatively, pending evaluation of flux monitors, it is known from the positions of the capsules in the reactor that $5 \mathrm{~A}$ recelved a larger exposure than $6 \mathrm{~A}$. The fact that the length changes for samples from the two capsules are about the same is undoubtedly coincidental, the higher dose in $5 \mathrm{~A}$ being compensated for by the lower temperature (and possibly higher sample boron content) of $6 \mathrm{~A}$.

It is important to be able to separate effects caused by fast neutrons from those due to boron fission. To that end, and also to enable reliable estimates of the heat-generation rate, chemical analyses of the boron concentration and distribution within the samples are being performed.

Flux Monitoring. The Fortran program, used to obtain neutron exposures from foil activation data, has been rewritten. Corrections are now made to account for burnout and in-reactor decay of both the 
fast and thermal neutron foil monitors. A memo has been issued, which outlines the derivation of equations and use of this program. Although it was written specifically for use with $\mathbb{N 1 - 5 8}$ and co-59 foll-activation data, it will readily handle activation data obtained from other types of folls.

Gas-Graphite Reactions: Radiolysis of co. The radiation chemistry of CO exposed to nuclear and ganma radiation at near atmospheric pressure has been studied by several investigators. 1-6 We have performed preliminary experiments at about $550 \mathrm{C}$ at pressures more nearly typical of gas-cooled reactors in "Y" test hole at C-Reactor. The CO was contained in sealed quartz capsules at test pressures in the range 1 to $18 \mathrm{~atm}$. Seven capsules comprifol this series. Following irradiation the capsules were opened anc. changes in gas pressure and composition were determined.

In all the capsules there was a decrease in the initial quantity of $\mathrm{CO}$, accompanied by the formation of $\mathrm{CO}_{2}$ and deposition of solids on the capsule walls. The formation of $\mathrm{CO}_{2}$ was proportional to the $\mathrm{CO}$ pressure and did not reach a limiting value. The average $\mathrm{CO}_{2}: \mathrm{CO}$ ratio and standard deviation were $0.42 \pm 0.07$. This value indicates an over-all reaction represented approximately by the equation $5 \mathrm{CO} \rightarrow$ $2 \mathrm{CO}_{2}+$ solids. The previously reported stoichiometry was $3 \mathrm{CO} \longrightarrow$ + deposit.

As shown by the equation there was an oxygen deficiency in the gas. From 71 to $84 \%$ of the original amount of oxygen was recovered from the gas at room temperature; however, the recovery improved to more than $90 \%$ after degassing the capsule at $1000 \mathrm{C}$ under vacuum. Thus, the deposit probably contained polymerized carbon suboxides (the monomer, $\mathrm{C}_{3} \mathrm{O}_{2}$, is unstable at the test temperature) and chemisorbed oxygen or carbon dioxide.

\footnotetext{
1 A.T. Cameron and W. Ramsay, J. Chem. Soc., 93, 982 (1908).

2 P.S. Rudolph and S.C. Iind, J. Chem. Thys., 33, 705 (1960).

3 S.C. Lind and D.C. Bardwell, J.A.C.S. , 47, $2 \frac{375}{675}$ (1925).

T.B. Copestake and N.S. Cormey, GCM UK/25.

R.E. Woodley, HW-31929.

R.E. Woodley, HW-40142.
} 
As suggested by previous investigators ${ }^{7}$, the reaction mechanism probably involves one or more of the carbon suboxide homologues, $\mathrm{C}_{2} \mathrm{O}, \mathrm{C}_{3} \mathrm{O}_{2}$, or $\mathrm{C}_{4} \mathrm{O}_{3}$, as irtermedlates in transporting carbon to the capsule wall. The first step involves the radiolysis of a molecule of $\mathrm{CO}$. Carbon suboxides are formed and polymerize and then partially decompose to yield $\mathrm{CO}_{2}, \mathrm{C}$ and a lower suboxide homologue.

The thermal decomposition of $C O$ was not studied in this invest1gation. However, it is generally belleved that a catalyst is required for this reaction to ocsur at an observable rate below 700 to $1000 \mathrm{C}$.

7. Graphite Radiation Damage Studies

Electron Microscopy of Irradiated Graphite. Comparison of replicas of ident1cal areas taken before and after Irradiation has been made on a second graphite sample 1rradiated at $700 \mathrm{C}$ in GEH-13-8 to an exposure of $1.1 \times 10^{21} \mathrm{nvt}, \mathrm{E}>0.18 \mathrm{Mev}$. The first sample studied was CSF graphite having a petroleum-coke ililer and coal-tar pitch binder. Broadening of microcracks in the coke particles during irradiation was reported earlier for that sample. The second sample was prepured with a natural-flake graphite f1ller and coaltar pitch binder. In addition to microcrack broadening simtiar to that noted previously, a serles of steps arranged in echelon across the sample surface developed during irradiation. The surfaces exposed on the steps are parallel to the well developed layered stmucture in the natural-flake filler. Shadowling on the step faces sugests that these surfaces intercept the polished surface or tine sample at an angle approximating the shadow angle of $35^{\circ}$. The step displacements measured would tinus be on the order of $80 \%$ of the actual displacements. Average dispiacements measured were $3 \mathrm{H}$, with a maximum of $4 \mu$ observed.

Thin sheets of binder material separating the natural-flake particles are readily detected on the pre-irradiation replicas. The displacements, which prodiced steps during irradiation, occurred at these binder-filler interfaces.

The presence of large displacements in the natural-flalie graphite and their absence in petroleum-coine jase graphite can be attributed

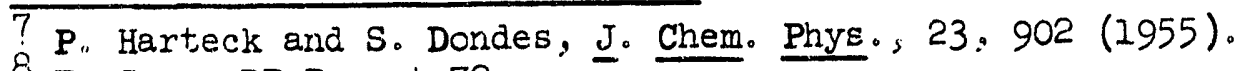

8 F. Coen, DR Report 72 . 
to several factors. Structural differences between birder and filler material and the assoclated differences in radiationinduced contraction are greater in the graphite made from natural flake and soal-tar pitsh thar. in the petroleum coke coal-tar pitch system. Stresses at binder-filler boundaries therefore increase with radiation dose at a higher rate in the natural-flake graphite. A low concentration of pinning sites at binder-filler boundaries provides the freedom necessary for large internal displacements when slip does occur, and these displacements are not transintted irom particle to particle as readily as in petroleum-coke base graphites having many more pinning sites.

The relationship of these observations to theories explaining bulk dimensional changes during irradiation is being explored. The accomodation of slip in highly ordered binder-filler graphite systems suggests lower internal stress exists in these graphites after manufacture because slip allows relief of some of the differential thermal contraction produced in cooling from graphitization temperatures. Since ordered graphites contract at lower rates than disordered graphites, the theory that bulk contraction is in part a process of stress relief is consistent with microscopic observations.

8. Aluminum Corrosion and Alloy Development

Dynamic Corrosion of Aluminum in a Norisothermal Loop. Four .20 -day runs have been completed in the nonlsothermal 1oop. The Pinst three runs were conducted with a small $\Delta \mathrm{T}(\sim 8 \mathrm{C})$, at $330 \mathrm{C}$ test section temperature, an aluminum area to $100 \mathrm{p}$ volume ratio of $1 . \mathrm{m}) \mathrm{In}^{2} / \mathrm{gal}$ and a refreshment rate of $0.1 .2 \mathrm{gal} / \mathrm{in}^{2} / \mathrm{hr}$. For the fourth run, the $\Delta T$ was increased to about $61 \mathrm{C}$, with the other variables held constant.

Corrosion penetrations were determined on samples from the same sample positions for all four runs $(4,5,8,9)$. The sample test section holds 12 samples, No. 1 being at the irilet end of the test section.

The first man at low $\Delta^{\mathrm{T}}$ showed a relatively high aluminum corrosion rate ( $1.4 \mathrm{mils}$ in 10 days). Rates observed during the second and third runs at low $\Delta T(0.96$ and $0.93 \mathrm{mlls})$ were similar to those observed in an 1sothermal loop operated at the same temperature.

At $\Delta \mathrm{T}=6 \mathrm{l} \mathrm{C}$, penetrations were high for samples at the inlet side of the test section and relatively low at the outlet side. Penetrations as a function of sarmle position were as follows: 
pos. 4, 1.9-mil; pos. 5, 1.8-mil; pos. 8, 0.95-mil; pos. 9, 1.03-mil. Flots of penetratior as a function of sample position were relatively flat for the low $\Delta T$ runs; at large $\Delta T$, the fier.trations were nearly a factor of two higher near the inlet than at sample positions 8 and 9. This strongly suggests that water entering the test section unsaturated, due to the large $\Delta \mathrm{T}$, rapldiy becomes saturated with corrosion product from the first few samples in the test holder and attacks the downstream coupons much less aggressively in the saturated stiate.

Effect of Oxygen on Aluminum Attack in pH-10 Water. Previous work on nickel-plated aluminum in high pH water inaicated an oxygen effect on the rate of attack or exposed aluminum. Further tests were mun to substantiate the observation. Two oxyger levels were investigated: $3-4 \mathrm{ppm}$ (normal $\mathrm{O}_{2}$ level in feed water) and < $0.1 \mathrm{ppm}$ : maintained by passing feed water through a Duclite-2 resin. In $300 \mathrm{c}, \mathrm{pH} 10.2$ water at $3-4 \mathrm{ppm}$ oxygen, the attack rate in a rine-day exposure was $0.82 \mathrm{mll} /$ day. At $\mathrm{pH} 10.3$ and $<0.1 \mathrm{ppm}$ oxygen the rate was $0.53 \mathrm{mIl} /$ day. Thus, the rate of attack was lower in the low oxygen system. A factor of five, previously indicated. was probably due to a combination of $\mathrm{pH}$, refreshment rate and oxygen differences.

Fabrication of C-1 Loop. Work on the C-1 loop has been progressing rapidiy during the month, and the shop work is $65 \%$ complete. About $85 \%$ of the 200 welds have been completed and have passed radiographic examinaticn.

Dynamic In-Reactor Corrosion Studies at High $\mathrm{pH}$. Analysis has been completed of the cor'rosion and film data from the first coupon test in H-1 Loop. This test ran for a total of 109 days, of wh1ch 46 days were at $550 \mathrm{~F}$, the remalrder being at low temperature. The average $\mathrm{fH}$ luring the high temperature operation was 7.9. Aluminum coupors exposed in the reactor core corroded at an average rate of about $1.0 \mathrm{mil}$ per morth compared to average rates of $1.9 \mathrm{mil} / \mathrm{mo}$ ard $2.7 \mathrm{mil} / \mathrm{mo}$ at water velocities of 15 and $25 \mathrm{ft} / \mathrm{sec}$, respectlvely, for aluminum coupons exijosed out-of-flux at the dowrstrean erd of the test section. No si-jniflcant difference was fiund between coupors exposed in-reactor at water velocities to 15 and 25 feet per second or between coupons exposed at the maximum radiation flux and those at about one-half maximum. There was no significant dif'ference between the corrosion rates of X-8001 and A-288 aluminum alloys compared or in-flux or cut-oi"flux bases. The higher corrosion on the out-of-flux coupors was in aereement with visual 
observation; they appeared more severely corroded than those exposed in flux. The above rates are averages over the 46day exposure at temperature. Since fresh aluminum surface corrodes at a high inftial rate, the equilibrium rate is less than this average. One out-of-flux holder was discharged in the midale of the test; from these data an equiliorium rate (during the latter half of the test) of $1.6 \mathrm{mils} / \mathrm{mo}$ was calculated.

The in-flux coupons were covered by a heavy brown crud deposit, which was not present on those exposed out of flux. Film weights (aluminum oxide plus deposited crud) were $9 \mathrm{mg} / \mathrm{cm}^{2}$ for the out-of-flux coupons and $12 \mathrm{mg} / \mathrm{cm}^{2}$ for those in flux. on the basis of visual appearance, the former was probably nearly all aluminum oxide while the latter contained a large fraction of iron oxide crud.

The out-of-flux corrosion rates are in agreement with those obtained ex-reactor (TF-6). It is considered likely that the crud deposit on the in-flux coupons protected the aluminum oxide from dissolution by the water and thus reduced corrosion. A spectrochemical analysis of the crud showed $\mathrm{Al}, \mathrm{Fe}$, and $\mathrm{Mg}$ to be the major constituents.

Examination at Radiometallurgy has been completed on the influx coupons from the second test in H-1 Loop. Conditions of this test were 37 days of operation at $550 \mathrm{~F}, 36$ days recirculation at low temperature, followed by 23 days on singlepass process water. The average pH was 4.9 (phospioric acid); the coolant velocity was $25 \mathrm{ft} / \mathrm{sec}$. The coupons of' aluminum and stainless steel, both in and out-of-flux, were covered with a fairly heavy rust-brown deposit similar to that in the first test. Similar deposition had occurred on the Zircaloy-2 but had flaked off from sizeable areas. Generally, however, the crud seemed somewhat more adherent than in the previous test at $\mathrm{pH}$ 7.9. The average weight gain of the in-i'lux Zircaloy coupons was $0.4 \mathrm{mg} / \mathrm{cm}^{2}$; the weight of crud removed was $1.1 \mathrm{mg} / \mathrm{cm}^{2}$. A spectrochemical analysis of this crud showed Al, $\mathrm{Fe}$, and $\mathrm{Mg}$ as major consittuents. The total corrosion of the stainless steel in-flux coupons averaged $0.05 \mathrm{mil}$; the crud depcsit, $5 \mathrm{mg} / \mathrm{cm}^{2}$. The aluminum and out-of-flux coupons are still being processed. 
9. Metallic Fuel Development.

ETR Irradiation of Thorium-Uranlum Fuel Elements. Irradiation of three tubular thorium - $2.5 \mathrm{w} / 0 \mathrm{U}$ (fully enriched) - $1 \mathrm{w} / 0$ $\mathrm{Zr}$, Zircaloy-2 clad fuel elements begar this month in the high temperature, high pressure EIR $8-7$ loop. The fuel is operating at a maximum specific power of $195 \mathrm{kw} / \mathrm{ft}$, a maximum surface heat flux of $978,000 \mathrm{Btu} / \mathrm{hr}_{-} \mathrm{ft}^{2}$ and a maximum core temperature of $565 \mathrm{c}$. The fuel elements, which are expected to go to a goal exposure of 3 a/o bumup, will be removed periodically and examined to determine swelling behavior and fuel performance.

Thorlum-Uranium Alloy. Two thorium - $2 \frac{2}{2} \% \mathrm{U}$ (normal) - $1 \% \mathrm{Zr}$ alloy billets for coextrusion to clad rod stock have been machined along with the copper and Z1rcaloy-2 components. Extrusion conditions for the rod stock will match those used on the enriched material. Samples will then be prepared for visual autoclave defect testing.

10. USAEC-AECL Cooperative Program or Development of Heavy Water Moderated Power Reactors

Thermal Hydraulics Studies

Two-Phase Psessure Drop Program. The experimental portions of the study of the two-phase pressure drop in standard comercial piping components were concluded. Approximately 2700 pressure drop measurements were obtained on 2-irch pipe and fittings. These fittings included:

(1) a branch tee,

(2) elbows with 2-, 3-: and 10-inch radius of curvature,

(3) expansions and contraction of $2 \times 3,2 \times 1 \frac{1}{2}$, and $2 \times 1$ inches,

(4) a 2-inch gate valve, ard

(5) a 2-inch globe valve.

Data were obtained at pressures of 800,1200 , and 1600 psia and flow rates of $1.0,2.0,3.0$, and $4.0 \times 10^{6} \mathrm{lg} / \mathrm{hr} / \mathrm{ft}^{2}$. Steam qualities up to $24 \%$ were considered.

Preliminary comparisons have beer made between the experimental data and the predicted pressure drop values obtained from the

UNCLASSIFIED 
Martinelli-Nelson two-phase pressure drop correlation. These comparisons have indicated that the ratio ( $\left.\phi^{\prime}\right)$ of the twophase pressure drop to the single phase pressure drop for elbows was 80 to $100 \%$ of the value predicted by the MartinelliNelson Correlation. This ratio was observed to approach the predicted values at the higher qualities considered. For contractions, the ratio $\phi^{\prime}$ was 50 to $65 \%$ of the predicted values, comparing better at the lower qualities. The ratio $\phi$ for the branch tee was about $70 \%$ of the predicted values throughout the quality range considered.

19-Rod Burnout Studies. Experiments were started to determine the bolling burnout heat flux limitations of 19-rod bundle fuel elements cooled by steam-water mixtures. Using an electrically heated test section, boiling burnout experiments are being performed at mass flow rates ransing from 0.5 to $2.0 \mathrm{lb} / \mathrm{hr}-\mathrm{ft}^{2}$ and inlet coolant qualities from 0 to $25, \%$ by weight at a pressure of 1000 psia.

The test section was made up of 19 inconel rods, each 0.587 inch in diameter and $19 \frac{1}{2}$ inches long. Spacing between the rods of 0.074 inch was maintained by "warts" or spacers located at two cross-sections on the heated portion of the bundle 6.25 inches from the ends of the heated section. Upstream from the heated section was an unheated portion on which a flow diverter was located. The purpose of the diverter was to suppress the possible occurrence of an annular flow pattern with respect to the pressure tube. The flow diverter was installed 14.5 inches from the end of the heated length and served to channel all of the coolant flow at that one cross-section to the inner portions of the bundle. Each of the tubes had a thermocouple installed at its downstream end to measure an average inside wall temperature. The test section was installed in a vertical 3.25inch ID pressure tube.

Initially, seven experiments were performed at the lower coolant flow rates. The boiling burnout heat fluxes determined in these experiments did not agree with values predicted with the ald of earlier data and, furthermore, they exhibited erratic trends. This behavior was attributed, in part, to the possible occurrence of flow surges in the piping between the electrically heated steam generator and the inlet of the test section. Such surges could be accompanied by large variations in the inlet coolant quality, and these varlations may have caused a premature initiation of the boiling burnout. Suitable 
changes were made in the inlet piping to preclude the future occurrence of flow surges, $:$ id the experiments are being rerun.

Dome Seal Type Closure. Initial tests on the dome seal revealed significant deformation upon thermal cycling. A second dome, with a $17 \%$ thicker dome and $17 \%$ shorter (narrower) seal contact edge, was fabricated and tested. After three assemblydisassembly cycles and 256 hours of steady-state operation, a peranent deflection at the center of the dome of 0.026 inch wras measured.

The second dome was reinstalled in the test nozzle and thermally cycled more slowly than in previous thermal cycle tests wherein the test sectior, was valved suddenly into and out of the hot $(570 \mathrm{~F})$, pressurized (1500 ps1) 100p. There was no additional dome deformation noted after the next three cycles (6 total). Two additional cycles ( 8 total) were sun before the dome was next checked, at which time an additional deformation of 0.007 inch was measured. There was no cetectable additional deformation after the rext ( $9 t h$ ) cycle.

The initial dome tightening torque is $100 \mathrm{lb}-\mathrm{ft}$. The disassembly torques for the 4th through the 9 th cycles have been $75,95,125,125,150$, and $165 \mathrm{lb}-\mathrm{ft}$, respectively.

The first dome, at the start of assembly-disassembly tests, had deflected 0.035 inch ard after five more cycies had deformed an additioral 0.041 inch. The second done at the start of "slow heat" assembly-disassembly cycles had deflected 0.026 inch, and after five additional "make-hreak" cycles had only deformed an aditional 0.007 inch.

It is believed that the previous procedure of keeping the loop at $570 \mathrm{~F}$ and then valving the rool test section back into this hot supply caused a thermal shock to the dome. The relatively thin dome would heat up and expard much faster than the massive nozzle. With the center of the dome rigidly restrained by the tightened nut ( $100 \mathrm{lb}-\mathrm{ft}$ at assembly) stresses developed in the center portion tended to permanently deform the dome.

The tests wherein the dome and nozzle are heated and cocled slowly tend to confirm this theory. However, the gradually increasing disassembly torques and the 0.007 -inch additional deflection after cycles 7 and 8 are presently unexpleined. It is still believed that the permanert deformation is the result of 
either testing techniques or the method of locking and restraining the dome in the seai rather than the result of simple stresses resulting from pressure on the dome. The testing is continuirg.

11. Advanced Reactor Concept Studies

Fast Supercritical Pressure Power Reactor. Further 18-group diffusion theory calculations were compieted to determine the effects of burnup on reactivity and power distribution. All calculations used "hot" U-238 cross sections for an average fuel temperature of $1000 \mathrm{C}$. Axial leakage effects were ulso Included in the calculations. The core arrangement is the same as reported last month except for the final radial dimen. slons which are as follows:

$\begin{aligned} \text { Flux Trap } & \begin{array}{ll}\text { Inner Core } & 47.6 \mathrm{~cm} \\ \text { Depleted U } & 55.6 \mathrm{~cm} \\ \text { ZrH Moderator } & 58.6 \mathrm{~cm} \\ \text { Depleted U } & 66.6 \mathrm{~cm}\end{array} \\ \text { Blanket } & \left\{\begin{array}{lr}\text { Outer Core } & 88.0 \mathrm{sm} \\ \text { Depleted U } & 92.0 \mathrm{~cm} \\ \text { ZrH Moderator } & 95.0 \mathrm{~cm} \\ \text { Depleted U } & 125.0 \mathrm{~cm}\end{array}\right.\end{aligned}$

The critical mass of this core design is about $1350 \mathrm{kgs}$ fissile plutonium for a six-foot core lengti. Enrichment redistributior. has obtained the proper power output for each coolant pass. ylelding a radial peak to average core power ratio of 2.2 .

Calculations show that enrichment of the depleted UO2 regiors with 2.0-2.5\% fissile plutonium results in a substartial reduction in critical mass and a flat reactivity transient with burnup. Recent calculations show a gain in reactivity of $0.8 \%$ $\Delta \mathrm{k} / \mathrm{k}$ over the initial three-year ccre exposure. Changes in the depleted $\mathrm{UO}_{2}$ region $\mathrm{Pu}$ enrichment and fuel density should result in good reactivity characteristics and power distribution over the core Iife.

Recent calculations also indicate that the coolant void coefficlent now tends to become more positive as core exposure increases. In the core considered the void effect varied from $0.0 \% \Delta \mathrm{k} / \mathrm{k}$ at the start of core 1 ife to about $+0.3 \% \Delta \mathrm{k} / \mathrm{k}$ at. three years of core exposure. This can easily be reduced by ininor adjustments in the core design. 
Previous calculations of the conversion ratio were found to be high because of an error in plutonium cross sections used to compute core average reaction rates. Values now used for this purpose indicate that the breedirg ratio will be in the range 1.1-1.2.

The power normalization subroutine in HFN was found to be incorrect. The error was in the integration of the fission neutron density over the core volume. The subroutine was corrected and recompiled such that fuel burnup may now be calculated directly from normalized reaction rates.

Drafting work was infliated on fuel element design and piping layout studies. Two major changes were made in the FSPPR fuel element. The first concerns the method of connecting the uppass and down-pass tubes to the mixing bowl. Approximately two feet of each coolant tube will be bent into a helical coil between the bottom of the lower axial blanket and the mixing bowl. This method is proposed to relieve the thermal stresses which would develop from rigidly connecting the hot up-pass tubes to the relatively cold down-pass tubes through the mixing bowl. The top of the mixing bowl was made spherical to generate more surface in which to weld the coolant tubes.

The second major change was in the method of ccoling the fuel element outer cladding. The pressurized helium cooling system was abandoned because of the complexity of supporting the fuel elements, and refueling through the pressure vessel which would be required. The fuel element cladding will be cooled by the tube-in-wall method. The down-pass coolant in each fuel element will be used to cool the cladding.

At present, adequate fission gas venting would be provided by closing the ends of the elements only with a fibrous ceramic insulation. At the lower end the insulation would be supported by an alloy plate perforated for loose fit on the coolant tubes. various fuel and core support methods are being studied to determine a method which appears most likely to reduce thermal stress and core mobility problems.

Preliminary studies of jumper layout between the fuel elements and headers were made. The compact core severely limits the space available for locating the coolant supply and return jumpers on the fuel elements. However, an acceptable arrangement is indicated. Each fuel element in the first and second coolant passes will be provided with one inlet and one outlet 
jumper. Jumpers are sized for maximum coolant velocities of $20 \mathrm{fps}$ at feedwater temperature $(540 \mathrm{~F})$ and $200 \mathrm{fps}$ at superheated vapor ten sratures (above 815 F). The third pass (core center) will require two irlst fumpers sized fior 200 fps maximum coolant velocity and one outlet jumper having a sinort rtn velocity in excess of 250 fps.

Ring headers are located concentric with and above tile core in a pipe gallery measuring about $15^{\prime}-18^{\prime}$ dia $x$ 10' high. The four pipes going to outside equipment (turbire and feedwat,er lines plus two reheat exchanger lines) are man in a fipe tunn: through the shield.

A maximum of 12 control and safety rods will be located in the inner moderator zone. All rods will be housed inside guide tubes which extend through the core, the jumper gallery above the core, and the top shield. Control nechanisms are iocatied above the shield.

The reactor tank is aluminum alloy, about 9' dia $\times 35-40^{\prime}$ long $x$ I" thick wall. The core is located at the top of the tank. The tank is lined with $\mathrm{S} / \mathrm{S}$ foil insulation on the inside ard water cooled on the outside.

Based on a cursory economic comparison of capital linvestment versus refueling down-time, a second (duplicate) reactor cornpartment is being provided in this conceptual desigr. to study 1ts effect on plant layout. Inltially, only the reactor tark: pipe tunnel, inaccessible piping and support stmucture, and a larger shield pool would be constructed. Ring headers, shiela plug, controls, and the fuel elements are purchased and ir.stalled only when the first core loading is ready for termira. tion. All radial shielding is by natural water. The shield plus above the reactor may be a water and steel combinatior to reduce thickness requirements.

Normal refueling is conducted batch-wise at lorg (two to fiveyear) intervals. Spent cores can be decay-cooled ir-situ until ready for shipment to a reprocessing plant. A "last-ditch" boric acid system is provided to flood the reactor tank. Containment is provided by vapor-suppression with steam ducted to the bottom of the shield pool by the pipe tunnel. The heat capacity of the shield water is very large compared to the stored energy in the high pressure coolant. Estimates of the energy release from thermal capacity, power transient, and decay heating of the fuel are under way; chemical reaction of the moderator wili be investigated. 
The Fast Supercritical Pressure Power Reactor Plant net efficlency is revised to $44.3 \%$ from the $43.8 \%$ previousiy reported. The increase has resulted from the use of tubein-wall method for cooling the fuel element jackets. This method employs the process feedwater and/or steam as jacket coolant and thereby permits the maximum utilization of heat for cycle heating and energy conversion. While secondary gas cooling system did allow transfer of all heat to the feedwater, none of the heat was directly convertible to electrical power.

Plutonium Fuel Spacecraft Power. An Informal report on the Plutonium Fuel Spacecraft Power concept study has been printed and is awalting recelpt of the lliustrations from printing to be issued.

Plutonium Fueled Rocket Reactor. A conceptual design study is being inftiated of a fast-spectrum nuclear reactor for rocket propulsion. The reactor type chosen for study is a $1000 \mathrm{Mw}$ fast spectrum reactor, fueled with a plutonfum nitridetungsten cermet fuel. Coolant (hydrogen) exit temperatures of about $4000 \mathrm{~F}$ are envisioned.

\section{DIVISION OF RESEARCH - 05 PROGRAM}

\section{Radiat1on Effects on Metals}

This program is almed at establishing the combined effect of impurities and neutron irradiation on the properties and structure of specific metals, and deducing from thermally activated recovery processes how the damage state can be altered. Studies on irradiated single crystal and polycrystalline specimens of molybdenum containing carbon as an intentional impurity are continuing. Similar studies have been initiated on the metals rhenium and nickel.

Single Crystal Molybdenum. Lattice parameter measurements have veen completed on molybdenum single crystals representing three levels of controlled carbon impurity. Specimens of each carbon level were measured in the unirradiated state and after $10^{18} \mathrm{nvt}(\mathrm{E}>1 \mathrm{Mev})$. All crystals showed varlations in lattice parameter from point to point on the crystal surface, with the higher values found nearer the center of the crystal rod. The total variation in each crystal ranged from 0.01 to $0.02 \%$. Each crystal was examined at three points; edge, halfway between edge and center, and center. Duplicate measurements 
were made at each point, making a total of six or more measurements on each sample crystal.

Comparison of corresponding points or the irradiated and unirradiated crystals revealed a decrease of about $0.01 \%$ In lattice parameter for the low carbon (10-20 ppm C) crystals and an increase of about $0.01 \%$ for the medium carbon (100-200 ppm C) and high carbon (400-500 ppm C). Since these changes are smaller than the point-to-point variation within an individual crystal, they cannot be considered a result of irradiation.

A number of unirradiated molybdenum crystals have been annealed for one hour at $2000 \mathrm{C}$ in an attempt to eliminate the lattice parameter variations described above. Measurements are also being inftiated on single crystals irradiated to $1019 \mathrm{nvt}(\mathrm{E}>1 \mathrm{Mev}$ ).

The molybdenum single-crystal rods available for this study have been restricted in rod orientations to a rather limited range between [0O1] and [011]. There were no specimens available with a rod axis near [111]. Since [111] is the close-packed direction, rods of this orlentation might provide useful information as tensile specimens or length-change specimens. Seeding experiments have therefore been initiated in order to obtain such specific orientations. A crystal with an orientation near [011] was bent until the [111] was parallel with the axis or the urbent rod, and a fact sut perpendicular to the [111] axis. The seed face and the polycrystalline molybdenum stock were placed in juxtaposition in the electron-beam zone-refining apparatus, and growth of the crystal was begun at the point of coricact. The finished single-crystal rod did lndeed show a [111] rod axis. The seeded rod is now being used for seeding and growth of additional rods. Other orlentations can be seeded as well, so that in the future crystal orientations need not be dictated by the material available.

Polycrystalline Molybdenum. Operational tests on the differential stored energy calorimeter are still in progress. The present control system supplies a maximu of 410 watts to the external heater surrounding the isothermal chamber, and with a heating rate of $2 \mathrm{c} / \mathrm{min}$ the maximum temperature obtainable is $400 \mathrm{C}$. Modifications are in progress to enable the external heater to produce over 2000 watts. Folls of mol ybdenum containing $10 \mathrm{ppm} \mathrm{C}$ as well as stock containing 
as high as 400-500 ppm C were irradiated to $10^{19}$ nvt (fast). Radiation damage has been studied by $\mathrm{x}$-ray and electron microscope techniques as a function of post-irradiation annealing to temperatures as high as $750 \mathrm{C}$. Similar foils have been annealed at $900 \mathrm{C}$ for two hours and examination is in progress. The lattice parameter of molybdenum foils containing $10 \mathrm{ppm}$ carbon, $100-200 \mathrm{ppm}$ carbon, and 400-500 ppm carbon returned to the pre-irradiated values following the $900 \mathrm{C}$ anneal. Some recrystallization may have occurred at $900 \mathrm{C}$ in the foils containing $400-500 \mathrm{ppm}$ carbon 8.5 tine (400) peak intensity is much lower than the pre-irradiated value. Examination of this foil in the electron microscope disclosed very few dislocation loops. This observation is markedly different for folls wich had been annealed at $750 \mathrm{C}$ and showed many large dislocation loops. There is an apparent breakup of defect clusters due to thermally-activated dislocation motion at the higher temperature. Results on the foils contalning less carbon will be forthcoming.

Foils of molybdenum irradiated to $10^{19} \mathrm{nvt}$ become severely cracked when stralned in the range 1-2\%. Samples wh1ch had been Irradiated to $10^{18}$ nvt exhibited considerable ductility and did not crack after 2-3\% strain. Electron microscope examination of the deformed folls ( $1018 \mathrm{nvt}$ ) disclosed dislocation tangles simliar to those found in unirradiated folls. Channelirg of dislocations, which was observed in folls $1 \mathrm{r}$ radiated to $1019 \mathrm{nvt}$, was not observed in the folls having the lower dose. Extensive embrittlement has occurred between the two exposures. Samples have been prepared for irradiation to 3 and $6 \times 10^{18}$ nvt to further investigate deformation modes. Microtensile samples have also been prepared and submitted for irradiation to $10^{19}$ nvt.

Foils of molybdenum, $2000 \mathrm{~A}$ thick, have been bombarded fission fragments. Examination of these folls discloseo is damage which could be directly ascribed to fission fragmeitis. The experiment will be repeated using a slightly enriched $\mathrm{JO}_{2}$ film as a source of fission fragments.

The initial step in the preparation of foids for trensmisision

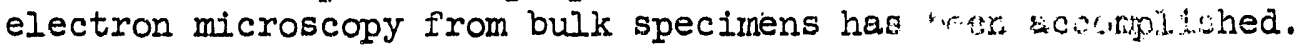
An electrolytic jet polisher has been used to crystals of molybdenum. X-ray analysis shows tha thange in dislocation density or distribution occurs as a resils of the sectioning. 
Rhenium. A total of 24 inches of high purity rhenium single crystals has been obtained from a commercial source. A standard stereographic projection for a hexagonal structure with an axial ratio corresponding to that of rhenium $(c / a=1.615)$ is being prepared. Once this is completed, the crystal orlentations will be determined.

Polycrystalline rhenium wire in two sizes has also been obtalned. Thirty feet of 0.100 -inch diameter wire and 100 feet of 0.020 -inch diameter wire are on hand. The larger wire will be used for tensile specimens and the smaller wire will be drawn to 0.005-inch diameter for electrical resistivity measurements.

Nickel. Quenching studies are in progress on a series of nickel wire specimens representing three levels of purity (99.97, 99.6, and 99.4\% Ni). This investigation is intended to establish the effectiveness of solute atoms as trapping sites for vacancies; the results will be used in the interpretation of irradiation effects in the same materials. Quenching treatments have been carrled out on 0.003 and 0.010-inch diameter, 99.4\% nickel wires. W1th the smaller wires, quenching rates in excess of $5000 \mathrm{c} / \mathrm{sec}$ have been attained; however, optical measurement of the temperature of these wires is subject to considerable error, and numerous specimens have been inadvertently melted while trying to control their temperature at $1430 \pm 10 \mathrm{c}$. The 0.010-inch diameter wires have been successfully quenched from $1440 \mathrm{C}$, with an estimated quenching rate of $2000 \mathrm{c} / \mathrm{sec}$. Quenched-in resistivity in this material has been found to be quite high; the value of $\Delta_{\rho} / p \circ$ is typically 40-50\%. Ischronal annealing of this wire is in progress. An annealing chamber for low temperature isochronal and 1sothermal annealing treatments has been assembled. The chamber is immersed in a bath of liquid nitrogen and temperature control is accomplished by adjusting the rower input to a small sheathed heater wound helically on the interior wall of the chamber. The chamber is pressurized to $10 \mathrm{psig}$ with helium to assist in heat transfer. Transfer of the specimen from the quenching furnace to the annealing chamber is made under liquid nitrogen; after sealing the chamber, the liquid nitrogen trapped within is pumped out and the chamber backfilled with helium. It has been found possible with this device to control temperature within $\pm 2 \mathrm{C}$ over the temperature range from $-190 \mathrm{C}$ to zero $\mathrm{C}$; the control is better at lower annealing temperatures. 
A serles of 1sochronal anneals has been conducted on the quenched $99.4 \%$ nickel wire, consisting of 10-minute pulses at $-175,-150,-125$, and $-100 \mathrm{C}$. No significant change in the value of $\Delta \rho / \rho \circ$ has been observed. This suggests two possibilities: (1) large vacancy clusters are formed during the quenching process, or (2) the activation energy for vacancy migration in nickel is higher than previously presumed and single vacancies are not mobile at $-100 \mathrm{C}$.

\section{Plutonium Physical Metallurgy}

The objective of this program is to determine some of the basic physical metallurgical properties of high purity plutonlum and to establish the effect of certain specific alloying additions on these properties. Two areas are under study: mechanisms of phase transformations and mechanisms of deformation and recovery.

Phase Transformations. Stidies on the kinetics of reversion of retained beta to alpha, as revealed by precision density measurements, have continued. X-ray diffraction apparatus for characterizing relationships between plutonium allotropes as well as identifying the ailotropes is being installed.

Deformation and Fracture Mechanisms. Working of alpha plutonium by roling is being investigated as a possible means for obtaining a highly textured stock which may lend itself to recrystalifzation and extensive grain growth in the alpha temperature range.

Since single crystals or at least coarse grairs are almost a necessity for a comprehensive study of deformation processes in any metal, considerable effort will be directed toward the preparation of alpha plutoniun single crystals. A second approach which has been prover successful in growing single crystals of beta uranium will be investigated. The technique in uranium is to pass a wire or rod progressively through the gama to beta phase transformation temperature. The success of this technique is attributied to the relative ductility oi the gamma and beta phases, in that the beta phase is not distorted during transformation. The beta to alpha transformation in plutonium is very similar in this respect, beta plutonium being exceedingly soft as compared to alpha plutonium.

A creep compression apparatus is being used to measure plastic deformation of the various plutonium allotropes subjected to 
a constant pressure during phase transformation. The experiments should yield some basic information concerning the allotropic phases of plutonium and the transformations between these phases. Plutonium is an ideal metal ior studies of this type, since plutonium has six allotropic phases of varying ductility and hardness, and the transformations between these phases occur at low temperatures.

The creep compression apparatus is mounted in a vacuum furnace. Experiments are conducted in a nitrogen atmosphere glovebox to minimize oxidation of the chemically reactive plutonium specimens. Plastic deformation under isothermal conditions is measured by means of two dial indicators. As yet the information obtalned is only preliminary and an interpretation is not justified.

Alteration of existing tensile apparatus to permit continuous stress-strain recording of the predicted Portevin-Le Chatelier effect in aluminum stabilized delta plutonium has been completed. Four I w/o aluminum stabilized delta plutonium tensile specimens have been cast for the initial tests. The specimens will be given a 200-hour $450 \mathrm{C}$ solution heat treatment prior to testing.

\section{E. CUSTOMER WORK}

\section{Radiometallurgy Laboratory}

Examinations and Measurements. The third full-sized NPR outer element irradiated in the CX-2 100p has been received and measured for length and outside diameter. No significant dimensional changes were found. A replica made of the inner surface showed that no fretting had occurred where the inner tube supports had rested. A detalled examination of the closures and support tabs is in progress (RM C-5,5).

Continued examination of a ruptured rod from FRTR $\mathrm{UO}_{2}-\mathrm{Pu}_{2}$ Vipsc element \#5113 has falled to reveal the cause of rupture. An unidentified second phase was found throughout the core material in the rupture area but what effe,t it might have had on the rupture is not known. (RM C621)

Examination of six of elght UO2 capsules, GEH-14-384-389, has been completed including replicas and autoradiographs of each (RM C-617). 
The nested tubular PRTR element \#1501 has been completely sampled and transverse sections from each element examined macroscopically. Small samples have been prepared for more detailed microscopic examination (RM C-618).

Several samples from the Inconel outer tube and 316 stainless steel inner tube from the 105 DR gas loop were cathodically etched and replicated for electron microscopic examination. The Inconel fracture surface was replicated with silicone rubber and several plastic reproductions were made (RM C-105).

The portion of PRTR process tube \#5540 which contained a 26-mil deep wire wrap mark was photographed and mounted for metallographic examination (RM 376).

Examination of the split fallure from 3584-C was completed. Metallography disclosed that the uranium temperature had not been above the alpha phase. The cause of the rupture could not be determined because the element was so badly fragmented (RM C-417).

Examination of a side-other fallure from 1275-F showed the cause of fallure to be mechanical damage incurred during the charging operation (RM C-419).

Room temperature tensile tests were completed on four $\mathrm{Zr}-2$ tensile specimens formed from irradiated KER process tubing (RM A-354).

Room temperature tensile tests and Rockwell hardness tests were completed on 14 irradiated KAPL-type specimens and two unirradiated control specimens (RM C-1.08).

Irradiated bend test specimens designated for corrosion studies have been machined to size and are being drilled per customer's specifications. This work has been completed on GEH-20-48, 64, and 82 (RM C-113)。

Tensile tests were completed on 72 notch tensile specimens from GEH-20-39, 40,61, 62, 71, and 72 and the data charts forwarded to the customer (RM C-500).

Equipment. Stereo Zoom Microscope: Basic optical and mechanical drawings have been completed by the vendor. 
Basin Filtering System: Approval has been obtained for installation of water demineralizer and distribution system in the 327 Building.

Ultrasonic Drill for Microsampling: Microsampling of irradiated $\mathrm{UO}_{2}$ was accomplished successfully in a mockup by using a 50 watt, $20 \mathrm{KC}$ ultrasonic drilling head and a trepanning tool. The tool was made from a 25 gage hypodermic tubing tip which was 0.020 -inch outside diameter by $0.010-$ inch inside diameter. Solid cylindrical cores of irradiated $\mathrm{UO}_{2}$ were removed from the surface of a sample which had been prepared for metallography. Several of the cores were fragmented because the $\mathrm{UO}_{2}$ was badly cracked. Removal of the cores from the trepanning tool was accomplished without difficulty except from areas where the sample had been impregnated with an epoxy resin. This drilling process is only applicable to materials with a hardness of about Rockwell C-65 or higher.

\section{Metallography Laboratories}

During the month over 700 metallographic samples were examined in support of an intensive effort to define the proper conditions for welding supports to $\mathrm{N}$-Reactor fuel elements.

A metallographic technique was developed for examination of welds in pure beryllium. This method consists of grinding through 600 grit on silicon carbide papers, followed by a preliminary polish on the syntron vibratory polisher using Iinde A abrasive on Metcloth with a mixture of $2 \%$ chromic acid $2 \%$ sodium dichromate in water. The final polish is done on the vibratory polisher using Microcloth, Linde A abrasive, and the same mixture of acids. After polishing, the samples are anodized at 40 volts in a bath of phosphoric acia, ethylene glycol, and ethyl alcohol, mixed 5:5:8 by volume. Microexamination and photography are done under polarized light.

The size and distribution of radiation induced swelling pores at the depleted uranium-enriched interface of a "duc-enriched" uranium rod were characterized by replication electron micrography.

Representative electron micrographs were obtained from the fracture surfaces of five Zircaloy-2 impact specimens which had been fractured at temperatures ranging from 72 to $-321 \mathrm{~F}$. 
A phosphorous-containing uranium specimen was subjected to cathodic vacuum etching and replication. The specimen had been prepared by arc-melting a button of derby metal uranium with $400 \mathrm{ppm}$ phosphorous which was then chill cast to finely distribute the eutectic phase. Electron micrographs were taken to characterize the second phase.

Other work will be reported in connection with the respective research and development programs served.

3. N-Reactor Design Testing

N-Reactor Charging Machine. The replacement Versa valve (three position) has been installed in the high pressure water system. This was done so that the charging pressure would be relieved back through the valve when the charging was completed. The valve has been tested and operates satisfactorily.

The hydraulic connections at the back end of the machine, for use with the magazine loading bridge, have been installed and tested.

The quick disconnect connections for the piston return equipment at the front of the machine have been installed and tested.

The annunclator panel and cover have been installed.

All small hydraulic hoses have been replaced with new factory assembled hoses. The original hoses, which were assembled locally, were not rated for the $1250 \mathrm{psi}$ at which the hydraulic system operates.

One Kates flow control valve used in the charging water supply ceased to function and was disassembled and cleaned. The valve now works satisfactorily。

All preparations have been completed for Design Test 22-B (charging with simulated fuel column back forces) and several charges of dummy spacers have been fabricated to test equipment. Charging of fuel elements will be undertaken in the near future.

N-Reactor Fuel Handling Tongs. Fabrication of the N-Reactor fuel handling tongs has been suspended perding recelpt of machined parts. Preliminary operational checks have been made on the tong tightening cjole. 
N-Reactor Fuel Magazine Loader. Preliminary tests have been made on the magazine loader. Final evaluation of these tests is still pending.

4. Special Plutonium Fabrications

High Exposure Al-Pu Fuel for Physics Tests. One hundred Al-Phi rods were completed to bring the total to 850 . Cores for essentially all the remaining 150 rods are extruded.

High Exposure UO2-PuO2 Fuel for Flux Monitor Tests. All six U02-PuO2 clusters were completed. Each contained three rods loaded with pellets and 16 vibrationally compacted rods. A rupture occurred in one of the vibrationally compacted rods during irradiation and a reflacement cluster will be made. This cluster will contain two pellet rods, one swaged rod with high-energy-rate impacted material, and 16 normal swaged rods.

Low Exposure U02-PuO2 Fuel for Physics Tests. A new die is being made for the U02-PuO2 pellet press which should permit sintering the pellets to the exact, required final dimensions. Approximately 700 pellets have been sintered.

Al-Pu Fuel for Corrosion Tests. Cladding on flve of the 14 X-8001 aluminum specimens corroded during autoclaving, apparently as a result of nickel segregation. Fourteen specimens clad in KYZ aluminum have passed bond testing and are ready for autoclaving.

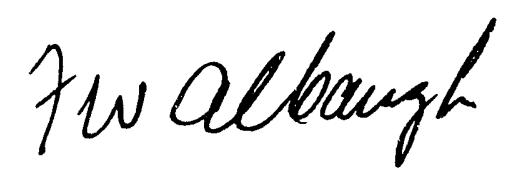

Manager, Reactor and Fuels Laboratory 
B-1

\section{PHYSICS AND INSTRUMENTS LABORATORY}

MONTHLY REPORT

APRII 1963

\section{FISSIONABLE MATERIALS - O2 PROGRAM}

\section{REACIOR}

\section{N-Reactor Exponential Experiments}

A value of the control strength of a single spline in a water filled crosscoolant tube in the center of the mockup exponential pile has been determIned to be about one-fifteenth that of the horizontal control rod in the same position.

The samarium balls to be used in remeasuring the ball-3x system strength have arrived. These measurements will be made using the exact channel diameter rather than extrapolating from measurements with smaller channels as was done previously.

\section{Analysis of N-Reactor Data}

All experimental $\mathrm{N}$-Reactor data have now been compiled. P-3 calculations have been done to fit the experimental flux traverses by adjusting the neutron temperature. The neutron temperature for the mockup and condensed lattices ought to be the same. Although the condensed-lattice neutron temperature compares favorably with theory, the mockup neutron temperature does not. The source of the problem is not known.

Work has been done toward calculating the effective internal surface fraction (for calculation of the resonance escape probability) using a collision probability technique. A collision probability subroutine has been included in a program whose results can then be used in calculating the effective internal surface.

Fortran program PULP (calculates lattice parameters from foil activities) has been revised to correct an error in the method of calculating the resonance escape probability. All N-Reactor data now have been re-analyzed using PULP.

\section{Optimization of Re-tubed Lattices}

One vertical and two horizontal traverses have been completed in the Cexponential pile vith dry CIIN fuel. The vertical traverse has also been

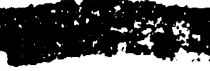


taken with six rods. Thought has been directed toward measuring the mixture of enriched and natural CVI fuel columns necessary to give a material buckling equal to the buckling of CIIN fuel. It appears that it is possible to measure the buckling at enriched-to-natural ratios of $1: 8,1: 3,1: 2$, and $1: 1$.

K Lattice PCTR Experiments

Preparations are under way for the PCTR measurement of absolute $k_{\infty}$ values for KVNS fuel pieces in zirconium process tubing. The worth of reactor splines will also be measured as a function of burnup. Materials are being assembled for this experiment. The center cell and core graphite, zirconium process tubing and plugs, uranium can and foil holders, and foil counting materials are ready.

\section{Computational Programming Services}

PADOED, the program which examines a binary program deck, is debugged. Several useful applications have been made.

Two codes, IFAP and ADDELT, were received on tape from Harwell, Angland. IEAP generates the thermal neutron scattering law of a material, given a tabulated function closely related to the phonon frequency distribution of the material. The related code, ADDHT, may be used to modify INAAP results where high energy "optical" modes are important in the phonon frequency spectrum. IFAP and ADDELT have been modified to conform with the Henford operating system. Both are in debug.

TRIPOO4 was prepared for offsite distribution.

\section{Instrumentation}

Linearity and stability of the slow gamma scan portion of the NPR Fuel Rupture Monitor were observed under test with other IFD and NRD groups. High voltage stability was measured under temperature, line voltage and load variations. Preliminary count-rate meter tests were also performed.

Building modifications required for installation of the NPR Experimental Fuel Rupture Loop instrumentation at the PRTR have been scoped and a work order issued for the work to be done. In addition, modifications are being made to coolant flow controlling equipment to accomodate higher pressures which are now planned. Unfortunately, this will necessitate changing equipment specification bids already placed. Other specifications were prepared for strip chart recorders planned for the instrumentation system.

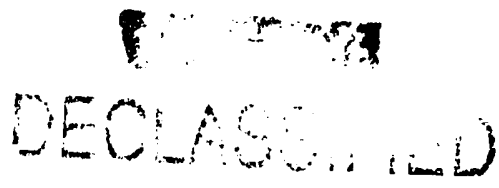




\section{DECLASSIFIED}

The ionization chamber cable continuity tests were completed in the laboratory。

Foil activation data obtained from $\mathrm{H}$ Reactor inner rod room were reviewed in order to evaluate the effect of increased rod clearance on neutron leakage. Results showed that increased clearances presently under consideration would be acceptable.

System Studies

A single-node, six-delayed group N Reactor simulation is being studied on the computer in order to obtain preliminary process standards guide data. Effects of varying reactivity and inlet water temperatures on peak power level, metal and water temperature, and power rate of change have been evaluated. For studies within the reactor power operating range, the primary control loop was closed around the reactor and an elementary model of one of the steam generators was 1ncluded in the simulation. The effects of primary loop mixing and transport lags were factored into the analog computations.

NPR pressurizer and injection pump simulations have been completeá.

Four comercial control systems planned for $N$ Reactor simulation studies have been received and are being installed in a transportable control panel which may alsc provide test data for NPR control equipment.

A two-dimensional $D$ Reactor simulation is under computer evaluation for the purpose of verifying new control optimization techniques. A related D Reactor test in which a digital computer program will be used to correlate analog simulation data with measured reactor values has been temporarily delayed.

The controller developed by IPD Equipment Development Operation was connected to the analog simulation of the $D$ Reactor in an attempt to study the control characteristics of the entire system. A successful test mu of the simulation with the controller has not yet been achieved.

\section{SEPARATIONS}

\section{Experiments with Plutonium Solutions}

Further critical mass experiments were conducted with plutonium nitrate solutions in the 11.5-in. diameter water reflected sphere. The data being obtained yield a curve of critical concentration versus nitrate, which may then be used to estimate the critical concentration for a homogeneous plu-

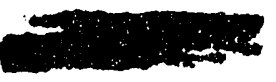


tonium water mixture in the absence of nitrate, or to evaluate the minimum mass of $\mathrm{Pu}$ in the sphere. Plutonium concentrations were in the range of $\sim 70-100 \mathrm{~g} \mathrm{Pu} / \mathrm{l}$ at very low acid molarities ( $\sim 0.2-0.9 \mathrm{molar})$. For an acid molarity as small as 0.2 , the data provide the smallest critical concentration measurable for $\mathrm{Pu}\left(\mathrm{NO}_{3}\right)_{4}$ solutions in the sphere - 86 srams/liter.

Foil irradiations were made with bare and cadmium covered gold foils for datermining the neutron flux distribution within the 11.5-in. sphere. Eighteen foils were irradiated at 1 -in. Intervals across the vessel diameter and extending into the reflector; the foils were positioned in a stainless steel re-entrant tube. During the irradiations the Pu concentration was $\sim 100 \mathrm{~g} \mathrm{Pu} / \mathrm{l}(\mathrm{H} / \mathrm{Pu} \sim 250)$; the nitric acid molarity was in the range $\sim 0.4-0.6$. Perturbations in the flux distribution caused by the control rod and stainless steel re-entrant tube have limited the usefulness of these data so far, but measures are being taken to correct this.

Although the flux was depressed in the central region of the sphere by the partially withdrawn control rod, the thermal gold activation data (bare minus cadmium covered foils) were used to determine an effective extrapolation length for this system. A least squares anelysis was made to the data in the region of constant cadmium ratio. On this basis an effective extrapolation length of $\sim 6.7 \mathrm{~cm}$ was computed. Although this value is subject to some uncertainty as a consequence of the flux perturbations above, it is in qualitative agreement with measured extrapolation lengths for water reflected $U 235$ solutions which are about $6.0 \mathrm{~cm}$ for spherical geometry.

Five lutetium foils were also irradiated at 2-in. intervals throughout the region of constant cadmium ratio (appraximately $10 \mathrm{~cm}$ on either side of the sphere center). These data, when the analysis is complete, will yield an effective neutron temperature for this system.

\section{Pulsed Neutron Source Experiments}

Pulsed neutron source experiments were conducted concurrently with critical mass measurements in the 11.5-in. sphere. The pulsing device used produced $\sim 107$ neutrons, of $14.3 \mathrm{Mev}$ energy from the D-T reaction, in a time interval of $\sim 5$ microseconds.

From measurements of the decay of prompt thermal neutrons near delayed critical, the mean lifetime of the prompt neutrons was determined. A value of $\sim 19$ microseconds was obtained for a $\mathrm{Pu}$ concentration of $73 \mathrm{~g} \mathrm{Pu} / \mathrm{s}$ ( $\mathrm{H} / \mathrm{Pu}$ atomic ratio of 346 ). In this determination the delayed neutron fraction was assumed to be 0.0023 .
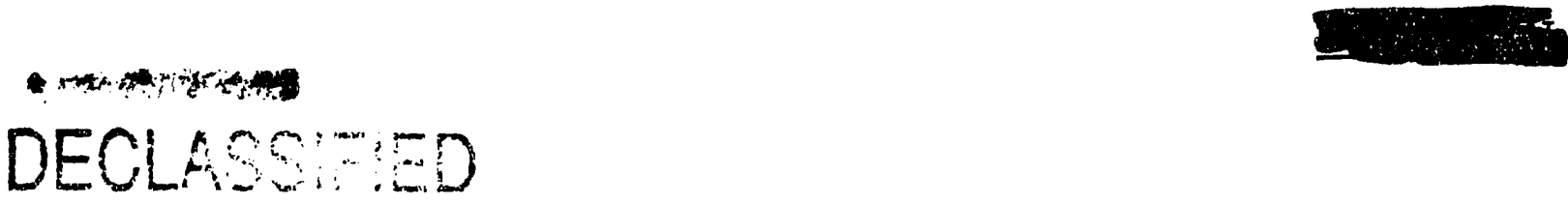


\section{DECLASSIFIED}

B- 5

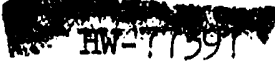

Measurements of $\mathrm{k}_{\text {eff }}$ were made for several other Pu solutions in the range up to $100 \mathrm{~g} \mathrm{Pu/l}$ during the critical experiments. The data from the measurements gave a $k_{\text {eff }}$ of 0.94 when the vessel contained about $60 \%$ of the critical volume in the reflected state. It remains to be demonstrated whether quantitative in situ measurements of $k_{e f f}$ can be performed on complex process vessels, which are well subcritical, for nuclear safety evaluations in the plant.

Theoretical Analysis of Plutonjum Solution Criticality in Water Reflected 11.5-in. Spheres

In connection with the correlation of critical mass experiments with theory, further effort was made to compute criticality for five of the solutions measured in the water reflected 11.5-in. sphere. Multigroup diffusion theory was used to calculate keff for solutions that were within 0.04 liter of criticality in the just full 11.5-in. sphere. The results of these calculations indicate that the critical masses could be calculatec. to within $3 \%$ of the experimentally determined values.

A theoretical extrapolation was also made to determine the concentration of plutonium in water that would be just critical in the 11.5-in. water reflected sphere, i.e., zero nitrate and $\mathrm{Pu}^{240}=4.6 \%$. The resulting critical concentration is $65.0 \pm 5.0 \mathrm{~g} / \mathrm{h}$.

\section{Calculations for Muclear Safety Applications}

The GAMIEC Code, which provides multigroup constants for heterogeneous systems for use in multigroup diffusion calculations, has been modified to calculate individual lattice physics parameters, $i_{0} e_{0}, \eta, \epsilon, p, \tau, L^{2}, k_{\infty}$ and material buckling. The code has successfully computed these parameters for a tube-in-tube fuel assembly in a graphite moderated lattice array.

Consulting Services on Nuclear Safety - Criticality Hazards

\section{Nuclear Safety in HI}

Temporary Specification No. 3 was issued for Coclant Systems Development, covering the storage and transporting of $\mathrm{J}$ and $\mathrm{C}$ fuel elements prior to processing in 100-K. These special fuel elements are in 12 approved birdcages and are to be stored temporarily by CPD in 200-W Area.

Several meetings were held with PRTR Technical Planning to discuss revised storage specifications in the 309 Building fuel element basins and nuclear safety in the PRCF. A final draft of the revised specification $K-1$ will be issued in May. The PRCF discussions centered around methods of assurine

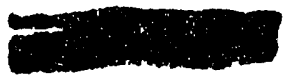




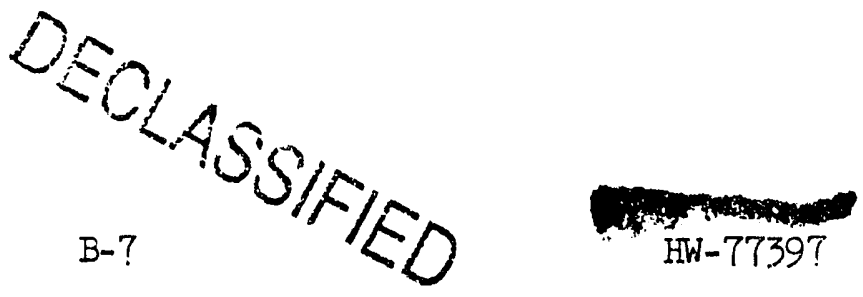

Visit to Rocky Flats Plant

The Rocky Flats Plant was visited on March 25, 26, and 27, 1963, to review data obtained from critical mass experiments and to discuss industrial nuclear safety. An excellent review of the in situ measurements that have been made to date and the measurements planned for the near future was obtained. The tour of the plant facilities proved to be very informative and provided an opportunity to discuss many aspects of nuclear safety philosophy.

\section{Instrumentation}

Tests to determine scramming time of the split-half assembly at the Critical Mass Laboratory are encountering difficulty due to variation in control rod rate of travel. Attempts are now being made to make three rods move with uniform velocity.

A servo-mechanism system incorporating semi-conductor detectors and designed to traverse the critical solution sphere at the Critical Mass Labora. tory was fabricated and satisfactorily bench tested.

An additional neutron monitoring channel is being addeä to Critical Mass safety circuits. The monitoring channels consist of a Keithly log N-period meter with a new safety circuit controller. Provisions have been made to connect this monitor into the circuit in case any of the present safety circuit channels fail. Work is proceeding to replace two fission counters, one with an ion chamber and one with a scintillation detector. The ion chamber is found to provide improved information reliability; the scintillation counter is intended for use in conjunction with a $10 \mathrm{~g}$ count-rate meter and a period meter.

\section{NEUTRON CROSS SECTION PROGRAM}

\section{Scattering-Law Measurements for Light Water at Elevated Temperatures}

Measurements of the inelastic scattering of slow neutrons from light water at $95^{\circ} \mathrm{C}$ continued during the month with the triple-axis spectrometer. Measurements have been made for eight different values of the neutron energy change on scattering which range from 0.0375 to $0.175 \mathrm{ev}$. During the measurements it was discovered that the water sample thickness had varied due to the pressure of evolved gases in the sample container. Some of the measurements which were made will have to be repeated.

Further measurements were made which are designed to evaluate the magnitude of some indicated systematic errors of the triple-axis spectrometer measurement methods. 
Iotating-Crystal Spectrometer

Invelopment of apparatus to measure slow-neutron inelastic scattering by +ime-0.flight was continued. Plans were made to study the characterisi-is of a different synchronous motor for the rotation of a chopper and ystai in phase.

A study of Hanford-produced $\mathrm{He}^{3}$ proportional counters for time-of-flight and other local problems was initiated. A prototype counter was fabristed and filled with a mixture of $\mathrm{He}^{4}$ and $\mathrm{CO}_{2}$. An Am24I alpha source inside the counter was used to simulate the ionization produced from absorption of a neutron by He3. The pulse-height characteristics of this detector were quite good. Further studies are planned of the mixture and pressure of filling gas and electrode geometry. Work is also under way to measure the uncertainty in ion-collection time (time jitter) of proportional counters for time-of-flight use.

Construction continued on the 6144-channel time-of-flight analyzer. System subsections were interwired and further debugged.

Fast-Neutron Cross Sections

Measurements were made of the total cross section for neutrons of 3 to 15 Mev for samples of 14 elements. These included the first Hanford measurements on the elements $\mathrm{Mn}$, Se, and $\mathrm{Te}$. At least two measurements have now been made on $\mathrm{Al}, \mathrm{V}, \mathrm{Cr}, \mathrm{Fe}, \mathrm{As}, \mathrm{Y}, \mathrm{Zr}, \mathrm{Nb}$, and $\mathrm{W}$, and the measurements of these elements are now nominally completed. Additional measurements were aiso made on samples of $\mathrm{Bi}$ and $\mathrm{Pb}$.

The data of the measurements which were made on $\mathrm{Pm}_{2} \mathrm{O}_{3}$ have been reduced to yield the total cross section of Pm147. The results show more structure in the cross section than is seen in the cross sections of adjacent elements.

REACTOR DEVELOPMENT - 04 PROGRAM

FLUTONIUM SECYCLE PROGRAM

High Exposure PuAl Lattice Studies

The measurements in the PCTR of 19 rod clusters of this fuel on a $6-1 / 2^{\prime \prime}$ pitch in graphite were begun and completed aluing the month. The fuel contains 2..2 w/o Pi which contains 20.6 at om $\%$ Pu-240. The mass of copper required to poison the central cell to a multiplication of unity was determined. This mass vas found to be only slightly dependent upon the flux. 

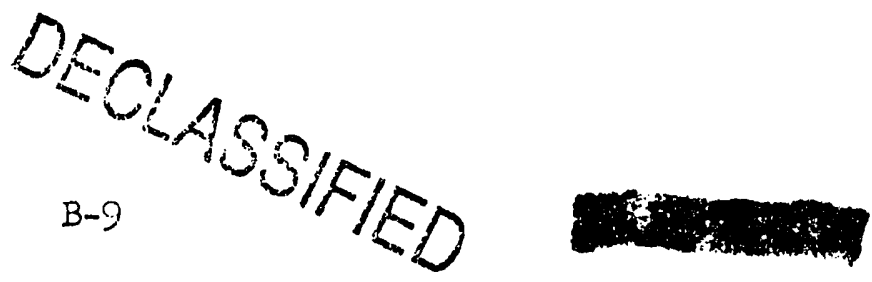

match between the central cell and buffer cells.

Foil irradiations were made for both the poisoned and unpoisoned lattices in the cases where the cadmium ratio of gold was nearly the same in the central cell and the surrounding eight buffer cells. In these irradiations the fine structure of the flux in the central cell was measured using copper foils for cell traverses and PuAl, U-235 Al, $\mathrm{Cu}$, and $\mathrm{Au}$ foils to cbtair relative activation rates in each fuel ring, at the cell. boundary and in the thermal column. The cadmium ratios for PuAl, U-235-Al, $\mathrm{Cu}$ and Au were also measured in each fuel ring and on the cell boundary. The variation in neutron absorption rate at various positions in the poison was measured.

The relative reactivity coefficients of $\mathrm{Cu}$ and $\mathrm{U}-235$ around the central rod were measured in both the poisoned and unpoisoned cases.

Plutonium Recycle Critical Facility Startup Experiments

The startup experiments completed during the month include the low and high power level calibration experiments, horizontal and vertical distributions of bare and cadmium covered $\mathrm{BF}_{3}$ neutron counting rates, bare $\mathrm{Au}$ foil counting rates at critical, moderator level coefficients for the initial critical loadings, partial control rod worth, traverse mechanism worth, and other worth measurements.

In addition, experiments to calibrate the safety and control rods by the rod drop method were performed. The worth of the safety rods was measured to be about one-half the value required ky the process specifications. The core of the PRCF was then rearranged to increase the worth of the safety rods and to allow flexibility for future experiments. The new core configuration consists of $22 \mathrm{UO}$ elements in the center with three safety rods 16 inches from the center, 27 PuAl elements surrounding the $\mathrm{UO}_{2}$ and three control rods 24 inches from the center. This configuration results in a core with a circular instead of hexagonal outer boundary and in six empty fuel positions (the corners of the hexagon) for future flexibility.

The new loading resulted in moving the safety rods 8 inches closer to the center of the reactor. 'Ihis increased their worth from $\sim 11 \mathrm{mk}$ to 21,27 , and $22 \mathrm{mk}$. The final values agree very well with that expected from a flux squared weighting and the worth measured in the original position. The total worth of the safety rods agrees with the minimum stated in the Final Safeguards Analysis. However, the Process Specifications state that in addition to the total worth criterion the worth of each safety rod. should be at least $25 \mathrm{mk}$. Experiments are planned to determine why some of the safety rods differ in worth by $\sim 25 \%$.

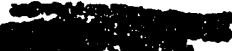


the worths of the control rods are $1.7,2.1$, and $1.6 \mathrm{mk}$.

Fieactor Kinetics Experiments

In preparation for analyses of the kinetics experiments in the PRCF, a nibroutine which was written for the Generalized Least Squares Program CiLEX is being used to analyze data from the TTR. The data were obtained for antireactivity insertion in a critical reactor. The data consisted of values of the flux for times up to one second after the insertion and for times between $4 \mathrm{sec}$ and $300 \mathrm{sec}$. When all six groups of delayed neutrons in the TIR are assumed to be effective for the TIR data the fitting process failed to converge because some of the groups were present in too small an intensity. However, convergence was obtained when only three groups were used for each time interval. The three shortest-lived groups fit the data up to one second and the three longest-lived groups fit the data between 4 seconds and 300 seconds. A fit was also made to the data between $O$ and $I$ second using only two exponentials. The results of this two group analysis will be compared with the results obtained by hand calculations.

Approach-to-Critical Experiments Using High Exposure PuAl

Experiments with $\mathrm{H}_{2} \mathrm{O}$ moderator, similar to those performed on the $1.8 \mathrm{w} / \mathrm{O}$ PuAl fuel rods, are planned for $2.0 \mathrm{w} / 0$ PuAl with $16 \%$ Pu-240 content. Elght hundred and fifty of the 1,000 fuel rods expected have been received. Six hundred and seven of the fuel rods have been placed in a lattice with 0.66 inch center-to-center spacing. A rough extrapolation indicates the critical number of rods will be greater than 1,000 .

Additional lattices that are being prepared for this experiment have fuel rod positions spaced $0.75,0.80,0.85,0.90$, and $0.95-$ inches center-tocenter.

\section{Neutron Thermalization - Theoretical Scattering Laws for Water}

Modified Gaussians have been used to study the effects of resonances with finite widths on the scattering law for water. An IBM-7090 program is used to evaluate the analytical expressions. As expected the agreement between theory and experiment at low momentum transfer is significantly better than can be obtained using zero width resonances. However, there are still serious discrepancies for high energy transfers and this region is now being studied. A report on the results obtained so far has been prepared for inclusion in the Physics Research Quarterly.

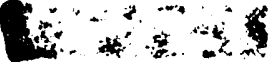

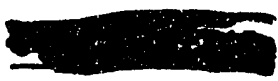

DEDSC 


\section{DECLASSIFIED}

B-11

\section{PRTR Fuel Cycle Analysis}

Calculations of the flux in the heavy water moderated, 19-rod cluster, natural uranium fuel element reported last month were extended to include a double $\mathrm{S}_{2}$ calculation to compare with IDIOT. A small change in the $\mathrm{I}_{2}$ calculation was made to be consistent with the temperature-dependent IDIOT absorption cross sections. $I_{2}$ and $s_{2}$ calculations predicted approximately the same normalized flux which decreases monatomically toward the center as opposed to the increase in the middle regions predicted by IDIOT. Thermal utilization factors were not significantly different from IDIOT results, however. The calculated values are 0.95276 (IDIOT), 0.95132 ( I $_{2}$ ), and 0.9524 (DS2). The calculated 8 factors, where

$g=\frac{\bar{\phi}_{\text {fuel }}}{\bar{\phi}_{\text {mod }}}$, were 0.65876 (IDIOT), $0.66062\left(I_{2}\right)$, and $0.66876\left(s_{2}\right)$.

The failure of IDIOT in the center regions for this specific case was not indicated by the balance check.

Operating Data Analysis

Several successful THERMOS cases have been run during the month. The detailed energy distribution of the neutron density about the 1 ev resonance in Pu-240 has been calculated using Doppler broedened cross sections from GROUSS. A similar study of the neutron density about the $0.3 \mathrm{ev}$ resonance in Pu-239 was run. In order to have a composite spectrum from 0 to 2.38 ev, a third case was run covering the energy range below the Pu-239 resonance in fine detail. Effective cross sections for the three groups (0-0.18 $\mathrm{ev}, 0.18-0.683 \mathrm{ev}$, and $0.683-2.38 \mathrm{ev}$ ) are calculated for an equivalent homogeneous model of the cell ( $1 / 2$ " Pu-Al rods on a $3 / 4$ " lattice spacing in light water).

In order to reduce the time required in preparing input data for THERMOS, the code is being chained to the RBU data tape. A subroutine, THBAR, was written and debugged. This subroutine accepts group boundary energies as input and calculates group velocities for THERMOS. The chain is presently being debugsed.

Code Development

UPDT

Program UPDT which updates a chain tape has been revised to permit its use with the physics chain tape which is used in the CAIX system. It is currently operational.
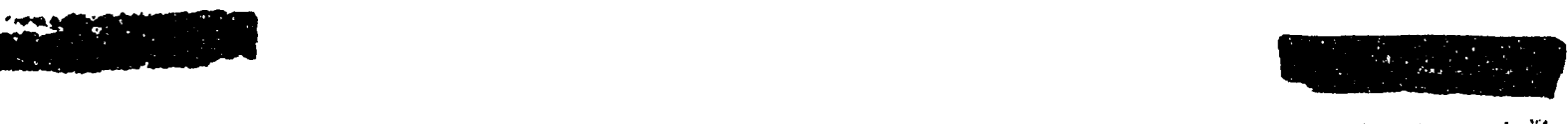
Program SIGMA-3H is being revised to ease data preparation which is currently quite redundant. The revision is $90 \%$ debugsed.

Pxogram CAIX will now perform endpoint searches in time satisfactorily, and :1ili stop properly when the reactivity falls below a certain value. It sometimes fails, however, when attempting to stop at a particular reactivity value. The source of this error is being sought.

HFN

Two bugs have been corrected in HFN. The iteration limit for criticality searches which formerly was ignored has been corrected. Also, an exror message is now printed out properly when the number of flux points exceeds memory.

An addition has been made to allow HFN to increment by the same amount all radii outside of the one specified when doing a criticality search. This change will facilitate calculations of importance to the Critical Mass Laboratory experiments.

\section{CLERR}

Document, HW-7552I, which describes the CLERK I (fast reactors), and CLERK II (generalized) cross section averaging codes is now in rough draft form. The addition of CLERK II to the PHYSICS CHAIN is being considered.

\section{ALTHAEA-MELEAGER}

AITHAEA-MELEAGER code is being changed so that the effective resonance integrals (calculated from dilute parameters) show the effects of all isotopes rather than being restricted to indicating the self-shielding effects as was done previously. A computer code has been written to calculate interference coefficients for all isotopes on all other isotopes of interest using the results of SPECIRE and/or other thermalization and slowing down codes. Preliminary results indicate that Pu-239 causes a reduction of the resonance integral for Fu-24I by about the same amount that the Pu-24l would by self-shielding on a per atam present basis of comparison.

These changes are expected to considerably improve the flux traverse criticality and burnup results which can be obtained with AITHAEA code. 


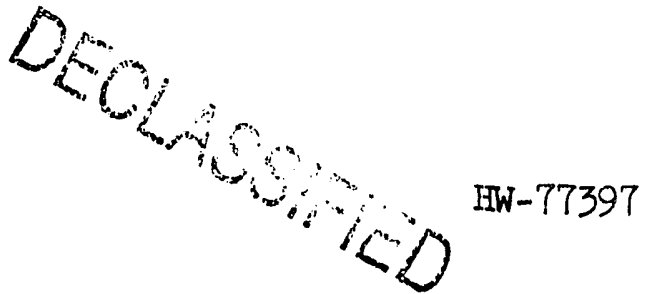

Cross Sections

Updated versions of the GAM-I, the G-2 19-level and MEMPEST cross section libraries have been made from RBU basic library $\left(\sigma_{a}, \sigma_{+}\right.$, and $v$ values being updated). The Westcott parameters corresponding to a $\Delta 4$ cutoff have been derived for the isotopes recently updated on the RBU library, and will be reported in HW-77389, entitled, "Westcott Parameters Derived from the RBU Basic Library for a $\Delta 4$ Cutoff."

Advanced Reactor Concepts

Plutonium Utilization Studies

A substantial part of the comparison study of $\mathrm{VO}_{2}, \mathrm{PuO}_{2}$, and $\mathrm{PuN}$ as fuels for small, compact, fast reactors is complete. The idealized two-region reactor considered in this study is comp sed of a spherical core surrounded by a $10 \mathrm{~cm}$ thick beryllium reflector. \% rore consists of void and fuel or void and a fuel-tungsten matrix. The voil fractions were varied from 0.20 to 0.80 , and two tungsten concentrations in the fuel of 0 and $50 \mathrm{v} / 0$ have been considered so far. The reflector is beryllium at $75 \%$ of its theoretical density to account for structural material and cooling holes in the reflector. In the calculations, the reflector is maintained at a constant $10 \mathrm{~cm}$ thickness, and the core radius is varied to achieve criticality.

The GE-HAPO S-XI transport theory code was used for all of the calculations in the $\mathrm{S}_{4}$ approximation and with 13-energy groups. The top ten groups of the energy-dependent cross sections (except tungsten), are taken from GAM-I, and the lower three groups are hand-averaged values from BNI-325. The tungsten cross sections are those used by R. S. Cooper of Los Alamos in criticality studies for fast systems. The 13-energy groups cover energies from $10 \mathrm{Mev}$ down to thermal. Although the systems are quite fast, the thermalizing beryllium reflector necessitates taking account of the lower energies in the calculations.

Figure $I$ is a plot of the critical spherical radius of the core vs, the core void fraction for the PuN, $\mathrm{PuO}_{2}$, and $\mathrm{UO}_{2}$ fuels with $\mathrm{O}$ and $50 \mathrm{v} / \mathrm{O}$ tungsten in the fuel loading.

The core volume ratio with $50 \mathrm{v} / 0$ tungsten in the fuel loading for $\mathrm{UO}_{2}$ : $\mathrm{PuO}_{2}$ : PuN is 1:0.35:0.20 for 50 percent void in the core and 1:0.39:0.21 for the tungsten free case.

For a flow area of 0.1 ft 2 the total reactor weights ratios are 1:0.52:0.40 with tungsten present, and 1:0.68:0.63 without tungsten. For a flow area of 
YOL

ENT-773y7

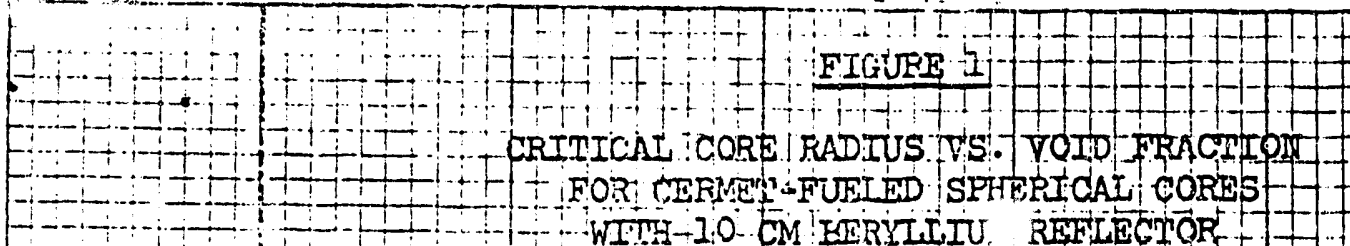

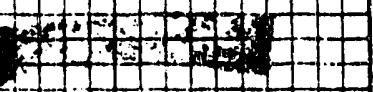

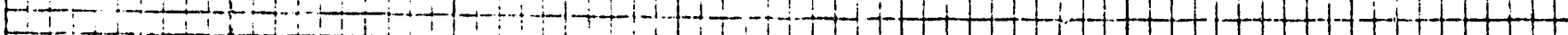

-

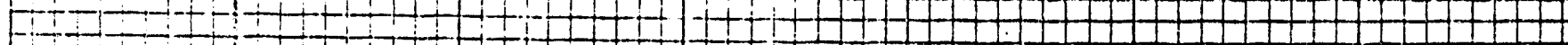

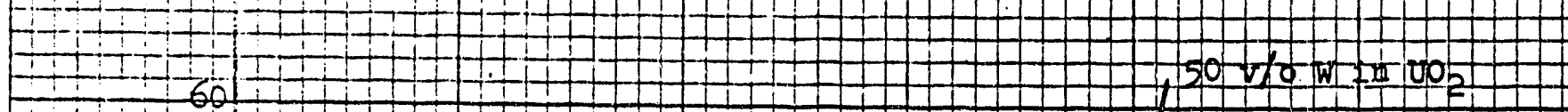

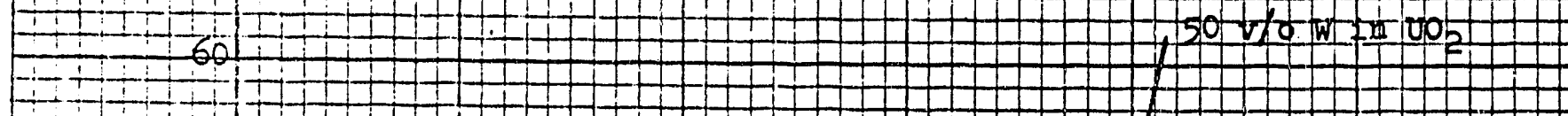

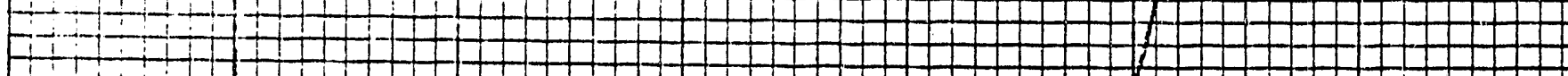

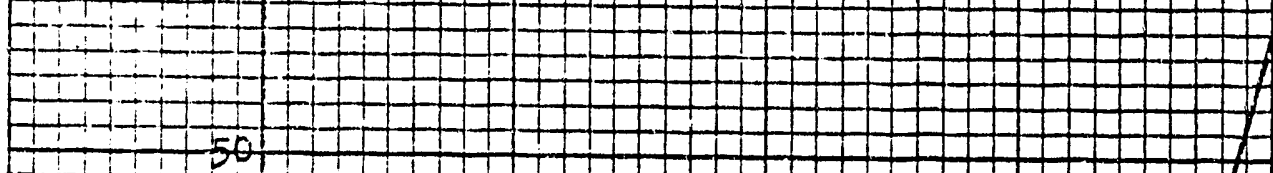

ㄴ.

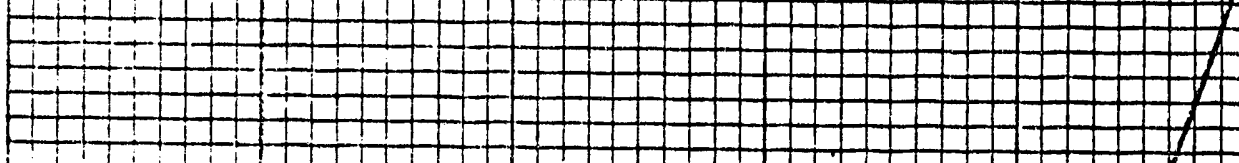

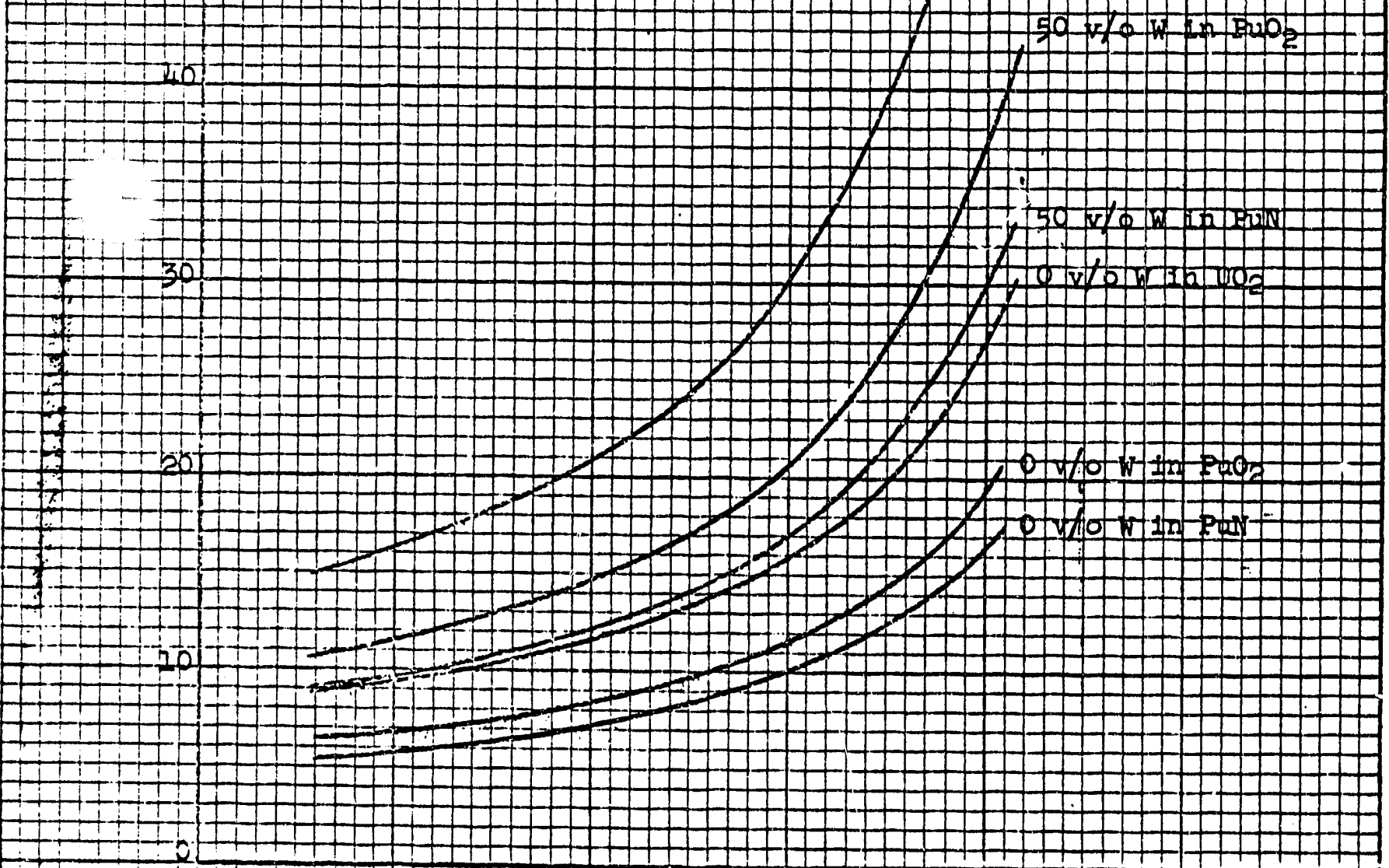

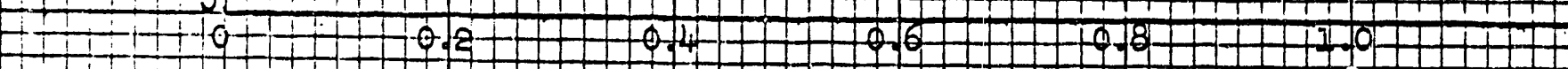

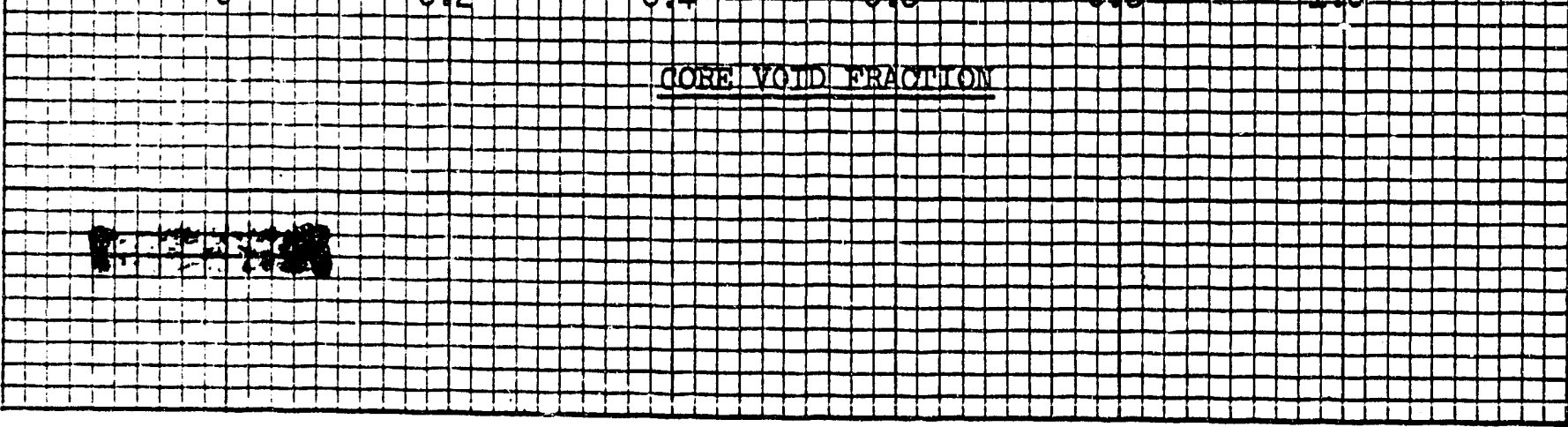



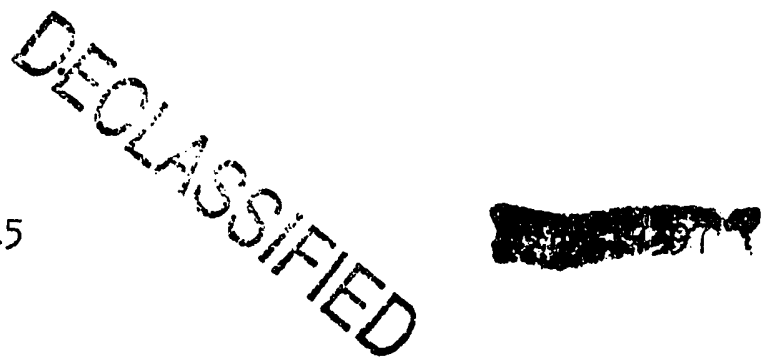

$1 \mathrm{ft}^{2}$ the weight ratios are 1:0.64:0.54 with tungsten and 1:0.77:0.74 without tungsten.

\section{Phoenix Studies}

\section{(a) Temperature Coefficients}

Temperature coefficient calculations for a typical Phoenix core are being carried out and some results have been obtained during the present reporting period. For a $70 \mathrm{~kg}$ Mark I $(\mathrm{M} / \mathrm{W}=1)$ core the temperature defect between $68 \mathrm{~F}$ and $500 \mathrm{~F}$ operating temperature has been found for a series of fuel compositions, with Pu-240 contents rangings from 5 to $\sim 20 \%$. These temperature defects have been separated into leakage and thermal base fffects. The average temperature coefficientis over the 68 to $500 \mathrm{~F}$ temp arature range are all very strongly negative, but are not a strong function of Pu-240 content. The net coefficient is about $\sim-2.1 \times 10^{-4} \Delta \mathrm{k} / C_{F}$, made up of a leakage component of $\sim-.8 \times 10^{-4} \Delta \mathrm{k} /{ }^{\circ} \mathrm{F}$ and $a \mathrm{isermal}$ base component of $\sim-1.3 \times 10^{-4}$ $\Delta \mathrm{k} / \mathrm{OF}^{\mathrm{F}}$. A temperature coefficient calculation was also carried out for a 50\% Pu-239, 31\% Pu-240, 17\% Pu-241, 2\% Pu-242 composition. The results are quite similar, yielding a slightly reduced over-all coefficient of $-1.8 \times 10^{-4} \Delta \mathrm{k} / \mathrm{OF}_{\mathrm{F}}$ consisting of $\mathrm{a}-.6 \times 10^{-4} \Delta \mathrm{k} / \mathrm{O}_{\mathrm{F}}$ leakage contribution, and a $-1.2 \times 10^{-4} \Delta \mathrm{k} /{ }^{\circ} \mathrm{F}$ thermal base component.

The contribution to the temperature coefficient due to Doppler broadening is being treated separately, since it is fuel temperature dependent. The GROUSS code has been used to determine Doppler broadened cross sections for Pu-240 at fuel temperatures of $750 \mathrm{~F}$ and $1750 \mathrm{~F}$, respectively. The reactivity change is then found via HFN calculations. For the 20\% Pu-240, $70 \mathrm{~kg}$ Mark I core the average Pu-240 Doppler coefficient was found to be $-7.6 \times 10^{-6} \Delta \mathrm{k} /{ }^{\circ} \mathrm{F}$.

(b) Cross Section Averaging Schemes

To ascertain the effert of cross section uncertainties on the time dependent reactivity behavior of Phoenix cores a variety of investigations are being carried out.

In one line of investigations the usual 4-group routine has been extended to an 8-group routine. The effect on $k$ and cross section ratios was found to be negligible.

In another line of investigations, the use of GROUSS in the calculation of the effective Pu-240 absorption cross section in group (3) first epithermal group] has been compared with the results of the 
GAM-DRESNER methods presently in use. The results show reasonable agreement:

\begin{tabular}{|c|c|c|}
\hline Method & Fuel Temp. & $\bar{\sigma}_{\mathrm{a}} 240$ \\
\hline GROUSS & $1750 \mathrm{~F}$ & 168 \\
\hline GROUSS & $750 \mathrm{~F}$ & 1601.36 \\
\hline GAM-DRESNERR & $-460 F$ & $1660.4 \mathrm{~b}$ \\
\hline
\end{tabular}

The fact that such agreement does exiot might not necessarily be a favorable development, since energy self-shielding is not yet considered in GROUSS.

(c) ARMF-MIR Experiments with Fluvonium Fuel

Preliminary results of measurements of the spectrum in the ARMF have been received. From these data, Westcott $r$-values and the neutron temperatures have been evaluated for the ARMF test positions. Using these values fission and absorption cross sections were estimated for the calibration samples in the ARMF test positions. The cross sections were combined with measured reactivity values to obtain the sensitivity of the ARMF to fission and absorption cross sections. The sensitivity values will be used to determine the maximum fission and absorption cross sections encountered in the irradiated samples. The purpose of the analysis is to determine if the calibration samples cover an adequate range of fission and absorption cross sections.

A special fuel element cluster is being designed for reactivity measurements (static and dynamic) of small samples in the PRCF. The first samples will be the irradiated PuAl capsules which have been used in the ARMF-MIR experiment.

\section{Mass Spectrometry}

The heavy-element mass spectrometer was used to provide uranium isotopic analyses on five samples for the Analytical Control Operation, CPD, and twenty-two analyses on Plutonium Recycle Program samples. The PRP analyses consisted of plutonium analyses of 4 samples from element No. 5051, 3 samples from No. 5095, and 5 samples from No. 5092, all Al-N1-Pu fuel elements, and the plutonium fraction of 10 samples from $\mathrm{UO}_{2}$ element No. 1041.

Instrumentation and Systems Studies

Tests were carried out on a picoammeter for use in the FRPP high level radiation detection system. The instrument proved to be acceptable in most

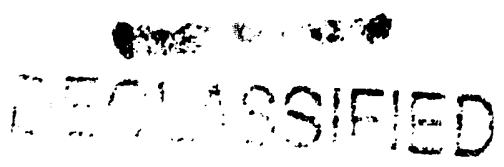




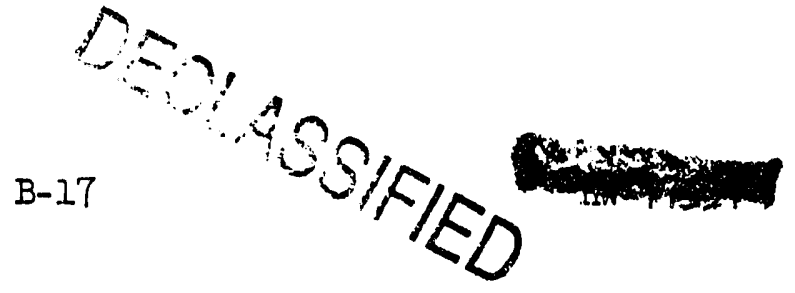

respects; however, it did not function properly with the long cable lengths required. Additional tests are planned with a second instrument.

Fabrication of the PRTR liquid effluent gamma monitor is progressing. The electronic chassis and panels are ready for wiring. One circuit card file and one probe are complete, and the card file and DC amplifier were wired for the prototype instrument. All laboratory tests of the PRTR under water garma scanning equipment have been successfully completed. When installed, this equipment will measure the gamma activity of irradiated fuel rods and wires.

The plutonium recycle critical facility was simulated using the parameters for light water moderation. Computer runs were made for hazards analyses to assess the effects of loss of the light water coolant. The results were obtained and given to the requesting personnel.

Assistance was given to the Mechanical Development Operation on the requirerients ior a data system incorporating a multi-channel oscillograpr, and capable or monitoring pipe vibration, fluid flow, and shroud sf'scing of a PRIIR process tube.

\section{HIGH TEMMEERATURE REACTOR IATTICE PHYSICS PROGRAM}

The HTLIR is being designed for the purpose of extending the type of experimental work that can be done with the PCTR to higher temperatures-ranging up to $1000^{\circ} \mathrm{C}$. Subjects for study at these higher temperatures are to include temperature coefficients, control rod strengths, lattice properties of gas and liquid-cooled fuel elements in solid moderators, and neutron spectra.

During the past few months a scope design of the reactor and facility has been in preparation. As pictured at present the reactor is to consist of a 10 foot cube of graphite containing a horizontal removable section $5^{\prime} \times 5^{\prime} \times 10^{\prime}$. There is provision at selected points throughout the stack for loading fuel elements and inserting electrical heaters. The reactor is surrounded by a shell consisting of thermal insulation and an outer containment layer. The nuclear power of the reactor will not exceed $2 \mathrm{kw}$. The electrical power required to heat it is $500 \mathrm{kw}$. Included in the proposal is a chopper with time-of-flight equipment for measurement of neutron spectra, and a neutron generator to be used both as the starting source and for experimental purposes. Other main features of the proposal are the gas handling systems for the reactor atmosphere and for ventilation cooline, a data logger in the control console, and the facility to house the reactor, associated equipment, and personnel.

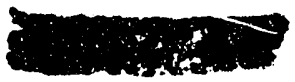


The present status of the project is that the preliminary proposal (1W-76408) has been completed and a draft of the design criteria (HW-76928) has been prepared. The proposal is under approval examination. The draft of the design criteria has been reviewed and the varlous corments and inanges are being assembled in preparation for writing the final design sriteria.

\section{NEUTRON FLUX MONITORS}

Microgram samples of plutonium, uranium, and cobalt irradiated in KE Reactor for experimental evaluation of neutron parameters $r, T$, $\phi$, were discharged and made ready for post irradiation analysis. The relative radioactivity of the cobalt samples was measured using a simple four-p1 ionization chamber calibrated with a NBS source, and these data were used to determine the cadmium ratio and the spectral parameter, $r$. Further data will be required, however, to establish the values and the uncertainty of the determinations. Based upon the cobalt activity, sample exposure was determined to be 4.6. $\times 1019$ nvt. Mass spectrometer analysis of the plutonium and uranium samples are planned for the near future.

Fabrication of an experimental regeneration detector is nearing completion. Upon determination of the neutron temperature, $T$, calculations $w 111$ be made to establish the composition of regenerating plutonium detectors for use in the magazine facility at KR Reacts: Plans are to have the detectors ready for reactor charging at an exten. tube outage scheduled for the near future.

The following table itemizes useful lifetimes (operating time for which detector sensitivity remains within ten percent of a median value) of detectors of various isotopic compositions. These values were computed for a $100^{\circ} \mathrm{C}$ neutron temperature, and a spectral perameter, $r$, of 0.04 . Detector size has been chosen to yield a maximum of $10^{10}$ fissions per second in a flux of $10^{14} \mathrm{nv}$.

\begin{tabular}{|c|c|c|c|c|c|}
\hline Detector & Isotope & $\begin{array}{c}\text { Cross Section } \\
\text { (Barns) } \\
\end{array}$ & $\begin{array}{l}\text { No. of } \\
\text { Atoms } 1017\end{array}$ & $\begin{array}{c}\text { Detector } \\
\text { Weight } \\
\mathrm{Mg} . \\
\end{array}$ & $\begin{array}{l}\text { Useful } \\
\text { Lifetime } \\
\text { (nvt) } 10^{20}\end{array}$ \\
\hline $\begin{array}{l}\text { I. Uranium } \\
\text { (regenerating) }\end{array}$ & $\begin{array}{l}U-234 \\
U-235\end{array}$ & $\begin{array}{r}105 \\
557 f+110\end{array}$ & $\begin{array}{l}13.7 \\
1.48\end{array}$ & 0.59 & 50.7 \\
\hline $\begin{array}{l}\text { 2. U-Pu } \\
\text { (regenerating) }\end{array}$ & $\begin{array}{l}U-238 \\
\text { Pu-239 }\end{array}$ & $888_{f}+409$ & $\begin{array}{c}85.5 \\
0.93\end{array}$ & 3.41 & 142.7 \\
\hline $\begin{array}{l}\text { 3. Plutonium } \\
\text { (regenerating) }\end{array}$ & $\begin{array}{l}P u-239 \\
P u-240 \\
P u-24 I\end{array}$ & $\begin{array}{r}888 f+409 \\
762 \\
1245 f+431\end{array}$ & $\begin{array}{l}0.93 \\
2.25 \\
0\end{array}$ & 0.127 & 12.04 \\
\hline $\begin{array}{l}\text { 4. Fission } \\
\text { 5. Alpha }\end{array}$ & $\begin{array}{l}U-235 \\
B-10\end{array}$ & $557_{f}+120$ & $\begin{array}{l}1.80 \\
0.26\end{array}$ & $\begin{array}{l}0.07 \\
0.00043\end{array}$ & $\begin{array}{l}2.80 \\
0.48\end{array}$ \\
\hline
\end{tabular}




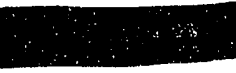

B-19

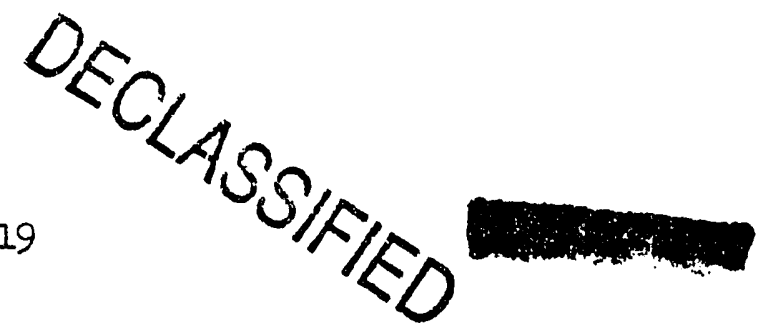

A bid was accepted for the commercial fabrication to HAPO specifications of three Boron-ll beta current neutron flux monitors. A parallei program to fabricate an experimental detector on site is being delayed by difficulties in obtaining suitable comercial components.

A solid state Helium-3 neutron spectrometer was ordered for evaluation as a neutron flux monitor.

The use of microwave techniques as a method of measuring neutron flux levels in an operating reactor is being experimentally investigated. Two approaches are being studied initially. One will attempt to correlate flux. level with microwave attenuation, the other will utilize coupling of microwave energy through a neon tube locatea at the point where the flux level is to be determined.

\section{NONDESTRUCTIVE TESTING RESEARCH}

\section{Electramagnetic Testing}

Attempts to extend the multiparameter eddy current test to four parameters has shown that the associated mathematics and instrument adjustments are markedly more difficult than the three parameter case. Preliminary measurements indicate that four parameters can be successfully separated, but the final results of this test have not been determined.

A two-channel, single-frequency, eddy current tester operating at $250 \mathrm{KC}$ and using a differential encircling coil having 400 turns of .002 inch copper wire was used to examine samples of $1 / 8$ inch diameter, .030 inch wall Zircaloy sheathed chramel-alumel thermocouple lead wires. Destructive examination performed by Fuels Design at ten selected positions along the sheathing revealed good correlation of instrument signals and sheathing condition in six positions. Signals at three other positions were caused by eccentric positioning of one of the thermocouple wires in two cases, and by a $10 \%$ thinning of the sheathing in a third case. The causes of signals at the two remaining positions were unconfirmed.

It is desired to adapt the graphical null balancing device for use with the multiparameter eddy current tester. Since several of these devices will be incorporated in one instrument, the simplest design meeting performance requirements is needed. A simplified design was conceived and incorporated in a new prototype single-frequency tester with good results. The new balancing unit is simpler and gives a more linear voltage plane plot than previous models. Detailed mechanical design to incorporate improved suspensions and bearings is proceeding.

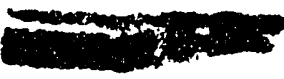


Heat Transfer Testing

Varlations in heat input were found to be a source of exror during heat transfer tests on $\mathrm{N}$ Reactor fuel element end closures. Factors affecting the plasma arc jet used as a heat source in these tests are being investige.ted in an attempt to obtain more reproducible heat input. Development of ihe emissivity independent heat transfer test is continuing.

Heat output of the plasma arc jet used in testing fuel elements is affected by gas flow and pressure, voltage and current, and other variable factors. Variations in the arc operating parameters are being measured in an attempt to evaluate causes of variations in heat output. Although these variations do not appreciably affect detection of fuel core to cladding bond discontinuities, they are important in tests to detect small differences in overall bond heat flow characteristics.

Telephone lines between 314 Building and 3707-C Building are being cornected to tie the tape delay unit in the analog computer facility to the heat transfer testing instrument so that continuous computation required for emissivity compensation studies can be made.

An infrared source was arranged on the present heat transfer testing instrument to allow frequent calibration checks on the infrared radiometers. This should allow greater reproducibility in the test results.

\section{Zirconium Hyaride Detection}

Fddy current measurements on short sections of $87 \mathrm{~N}$ Reactor process tubes have not revealed random signal variations large enough to mask signals due to hydride. However, further tests involving comparisons of signals before and after exposing the tubes to hydriding will be necessary before optimum instrument sensitivity can be determined.

A literature search made to determine the effect of Irradiation on the electrical conductivity of Zircaloy-2 indicates that no change in conductivity occurs at exposure temperature around $140^{\circ} \mathrm{C}$. No higher temperature data are available. Irradiation temperatures less than $100^{\circ} \mathrm{C}$ are known to increase zirconium conductivity.

Zircaloy samples hydrided to $7000 \mathrm{ppm}$ have been tested in a 12,000 gauss magnetic field in order to more precisely determine the cause of eddy current indications. The results indicate that the eddy current response is due to an actual conductivity change rather than precipltated ferromagnetic phases.

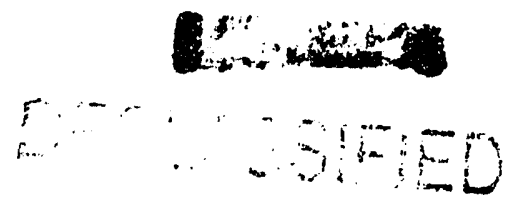




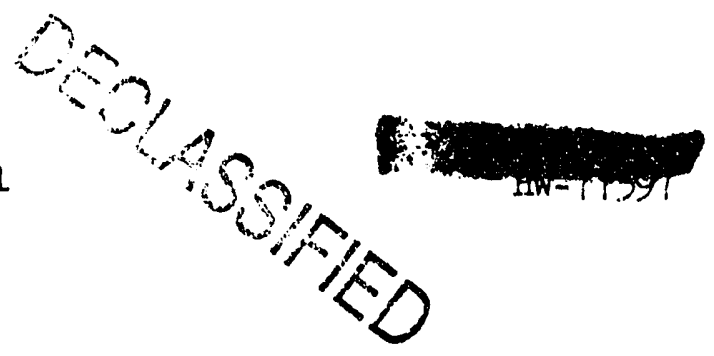

Fundamental UItrasonic Studies

The acoustic properties of a glycerine-kerosene interface has been analytically studied, and equipment assembled for continuing experimental investigations. In order to more precisely determine the structure of ultrasound wave fronts propagating between liquid layers, techniques of sampling small portions of the waves are needed. Ultrasonic receivers which have been commonly used for beam sampling are large compared to ultrasound wavelengths and reduction beyond about 0.090 inches in diameter appears to be presently impractical. By using hypodermic needles as collimators, however, it is possible to reduce the sampling diameter to 0.007 inch. Present efforts are investigating the use of two hypodermic needles arranged in a binaural configuration which is expected to reveal both wave front shape and direction of ultrasonic fields.

The successful u.se of the hypodermic needle collimator as a small ultrasound receiver has also suggested the possibility of injecting ultrasound for nondestructive testing purposes into extremely small and confined damains. Tests which have successfully transmitted sound waves through needles having an internal bore of 0.019 inches diameter have confirmed the feasibility of this idea, although improved probe design will be required before such probes could be practically applied.

Theoretical work continued on Lamb waves in a hollow cylinder. Previous studies indicated that the possibility exists that the frequency equation might be factored under some conditions. Such a factorization has been found. This indicates that for a particular combination of radius and wall thickness two types of waves can exist, analogous to the symmetrical and asymetrical waves in a flat plate. The physical significance of this is not apparent, and numerical calculations will probably be needed to determine the nature of the two waves, and whether the conditions for their existence apply to a physically realizable configuration. It has been calculated that the order of the Bessel functions in the frequency equations is higher than those tabulated in existing publications, as far as is known. Work has been started on developing a calculation procedure.

USAEC-AECL COOPERATIVE PROGRAM

Nondestructive Testing of Sheath Tubing

Program efforts continue to be directed toward the ultrasonic inspection. of Zircaloy tubing with wall thicknesses in the range of 0.017 inches. Recent work has further confirmed the superior performance of wide band test frequencies and small, focused transducers for this application. Reliable tests are now avallable for tubing in this range of wall thickness

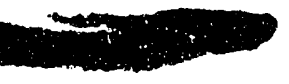


under carefully controlled laboratory conditions. Sultable equipment or test procedures have not yet been developed, however, with which the test could be applied under routine, field conditions.

Sonsequently, current efforts are aimed at developing a simplified test system, including electronic circuitry, mechanical tube scanning equipment, ind instrument setup procedures with which the test may be practically applied. In this regard, a two transducer send-receiver system in which the presence of a defect is revealed by a decrease in energy reaching the receive crystal has been evaluated. With proper crystal alignments, 0.001 inch surface notches are readily detected by a fifty percent reduction in receive signal amplitudes. Difficulties experienced in suitably adjusting the two crystals, however, make this method unattractive, even though it is relatively insensitive to the physical orlentation of defects within the tube wall.

More promising results are being obtalned from a method which positions a transducer-mirror assembly inside the tube such that the ultrasonic beam is directed toward the tube surface at the desired angle. With the mirror adjusted to reflect the beam at twenty-five degrees with respect to the tube radius, both inside and outside notches were reliably detected. While the signal-noise ratio was not as favorable as has been obtained with other test methods, continuing investigations are being made in an attempt to exploit the simplified tube scanning requirements of this approech.

Perhaps the most pramising results obtained to date are being obtained with a third method which uses a large transducer positioned on the outside of the tube. The transducer is masked in such a way that it generates two separate rectangular ultrasonic beams whose dimensions are about three-elghths by one-sixteenth inch. In practice the longer dimension is oriented parallel to the longitudinal tube axis. The mask is carefully designed to separate the two identical beams an amount necessary to permit each to impinge upon the tube surface at an angle of $25^{\circ}$ with respect to the tube radil. Rotating tubes interrogated in this manner produce two indications for each defect, one for each beam, making the system less sensitive to the orientation of defects within the tube wall. Importantly, the wider beam dimensions allow a greater scanning pitch and a reduced testing time. It is also found experimentally to produce a more constant tube surface echo from which gating circuits may be more accurately timed.

BIOLOGY AND MEDICINE - 06 PROGRAM

Atmospheric Physics

Work on the analysis of atmospherlc dispersion data collected over the past three years continued, with emphasis on relating measurements of
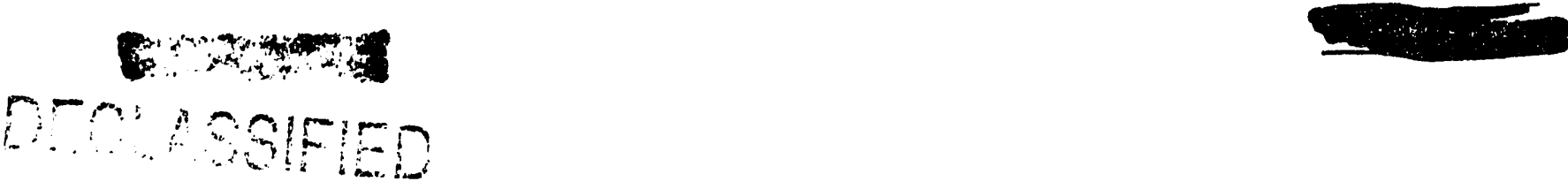


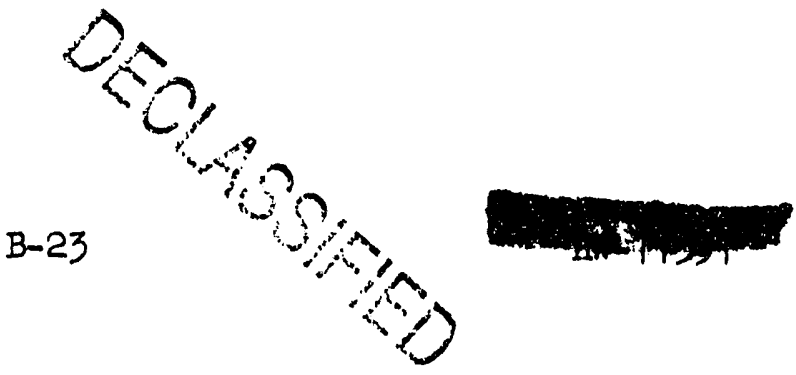

dispersion to meteorological variables. A significant improvement in data stratification was obtained by correlating the lateral spread of the diffusing plume with the time of travel from the source to the sampler location. Although this correlation results from fundamental turbulence theory, it has not been generally used by investigators because of difficulty in identifying the transport velocity. Basically, the cross-wind or lateral variance of the sampled mass distribution should increase directly with the square of the travel time near the release point, changing to a first power dependence on time at the larger distances.

Data from 43 Hanford experiments support the fundamental time dependence relationship, permitting prediction of the lateral growth of the plume using solely meteorological measurements. The scaling parameter required for prediction was the product of the standard deviation of the wind direction record obtained at the height of release and the mean wind speed at the same height. Both quantities were determined over the period of tracer release, 30 minutes. The relationshlp between the observed meteorological parameter and the turbulent fluctuations in the atmosphere was identified with the transverse turbulent energy of the air motions. Thus far, the range of data permits predictions to 30-minute travel times throughout the full spectrum at atmospheric stabilities.

Five fleld tests were conducted during the month. Three of these were run during unstable meteorological conditions with the source height at 61 meters to simulate a stack discharge. Samples were taken at 1.5 meters above ground level to a distance of 1600 meters. Two tests were conducted using a 6.7-meter stack height during stable conditions with sampling on both the horizontal and vertical grids to a distance of 3200 meters. These later experiments were designed to evaluate vertical dispersion without the complexity of deposition on the ground.

Precipitation scavenging studies progressed through partial reduction of the larger number of samples collected during last month's field trial. Over 10,000 particles were sized microscopically on filters and on Diazo raindrop autographs. In our cooperative effort with the Department of Environmental Sciences, University of Washington, 200 impaction samples obtained in the Carbon Valley Area were assayed, and the results forwarded to them.

\section{Dosimetry}

The first results are available from our survey-by-urinalysis program in Alaska. A group of ten samples from Fort Yukon indicated body burdens in the range 33 to $294 \mathrm{nc}$ of $\mathrm{Cs}-137$, with an average of about $155 \mathrm{nc}$. Eight of the samples vere from women; women tend to have burdens only 60

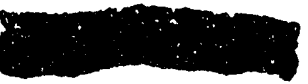


:0 $80 \%$ of those of men. These burdens are lower than found at Anakturik Fass last sumer but higher than found at Barrow, Polnt Hope, Kotzebue or Diomede. The principal meat in the diet at Fort Yukon is moose rather than caribou or reindeer as at the other villages. Presumably the moose $\therefore i$ e the source of the Cs-137 for the Ekimos there. Urine samples are wpected fram Tanana and Bethel also, to give a rough survey of parts of $\therefore$ ine state not visited last sumer. Samples from these locations have been delsyed due to the difficulty of tiansportation in Alaska in the winter.

Preparations are under way for this sumer's whole body counting study in Alaska.

A second type of plastic phantom was purchased for comparison with the one we already had for calibration of whole body counters. A study of the calibration of the shadow shield whole body counter for potassium was completed. It gave a result within $1 / 2 \%$ of the value obtained by our standard calibration techniques. In addition, an extra quantity of potassium was placed in the approximate position of the heart. It was counted with an efficiency two to three times greater than that of the potassium distributed throughout the body. This has a bearing on our measurements of the potassium loss of patients being treated with an artificial kidney (measurements at Swedish Hospital last fall). Our results were apparently too high; this can be explained if most of the loss has been from the blood system of the body and part of this is counted with higher than average efficiency.

Study of the detection of beta rays emitted from the surface of the body continued. A new counter was made for this purpose. It was used on our cooperating P-32 patient in preparation for calibration the next time he receives an injection of $\mathrm{P}-32$.

Another batch of the gas germane was prepared and studied for use in X-ray proportional counting. The results were inconclusive. Supplies are bel.ng received for assembly of a large scintillation counter for $X$-rays.

Whole body counter calibrations for I-132 and Au-198 were performed. These will be valuable in event of an accident.

Assistance was provided Radiation Protection Operation in fitting a recently received extra large NaI(TI) crystal into the shaiow shield counter in their truck. A double crystal holder is being prepared for the regular whole body counter calibrations.

The positive ion Van de Graaff operated satisfactorily during the month.
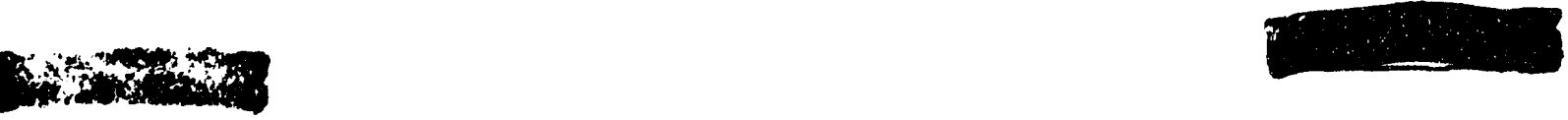


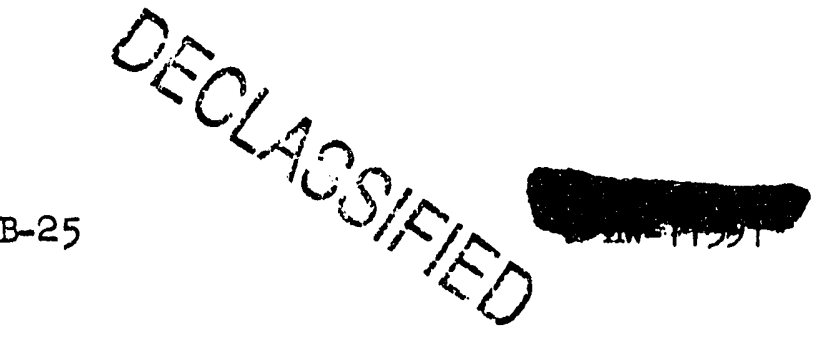

I. W. Seagondollar, professor of physics at the University of Kansas and consultant to Radiological Physics, spent eleven days at our laboratory-most of it working on the charge separator he designed last summer for use with our helium ion source. Assembly and bench testing of the system were completed. It appears to work very well and to be ready for installation on the Van de Graaff. Final conclusions cannot bo reached until it is in operation on the Van de Graaff.

The search continued for an explanation of the shift in calibration of the precision long counter that had been sent to Mound and Argonne Laboratories. Another precision counter that had stayed in our laboratory was recalibrated to make sure that there had been no unnoticed change in our procedures. This counter was within $0.1 \%$ of its previous calibration so we feel that no such change took place. At present we are investigating the possibility that the shift was due to a temperature difference.

The energy sensitivity of a tissue equivalent chamber system is being determined for neutrons and photons.

A helium-3 proportional counter was studied for use as a spectrometer for low energy fast neutrons. It has good resolution and efficlency. However, high energy fast neutrons produce helium-3 recoils that interfere with analysis of the 1 ow energy neutrons by the $\mathrm{He}^{3}(\mathrm{n}, \mathrm{p}) \mathrm{H}^{3}$ reaction.

Calorimetric measurement of the specific power output of promethium-147 was completed. Two samples were measured. The results were 0.3314 and 0.3295 watts per gram, respectively; the uncertainty due to the calorimetry was about 0.0007 watts per gram. Thirty data points obtained in an eleven day run were used to determine a half-life; the result was $2.73 \pm 0.08$ years. The best published half-life is 2.65 years. Recent measurements at Hanford have given 2.69 years.

About a year ago, during studies of radiation damage to graphite by electrons from the Van de Graaff, a phenomenon was observed which was interpreted as a significant change in thermal conductivity at a surprisingly low electron fluence. A new sample was irradiated and its thermal conductivity measured with Graphite R\&D's thermal pulse apparatus. The change in conductivity was observed but at a much higher. fluence than for the effect first noted.

\section{Instrumentation}

The mold fabrication of moderating material for the experimental multipledetector neutron dose meter was completed. Operation of the thermal and resonance detectors was tested with the detectors inside the moderators.

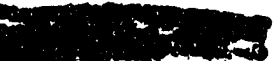


rabrication of aluminum caps to be used over the fission detectors has jen initiated. The caps will employ a $13 \mathrm{mg} / \mathrm{cm}^{2}$ thickness of Americium3 I.

... remaining difficulty with the personnel ganma dose meter is that stickng occasionally occurs between the Aquadag coated center rod and the platiin fiber through which the unit is recharged. Effort is now being made ic eliminate sticking between the two by replacing the quartz rod with a "od made from conducting Teflon. Results to date are encouraging, although i completely satisfactory method of molding the Teflon rods to the desired shape has not yet been developed. The use of argon as a means of reducing the tendency to stick has also been investigated with negative results. Instrument layout has been redesigned to physically separate so far as possible the sensor from the instrument battery. One prototype unit is presently under evaluation by Radiation Protection Operation.

A new alpha air monitor employing an experimental CsI detector was tested during moderate atmospheric temperature inversions. The technique appears to successfully differentiate Fu-233 from radon and thoron activity. A proposal was made to Biology personnel to convert one of their alpha air monitors to the new method.

Experimental development of the biological data telemetering system is continuing. Demodulation of animal respiration and heartbeat signals was developed on a preliminary basis. Temperature effects on the performance of the electronic circuitry have been found to be negligible up to $150{ }^{\circ}$. A special instmument for measurement of both respiration rate and volume was completed and delivered to the Biology Laboratory, HIL.

Commercial components were ordered for three experimental phosphorescent particle detection instruments. A new light trap design which increases air flow through the unit is expected to improve instrument sensitivity by reducing the time between $\mathrm{U}-\mathrm{V}$ simulation of the $\mathrm{ZnS}$ particles and phototube detection of the phosphorescence. Moreover, it is possible the new detection head will be directly adaptable for use in an airplane for plume investigations.

Scintillation detectors for use in measuring filter entrapped beryllium were completed, and purchase of a Polonium-210 alpha activation source initiated. General tests were completed on the electronic circuitry and detection heads, which for safety reasons are being assembled in a sealed glove bax.

The problem of obtaining gamma dose rate measurements over a large number of decades is being investigated along two avenues of approach. For
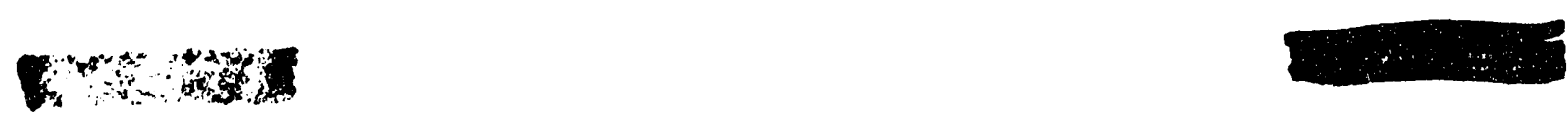


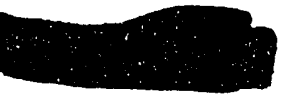

B-27

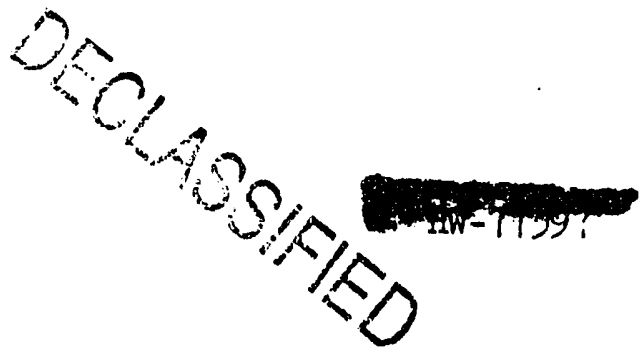

portable instruments, autamatic control of scintillation detector voltage (using solid state silicon amplifiers) is being investigated in order to maintain constant phototube output current. A compact instrument incorporating rechargeable batteries and providing a logarithmic response from I $\mathrm{mr} / \mathrm{hr}$ to $10 \mathrm{r} / \mathrm{hr}$ is envisioned. Concurrently, extended range line operated gamma area monitors are being developed which employ photctubes which have their bases removed to reduce anode leakage ourrents, high gain amplifiers, and 500 CPS vibrating capacitors. Autcmatic voltage control is also employed to provide constant anode currents at about one nanoampere. Use of 10 stage phototubes will provide four decades of logarithmic response; a 14 stage phototube should extend the logarithmic response to six decades. Breadboard circultry for both the portable and lineoperated instruments is being evaluated.

Development and assembly of the atmospheric physics experimental portable mast system has continued. A noise study of the wind speed channels was made and isolation transformers were installed for noise reduction on the tower power lines. The general system, excluaing temperature channels, was operated satisfactorily in laboratory tests. A number of circuit drawings were completed. Work is proceeding at a slightly reducer effort in order to accelerate revision of HAPO Radiotelemetering System.

Wind speed and direction are being recorded from eight different levels on the 400 foot Meteorology Tower near 200-W Area. It is required that a five to ten second average of the deviations from a five to twenty minute average of the wind velocity components be recorded. These data are lised for maintaining climatological records and estimating the diffusive capacity of the atmosphere. Recordings of wind speed and direction have been taken on a magnetic tape recorder. The required five to twenty minute average of the mean velocity vector were computed on the analog computer. The magneti: tape recordings of wind speed and direction were used as inputs to the analog computer to simulate actual wind conditions. The long averaging times seem to pose no problems. The data taken from the analog computer is now being analyzed to determine the accuracy. The analog method will be compared with a digital method for producing the same information.

A meeting with Blology personnel was held to determine the applicability of an analog computer for the analysis of the disposition of Tellurium-132 and Iodine-132 in the body of sheep. The study involves the disposition of tellurium and lodine obtained in a single dose and its disposition in the plasma and the milk of the animal. Equations were formulated for the study. 


\section{HASHINGTON DESIGNATED PROGRAM}

\section{Isotopic Anslysis Program}

Siotopic analyses of program samples continued at a very high rate during ine month. The heavy-elemenc mass spectrcmeter for this program was out operation for a week due to a leak in a bellows on a cut-off valve inich occurred after four years of operation.

Design was completed for a scintiliation-type ion detector for the mass spectrometers. The detector is now being fabricated.

Development work was cortinued on a quick-change vacuum-lock sample holder for the mass spectrometer.

\section{TEST REACTOR OPERATIONS}

Operation of the PCIR continued routinely during the month. There were three unscheduled shutdowns saused by electronic fallure. The experiment to determine $k_{\infty}$ for $2.2 \%$ Pu-Al (20.6\% Pu-240) 19 element clusters in a 6-1/2-inch graphite lattice was completed. Null reactivity and foll activation measurements were made. A set of Hastalloy $X$ and Hastalloy $X$ plus $0.1 \% \mathrm{Gd}$ samples was measured to detect the presence of the Ga. A small but signifinant difference existed between the sets of samples.

The TIR was not operated during the month.

The critical approach tank, which uses the TIR safety circuitry, was reactivated. Measurements are being made using $1 / 2$ in. $2 \%$ Pu-AI ( $16 \%$ $\mathrm{Pu}-240$ ) in a $0.66 \mathrm{in.}$ light water lattice. 850 rods have been loaded. Additional rods up to 1000 total will be added when available.

\section{CUSTOMER WORK}

\section{Weather Forecasting and Meteorological Service}

Consultation service was rendered on meteorological and climatological aspects of axides of nitrogen release in 300 Area, and exhaust fume release from the Bioassay Building.

Meteorological Services, viz., weather forecasts, observations, and climatological services were provided to plant operations and management personnel on a routine basis.

\footnotetext{
then
} 
Weather Summary

Type of Forecast

8-Hour Production

24-Hour General

Special
Number Made

90

60

172
\$ Reliability

80.8

84.3

91.3

April was much cooler than normal and was the wettest on record with precipitation totaling 1.17 inches. Normal precipitation for Apxil is only 0.37 inch and the previous high for the month was 0.96 , recorded in 1932.

\section{Instrumentation and Systems Studies}

Plans were formed to develop a soll molsture content measuring probe using a Pu-Be neutron source and a neutron detection probe. The development work will be carried out for Advanced Technical Planning, CPD, and Chemical Effluents Technology, HL.

Design work was completed to convert one alpha-beta-gama air filter sample counter at the 231 Building to a coincidence-count type filter counter. Fabrication is nearly done.

Suggestions were made to Blology personnel regarding useful methods for eliminating $60 \mathrm{cps}$ pickup in electrocardiogram instruments.

Discussions were held with CPD personnel from 234-5 Building regarding their acquisition of oincidence-count filter counters.

Evaluation tests were performed on a solid state out-of-limits detector which has specifications compatible with the temperature limiting philosophy of the uranium swelling program. The device, manufactured by Daystrom Inc. as the "Magsense", is capable of continuously monitoring a thermocouple and infiliting an out-of-limits alarm when an adjustable setpoint is exceeded. Preliminary test data indicate the device has a repeatability of $\pm 1^{\circ} \mathrm{C}$ at constant ambient temperature and a repeatability of $\pm 2^{\circ} \mathrm{C}$ over an ambient temperature range of $20^{\circ} \mathrm{C}$ to $60^{\circ} \mathrm{C}$.

A differential amplifier was designed which will detect the error signal in the uranium swelling program temperature control loop and initiate data logging when the error exceeds an adjustable setpoint. The device will assure logging of any out-of-limits data.

Specifications were written for silicon controlled rectifiers which will be used in place of the magnetic amplifier-saturable reactor units in the uranium swelling program temperature control system. The SCR's will provide higher power capabilities, better linearity, and faster response time 
without a sacrifice in reliability. In addition, space w1ll be saved and system analysis made easier. A triggering circult for the SCR's bas been developed and the components have been ordered.

Specifications for a line voltage recorder and a pyrameter potentiometer were written for Physical Metallurgy Operation.

Advice was rendered Reactor Metals Research Operation on procedures and hardware for measurement of the response time of a system used to measure the internal energy of irradiated metals.

Advice was rendered Phys1cal Metallurgy Operation on the hardware requirements of an oven temperature control system.

A clrcult was designed and bullt which wlll allow two creep capsule micropositioners to be controlled and read out by the same digital control device now on line at $100-\mathrm{KW}$.

Construction of the creep program 96 point data logger is continuing and some debugging was started this month. It is expected that the system will be completed within two months.

The 333 Bullaing autoclave temperature control system is being altered to control the temperature fram only one thermocouple instead of from an average of a mimber of thermocouples. A test is planned on an autoclave to determine the effect of the change. Successful completion of the test with favorable results w1Il lead to all systems being changed accordingly.

Work on the eday current PRIR fuel element vibration analyzer is continuing on schedule. Fabrication of the six-channel electronic instrumentation is approximately $30 \%$ complete. Vibration testing of the sensing coils revealed the need for changes in the procedures with which the fuel elements are assembled in order to eliminate chipping of the quartz coll forms.

A special request to test some 1/4" O.D. $x .049 "$ well Inconel tubing samples prior to shipment for offsite fatigue testing was recelved from NRD. The material supplied was eddy current tosted using the Model 1003 tester. Five samples were selected and submitted to Process Design Operation, NRD.

An Investigation is being conducted to evaluate the possibility of using a Model C Cyclograph eddy current tester as a production line tool for classifylng fuel elements with respect to gross differences in grain size

\section{and}

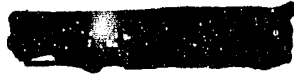


and/or heat treatment. This work to date has been largely of an investigation nature and no definite conclusions have been reached.

At the request of Chemical Development Operation, HI, nondestructive methods of measuring the wall thickness of waste calcination storage tanks are being invest1gated. A study was conducted to evaluate the feasibility of applying several conventional nondestructive techniques to this problem. Since the measurements must be made remotely in an extremely high radiation field, reliable inspection methods will be required. The relative merits of several possible approaches to this problem were evaluated and a memo outlining the results of the study was submitted to the customer.

Installation of the ultrasonic plutonium tester in a hood was completed for Plutonium Metallurgy Development, HL. Testing of plutonium specimens was infitiated. . Due to the high attenuation losses, the planned 15 megacycle test frequency was lowered to five megacycles. The tester will detect $16 \mathrm{mil}$ voids located from $20 \mathrm{mils}$ to $90 \mathrm{mils}$ below the surface at the lower frequency. Rough specimen surface makes it difficult to separate signals due to surface roughness from those due to defects. Present plans are to install additional logic clrcuits which will blank out these rough areas.

A method of attaining higher resolution with standard ultrasonic crystals was attained. Since ultrasonic attenuation increases rapialy with increased frequency, a careful cholce of coupling medium can be used to filter out high frequencies. By using a high frequency crystal ard broadband excitation, an oil coupling medium was used to filter out tine high frequencies, thus producing very definitive low frequency return. information.

Methods of coupling ultrasonic energy into specimens for tensile measurements at elevated temperatures are being investigated. By using a suitable, heat resistant coupling material, it is hoped these measurements can be made with standard crystals. Since quartz has very low ultrasonic attenuation and also good heat insulation properties, its use is being evaluated. Longitudinal and shear velocities have been measured in specimens with the use of quartz coupling rods. Continuing attempts will be made to design optimum coupling rod designs in order to reduce interfering reflections which occur within the quartz.

A paper tape punch readout system for recording tensile machine data has been installed and made operational in 326 Building. Specifications have been prepared for a similar system to be used by Fuels Development Operation, HII.
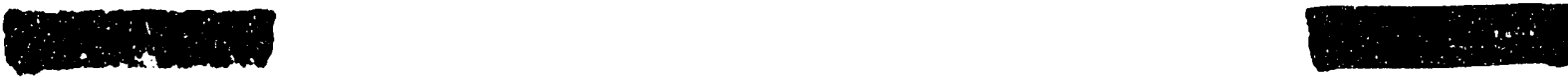
$\therefore$ isistance was provided Chemlcal Development Operation, HI, in scoping code

irunslation requirements for a binary digital transducer.

:sultations were held with Quality Control Operation, IPD, regarding

ifital data logging system for the fuel production facility.

.t. the request of Reactor Materlals Research, II, development work has ves: Inftiated on a device which is to autcomatically examine photomicrosrephs and readout grain size, pore distribution and crack length information.

\section{Optics}

The Electrical Readout Traverse Mechanlsm was callbrated in a full length reactor process tube of known distortion at 189-D Bullding by taking 38 traverse readings at one foot intervals along the length of the tube. The least squares fits of the data were good to $0.080 \mathrm{Inch}$; averaging readings ror all test runs resulted in a maximum error of less than $3 / 8$ inch.

During the four week period (March 17 to Apr1l 14) included in this report, a totai of 472 manhours shop work was performed. The work 1ncluded:

1. Assembly of four quarter-wave retardation plates for Mater1als Bng1neering, HIL.

2. Repalr of two crane periscope heads for Purex.

3. Servicing of one slave crane periscope for Purex.

4. Fabrication of 18 mirrors and eyeplece guards for Materials Fingineering.

5. Modification of the eyeplece of the PRIR Profilameter.

6. Fabrication of 50 pyrex welding shields for INR.

7. Fabrication of glass absorption standards for Separations Chemistry Laboratory, CPD.

8. Fabrication of a weld inspection microscope for NRR Fuels fabrication.

9. Fabrication of several components of ultrasonic probes for Physical Messurements.

10. Evaporation of cobalt to form twelve nuclear targets for Mucleonic Instrumentation.

11. Modification of a borescope camera for Testing Methods, NPR.

12. Fabrication of six thin scintillation glasses for Process Control Development, HIL.

13. Fabrication of a lead sulphide radiometer.

Physical Testing

Testing services continued to increase during the month. Thirty BAPO components and two AEC contractors requested a total of 23,767 tests, nearly 


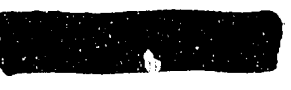

aouble that of the previous month. Total items tested were 6,366 .

Assistance was provided IPD in the elimination of a major Zircaloy-2 process tube cracking problem. It is necessary to form Vanstone flanges on the process tube ends prior to their use. Normally one end is flanged prior to reactor installation and the other end flanged after installaion. In practice, however, it was necessary to reject up to fifty percent of the pre-installation flanges because of severe cracking that occurred as the tube ends were flared. The cause was correctly diagnosed to be small intermal surface scratches which were acting as stress risers. A method of removing the scratches by dry honing the inside surface with a controlled grit blasting process was developed, demonstrated and incorporated as a regular step in the tube preparation process. Results have shown the technique to have virtually eliminated the problem.

Twenty percent of seventy-two Zircaloy-2 tubes, 0.422 inch $0 . D$. by 0.020 in. wall, were rejected with ultrasonic response amplitudes equal or exceeding the 0.001 inch deep standard notch amplitude. These tubes were previously eddy current tested at Argonne National Laboratory, where eight percent were designated as rejects. Measurements of several rejects on O.D. surface indications have verifled the ultrasonic test data. Further correlation and metallographical examination of the ultrasonic indications are in progress.

Physical Testing Operation provided ultrasonic qualification tubes per HWS-5944, "Specification for UItrasonic Testing of Seamless and Welded Tubing, "for certification of vendor equipment to test the titanium heat exchanger tubing for the Hanford Laboratory calcinator facility. Electromachined notches were fabricated in both 1 inch $0 . D$. by 0.065 inch thick wall and 0.75 inch $0 . D$. by 0.065 inch thick wall titanium tubes. The outside and inside surface notch dimensions were measured by replication techniques and the ultrasonic response from each notch measured.

The field unit activities for the month of April include magnetic particle and fluorescent penetrant examination for incipient failure detection of pump shaft couplings, overbore fuel element nozzles, tru-arc retaining rings, rear-face crossheaders, parker fittings, and vertical risers on the 105 reactors. Radiography for weld integrity and code compliance was conducted on the calcinator project for the 324 Building, C-1 Loop Piping, High Pressure Helium Piping, and DeLaval Pump Impellers. Radiography was also conducted on the 105-N Bullding Nitrogen System, welds in the 165-KE and KW Valve Pits, and on the Rupture Loop in PRTR. Stress analysis was conducted on a crossheader on the rear face of 105-C Area to delineate the areas requiring maintenance or replacement. Ultrasonic thickness measurements were conducted on a waste tanker trailer to detect areas of possible

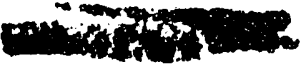


inetration through the tank walls.

- whingues in radiography image amplification and magnification are being ijied to reduce some very definlte limitations in X-ray radiography.

$\therefore$ is now possible, with certain image intensifiers and magnifiers to ine magnification of as mach as $12 x$ on fine thermocouples with reso$\therefore$ ion comparable to $2 \%$ radlography. Neutron radiographic generetors are bcing studied for the radiography of bonds and cladding studies on fuel isments without the image interference from the dense uranium encountered with conventional X-rays.

Sixty-four memoranda reports were issued detailing test findings.

\section{ANALOG COMPUTER FACIIITY OPERATION}

Analog computer problems considered during the reporting period included:

1. PRTR Critical Facility.

2. NPR Kinetics.

3. Meteorology Data Handling.

4. D Reactor Control.

5. Task Network Computer.

The computer utilization was as follows:

\begin{tabular}{rrl} 
GEDA & EASE & \\
270 & 252 & Hours Up \\
20 & 20 & Hours Scheduled Down Time \\
30 & 48 & Hours Unscheduled Down Time \\
0 & 0 & Howrs Idle \\
\hline 320 & 320 & Hours Total
\end{tabular}

The utilization time given above is based on day shift only and does not include swing shift usage.

The bid review for the new analog camputer was completed. A letter was written to G. E. Purchasing accepting the proposal of the low bidder. The purchase order is now in the process of getting necessary approvals.

A new computer technique of remembering peak transient values was successfully applied this month. The new method is useful in studies where it is necessary to define performance criteria of systems as a function of one or more variables. This application is important in system optimiza-

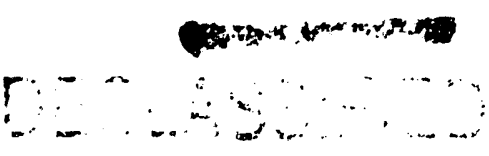



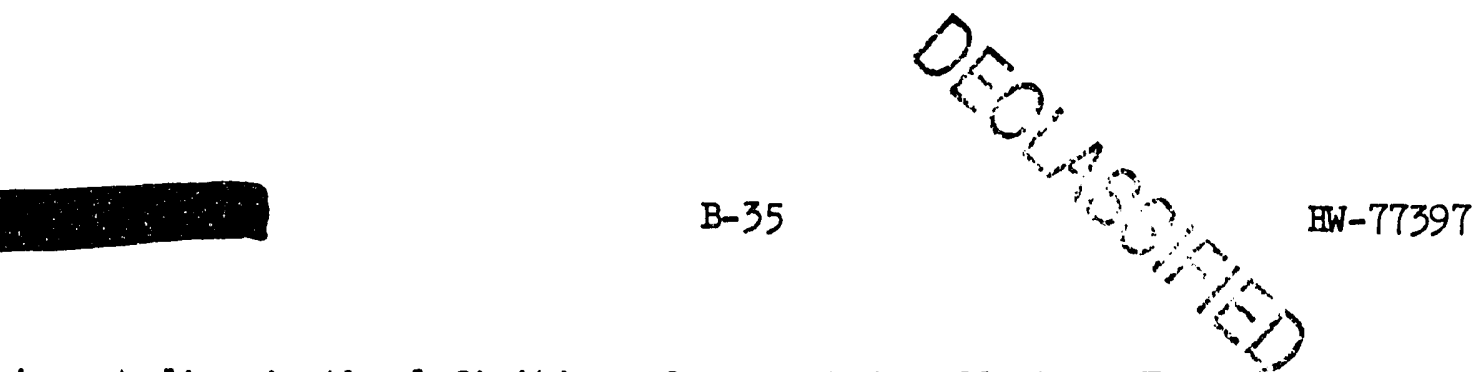

tion studies in the definition of parametric effects. The first application is to define peaks NPR transients during scram muns with trip settings and reactivity input rates as parameters.

\section{INSTRUMEANT EVALUATION}

Minor circuit changes were made on the experimental solid state portable radiation survey meter to improve performance under varying temperature conditions. Complete temperature retesting was started.

Evaluation tests were started on the prototype scintillation solid-state beta-gamma hand and shoe counter which employs gamma background compensation circuitry. Initial tests indicate the standard HAPO test source of $2.4 \times 10^{4} \mathrm{~d} / \mathrm{m}$ Ra $\mathrm{D}-\mathrm{E}-\mathrm{F}$ can be detected when the instrument is in a uniform gamma field of I mr/hr. This is a substantial improvement over the present HAPO beta-gamma hand and shse counters.

A review was made of IIne-operated alpha monitor operation in the 309 Building. Recommendations were made to improve the performance of the scintillation probes and Scintran monitors. In addition, it was recommended that an operator training program regarding use of the instruments be initiated.

Purchase specification information was supplied to Radiation Protection Operation for the purchase of extra alpha scintillation probes for use with the Model II Scintrans on plant.

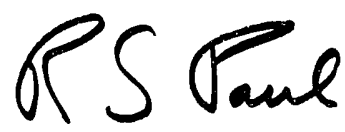

Manager

PHYSICS AND INSTRUMENTSS LABORATORY

RS Paul:mes 


\section{CHEMICAL LABORATORY \\ RESEARCH AND ENGINEERTNG}

FISSIONABLE MATERIALS - 02 PROGRAM

IRRADIATION PROCESSES

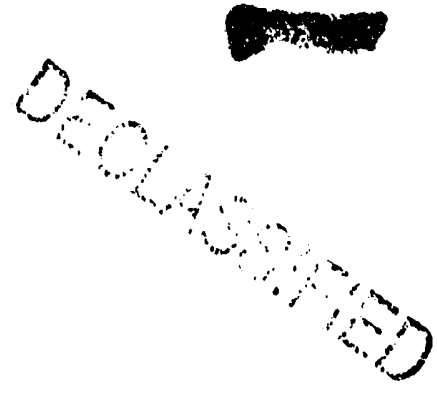

Effluent Water Radioisotope Studies

Water produced during this period had a pH of 6.6 with the alum addition rate varied to maintain the zeta potential at $0 \pm 1 \mathrm{mv}$. The radionuclide concentrations in the effluent water from these tubes showed a gradual decrease during this period while the concentration in the main reactor effluent showed a characteristic annual spring increase which, in the case of some radionuclides, was as much as a factor of three. Although this latter increase was due in part to a reduction in the alum feed rates, this test does show that with suitable zeta potential control, low radionuclide production and release to the effluent can be maintained at a pH of 6.6 .

\section{Deionized Water Studies}

Delonized water was supplied during this perlod to a zirconium tube with zirconium clad fuel elements and an aluminum tube with zirconium clad fuel elements. In the all-zirconium system the radionuclide concentrations were very low and slowly decreasing. This probably represents changes from the previous fuel elements clad with aluminum. In the aluminum tube, zirconium clad fue? element system, the radionuclides generally decreased with the exception of Np-239 which increased slightly. Background data and corrosion rate estimates from Na-24, $\mathrm{Ga}-72$ and $\mathrm{Ni}-65$ concentrations have now been obtained and these tubes will be refueled and tests will begin with addition of silicate.

\section{D-Reactor Test}

The Ga-72 concentrations in the effluent water from the two sides of the reactor indicate a reduction in corrosion rate on the $\mathrm{pH}$ 6.6 side of about 20 percent as compared with the $\mathrm{pH} 7$ side. This result is similar to the reductions in Ga-72 observed in other $\mathrm{pH}$ tests in tubes at the $\mathrm{KE}-$ Reactor,

\section{Ni-65 as a Fuel Jacket Corrosion Indicator}

The X-80Q1 aluminum used for fuel element jackets contains 1 percent nickel while the aluminum tubes contain less than 0.05 percent nickel. 
This indicates the possibility that the Ni-65 content of reactor effluent water might be a useful measure of the instantaneous corrosion rate of the fuel element jackets. Some values to date indicate $\mathrm{Ni}-65$ is present at about $5 \times 10^{-6} \mu \mathrm{c} / \mathrm{ml}$ in reactor water from a zirconium reactor process tube in KE-Reactor with aluminum clad elements. This would indicate a corrosion rate of about one-half the two mils per month rate expected. Further investigations are planned to compare the $\mathrm{Na}-24, \mathrm{Ga}-72, \mathrm{Ni}-65$ values as indicators of corrosion rate.

\section{Surface Chemistry of Uranium}

The effect of $\mathrm{UO}_{2}\left(\mathrm{NO}_{3}\right)_{2}$ content in the desmutting solution was studied by EMF measurements. For the solution $8 \underline{\mathrm{N}} \mathrm{HNO}_{3}-0.5 \mathrm{M}$ $\mathrm{UO}_{2}\left(\mathrm{NO}_{3}\right)_{2}$ at $40 \mathrm{C}$, the minimum effective desmutting time remains at four minutes but the rate of passivation of the cleaned surface is $10 \mathrm{mv} / \mathrm{min}$ compared to the rate of $5 \mathrm{mv} / \mathrm{min}$ for $8 \mathrm{~N} \mathrm{HNO}_{3}$ with no initial $\mathrm{UO}_{2}\left(\mathrm{NO}_{3}\right)_{2}$. For the solution $8 \mathrm{~N} \mathrm{HNO}_{3}=1.0 \mathrm{M} \mathrm{UO}_{2}\left(\mathrm{NO}_{3}\right)_{2}$ at $40 \mathrm{C}$ the minimum effective desmutting time is somewhat decreased and the rate of passivation of the cleaned surface has again doubled to a value of $20 \mathrm{mv} / \mathrm{min}$.

The preceding measurements were made on $4 \mathrm{~cm}$ long beta heat-treated uranium cylinders obtained by rolling an ingot uranium fuel element to $0.8 \mathrm{~cm}$ diameter. To determine the applicability of this measurement technique to whole futl elements the EMF in $0.5 \mathrm{M} \mathrm{NaClO}$ was measured as a function of desmutting time in $8 \mathrm{~N} \mathrm{HNO}_{3}$ at $40 \mathrm{C}$. The minimum effective desmutting time for an 8 -inch $I$ \& $\mathrm{E}$ fuel element anodically etched in $5.4 \mathrm{M} \mathrm{H}_{3} \mathrm{PO}_{4}-0.29 \mathrm{~N} \mathrm{HCl}$ is about three minutes and the rate of passivation of the cleaned surface is $15 \mathrm{mv} / \mathrm{min}$. A 1/40th segment of a fuel element (similar in surface area to the $0.8 \mathrm{~cm}$ diameter cylindrical uranium specimen) exhibits the same minimum effective desmutting time and rate of passivation as a whole slug. Thus the EMF measurements in $0.5 \mathrm{M} \mathrm{NaClO} \mathrm{M}_{4}$ can indeed be applied to whole slugs as well as small pieces of uranium.

\section{Release Studies}

Tests on the release of Po-210 from aluminum-clad, irradiated bismuth have shown that: ( 1 ) at $1300 \mathrm{C}$ in an air atmosphere, the release apparently is linear over the first hour at a rate of 0.3 percent per minute; (2) oxidation is the major release-controlling mechanism for conditions mentioned in (1) as indicated by the release rate in a helium atmosphere of 0.02 percent per minute compared to 0.3 percent per minute in air; and (3) the 8.5 and 59 percent Po-210 releases from aluminum-clad and unclad bismuth specimens in 30 minutes highlight the effect of cladding on release parameters.

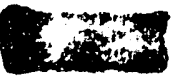

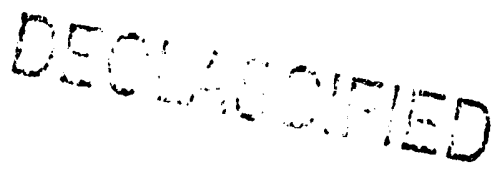


Disposal to Ground

The 216-2-9 (Recuplex) crib-bottom core-sampling was concluded this month. Six-foot cores were obtained at seven locations, and an 8-foot core was obtained from an eighth site. The drive-type core barrels and allied equipment performed satisfactorily, and core recovery was better than 75 percent. These soil samples are being analyzed by the Redox Analytical Operation to determine the plutonium distribution in the sediments underlying the crib bottom. Justification and need for additional samples is dependent upon the analytical findings.

The concentration of gross beta-emitters in the ground water beneath the 216-A-10 Purex process condensate crib reached a high of $7 \times 10^{-3}$ $\mathrm{\mu c/cc}$ this month. Isotopic analyses of the ground water samples showed a maximum $\mathrm{Sr}-90$ concentration of $3 \times 10^{-8} \mu \mathrm{c} / \mathrm{cc}$, which is less than the recommended maximum ground-water limit, $1 \times 10^{-7} \mu \mathrm{c}$ $\mathrm{Sr}-90 / \mathrm{cc}$. Based on recent analyses of crib influent samples, 1-2 $\times 10-7$ uc Sr-90/cc, it does not appear likely that the ground water limit will be exceeded in the near future; however, additional decontamination of Sr-90 from the waste is desirable. Soil column tests are scheduled to evaluate the dicontamination benefits and prolonged crib life which might result by adding caustic to the crib influent.

Analytical results from several wells near the Columbia River and north of the 300 Area show detectable tritium concentrations, $>1 \times 10^{-5}$ $\mathrm{Hc} / \mathrm{cc}$. One well four miles north of the 300 Area, 699-S3-El2, contained tritium at a concentration of $2 \times 10^{-5} \mu \mathrm{c} / \mathrm{cc}$. There is no indication of vertical flow within the well. This supports the earlier evidence that ground-water contaminanats are not moving significantly more rapidly in the confined strata overlying the basalt (previously noted in Well 699-20-El2) than in the unconfined ground-water zone.

\section{Plutonium Electrowinning}

A series of experiments have been started to try to correlate various parameters present in the plutonium electrowinning cell with current efficiency and the appearance and extent of extraneous phases. The parameters of interest include: cathode and anode current density; cell geometry, as expressed by the anode to cathode spacing; temperature; concentration of the $\mathrm{PuCl}_{3}$ solute; and the effect of impurities, in particular, oxide ion.

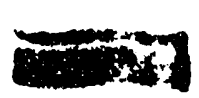


The cell itself is composed of a graphite crucible which is used simply as a container, a small $\mathrm{Al}_{2} \mathrm{O}_{3}$ crucible which is used to hold the plutonium metal cathode and to define the surface area of the cathode, and a cylindrical anode, made up of a solid piece of $1-1 / 2$ inch graphite bar stock, which is positioned directly over the cathode pool. The anode is made in such a way that it can be raised and lowered, thereby varying the anode-cathode spacing.

Equimolar $\mathrm{LiCl}-\mathrm{KCl}$ containing about 30 weight percent $\mathrm{PuCl}_{3}$ is conditioned prior to the electrolysis by sparging the melt, contained in a graphite crucible, with chlorine for about six hours at a temperature of $550-600 \mathrm{C}$. The charge is melted under a chlorine atmosphere and a chlorine sweep is kept over the melt during the electrolysis.

In the first series of runs the effect of cathode current density was investigated. A marked increase in current efficiency is noted at higher current densities accompanied by a lessening and finally a disappearance of extraneous phases. An expianation for this cannot be made until more experimental work has been completed. It might be added that it was possible to distinguish the deposited metal from the parent cathode pool because the former was deposited on the cathode in the form of small nodules. In spite of this the nodules adhered very well to one another and to the parent metal.

\section{Solid State Electrolysis of Uranium}

A 50-hour uranium electrolysis run was completed. At the conclusion of the run, the specimen was cut into one $\mathrm{cm}$ segments which were weighed, oxidized to $\mathrm{U}_{3} \mathrm{O}_{8}$ and analyzed spectrographically. Quantitative analyses for $\mathrm{Ni}, \mathrm{Si}_{i}$ and $\mathrm{Fe}$ indicated no detectable migration of these impurities. In addition, qualitative analyses for $\mathrm{Al}, \mathrm{Cu}$ and $M n$ indicated no significant migration of these elements.

These results are in agreement with preliminary results on uranium obtained by $T$.A. Henrie (private communication) and with predictions derived from radius-ratio considerations. In general, the data do not indicate that the actinide elements will behave similarly to the lanthanides. However, the specific case of plutonium remains of considerable interest because of the unique and potentially favorable properties of the plutonium metal system.

\section{Losding of Plutonium on Oxalate-Supernate Column 234-5 Building}

The reasons for high loadings of plutonium obtained on one column in the oxalate supernate anion exchange facility in 234-5 were 
determined. The results show that a batch of resin (Permutit SK) with better than normal kinetics was being used, A loading (to 50 percent breakthrough) of $106 \mathrm{~g}$ Pu/l was obtained under conditions where about $75 \mathrm{~g}$ Pu/L would have been expected with earlier resin batches. The product concentration was also above normal with an average of $62 \mathrm{~g} / \mathrm{l}$ for the entire product vs, $58 \mathrm{~g} / \mathrm{l}$ for the maximum cut on previous resin batches. It would appear that this batch of resin is probably somewhat lower in sross-1inkage than previous batches anc allows improved loading kinetics.

WASTE MANAGEMENT AND FISSION PRODUC'T RECOVERY

Trilauryl Amine (TLA) Extraction of Nepiunium and Plutonium from Purex IWW Solution

Purex plant IWW solution, produced in March 1963, was made $0.02 \mathrm{M}$ in hydrazine and allowed to stand 30 minutes at $25 \mathrm{C}_{\text {。 }}$ In a subsequent batch contact of the solution with an equal volume of 0.3 M TLA-Soltrol, 98-99 percent of the plutonium and 87-89 percent of the neptunium were extracted. About 80 persent of the extracted neptunium and plutonium was stripped on contact of the organic with an equal volume of $0.1 \mathrm{M}$ oxalic asid. These results compare favorably with results obtalned in similar studies with simulated solutions. Analytical data to define decontamination are not yet available. Gelatinous solids present in the plant IWW did not impair plutonium and neptunium extraction behavior or produce dispersion and disengaging problems.

In studies to determine effects of TLA in Purex plart zslient, tracer-level miniature mixer settler runs simulating the Purex HA and HS columns were completed. Uranium and plutonium losses were not affected by the presence of up to five volume percent TLA in the extractant. Gross gamma decontamination was not affected by up to one volume percent TLA in the solvent but was significantly decreased at higher TLA concentrations.

Another tertiary amine (Adogen 364 , a product of Archer-DanielsMidland, containing 60 percent eight-carbon chains and 40 percent ten-carbon chains) was tested. Third phase formation occurred when $0.1-0.6 \mathrm{M}$ Adogen 364 - Soltrol solutions were contacted with simulated Purex 1 WW solution。

CSREX Extraction Mechanism

Use of nuclear magnetic resonance (NMR) measurements to study the synergistic reaction which results in the extraction of 
cesium at low $\mathrm{pH}$ by BAMBP-D2EHPA mixtures was undertaken during the month, with very promising results. Preliminary indication is that the BAMBP (probably four moles per mole of cesium) solvates the cesium and that the D2EHPA then extracts the solvated species. In the absence of BAMBP, cesium extraction into D2EHPA is accompanied by several moles of water. In the presence of BAMBP, little or no water is extracted. In a BAMBP-only system, a fifth molecule of $\mathrm{BAMBP}$ is the extractant, but a high $\mathrm{pH}$ is required to ionize the BAMBP - and hence is required for the extraction - whereas D2EHPA is ionized, and hence effective, at low $\mathrm{pH}$.

\section{CSREX Process - Laboratory Studies}

Further tracer-level mixer-settler runs were made with simulated feed to test Flowsheet No. 2 conditions for extraction of cesium, strontium and rare earths from Purex $F^{\prime}$ W. Under extraction column conditions, decontamination factors for iron and chromium were 34 and $>480$ respectively, in good agreement with earlier data under Flowsheet Nn. I conditions. Yttrium loss under extraction column conditions was about seven percent; yttrium decontamination factor in the partition column was 340 . Less than one percent of the yttrium stripped under strip column conditions.

Batch contact studies of means for removing yttrium from the D2EHPABAMBP-Soltrol solvent were made. Most effective yttrium removal (DF of 2000 to 3000 ) was attained by contact of the solvent (ICW) with an equal volume of $1-3 \mathrm{M}$ sodium hydroxide or $0.1 \mathrm{M} \mathrm{NaOH}$ $0.1 \mathrm{M}$ complexing agent (DTPA, EDTA, etc。) solution, Oxalic acid wastes removed little or no yttrium. Third phase formation occurred when the solvent was contacted with $5 \underline{M}$ sodium hydroxide

When CSREX solvent is contacted with an aqueous phase containing nitrite, the solvent darkens and cesium extracting capacity decreases. In equal volume contacts between solvent and simulated CSREX feed ( $\mathrm{pH} 4.5)$ containing added nitrite, 3-4 BAMBP molecules were inactivated (with respect to sesium extrostion) per nitrite initially present in the aqueous phase. There is some evidence that a minimum nitrite concentration in the system exists below which BAMBP deactivation does not occur.

Another type of nitrite reaction, an apparently autocatalytic reaction in which the cesium extracting capacity of the solvent is almost completely destroyed, can occur when the solvent is in contact with nitric acid. Incidence of this type reaction is a function of aqueous nitric acid concentration and temperature of the system. It was observed at nitric acid concentrations as ryons $0.9 \mathrm{M}$ when the system was at $50 \mathrm{C}$ 。 
CSREX Process - Engineering Studies

Two flowsheet concepts designed to maximize the extraction of cerium and other rare earths were successfully demonstrated during the month. The first involved operation of the $1 \mathrm{~A}$ column at 45-50 C. To permit adequate cesium recovery at this temperature, the BAMBP concentration of the solvent was adjusted to a nominal $0.8 \mathrm{M}$ (vs. previous $0.3 \mathrm{M}$ ) and the $I B$ column temperature was increased to 45-50 C. The second flowsheet simply substituted $0.185 \mathrm{M}$ tartrate for the normal $0.135 \mathrm{M}$ citrate - $0.05 \mathrm{M}$ tartrate complexing agent in the IA feed. It operated at ambient temperature and with a nominal $0.3 \mathrm{M}$ BAMBP in the solvent. All runs were made in 3-inch diameter gle: 3 pulse columns operated in cascade with cartridge heights of nine to ten feet. The feed flow rate was 0.5 liter/ minute; the nominal flow ratios for the system were $1 \mathrm{AF} / \mathrm{IAX} / \mathrm{IAS} /$ $1 B X / 1 C S=1 / 2 / 0.4 / 1.6 / 0.4$ 。

Highlight results of these runs are as follows:

1. Cesium extraction is affected aciversely by increases $L_{i}$ temperature when using $0.3 \mathrm{M}$ BAMBP, but can be sought back into line at the higher temperature by increasing the BAMB concentration to $0.8 \mathrm{M}$.

2. Cerium losses are decreased to two to four percent oy operating at the higher temperatures.

3. Strontium recovery is not seriously affected by the higher extraction temperatures.

4. Strontium and cesium recovery in the $I B$ colum is greatly improved by elevated temperatures.

5. Changing from mixed citrate-tartrate feed complexants to tartrate-only reduced IAW cerium losses from 23 percent to three percent at $25 \mathrm{C}$ and $0.3 \mathrm{M}$ BAMBP solvent. However, the lower courplexing ability of the tartrate ion may present some problems. For example, the ferric ion concentration in the solvent increased from $0.18 \mathrm{~g} / \mathrm{l}$ using a heated citratetartrate flowsheet to $0.28 \mathrm{~g} / \mathrm{l}$ using the tartrate-only flowsheet. Zirconium extraction is also expected to increase. No effort was made in any of the runs to remove iron from the solvent; the indicated losses were obtained despite the iron loading.

6. Cerium losses in IC column typically_ranged from four to ten percent. 
The solvent used in these tests was partially degraded from reaction with nitrite ion, as reported last month. The only observed adverse effect of the degradation product (an estimated $0.2 \mathrm{M}$ ) was its extremely dark color which interfered with column observations. All three columns had excess capacity (typical flooding frequencies at the indicated flow rates were in the range of 60 to $90 \mathrm{cycles} / \mathrm{min}, \mathrm{I}$ in. amplitude).

\section{Adsorption of Trace Components by Solids in Purex FTW}

Simulated Purex FTW slurries were prepared by concentration and formaldehyde treatment of solutions representing current feed to the Purex wast 9 concentrator. These were traced with various components of interest in the waste management and fission product recovery programs. About 35, 85, 11,40 and 65 per cent of the strontium, cerium, cesium, neptunium, and plutonium, respectively, were present on the six volume percent of solids present after formaldehyde treatment. The data for strontium, cerium and cesium are in fair agreement with data obtained on plant materials (personal communication, S. J. Beard). Several leaching reagents (water, nitric acid, sodium hydroxide, citrate, tartrate, and EDTA) are being evaluated for removing the adsorbed elements from the solids.

\section{Cesium Removal from Alkaline Supernates}

Additional studies were made on the flowsheet for removal of sesium from alkaline supernatant wastes. Data from column runs in whi th the waste was spiked with Na-22 indicate there is essentialy no iff srence in the amount of sodium removal per unit volume of scrub for flow rates of one to elght column volumes per hour. With Duolite C-3 or clinoptilolite, 99 percent of the sodium was removed by seven column volumes of $0.2 \mathrm{M}\left(\mathrm{NH}_{4}\right)_{2} \mathrm{CO}_{3}$. However, with IInde AW-400 and AW-500, only 91 to 95 perceht of the sodium was remover readily with the rest being removed slowly and partly in the eluate. This accounts for the Iower $\mathrm{Na} / \mathrm{Cs}$ ratios in the eluate with clinoptilolite. Since $A W-400$ and $A W-500$ have the same binder but otherwise are not similar, it is suspected that the sodium holdup is in the binder. Negotiations are in progress to obtain AW-400 with a more suitable binder.

\section{Zeolite Loading Est1mates}

In order to obtain reliable estimates of cesium or strontium loadings on zeolites from binary ion exchange data, it is necessary in some cases to use the activity coefficient ratio of the major accompanying cation to the cesium ion or sivontium ion. An example of this was found when using binary ion exchange data, determined with chloride 
solutions, to predict cesium loadings on AW-400 zeolite from a sodium carbonate solution containing cesium. The activity of sodium carbonate is about half that of sodium chloxide in a IN $\mathrm{Na}^{+}$solution, and results in Eignificantly higher cesium loadings from carbonate solutions. All binary ion exchange data to be used for predicting $\mathrm{Cs}^{+}$or $\mathrm{Sr}^{++}$loadings on zeolites are being calculated in terms of activity ratios rather than equivalent ratios.

Since the solution concentrations involved are beyond the range of the classical Débye-Huickel treatment, Glueckauf's equation (Nature, 1949, 163, 414) was used to calculate activity coefficient ratios. Simplified equations can be derived from Glueckauf's equation where the valence of the two cations is the same. Three cases are of interest: (1) two univalent cations with a common univalent anion; (2) two univalent cations with a common divalent anion and (3) two divalent cations with a common univalent anion. The first case is given by Barrer and Samon (Journo Chem. Soc. Iondon, 1955, p. 2838-2849), i.e.

$$
\frac{f_{A_{B}}}{f_{B_{3}}}=\frac{f_{A X}}{f_{B X}}
$$

The following equations were derived for cases 2 and 3.

$$
\frac{f_{A_{s}}}{f_{B_{3}}}=\left(\frac{f_{A_{2} X}}{f_{B_{2} X}}\right)^{3 / 4} \text { and } \quad \frac{f_{A_{S}}}{f_{B_{S}}}=\left(\frac{f_{A X_{2}}}{f_{B X_{2}}}\right)^{3 / 2}
$$

where $f_{A_{s}}$ and $f_{B_{S}}$ are the rational activity coefficients of cations $A$ and $B$ in the solution mixture, and $\left(f_{A X}\right),\left(f_{A_{2} X}\right),\left(f_{A X}\right),\left(f_{B X}\right)$ 。 $\left(f_{\mathrm{B}_{2} \mathrm{X}}\right)$, and $\left(f_{\mathrm{BX}_{2}}\right)$ are the mean rational activity coefficients for the pure solutes in solution.

Where the cations differed in valence no simplified equations could be derived; however, the activity coefficient ratio of the two ions can be calculated from Glueckauf's equation.

\section{Storage of Cesium and Strontium on Zeolites}

Objectives of the planned hot-cell tests of the Hanford Waste Management storage concept were described last month. A full level B-Cell demonstration experiment with one mole (7500 curies) of Hot Semiworks strontium -90 was initiated during the current month, with

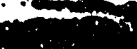


the period of observation of the loaded bed continuing at month end. Although possible deficiencies may exist in the proposed flowsheet for loading the cartridge, no radiolytic decomposition was observed and the results were generelly favorable.

The first attempt to load the bed was with a synthetic Waste Management feed prepared from purified Semiworks strontium-90. Chemical composition of the feed was: $0.035 \mathrm{M} \mathrm{Sr}, 0.2 \mathrm{M} \mathrm{Na}, 0.01 \mathrm{M} \mathrm{Ca}$, and $0.005 \mathrm{M}$ citrate adjusted to $\mathrm{pH} 50$ Purpose of the citrate was to prevent yttrium loading (which would cause a "hot spot" in a full-size cartridge。) Flow rate during loading was 12 column volumes per hour at a temperature of $80 \mathrm{C}$. Only about 25 percent of the strontium (but half of the yttrium) loaded. A second attempt was made with the same feed (after readjusting to $\mathrm{pH} 5$ ). Little or no additional loading occurred. A third pass was made at a reduced flow rate of six column volumes per hour which gave an increase of about 15 percent in loading. A fourth pass with the same effluent but at only 1.2 column volumes per hour was much more successful and resulted in final ioading of all but about 20 percent of the initial feed strontium - equivalent to about two miliiequivalents of strontium per gram of zeolite. Virtually all of the yttrium loaded. Reasons for the poor loading (possibly due to poor kinetics or channeling) are being investigated with a duplicate cartridge and synthetic feed. Either adverse column geometry or prior heat treatment of the zeolite (which had been subjected to temperatures of $500 \mathrm{C}$ in Cold Semiworks studies and to $620 \mathrm{C}$ in hot-cell heater testing prior to loading) may have been responsible.

After loading, the bed was dried by heating to $400 \mathrm{C}$ and passing air at a rate of one liter per minute for four hours. "Moist" room air (estimated relative humidity about 50 percent) was used, simulating failure of the gas dryers planned for use in the plant. The bed was then sealed and observed for pressure build-up. None occurred in four days at $400 \mathrm{C}$. The temperature was then raised to $500 \mathrm{C}$. A prompt (gas law) pressure increase of about two pounds per square inch was observed, however, the pressure did not increase further implying negligible radiolysis. Temperature was then raised to $600 \mathrm{C}$. The pressure immediately increased to over $85 \mathrm{psi}$, and the capsule was vented to prevent a further excursion。 The temperature was dropped $\left(10^{\circ}\right)$, but pressurization was still dangerously rapid. The temperature was returned to $500 \mathrm{C}$ and a low, constant, pressure has been maintained since. Observation is continuing. The sudden, excessive, pressurization at $600 \mathrm{C}$ - which was not observed or looked for, in the semiworks studies, is believed due to sudden release of retained residual water and is not inconsistent with extrapolation of published isotherm data. In the drying cycle and storage conditions planned for plant application, this pressurization condition will not exist. 
Spectographic Determination of Strontium and Calcium in Uranium

A sensitive and precise spectrographic method was developed for determining the calcium and strontium content of incoming Hanford fuel elements. Uranium is separated from calcium and strontium by adsorbing the uranium on Dowex-1 resin from $6 \mathrm{M} \mathrm{HCl}$. The uranium-free effluent is evaporated on copper electrodes and excited by high voltage spark discharge. One part of strontium and five parts of calcium per million parts of uranium can be determined with a standard deviation of \pm 6 percent.

\section{EQUIPMENT AND MATERIALS}

\section{A1r Pulser Control System}

An Instrumentation system is under development for controling pulse amplitude in the air pulser for the new Plutonium Reclamation Facility. A signal relating to pulse amplitude is derived from a bi-directional measurement of liquid flow in the pulse leg. Three flow measuring systems have been evaluated and tested: a strain gauge flow transducer, strain gauge differential pressure cell, and a daphragm-type differential pressure cell. Based on the test results to date the diaphragm-type $D / P$ cell, has the best characteristics for incorporation into the closed-loop control system. Advantages of this device include (1) high level output, (2) no $A C$ to $D C$ conversion requirement, and (3) no common mode problem. An averaging amplifier used with the $D / P$ cell provides an output signal suitable as input to a controller.

\section{Stress Corrosion Cracking of Mild Steel}

The three feet by three feet square welded samples being exposed to simulated Purex stored waste (alkaline) were inspected in April. A weldment fabricated from ASTM A-201 was cracked. The crack appeared to originate in a weld repair area; this weld repair had been made on the sample 67 days before the inspection. Two other A-201 weldments (one as-welded and one with a weld repair) are also being exposed in the simulated stored waste. At inspection time these weldments had been exposed only 15 days; neither had cracked. The manganese content of these A-201 samples is about 0.4 percent. It is known that manganese imparts properties to the steel which should reduce the tendency toward stress cracking. A sample of onehelf-inch-thick A-201 plate containing 0.94 percent manganese was obtained. Tests on both large $\left(3^{\prime} \times 3^{\circ}\right)$ weldments and small notched and stressed samples of this steel will be made to determine its tendency toward stress cracking and to measure the cathodic current density required to prevent stress cracking.

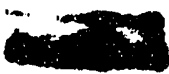


Gadolinium-Containing Stainless Steel

A 57-pound ingot of stainless steel corresponding to 304-L specifications but containing 1.7 weight percent gadolinium was obtained from the Oregon Metallurgical Corporation. The ingot will be forged and rolled to 3/16-inch sheet prior to metallurgical examination and corrosion testing.

\section{Anodic Passivation}

As reported last month, the corrosion of 304-L stainless steel by Zirflex dissolvent ( $\mathrm{NH}_{4} \mathrm{~F}-\mathrm{NH}_{4} \mathrm{NO}_{3}$ solutions) can be inhibited by anodic passivation. The effective potential range is about 300 millivolts ( -400 to $-100 \mathrm{MV}$ vs. a standard calomel electrode). An attempt was made to maintain this potential through use of chemical additives. No agent was found which is superior to $\mathrm{Cu}$ (II) even though the potential maintained by $\mathrm{Cu}$ (II) is about $100 \mathrm{MV}$ more passive than desired. The main problem with $\mathrm{Cu}$ (II) is loss of oxidant with time. The inhibiting effect of $\mathrm{Cu}$ (II) in Zirflex solutions has been known for some time, but the mechanism has not.

Corrosion Tests on Rigimesh 304 Stainless Steel Filters

Samples of as-welded Rigimesh 304 filters were exposed to 0.25 , $0.5,1.0$ and $2.0 \mathrm{M}$ nitric acid solutions at about $95 \mathrm{C}$ for 84 days. All of the samples showed some loss or penetration of the three layers of material comprising the filter. It was concluded that these filters are not suitable for long-term exposure in nitric acid solutions.

Corrosion of Aluminum, 304-L Stainless Steel and Tool Steel in Carbon Tetrachloride

Samples of 6016 aluminum, 304-L stainless steel and an "0" type tool steel were exposed at room temperature to carbon tetrachloride and carbon tetrachloride containing one volume percent added water. Only the 304-L stainless steel shows no evidence of corrosion in either medium.

\section{PROCESS CONTROL AND DEVELOPMENT}

\section{Plutonium Detection Test System}

Installation of the plutonium detection test system in 222-S Building was completed and preliminary operational tests have been initiated using non-radioactive solutions. Plans for testing an in-line

\section{(4)}




\section{Pand}

scintillating glass alpha counter in the system have been modified because of recent experimental information that the present glass, obtained from England, lacks resistance to dilute nitric acid solutions. However, a high-silica scintillating glass is made which should be suitable for service under the anticipated process conditions.

Initial plutonium detection tests will be performed using a thin (2 $\mathrm{mm}$ ) sodium iodide crystal with a beryllium window to detect the $17 \mathrm{kev}$ plutonium X-rays. In addition, a detector has been fabricated using a sodium iodide crystal for detection of $384 \mathrm{kev}$ gamma radiation.

\section{C-Column Mathematical Model}

Excellent performance of the experimental C-column was experienced during the month; ten runs of the final block of 16 runs were completed. About 3600 analyses were made on samples from 15 experimental runs. Two specially-designed runs were made to determine the within-run reproducibility of the organic volume fraction estimation, the mid-column photometer estimation of the aqueous phase uranium concentration, and the absorptiometer estimation of the "total" uranium concentration as a function of distance up the column. This information is necessary in order to ass: weights to the various pleces of data, and to determine the $: i-$ mum deviation within which the mathematical model must fit tose experimental data and still be statistically significant.

A computer program has been written to obtain initial estimates of the mass transfer coefficients and the aqueous back-mixing coefficients from the reduced run data. These estimates are to be used in the analog and digital determinations to follow. The estimate for the mass transfer coefficient determined this way is fairly good (essertially a determination of the number of transfer units) but the determination of the back-mixing coefficient is poor because it depends on an estimation of second deriviatives and because it is quite small. Two computer table search routines, which are used in the subroutine which calculates the uranium concentration as a function of distance by means of the model, have been reprogrammed to increase their efficiency and speed. The subroutine is used several times per iteration by the nonlinear least squares program, and these table search routines are used up to 75 times for each pass through the subroutine. The speed of these routines has been increased by 50 to 100 percent over the original FORTRAN versions.

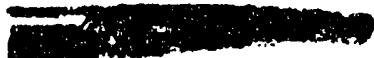


REACTOR DEVELOPMENT - 04 PROGRAM

PLUTONIUM RECYCLE PROGRAM

Salt Cycle Process

Precipitation Studies with Cerium Stand-In for Plutonium - A recirculating gas lift was tested in the 2.5 LiCl-KCl salt bath at $580 \mathrm{C}$ to determine how much $\mathrm{CeO}_{2}$ could be collected on this piece of equipment alone. The gas lift consisted of two concentric pieces of quartz, $51 \mathrm{~mm}$ and $10 \mathrm{~mm}$ in diameter, the $51 \mathrm{~mm}$ tube tapered to a $20 \mathrm{~mm}$ opening at the bottom. Gas was adnitted through the $10 \mathrm{~mm}$ tube. A 24-hour 70 percent $\mathrm{O}_{2}-30$ percent $\mathrm{Cl}_{2}$ treatment resulted in precipitation of 85 percent of the cerium and recovery of 43 percent of cerium on the apparatus. Most of the recovered $\mathrm{CeO}_{2}$ was deposited on the sloping surface where the $51 \mathrm{~mm}$ tube narrowed to a $20 \mathrm{~mm}$ opening and was easily removed by soaking in $0.5 \mathrm{M} \mathrm{HNO}_{3}$. Additional sloping surfaces should result in greater recovery of $\mathrm{CeO}_{2}$.

Aqueous Washing of Electrolytic $\mathrm{UO}_{2}$ - Crushed and sized $\mathrm{UO}_{2}$ particles from a 21-pound deposit produced in a $2.5 \mathrm{LiCl-KCl}$ salt bath at $560 \mathrm{C}$ and 0.7 volts reference potential were washed with tap water to remove salt. The lithium, potassium and chloride contents of the washed $\mathrm{UO}_{2}$ were independent of the particle diameter in the range 1/16-inch to $3 / 4-i n c h$ and of the washing time in the range two hours to 30 days. Although the accuracy of the analytical technique for chloride is still poor, the estimated chloride content of 20 samples taken during the runs ranged from 155 to $422 \mathrm{ppm}$, while the lithium and potassium contents were $15-18 \mathrm{ppm}$ and $70-100 \mathrm{ppm}$, respectively. The results indicate that product $\mathrm{UO}_{2}$ in the $=8+10$ mesh size range needed for vibratory compaction contains occluded salts which are not removed by aqueous washing.

Fuel Processing Economic Study - An initial study has been completed comparing the conventional fuel processing costs with Salt Cycle type close-coupled fuel processing for a large ( $1000 \mathrm{MW}$ ) light water moderated reactor recycling self-generated plutonium on a graded fuel cycle. Fuel exposure for each recyale step is constant, approximately $14,500 \mathrm{MWD} / \mathrm{T}_{\text {, }}$ and equal to the exposure for the initial uranium-only fueled step. Both stainless steel and zirconium-clad oxide fuel elements and a broad range of cost inputs are considered.

To minimize the cost penalties associated with mixed $\mathrm{PuO}_{2}=\mathrm{UO}_{2}$ fuel fabrication, plutonium is segregated in a calculated optimum fraction of the total fuel, and fuel cycle costs are compared on the basis of

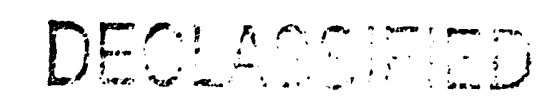

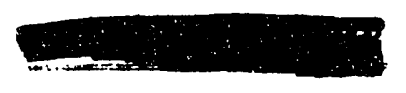




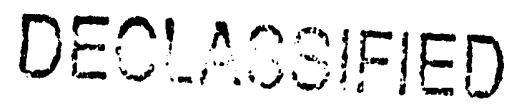

optimized costs. Sarings with Salt Cycle processing relative to central plant processing are based on average fuel cycle costs for four plutonium recycle steps. Plutonium is valued on the basis of the average value of fissile plutonium in each economics case as a replacement for U-235 enrichment. Four economic cases are considered. Fuel cycle costs are grouped into a low cost estimate case and a high cost estimate case and, for each of these, both lease and purchase of enriched uranium are considered. Input data includes fuel cycle losses, inventory periods, burnup and unit costs.

For the reactor cases evaluated to date, a potential savings of 0.10 to 0.25 mills/KWH for close-coupled Salt Cycle type processing is indicated to be a reasonable possibility with plant capital cost limited to a range of $\$ 5$ million to $\$ 10$ million. This is considered a realistic capital cost target for the small (approximately $0.2 \mathrm{TU} /$ day) simplified single-purpose plant as visualized. The larger savings are realized at the lower end of the capital cost range and potential savings are greater for stainless steel. clad fuel than with zirconium clad fuel. In other terms, the savings range from $\$ 12$ to $\$ 30 / \mathrm{K}_{g}$ of fuel processed or $\$ 700,000$ to $\$ 1,750,000 / \mathrm{yr}$ 。 for a $1000 \mathrm{MW}_{\mathrm{e}}$ reactor complex.

Numerous possible applications remain to be evaluated for Salt Cycle process application. These include higher fuel exposure cases, semi-batch and batch reactors, plutonium enrichment other than self-generated recycle and special reactor combinations such as a fast-thermal combination. It is also planned to make an early evaluation of fission product poison decontamination requirements for research and development guidance.

\section{RADIOACTIVE RESIDUE PROCESS DEVELOPMENT}

Full-Level Radioactive Calcination Studies

Two pot calciner runs were made during the month, the first under high sodium nitrate conditions to determine the storage stability of nitrate-containing melts, and the second under high sulfate conditions with excess calcium nitrate added to prevent sulfate volatilization. In both runs, only the condenser and "absolute" filters were used to decontaminate the off-gas, which apparently met allowable discharge limits with this simple treatment only (definitive analytical results not yet available)。 The runs were uneventful, except for a plug which formed in the off-gas line during the boildown phase of the high-nitrate run and which caused pressurization to about five pounds per square inch before power was shut off. The run was resumed after dissolving the plug. The plug was probably caused by foaming and associated with the fact that a draft tube was not used in this run. Another 
interesting observation (prokably caused by the high-sodium, lowsulfate conditions of the run) was the appearance of gross concentrations of cesium in the condensate during melt-down. Details of the runs are included in the January March Quarterly Progress Report on the Fixation of Radioactive Residues (HW-77299).

Eighteen-Inch Radiant-Heat Spray Calciner

Six runs were made in the Cold Semiworks radiant-heat spray calciner to evaluate the off-gas filter blow-back system and to explore the capacity of the reactor.

Pressure drops across the filters were maintained at less than 14 inches of water using both air and superheated steam as a blowback media.

Five different types of venturi arrangements to direct the blowback fluid are being tested on the outlets of the filter elements. The venturis characterized by thin throats, less than one-inch in diameter, and gradual divergence, less than 30 degrees, appear to produce superior performance.

A large, external-mix pneumatic nozzle (Spraying Systems Co. Setup No. 70 ) and a smaller, internal-mix pneumatic nozzle (Spraying Systems Co. Setup No. 42) were run at $20 \mathrm{gph}$. The external-mix nozzle required about 0.45 pounds of steam per pound of feed for adequate atomization, as compared with about 0.10 pounds of steam per pound of feed for the internal-mix nozzle. However, the former nozzle has the advantage that the feed stream need be under no pressure, while with the latter the feed must be under pressure just slightly less than the steam pressure - in this case 37 psig. Calcine buildup on the reactor walls was very light with both nozzles. On the inside of the draft tube the smaller nozzle produced a somewhat greater buildup, perhaps because it was operated beyond its intended capacity and was not producing as fine a spray。

\section{Waste Calcination Instrumentation}

The waste calcination and solidification processes now under investigation will discharge to, or produce their products in pots or canisters. Normally the nature (liquid, powder, or melt) of the material in the canister will be known, but off-standard conditions can abruptly change the nature of the material.

An experimental program has been initiated on means of measuring the level and type of material in the calciner pots. Initial
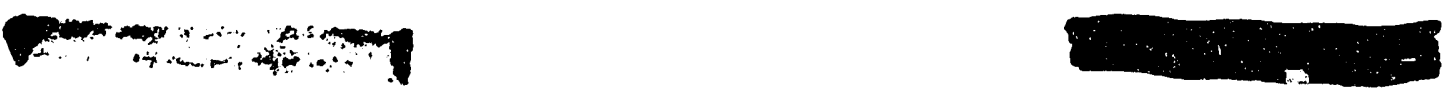

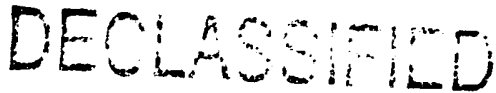


experiments are being conducted in a four-inch-diameter inductionheated pot using a thermocouple measurement system similar to that employed at ORNL for liquid systems. Preliminary results indicate that this system will detect powder levels.

\section{Zeolite Properties}

Work continued on zeolite equilibria in several systems of interest for application to strontium and cesium packaging solutions. The area of zeolite loading covered was zero to 100 percent. Previously reported zeolite equilibria with the systems below covered only the dilute cesium and strontium solution concentrations with from zero to ten percent zeolite loading. The systems included strontium-calcium. sodium-calcium. strontiumsodium, cesium-strontium, cesium-ammonium and sodium-cerium. Cesium-cerium, strontium-cerium and the cesium-rubidium systems are under study. These basic equilibrium data are to be utilized for the determination of zeolite capacities in multi-component systems. Only Linde $13 \mathrm{X}$ and $4 \mathrm{~A}$ were found to remove appreciable amounts of cerium from sodium-cerium solutions. The $13 \mathrm{X}$ is much more cerium-selective than $4 \mathrm{~A}$.

The cerium selectivity coefficient of $13 \mathrm{X}$, uncorrected for ion activities, is substantially improved by heating to $70 \mathrm{C}$. The more rapidiy increasing mean activity of the cerium chloride in relation to sodium chloride with the addition of heat is the probable cause of the selectivity coefficient, increase. A similar, but less pronounced, increase in the strontium selectivity coefficient of $13 \mathrm{X}$ was noted in the strontium-sodium system.

\section{Condensate Treatment}

A small-scale experiment was performed to study the ruthenium removal from steam-stripped Purex tank farm condensate by a thin bed of strong base anion resin in the hydroxyl form. The condensate was passed through a bed of $200 \times 400$ mesh Dowex $1 \times 8$ at a flow rate of about $? \mathrm{gpm} / \mathrm{ft}^{2}(13.5 \mathrm{cv} / \mathrm{min})$. The bed, which was $5 \mathrm{~cm}$ in diameter and $1.5 \mathrm{~cm}$ high, removed 94 percent of the ruthenium at the beginning of the run. After about 3500 column volumes had been treated ${ }_{z}$ nitrate and nitrite ions had saturated the bed, and the ruthenium removal efficiency decreased to 84 percent removal. The effluent concentration of $\mathrm{Ru}=106$ was less than its $M M_{W}$ value for the entire run during which 9800 column volumes of waste were treated. Pressure drop across the bed increased from four pounds per square inch at the start of the run to eight pounds per square inch when the test was ended.

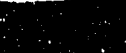




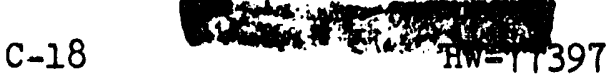

Electrostatic Bubble Scrubber

Experiments were performed to measure the net efficiency of charged particle scrubbing in a $1 / 6$ square foot area bubble scrubber as a function of corona current in the charging section. Care was taken to differentiate between collection on surfaces ahead of the scrubber and within the bubble scrubber itself to permit the bubble scrubbing efficiency to be measured discretely. Several arrangements were tried to find a configuration which did not result in virtually all particles being precipitated on the grounded surfaces making up the inlet passage. The net efficiency was found to increase with charging current to a maximum, then decrease with further current increase. The maximum efficiency for $3.3 \mathrm{~cm}$ depth of liquid and for 0.032 -inch sieve plate holes was found to be only about 50 to 60 percent, about three to four times that for similar uncharged particles. Initial experiments suggest that smaller holes in the sieve plate will result in higher scrubber efficiencies 。

The immediate effort in this study is to obtain understanding of the parameters controlling electrostatic precipitation to a bubble wall, rather than to determine empirically an optimum geometry for overall system efficiency. These initial experiments suggest that electrostatic deposition on surfaces ahead of the scrubbing section may be materially effective in removing particles unless geometries are selected deljberately to avoid this precipitation.

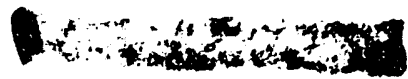

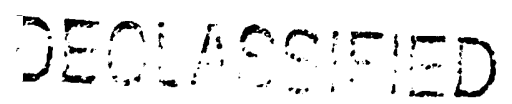


BIOLOGY AND MEDICINE - OS PROGRAM

TEREESTRIAI EIOLOGY EARTH SCIENCES

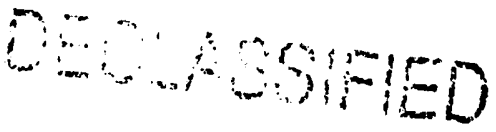

Hydrojogy and Geology

The elecrical analog of the project ground water flow system will use a discrete network of resistors to simulate the soil continuum. The dis:rers resistors permit the spatial conductance (permeability) variation to be easily represented, and internal measurement of analog potentials is simplified. The error due to discretizing the fl-ow system san be reduced to any desired level through ise of sufficiently small grid spacings. The very large horizontal dimensions of the project (miles) as compared to the rather small vertical flow dimension (several hundreds of feet to basalt; suggests using a smaller network spacing in the rertical dimension than in the horizontal dimension. Such a spacing will permit simulation of adequate vertical detail and at the same time reduce significantly the number of resistors required for the analog.

Studies were made to learn what ratios between horizontal and vertical grid spacings can be used without introducing appreciable error. An equation was obtained which estimates the truncation error associated with discretizing the soil continuum. The equation insludes the effects of unequal grid spacings; therefore, the reduced case, $i_{1} e_{0}$, equal spacing, truncation estimate is also available by setting the appropriate ratios to one. Upon comparing the urequal and equal grid spacing truncation error estimates, the probable increased error due to unequal spacing should be obtained. Programming and application of the error analysis to the preliminary test analog is underway。

A FORTRAN program was written to solve a three-dimensional flow system (test anaiog) for which an analytical solution exists. The program generates a set of Fourier coefficients and evaluates the potential at every grid point. The formulation insiudes the ability to use unequal grid spacing in any dimension (restricted to iess than 8000 nodes)。

The purpose of the program is to provide a known solution to check fitting functions generated by GENORO, as well as to serve as a first model for the test analog. To further the error evaluation sapability, a deck of the "Steady Darcian Flow" program has been altered to permit calculating with reduced grid spacings in the vertical dimension. 
A column of soil having a uniform bulk density is needed for laboratory determination of soil parameters. A jevice was designed for packing a column of soil to a uniform and reproduceable bulk density, and shop drawings are being prepared. The packer will

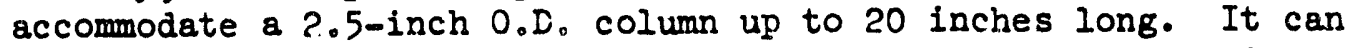
be modified easily to accomodate smaller diameter columns down to 1.25 inches.

A preliminary isopach map of the Prosser bed, the confined aquifer high in the basalt series, was completed. The map shows that the bed was deposited as an alluvial fan by an eastward-flowing stream (the ancestral Yakima River?) probably joining the Columbia River along the east side of the Hanford Works Area. The bed is thickest in the synclina areas and thinnest over the anticlinal ridges. This suggests that it was deposited during deformation in the region. That conclusion is substantiated by a similar conclusion resulting from Ringold Formation studies. Hence, the Prosser bed can be expected to the southeast within the Pasco syncline.

Areas where the overlying Saddle Mountain No. 3 basalt flow has been eroded (beneath the Separations areas and vicinity) and where the flow terminates to the east, are locales for recharge of the Prosser bed, one of the more significant factors in determining the path of water movement in that confined aquifer. The Saddle Mountain No. 3 flow, where recognized at the ground surface, oftentimes is highly jointed and clearly not wholly impermeable to ground water movement. Hence, some recharge of the Prosser bed through the Saddle Mountain No. 3 flow and the discharge of waters and contaminants from the bed upward through the basalt flow are at least locally possible.

RADIOLOGICAL AND HEALTH CHEMISTRY

\section{Uranium Ore Inhalation Studies}

A major problem in studies of the inhalation of uranium ores by experimental animals is the measurement of the total uranium which has been deposited in the animai. Preliminary measurements with phantom rats showed that the total deposited uranium ore could be measured to within $\sim 0.5 \mathrm{mg}$ by counting for 10 minutes in the 9-3/8 inches well crystal. Although the deposited uranium was expected to be about $20 \mathrm{mg}$, after three exposures it has been possible to deposit only $2-3 \mathrm{mg}$ in rats. At these low levels the above method is useful but not as accurate as desired. 
Tritium Gas Chromatography

In studies of the use of a polyethylene glycol chromatographic column for fracionaliun of $\mathrm{HCN}$ and $\mathrm{CO}_{2}$ from reactor condensate samples an interesting observation was made that this column retains tritium from both the tritiated water and the ammonia present in the samples. This prosess will be examined further as regards its possibilities as a means of concentrating tritium for analysis.

\section{Radiation Chemistry}

Commercial $\mathrm{N}_{\mathbf{i}} \mathrm{N}$-dimethyl-p-phenylenediamine was purified and used to prepare the relatively stable fre: radical known as wursters Red. This radical was prepared in aqueous solution by oxidation either with molecular oxygen or chlcranil. Hyperfine interaction of the urpaired electron with the two nitrogen atoms, the six methyl protons, and the four ring protons produces an elaborate ESR spectrum which provides a convenient magnetic field marker since its lines are evenly spaced 1.2 gauss apart. This radical is very suitable for rate measurements and a comparison of its reactivities with those of the hydroxyl radical should prove useful.

\section{Film Thickness Measurement Technique}

Measurement of the thickness of films used in radiation chemistry studies is necessary to determine the concentration of the materials in the film. A method for determining film thickness to within five percent for films of $10 \mathrm{H}$ or greater was developed which uses a light interference method in the near infra red region. The method can be used with the Beckman DK2 spectrophotometer or with greater accuracy using the Cary i4 spectrophotometer.

\section{ATMOSPAERIC RADIOACTIVITY AND FALLOUT}

\section{Particle Deposition in Conduits}

The deposition parameter, $K / V$, has been found to correlate with $S^{+}$. These terms are defined as:

$$
\begin{aligned}
K & =\text { deposition velocity } \\
V & =\text { average velocity in the conduit } \\
S^{+} & =d_{p} \rho_{p} f\left(\text { Re) } / 40 \text { og } D^{2}\right. \\
d_{p} & =\text { particle diameter }
\end{aligned}
$$

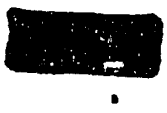




$$
\begin{aligned}
P_{P} & =\text { particle density } \\
f & =\text { friction factor } \\
R e & =\text { Reynold }{ }^{\circ} \text { s number } \\
P_{Q} & =\text { gas density } \\
D & =\text { conduit diameter }
\end{aligned}
$$

A relatively simpler correlation than that previously used was identified for a range of $\overline{\mathrm{K}} / \mathrm{V}$ values from $10^{-7}$ to $10^{-2}$. This correlation equation is:

$$
K / V=4 \times 10^{-5}\left(S^{+}\right)^{2}
$$

Although this simple equation may be suitable for estimation purposes, a wide scatter in the current available data exists. Two sets of data would suggest that $K / V$ may not be linear with $\left(\mathrm{S}^{+}\right)^{2}$. As $\mathrm{S}^{+}$ranges to lower values, 0.1 to $1.0, \mathrm{~K} / \mathrm{V}$ tends to approach a constant. This tendency was investigated.

The deposition velocities were estimated from iodine vapor deposition and $40 \mathrm{~A} \mathrm{Al}_{2} \mathrm{O}_{3}$ deposition iata. Although deposition mechanisms are different for these substances, the estimated deposition parameters, $\mathrm{K} / \mathrm{V}$, were of the order from $10^{-3}$ to $10^{-2}$ with $\mathrm{S}^{+}$values smaller than 10-8. These deposition parameters are as high as the highest $\mathrm{K} / \mathrm{V}$ values obtained for micron-size particles. In order for this to occur, the conclusion is that a definite but unknown curvature exists in the correlation between $\mathrm{K} / \mathrm{V}$ and $\mathrm{S}^{+}$.

Since deposition velocities for each particle size have not been directly measured in a three-inch tube, such a curvature may be the explanation of the high, six percent deposition obtained in these larger diameter tubes. In order to investigate the effects of particle size on deposition in the three-inch tubing, and to determine the correlation curvature, narrow size distribution particles will be mandatory. To this end the spinning disc aerosol generator was operated to establish performance characteristics for this continued study.

\section{Aerosol Sampling Study}

The two-foot square wind tunnel for measuring sampling errors in confunction with Atmospheric Physics rainout studies was operated with attention given to controlling velocity profiles and to determine general operational features for the ensuing experiments. Velocity profiles in the test section were found to be sensitive to small changes in the diffuser cross section geometry. Various baffles and orifice plates were used to establish near uniform velocity in the test section. Sampler configuration and particle delivery to the duct were studied.

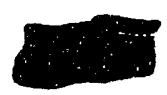


ISOTOPES DEVELOPMENT - 08 PROGRAM

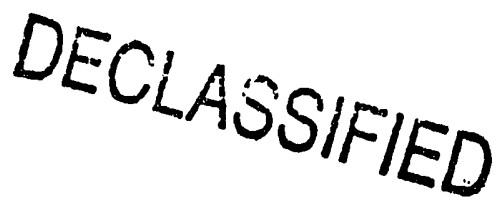

Fission Product Encapsulation

A serles of further experiments have been performed on the formation of strontium titanate compacts by the high rate densification process and an extension of the process to cesium. It was concluded that sintering temperatures of 1250 to $1300 \mathrm{C}$ are necessary to obtain truly high density strontium titanate. Since these temperatures are at shout the upper limit of can material stability, allowing the cai to cool a hundred degrees immediately prior to high rate densification processing may be required to strengthen the can. The Mark II can design has continued to give good results.

Attempts to date to form cesium compects by the high rate densification process have been less successful. Cesium chloride was compacted to a density of $3.68 \mathrm{~g} / \mathrm{cc}$ (93 percent of theoretica?): however, the can ruptured, apparently due to a spring-bick phenomenon associated with the low melting point of cesium chloride. Cesium sulfate $\left(\mathrm{Cs}_{2} \mathrm{SO}_{4}\right)$ might be a more desirable material for compaction and will be tried. Efforts to form cesium boro silicate glass by compacting a mixture of oxides were also unsuccessful. Besides difficulty in welding the cans (due to outgas holes in the weld), the vent line tended to plug during the heat soak step, and one can exploded in the furnace. It appears that high rate densification processing may have no advantages over conventional technology for cesium glass formation.

\section{Engineering Study}

Architectural, site plan, ventilation, process flow and equipment layout drawings were issued for comment during the month on the main study case. Overall engineering design efforts are nearing completion, leaving the preparation of the study report as the principal activity for the remainder of the year.

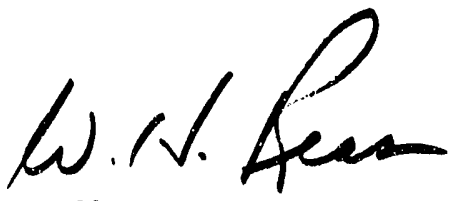

Manager

Chemical Laboratory

WH Reas: cf 


\section{BIOLOGY LABORA TORY}

A. ORGANIZATION AND PFRSONNEL

No significant changes occurred during the month.

B. TECHNICAL ACTIVITIES

FISSIONABLE MATERIALS - 02 PROGRAM

Effect of Reactor Effluent on Aquatic Organisms

The test at 100-KE to compare the biological effect of two corrosion inhibitors, Quachrome Glucosate and dichromate, in reactor effluent on young chinook salmon continues. The results at the end of the third month of test are essentially the same as reported last month. No difference in mortality or growth can be attributed to the type of corrosion inhibitor used, but the effect of effluent concentration is evident by the growth depression observed for the higher 6\% group.

To augment the above low-level, chronic test, a short-termed acute toxicity test of Quachrome Glucosate was undertaken. Preliminary results show that young chinook salmon suffer no mortality at about $5 \mathrm{ppm}$ of Quachrome Glucosate (expressed as equivalents of hexavalent chromium) and 100\% mortality occurs at $125 \mathrm{ppm}$ for 72 -hour exposures. The significance of the result is that no significant difference in the lethal nature of the chromium toxicity appears to exist between the inorganic dichrcmate and the organic Quachrome Gluccsate.

\section{Columnaris}

Trout exposed in 1962 to columnaris were retained in normal river water until late winter when their water suoply was gradually heated to $63 \mathrm{~F}$ to simulate the temperature rise characteristic of early sumer. Fish dying since that time showed no evidence of any columnaris as shown by plating from gill scrapings.

Isolates of columnaris taken from these same groups of trout during 1962 were tested for relative vimulence. There was no evidence that the virulence during the two-week pericd of maximum death was any different from virulence of strains isolated later in the year when deaths were rare.

BIOLOGY AND MEDICINE - O6 PROGRAM

METABOLISM, TOXICITY, ANT) TRANSFER OF RADIOACTIVE MATERIALS

Zinc

The concentration of $\mathrm{Zn}^{65}$ in trout blood after a single oral dose can be described as an exponential decrease after a maximum is reached at about 24 hours post-administration. The concentration in the plasma is much 
higher than in the erythrocytes for several weeks. Most of the isotope in the plasma is apparently in a protein-bound form. Results of 24 -hour dialysis of plasma samples obtained from trout killed at various time intervals of a few days show that only about 10 to $20 \%$ of $\mathrm{Zn} 65$ is dialyzable.

Strontium

The reserve capacity of the hematopoietic system of three control swine and two swine ingesting $125 \mu \mathrm{c} \mathrm{Sr} 90 /$ day is being evaluated to assist us in determining the effect of continuous incestion of high levels of $5 r^{90}$ on hematopoietic function. In order to stress the hematopoiatic system, a quantity of blood equal to $1 \%$ of the animal's weight is removed at weekly intervals. Standard hematological tests along with determinations of $\mathrm{Cr}^{51}$ tagged blood cell survival, Fe59 plasma clearance and erythrocyte uptake will be used to assess the functional status of the hematopoietic system.

\section{Iodine}

Nineteen yearling sheep which were given a single feeding of $I^{131}(1.25-5 \mathrm{mc})$ or exposed to X-irradiation of the thyroid region $(750 \mathrm{r}-4500 \mathrm{r}$ ) were killed nine weeks post-exposure in order to evaluate the comparative effects of these sources of irradiation on the thyroid and contiguous structures. The most severe gross changes observed were in animals fed the larger doses of Il3l in which shrunken fibrotic thyroid glands appeared. The subcutaneous tis zue surrounding the thyroid of the X-irradiated animals was somewhat edematous and fibrotic and the area was superficially delineated by the wool loss which occurred.

$\mathrm{I}^{132}-\mathrm{Te}^{132}$

Lactating ewes were administered consecutive single oral doses of $\mathrm{Te}^{132}$ Il32 four weeks apart and concentrations in the milk were measured at intervals in two ewes up to 96 hours. Results indicated that less than $0.2 \%$ of the $\mathrm{Te} 132$ administered was secreted in milk for any 24 -hour period following administration. Although high concentrations of Il 32 were found in the milk at collection, with its rapid decay rate (2.2 hour half-life), the concentration present after 24 hours was dependent on the content of $\mathrm{Te} I 32$ which was relatively low. Measurements for $\mathrm{Te} 132$ concentration in major tissues were performed for three ewes sacrificed at 48,72 , and 96 hours after the $\mathrm{Te} 132$ administration. Peak concentrations of 0.006 and $0.0015 \%$ of administered dose/g were observed in the thyroid and kidney, the organs showing the highest concentration. The values obtained for thyroid, however, may lack reliability due to the high relative concentration of II3I, a contaminant in the administered material. (These results suggest the earlier estimates of the importance of II32 in the food cycle of man in early fallout were over-estimated. However, these studies may be extended to cattle during the summer.) 
Promethium

Two ycung adult miniature swine were administered $10 \mathrm{mc}$ of $\mathrm{Pm} 147$ orally and killed ten days later to determine the gastrointestinal absorption and retention of $\mathrm{Pm} 147$. Preliminary radioanalytical results indicate that less than $0.05 \%$ of the oraliy administered dose is absorbed and retained. This figure is preliminary in that skeletal concentrations were below the level required for accurate de ermination by ordinary counting and will require chemical separation of the $\mathrm{Pm} 147$ t,c provide samples for accurate detection. (A value of $0.01 \%$ for absorption is used by the ICRP.) A rather uniform tissue distribution was observed, tissue concentrations varying by less than a factor of 10; this is in contrast to 100-fold variations noted previously following intravenous administration.

\section{Neptunium}

An experiment is in progress to determine the effect of simultaneous $\mathrm{Pu} 239$ administration on the excretion of $\mathrm{Np}^{239}$ with and without TTPA treatment. Only Np239 excretion data are thus far available, and these are samewhat uncertain due to counting difficulties. As previously noted, DTPA is not very effective in neptunium removal. It seems to be more effective, however, in the presence of large amounts of plutonium ( $5 \mu \mathrm{c}$ per rat). An unexpectedly high excretion of neptunium was noted in the feces. This continued at a high level over a five-day period and often exceeded the total urinary excretion. This enhanced fecal excrotion was observed in both DTPA-treated and non-DTPA-treated animals.

\section{Plutonium}

Plutonium-238 and $\mathrm{Pu}^{239}$ sclutions with varying amcunts of citrate added, which displayed differing toxicities, were studied by ultrafiltration techniques. No differences in ultrafiltrability were noted wich could be correlated with the toxicity differences.

Further studies are being made of oral effectiveness for plutonium removal of TTHA, DTPA and TTPA ester. A new TTHA preparation, of greater apparent purity than that previously available, appears from preliminary results to be considerably more effective than DTPA or the previously employed TTHA. The DTPA ester is decidedly more toxic than either DTPA or TTHA.

Radiation, Copper and ilolybdenum Inter-Relationships

A paired feeding study is in progress to study the decreased urinary copper excretion of irradiated animals. Rats on a stock diet, a $750 \mathrm{ppm}$ molybdenum diet and a 1000 ppm copper diet all exilibited decreased urinary copper excretion following $850 \mathrm{r}$ total body radiation. Preliminary indications are that the decrease is due, in la rge measure at least, to decreased rood intake subsequent to irradiation. 
Inhalation Studies

Analyses of tissue samples from a dog that died 3 years and 2 months after a single exposure to $\mathrm{Pu}^{2} \mathrm{SO}_{2}$ were completed. The total body burden was $1.4 \mu \mathrm{c}$ of which $50 \%$ was in lung, $42 \%$ in bronchial and mediastinal lymph nodes, $4 \%$ in bone, and $2 \%$ in liver. It was estiniated that $4 \mu \mathrm{c}$ was initially deposited in the lung. Another dog died 3 years and 3 months after exposure to $\mathrm{Pu}^{2} 3 \mathrm{O}_{2}$. Analytical and histological data are not complete.

Two dog,s were exposed to vapor released from $150 \mu \mathrm{c} \mathrm{I} I^{131}$, and two exposed to vapor released from $150 \mu \mathrm{c} I 31$ plus about 2 grams stable iodine. The ratio of I127 to Il31 in the aerosol (on a weight basis) was about $1 \times 10^{9}$. Dogs exposed to carrier-free iodine deposited about $1 \mu \mathrm{c}$, and 14 to $18 \%$ appeared in the thyroid. Dogs exposed to $I_{2}^{131}$ with stable lodine deposited 4 to $10 \mu \mathrm{c}$, and about 3 to $6 \%$ appeared in the thyroids. Thus, the release of stable lodine with radioiodine vapor increased the total radiolodine deposited in the dogs, yet reduced the percentage of the deposited iodine that appeared in the thyroid by a factor of two. The net effect was that the radioiodine uptake of the thyroid, as well as the biological retention, was essentially the same for both rroups of dogs. These results, which were less favorable than those obtained in rat experiments, do not support the suggested use of gensrators to release stable iodine to the atmosphere in the event of a reactor release of radiolodine to reduce thyroid deposition of radioiodine.

Two experiments were completed in which about eight therapy combinations were tested for effectiveness in removing inhaled $\mathrm{Pu}_{2} 39 \mathrm{O}_{2}$ fram rats. Isuprel, a bronchodilator drug, showed some slight promise and will be investigated further.

Seven months after exposure to $\mathrm{Ce}^{144_{\mathrm{O}}}$ one dog which deposited about $2 \mathrm{mc}$ is beginning to show severe symptoms. The respiratory rate is high and weight loss is marked. Other dogs which deposited less than a millicurie are asymptomatic.

Thirty-six rats were given three exposures to pitchblende uranium ore dust tc obtain lung burdens of 2 to $3 \mathrm{mg}$. Rats are sacrificed at weekly intervals to determine whether the daughter products of uranium remain in equilibrium in the lung.

Gastrointest,inal Radiation Injury

Rats subjected to lethal irradiation of the abdominal region ( 1200 to $1500 \mathrm{r}$ ) were troated with a bile salt sequestrant (cholestyramine) continually perfused thrcugh the small intestine. Rats so treated outlived control rats by a few days and did not develop diarrhea, but ultimately died for reasons as yet undefined. These studies furnish further evidence for the involvement of bile in radiation diarrhea. Attempts will be made to improve survival by nutrient and electrolyte replacement in addition to the resin treatment. 
In an effort to elucidate the mechanism by which bile causes diarrhea, rats were administered a synthetic bile salt, dehydrocholate, which, unlike the natural bile salts, does not lower surface tension. This synthetic bile salt does not appear to cause diarrhea, suggesting that the principal effect of the normal bile salts may bo concerned with surface tension effects.

\section{Kidney Function}

A radioisotope technique is being developed for use in evaluating kidney function of miniature swine. Iodine-13l-labeled iodohippurate is administered intravenously (via the anterior vena cava) and it subsequent appearance in and clearance from the kidneys is followed utilizing a twoprobed scintillation detector, one probe positioned over each kidner. The iodohippurate is selectively taken up by the kidney and excreted in the urine. (The concentration of $\mathrm{I}^{131}$-iodohippurate in the kidney as determined by external monitoring is seen which consists of three phases. The first phase, with rapid increase in activity, is due to vascular filling; the second phase, with a slower increase in activity is due to the selective uptake of the II3I-iodohippurate by the kidney tubule cells; the third phase is characterized by a slow loss of activity as the Il3l-iodohippurate is excreted in the urine and is moved to the bladder.) Adaptation of this test for use in the miniature swine should prove useful in studying ghanges induced by irradiation of the kidney, such as in our high level Ra226 animals.

\section{Microbiology}

Developing eggs of cichlid fish are most sensitive to $D_{2} O$ during the first eight hours. From stuaies of the developmental pattern this corresponds to the period of celli division preceding any differentiation. It is possible that the period of greatest toxicity corresponds with the period of single cell blastcdermal proliferation.

The relation between the rate of glucose uptake at different temperatures and $\mathrm{D}_{2} \mathrm{O}$ effects on this uptake indicates that toxicity is exerted on the protoplasmic side of the membrane. Thus the effect is on an internal carrier complex rather than on entrance of the glucose into the membrane.

Rate of cell division of diploid yeast cultured in $\mathrm{D}_{2} \mathrm{O}$ is about 0.1 that of yeast grown in $\mathrm{H}_{2} \mathrm{O}$. Growth, as measured by cell mass, is affected only slightly, if at all. The inhibitory effect of $\mathrm{D}_{2} \mathrm{O}$ was sreater on a yeast strain which derived all its energy from oxidative reactions than on a strain which carried on both oxidative and fermentative metabolism. This was also demonstrated by the maintenance energ" requirements which were increased in $D_{2} O$ by about tenfold in the oxidative but no change in the oxidative-fermentative strain. 
Radiation Iffects on Insects

A study of the ef ects of $X$ ray on the developing reproductive system of Ephestia females exposed in immature life cycle stages was initiated. Gross microscopic examination of ovarioles dissected from adults revealed no alterations in those from 5 and $10 \mathrm{kr}$ groups exposed as pupae.

Ovarioles from groups given 15 and $20 \mathrm{kr}$ as pupae were obviously abnormal. They were reduced in length due to fewer developing egg cells. Some ovarioles contained only one or two oocytes which were abnormally small, others contained oocyte-trophocyte complexes which were incompletely $\mathrm{di}$ "ferentiated and develcped. In all cases, the normal number of eight ovarioles was found.

A quantitative study is planned to correlate radiation exposure with ovaricle development.

Plant Studies

With repeat cropping the uptake of $w^{185}$ into plants appears to markedl increase. Whether this increase was due to the longer time of the wl85 in the soil or to the heavier watering regime used in the second cropping is not yet slear.

Pea root meristematic tissue shows a decreased frequency of dividing cells following exposure to a solution containing $\mathrm{Cs} / \mathrm{K}$ in a ratio of one or more. Thether this effect on cell division is the cause of the root toxicity as grossly observed is not yet defined.

Plant Fcology

Comparison of soil moisture as measured in buried cans in a greasewood habitat on April 15, 1963, showed the cans with cheatgrass established since October to contain an average of $275 \mathrm{~g}$ of water (SE +14 ) as compared to an average of $383 \mathrm{~g}$ (SE \pm 28 ) contained in cans without grass cover. The greater moisture loss from the vegetated cans is attributed to plant influences on soil moisture.

Rattlesnake Springs Limnology

Forty periphyton slides were placed in the spring to culture organisms to be used in the $\mathrm{Rb} .{ }^{85}$ experiments. Analysis of water samples taken at the headwaters of the spring and at the gauging weir revealed distinct chemical changes. Concentrations of $\mathrm{K}, \mathrm{Na}, \mathrm{Ca}, \mathrm{SO}_{4}, \mathrm{Cl}$, total dissolved solids, and alkalinity decreased significantly downstream, while ing and $\mathrm{NO}_{3}$ increased. Zinc, $\mathrm{Se}, \mathrm{Si}, \mathrm{B}$, and $\mathrm{PO}_{4}$ remained relatively unchanged. 
Columbia River Limnolcgy

Counting of plankton collected in the 100-F Area was completed. Gross examination of the periphyton substrates placed in the thermal seepage basin below $107-F$ revealed that diatoms were predominant at the lower, or cooler, end of the slough, whereas blue-green algae were the main organisms in the hotter water.

Fallout

Radioiodine concentrations in North American deer thyroids decreased during late March and then increased slightly, or remained steady, during early April, apparently due to introduction of Il3l from a French nuclear weapons test in North Africa on March 17. Values at the various sanpling locations were as follow:

Location and Sample Type

New York deer California deer Montana elk Maryland deer
Number of Animals

1

7

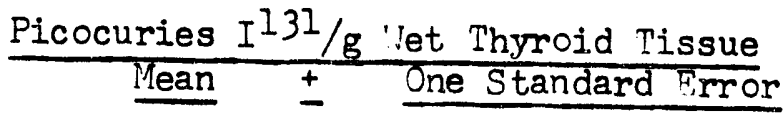

33

14

11

Not detected
9.2

1.4

Population Dynamics - Vaterfowl

The annual survey of nesting Canada geese within the Hanford Reservation was begun. An average of 296 territorial pairs was found, representing a $7 \%$ increase over last year and the greatest number of potential nesting pairs present since 1958.

Sampling and Analysis of Natural Populations

A study of the theory of the so-called "distance" methods for estimating abundance and spatial pattern of natural populations is being continued. Results thus far obtained cover cases of regular, random, and one form (negative binomial) of contagious distribution.

Bunch-grass (Agropyron), elk, and mule-deer fecal pellets collected on the Vooten Game Range (Blue Mountains) were used in a preliminary study of the prospects for using the portable radiation analyzer in field sampling.

Ixperimental gama-ray counts (Aquatic Biology single-channel analyzer) were conducted on $\mathrm{Rb} 86$ solutions over sand from Rattlesnake Springs. 
The analyses were designed to obtain a rough notion of the rates at which $\mathrm{Rb}^{86}$ mirtht be removed from the stream in a proposed study of radionuclide transfer in a natural system. Results indicate rather rapid removal under turbid conditions, but sufficiently slow removal under clear conditions to make tests under field conditions seem practicable.

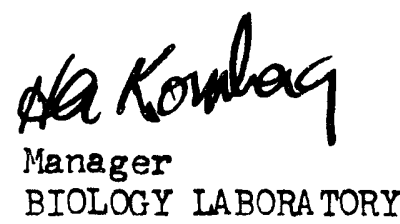

HA Kornbnrg:es 
TECHNICAL INTTRCHANGE DATA BIOLOGY LARORATORY

\section{Speeches Presented}

a. Papers Presented at Society Meetings and Symposiums None

b. Seminars (Off-Site and Local)

W. H. Rickard. Fallout in relation to natural landscapes. (Fxchange Seminar Program) Jashington State University, Pullman, Washington.
April 24, 1963.

c. Seminars (Biology)

Clarke, W. J. Research pathology. April 9, 1963. Bair, W. J. Lymphocytic effect of inhaled $\mathrm{Pu}^{239}$ on adrenalectomized
rats. April 9, 1963.

Stephen, W. P., Biology Department, Oregon State College, Corvallis, Oregon. Accelerated evaluation through irradiation. April 16,
1963.

Vaughan, B. E., Head, Biophysics Branch, USNRDL, San Francisco, California. Effect of irradiation on intestinal transport and bioelectric phenomena. April 19, 1963. Olson, P. A. Observations on the fish disease organism, columnaris.
April 23, 1963.

Ballou, J. E. Comparative studies with $\mathrm{Pu}^{239}$ and $\mathrm{Pu}^{238}$. April 23,
1963.

Moll, T., Department of Veterinary Microbiology, Washington State University, Pullman, Washington. Present concepts regarding the nature of viruses and their activities. April 26, 1963.

Groff, E. H. Biology Library Procedures. April 30, 1963.

Kornberg, H. A. Information meeting. April 30, 1963.

d. Miscellaneous

Uyeki, E. M. Cellular Radiobiology. University of Washington Graduate Center, Richland, Washington. April 24, 1963. 
II. Articles Published

a. Hil Documents - ione

b. Open Literature

Hanson, W. C. 1963. Census of ring-billed and California gull colonies in Tastern Washington. The Condor 65(2):163-164.

McClellan, R. O. and I. K. Rustad. 1963. Strontium-90 and calcium in milk of miniature swine. International $\mathrm{J}$. of Radiation Biology 6:173-180.

Marks, S. and L. K. Rustad. 1963. Thyroid neoplasms in sheep fed radioiodine. J. National Cancer Institute 30: 661-667.

Watson, D.G., J.J. Davis and W. C. Hanson. 1963. Interspecies differences in accumulation of gamma emitters by marine organisms near the Columbia River mouth. Limnol. and Jcean. 8: 305-309.

Uyeki, E. M. 1963. Serum haemagglutinins in heterologous chimaeras. Nature 198: 196-197.

III. Visits and Visitors

a. Visits to Hanford

4/1/63 Wives of Washington State Supreme Court and Federal Judges (12). Tour of Biology.

4/1/63 Jashington State Supreme Court and Federal Judges (14). Tour of Biology.

4/2/63 Dr. Thomas Bogyo, Washington State University, Pullman. Discuss research with Drs. Eberhardt and Nakatani.

4/3/63 William F. Nouss, Fisheries Research Institute, University of rashinton, Seattle. Discuss research with Nakatani.

4/3/63 About 40 students from Pendleton High School toured.

4/3-4/63 Dr. W. E. Lotz, Division of Biclogy and Medicine, USAEC, Washington, D.C. Discuss research program with staff.

4/8/63 Industrial Committee - tour Biology.

L:/9/63 Elmer Johnson and John Neff, Acme Refrig. Co. Discuss plant growth chamber with Cline.

4/10/63 Dr. R. W. Dougherty, National Animal Disease Laboratory, Ames, Iowa. Discuss research with Drs. Bustad and McClellan.

4/11/63 Dr. Leon Dmochowski, Baylor University, Houston, Texas. Discuss research.

4/16/63 Dr. Kussell Poor, AEC, Washington, D.C. Discuss research.

$4 / 15 / 63$ Dr. $\because$. P. Stephen, Oregon State University, Corvallis. Present a seminar. 
4/18/63 J. P. Chapman and Oleta Atkins (with local A TC escorts), A IC Division of luabor Relations, Washington, D.C. Tour.

4/19/63 Dr. Burton פ. Vaughan, ISNRDL, San Francisco, Calif. Present seminar.

4/22/63 G. E. Tibbetts, GE Monogram, Schenectady. Tour.

4/22/63 R. Daubenmire, Dept. of Botany, WSI, Pullman. Check research plots with Dr. Rickard.

4/22/63 Dr. Wvatt Cone, Irrigation Jxperiment Station, Prosser. Check research plots with Dr. Rickard.

4/23/63 Dr. Erling J. Ordal and Robert Pasha, University of Washington, Seattle. Obta in cultures of $\mathrm{C}$. columnaris and discuss research.

4/25/63 Louis B. Van Dyck, Roy L. Johnson, and G. W. Marsh, GI New York Accounting Services. Discuss research and tour.

4/26/63 Seattle Business Men (50). Tour.

4/26/63 Dr. T. Moll, Washington State University, Pullman. Present exchange seminar.

4/27/63 Dr. I. G. Moorehouse, National Animal Division Laboratory, U.S. Department of Agriculture, Washington, D.C. Discuss pathological problems with Dr. Clarke.

b. Visits Off-Site

3/31-4/6 A. C. Case attend the ACS meetings in Los Angeles.

4/3 V. G. Horstman inspected feed at Anders on Feed, Othello.

4/7-II E. M. Uyeki attended the Conference in Gatlinburg, Tennessee.

4/8 F. P. Hungate attended the program review at the University of Washington Laboratory of Radiation Biology, Seattle.

4/9 V. G. Horstman inspected feed at Anderson Feed, Othello.

4/8-10 4. A. Ragan attended a conference at Washington Sta e Universitv.

4/12-13 L. K. Bustad worked on the icnizing radiation study at the University of Washington.

4/13-20 $\mathrm{i}$. G. Tombropoulos attended the Federation Meetings in Atlantic

4/21-23 City and discussed research with Dr. L. J. Casarett at the University of Rochester.

4/15-18 H. A. Kormberg attended the business meeting of the Society of Experimental Biology and Medicine and attended sessions of the Federation "eetings in Atlantic City, New Jersey.

4/16-18 E. M. Uyeki at ended Federation Meetings in Atlantic City. 
$4 / 15-20$ \&

$4 / 21-24$

$4 / 20-25$

$1 / 24$

$4 / 29$

$4 / 29-5 / 1$

D. D. Mahlum attended the Federation Meetings in Atlantic City and conferred with NS Hall at the UT-AEC Project, Oak Ridge.

R. C. Thompson attended the AEC Bio-Medical Program Directors leeting at Westerm Reserve University, Cleveland, Ohio.

W. H. Fickard, Jr. presented an exchange seminar at Washington State University, Pullman, Wash.

L. L. Eberhardt and H. A. Sweany collected plant and animal specimens for radionuclide content at the Wooten Game Range in the Blue Kountains.

C. E. Breckinrid e delivered dogs to the Testing Ground, Tonopah, Nevada.

IV. Achievements

No degrees were earned, nor did any professional licensing or certification occur.

V. Honors and Recognitions

Certificates of Participation from Joint Task Force Eight were awarded to $\mathrm{Dr}$. R. E. Nakatani, Manager, Aquatic Biology, and Capt. H. W. Casey, USAF (VC) (on assignmeni with Biology) for their participation in Operation Dominic in 1962.

VI. Professional Group or Organization Assignments

None
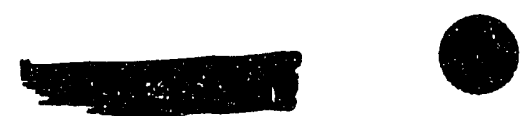
APPLIED MATHEMATICS OPERATION

MONTHLY REPORT - APRIL, 1963

ORGANIZATION AND PERSONNEL

Pauline Z. Stewart tiansferred to Theoretical Physics effective April 22, 1963. Rosalie S. Argo has been named as her replacement effective April 29. 1963.

\section{OPERATIONS RESEARCH ACTIVITIES}

The Reactor Simulaticy Studies are continuing with current emphasis on establishing accurate reactor outage activity data. Discussions have been held with personnel from $\mathrm{KW}$ and $\mathrm{H}$ Reactor arens to design data records and specifications.

Work on the HAPO-Tri-City Model was resumed. Discussions were held to establish data needs and arrange for data collection. Additional data is being sought from U.S. Government sources, and arrangements will be made to collect selected local data. A first crude model should be operative by the end of June.

Work on a HAPO Structural Functional model is also progressing. Conferences are being held with production people to develop details on production functions, activities, and resources.

\section{STATISTICAL AND MATHEMATICAL ACTIVITIES FOR OTHER HAPO COMPONENTS}

\section{N Reactor Department}

Assistance is being given in the interpretation of results from MERCY runs. Recent difficulties have pointed up the need to have the variation in the "true" or base run values large relative to the precision of the measuring instruments.

A study is being made to see if the diametrically-opposed areas of the lateral surface of the NIT and NOT fuel elements experience different cooling rates due to convection in the cooling process and/or due to the presence of hot neighboring fuel elements in the cooling basket.

Improved techniques for parameter estimation in the weld crack problem associated with NPR primary piping are currently being programmed for digital computation.
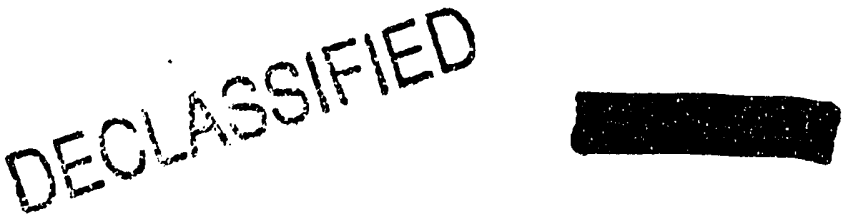


\section{Irradiation Processing Department}

Data are being analyzed to determine the optimum conditions for up-sizing and down-sizing the rails for self-supported K-Reactor fuel elements which have failed to conform with minimum height specifications. In support of these objectives functional relationships have been obtained, for both KVE and KVN fuel element rails, between the mils up-sized/mils down-sized ratio and the deflection per 100 pounds, between the total deflection and the load, and between the permanent deflection and the load.

Functional relationships relating " $R$ " values, which measure the distribution of outlet temperatures in process tubes, with location have been obtained for a number of tubes. This continuing program is designed to predict the location and magnitude of the maximum outlet temperature.

A polynomial relationship was determined between the temperature imbalance in a tube as measured by the " $R$ " value and the fuel element placement within a tube as measured by the eccentricity。 of particular interest is the significance of the quadratic term indicating the amount of incremental imbalance above the linear effect for the larger eccentricities.

More yield variable characteristics from the second end bonding test on production fuels have been analyzed。

Thermocouples were placed in fuel element cores to study the patterns of accretion and dissipation of heat during preheating, sizing, and cooling of fuel elements in the hot-die-sizing canning process. These data are being analyzed to provide the average, linear and quadratic effects of the heat as measured along the axis of the core as a function of time. The location of the maximum and minimum points of heat, their values and the amount of effective heat for bonding as functions of time are also being determined.

A MERCY run was performed and interpreted which compared the process tube thickness measurements obtained by a micrometer and an air gage. The effect of different operators was also assessed.

Work was continued on estimating the amount of various isotopes in process tubes. In all the previous work it was expedient to obtain a function relationship between the activity per foot of an isotope and the distance along the process tube. The most recent data were of such irregularity, however, that the amounts were more closely estimated by direct numerical integration of the data. A problem of concern here is that the peak isotopic activities occur somewhat downstream from the peak flux.

A discussion was held on the operating characteristics given by different sampling plans involved in the acceptance of Venturi flow meters.

A discussion was held on methods of detecting changes in the measurement characteristics of bond count testers, particularly bias. 
Advice was given on the use of the chi-square test to assess whether there are trends in the counting data indicating drifts in the counter.

Previous work on the rail beight specification for self-support K-Reactor ruels is being extended to a consideration of the distribution of minimum annull under different conditions of fuel element ellipticity.

\section{Chemical Processing Department}

Work continued on the refinement and programming of a mathematical model of spare parts and general inventory control.

Data dotained on plutonium metal assay from sample exchanges between four laboratories (Hanford, Rocky Flats, Los Alamos, and Savannah River) over a five-year period were reviewed using analysis of variance techniques. During the five-year period, a bighly significant decrease in residual variance ("measurement error") occurred. The major source of variation is the Laboratory-Exchange interaction, indicating shifts in bias between the four laboratories both during and between the five years examined.

A similar review was made of the practice of making monthly analytical bias corrections based on data obtained each month from analyses of a standard. This review indicated that the current practice of making monthly adjustments should be retained. The use of more than one standard with plutonium concentration at different levels was suggested to provide a better assessment of analytical bias.

A review was made of the plutonium material balance in Z-Plant from January, 1961, through February, 1963, to provide an objective basis for future plutonium MUF control. The resulting recommendations were presented to the Measurements Operation of Nuclear Materials Control.

Relations and Occupational Health Operation

Consultation services were provided on the interpretation of relationships between various attitude survey indices of job satisfaction and the magnitudes of salary changes over the past several years.

STATISTICAL AND MATHEMATICAL ACTIVITIES WITHIN HL

2000 Program

Pulse Column Facility

Further analysis was done on the organic volume fraction profile data from a block of 16 runs on the pulse column. The purpose of the analysis is to construct a family of functions of common mathematical form which express organic volume fraction profile in the column. The parameters which identify 


\section{DECLASSIFIED}

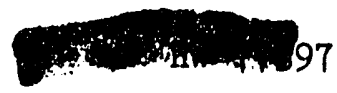

the individual functions in the family will be extractant stream temperature, extractant stream acid concentration, feed stream concentration, feed stream and extractant stream flow rates, and pulsing frequency. These variables determine the operating conditions of the column。

The EDPM Program which simulates the chemical reactions between, and the relative proportions of, NPR stack gases is now in routine operation. Data obtained from this program should yield valuable information about the ZirconiumGraphite compatibility problem.

\section{Program}

Recent tests on metallic shapes which have been shear-spun from HAPO-designed blanks demonstrate that the rather severe dimensional and radiographical specifications can be met. Moreover, there is considerable evidence that the finished product is superior to those fabricated by more conventional methods.

Consultations were held with Plutonium Metallurgy Research on statistical techniques applicable to some experimentally obtained data。

\section{Program}

Mathematical studies on the propagation of sonic waves in layered elastic media are continuing. These studies are oriented toward obtaining methods of detecting and interpreting signals received from nondestructive testing devises。

Investigations are under way to construct a mathematical model of the flow pattern in the partial recirculation loop of a waste calciner so as to study the effects of specific design parameters on the efficiency of the total process.

5000 Program

Crystal Indexing

Work progressed on the documentation of the project to index hexagonal crystals. The computer program is now in routine use. After a variety of samples were run on the orthorhombic program, it was decided the program, although effective, was too slow for routine use. Efforts are now being directed toward development of a new counting routine which will significantly increase the speed of the program。

\section{Radiochemical Analysis}

Work continued on improvements and correction of errors in the new IRA II system。 The system is being used routinely to process radiochemical data.

\section{General}

A discussion was held to consider the incorpuration of the GEM program and possibly the IRA II system philosophy in the routine processing of analytical 


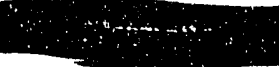

laboratory gamma pulse-height spectra. A decision was made to outline exactly what future needs will be independent of the existing capabilities of GEM and IRA II and then see exactly how completely these needs can be met with existing routines or modifications of them.

Assistance was given in the construction of sequential tests of the null hypothesis $\lambda=\lambda_{0} \mathrm{c} / \mathrm{m}$ against the alternative hypothesis $\lambda=\lambda_{0}+\Delta \mathrm{c} / \mathrm{m}$ with specified $\alpha$ and $\beta$ risks。

A simulation of a system similar to the Radiometallurgy Laboratory was prepared and debugged. The results were presented as illustrative of the new GPSS. system as an analytical tool. They propose to assign one new engineer to gather data for use with a GPSS model。

Final statistical details were prepared for the bi-monthly employee opinion survey by $R$ and $O H O$ personnel. The first set of returns were not lound adequate for drawing significant conclusions. The second set of returns is due in during the first week of May。

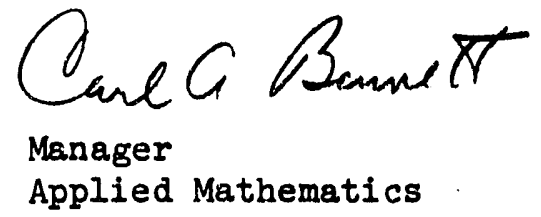

CA Bennett:dgl 
REACTOR DEVELOPMEHTT - 04 PROGRAM

\section{PLUTONIUM RECYCIE PROGRAM}

Cur1um-244 Production

In the production of $\mathrm{cm}-244$ as a heat source, it is important that the purity be as high as possible. Curfum-242, which always appears with reactor produced cm-244 from plutonlum, has a much higher heat producing rate (about 50 times greater than $\mathrm{Cm}-244$ ) which can mask the cm-244 heat production. Thus, in the investigation of neutron spectra most favorable to $\mathrm{cm}-244$ production, it $1 \mathrm{~s}$ important to observe both curlum production and purity.

An investigation of neutron spectrum effect on production and purity has been completed for one of the more favorable fueling schemes. The scheme used was plutonium ( $76 \% \mathrm{Pu}-239,18 \% \mathrm{Pu}-240,5 \% \mathrm{Pu}-241$, and 1\% Pu-242) enrichment of thorium. Similar results could be achieved from plutorium with U-238 (depleted or natural) by keeping the feed plutonium and U-238 physically separate. Either of these methods produces $\mathrm{Cm}-244$ of higher purity than that from plutonium mixed in U-238. In the latter case new Fu-239 is formed which eventually increases the Pu-24l concentration and results in high Cm-242 formation via neutron absorption in Am-24l formed by decay of Pu-241.

The Cm-244 production is strongly affected by the Pu-242 effective cross section which can be increased by hardening the neutron spectrim (increasting the average neutron energy), although the Pu-240 cross section also Increases with harder spectrums. The spectrum can be hardened by increasing the moderator temperature and/or adjusting the reactior lattice. Flgure 1 is a plot of $\mathrm{Cm}-244$ production and purlty against fuel. exposure for varlous spectral indexes $(r)$ and moderator temperatures. As the value of $r$ or temperature increases, the spectrum becomes harder. It can be seen from these curves that gains in $\mathrm{Cm}-244$ production and qual.ity cars be made by hardening the spectrum. The Pu-242 cross section increased from 75 barns at $r=0.05$ to 320 barns at $r=0.25$, while the Pu-240 cross section increased from 430 to 1030. The Fu-239 and Pu-241 cross section changed very little over this range. 


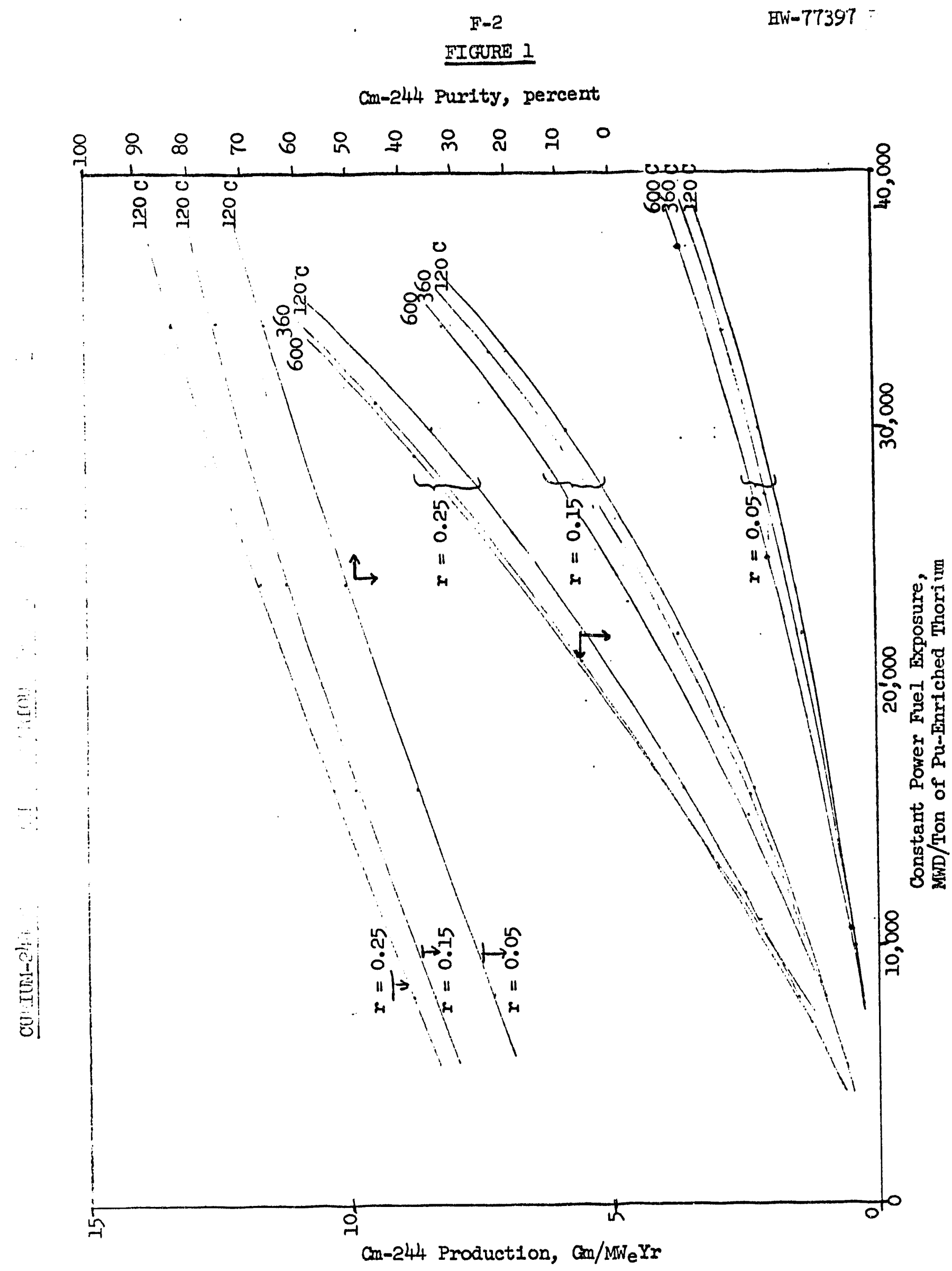


Discounting Cm-244 Price with Purity

As noted above, the value of $\mathrm{cm}-244$ is a function of the amount of $\mathrm{cm}-242$ present; but, after discharge from the reactor, the purity of Cm-244 will increase with time because of the short (163 day) cm-242 half I1fe. So, the price one would pay for $\mathrm{cm}-244$ is dependent on how long a purchaser would have to hold it before the purity would be acceptable for use. During this period, the purchaser would pay interest on the purchase price; hence, the price upon reactor discharge is discounted by this interest charge. During the decay jeriod, Pu-238 is formed by alpha decay of cm-242. This product also has value and the selling price is credited to the initial curium. Hence, the $\mathrm{Cm}-244$ price $=\mathrm{Cm}-244$ price (@ 98\% pure) minus net interest charges plus Pu-238 credit. The "QUICK" economlc code now values curium in this manner. Interest charges are levied compounded because several years can be involved.

\section{General Fuel Cycle Analysis}

The MELEAGER code wa revised to permit a designated number of the fuel isotopes to be treated as always in equilibrium with their sources. This will permit computations involving such isotopes as 16-hour Am-242 without increasing computation time. Provision was also made for including cross shielding resonance effects. This will permit consideration of, for example, the reduced reaction rate of Pu-24I due to the absorption of neutrons in the Pu-239 resonance, which is at nearly the same energy as the resonance of Pu-241.

Calculations of the production of fission product strontium, cerlum, technetium, and promethium for slightly enriched uranium fuel in watermoderated reactors are summarized in Tables $I$ and II. These calculations were made for a spectfic power of 10 megawatts per ton. Calculations of other isotope yields (cesium in particular) and extension of these calculations to other reactor types and for various speciflc powers is under way. In addition, the QUICK code can now credit up to seven specifled flssion products for sale.

The higher yields of $\mathrm{Sr}-88$ at low exposures reflect the higher fission yleld of U-235 which is predominant in fresh fuel versus the lower yield from plutonium 1sotopes which predominate in highly exposed fuel. The lower yield of short half life 1sotopes such as Ce-141, on the other hand, are due to the saturation effect of high exposures (1.e., their rate of decay equals their rate of production). Sr -89 ylelds are influenced by both effects. The potential production of isotopes for decay heat sources from fission products appears signiflcant. 


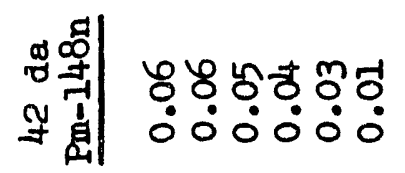

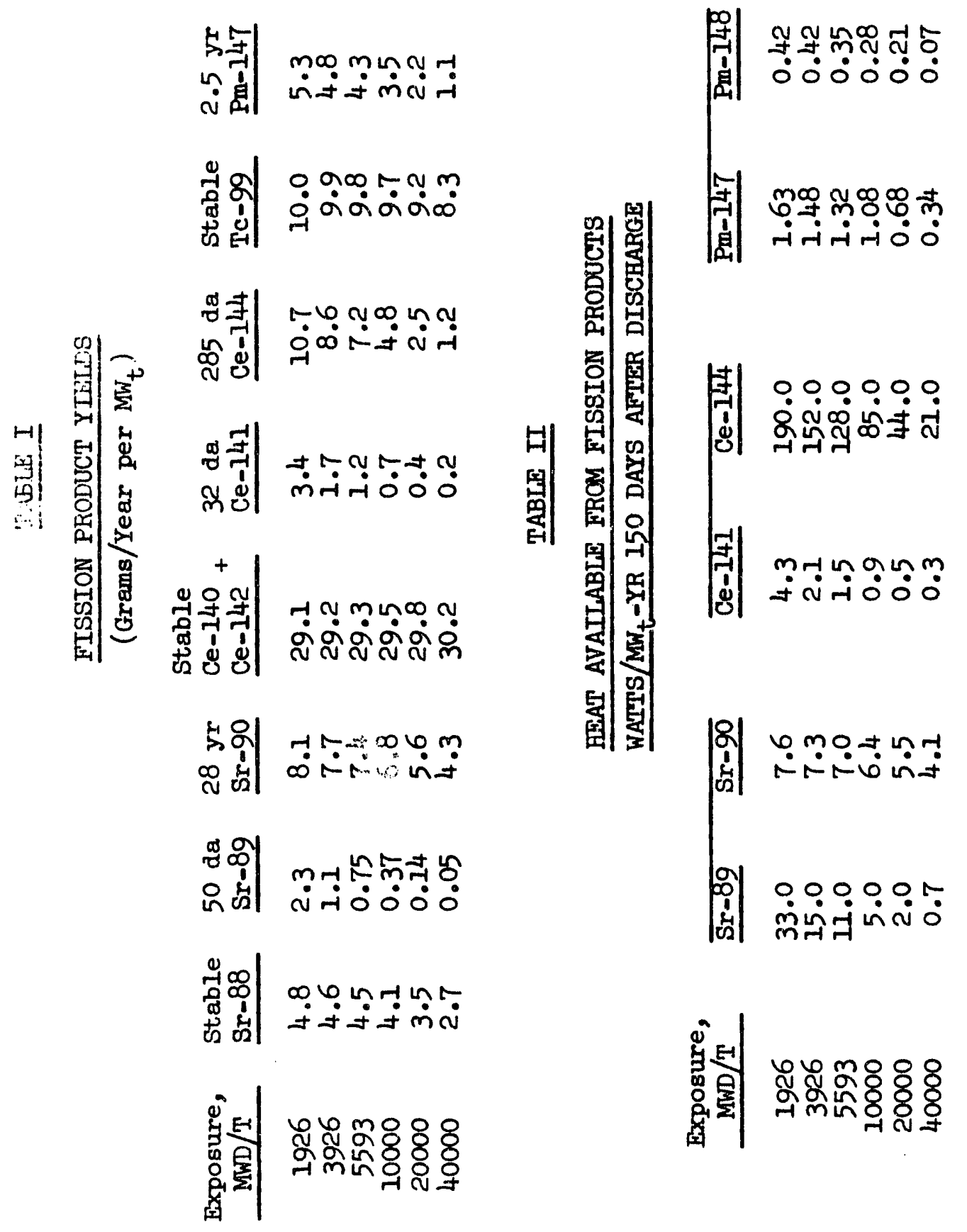

UNCLASSTFIED 
Code Development

During the last several months many modiflcatiors have been made ir, the MEIFAGER-AIIHAFA code. The machine efficlency of the code has been increased and the readablilty of the printouts has been improved. These changes have made it necessary to modify JASON, the lattice parameter code that provldes flux welghted cell parameters for MEIFACER. Mhese modiflca. tions were completed and a version of IASON 1s now avallabie that is compatible with the latest version of the MEITAGER-AIFHAFA computer code.

The "non $1 / v$ " factors, $g$ and $s$, used in Westcott's cross section formula are functions of the neutron temperature. The Westcott formulation is $\hat{\sigma}=\sigma_{2200}(g+r s)$ where $r=$ spectral index. The spectral index $r$ is a measure of the neutron fraction above an arbitrary cutoff currently set at $3.68 \mathrm{kt}_{\text {neut }}$. In turn, $t_{\text {neut }} 1 \mathrm{~s}$ determined from the moderator temperature and the degree of thermal absorption and scattering. MEIEAGER calculates $t_{\text {neut }}$ at each burmup step; hence, the value changes many times durlrg a MEIEAGER "run." Therefore, some conclse method of representing the temperature dependence must be included in the MELFAGER code. Presently, the maximum neutron temperature permitted in MELEAGER is $600 \mathrm{C}$ and a fourth order polynomial has been adequate. However, experiments have shown that this function is not adequate for the range of neutron temperatures from $20 \mathrm{C}$ to $1.300 \mathrm{C}$ which is contemplated.

The most logical improvement is merely to increase the order of the polynomial unt11 an adequate representation 18 obtained. This approach works for the 8 factors; but, because in many cases a neutron temperature around $600 \mathrm{C}$ places a resonance below the cutoff energy, the $\mathrm{s}$ factor vs. temperature curve has a complicated shape. (Roughly speaking, the s factor accounts for the resonance effects.) A twelfth order polynomial is often required to give a flt over the 20 to $1300 \mathrm{C}$ range that is cumparable with that of a fourth order polynomial in the 20 to $600 \mathrm{C}$ range. A large number of coefficients are unsatisfactory because of the additional computing time required ( $1 . e .$, the polynomial furction w111 be interrogated some 2000 times during an average burnup calculation) and because additional memory locations must be allotted. Two alternative thods are currently belng investigated to avold these difficulties - a Fourier series fit of $s$ and a polynomial fit of the resonance integral.

The Fourier series was suggested by the fact that the s factcrs plotted as a function of temperature roughly resemble the cosine functicr. So far, the flts by a half-range expansion have been promising; but, because a good numerical integration subroutine is lacking, adequate convergerce has not been attained. It may be desirable to program the Fourier series as a part of the IFMON code, whlch presently computes polynomial fits by the least squares technique. 
The second method is to represent the resonance integral as a function of temperature and -- once established -- calculate the s factor from it in MELEAGER. The resonance integral is a smoother function, although it has the same general shape as the $s$ factor. It appears that a good representation can be obtained with as little as a fifth order polynomial.

\section{JTRAL}

\section{Sotopic Heat Sources}

Hew of the continued interest in same of the radiolsotopes with half$\because:$ of less than one year, namely, Ce-144, Po-210, and Cm-242, a revlew - nade of all potential candidate isotopes with half-lives in the range -.. i) days to one year. The other criterla for selection as applied to $\because \because$ longer-lived 1sotopes in $\mathrm{HW}-76323$ were retalned. Of the 32 candidate

...mens only the three mentioned above (and also discussed in HW-76323) o have reasonable expectation for production and use in multigram $\therefore$ Discounted from the list because of anticlpated excessive cost whe alpha emitters Bk-249, Cf-248, and Es-252.

$\cdots \cdot$ chose isotopes with half-Iives greater than 100 years, only Am-24I (as noted in $\mathrm{HW}-76323$ ) has any potential as a heat source. This potential $\therefore \because$, however, low because of the low speciflc power of about 0.1 watt per i) ram which is below that of even the lowest among the more conventional $\therefore \ldots$ alies, such as Cs-137. However, the power density of Am-241 (watts fies cubic centimeter) is about the same as that of strontium titanate. At though its present cost puts it far more expensive per watt than today's L... costly material (Pu-238 at $\$ 2000$ per thermal watt), Am-24l may eventually ... ome a falrly cheap by-product of large scale recycle plutonium processing. this reason it should not be completely discounted. It 1s, of course, .... Larget material for the preparation of $\mathrm{Cm}-242$ and also Pu-238 $\mathrm{vla}$ the $\therefore$ ucess based on the decay of $\mathrm{cm}-242$.

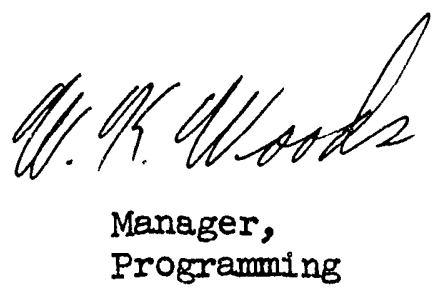

WK Woods: jm 
RADIATION PROTECTION OPERATION

REPORT FOR THE MONTH OF APRIL 1963

\section{A. ORGANIZATION AND PERSONNEL}

Allen R. Mak1 transferred from Environmental Studies and Evaluation to Radiation Monitoring. Robert J. Beaver transferred from Radiation MonitorIng to Environmental Studies and Evaluation. Louise $E$. Nunn accepted a temporary assignment with Radiological Development and Calibrations. Mable H. Davis trensferred from Internal Dosimetry to the Physics and Instrument Laboratory. Joy B. Knight transferred from Construction Engineering and Utilities to Internal Dosimetry.

\section{B. ACTIVITIES}

\section{Occupational Exposure Experience}

An IPD maintenance man received a whole body exposure of $5 \mathrm{r}$ gamma on April 17, 1963, while removing a gunbarrel from the rear face of the 105-B reactor. The reactor was shut down to discharge a ruptured fuel element. During the operation, a gunbarrel fell free, exposing the employee to a high dose rate. Inspection of the gunbarrel under water indicated the presence of at least a portion of the ruptured fuel element in the end of the gunbarrel. This incident was formally investigated.

There were no new plutonium deposition cases confirmed during the month. The total number of deposition cases that have occurred at Hanford is 316 of which 229 are currently employed.

Ten plutonium incidents required special bioassay sampling of personnel involved to determine if internal deposition occurred. The following is a brief description of the more significant incidents. Bioassay results are now pending.

Three CPD operators were exposed to high airborne contamination in the 234-5 Building on April 12, 1963, when a fire occurred in the \#2 furnace vessel. The fire burned two hood sloves permitting release of plutonium contamination to the room. The two employees in the room at the time immediately sounded the alarm and within ten seconds put on respiratory protection. A third employee, hearing the alarm, put on respiratory protection and entered the room to assist. As a result of the fire, contamination up to $40,000 \mathrm{~d} / \mathrm{m}$ was found around the hood and the air sample filters initially read $40,000 \mathrm{~d} / \mathrm{m}$ as measured by a Juno. Nasal smears of the three employees involved ranged from $8 \mathrm{~d} / \mathrm{m}$ to $284 \mathrm{~d} / \mathrm{m}$. 
An HL operator, while performing an operation in Cell 4 of the 231 Buildint, received a plutonium contaminated injury. While handling a piece of bare plutonium he received a cut through the hood and surgeon gloves. Examination at the plutonium wound counter revealed the presence of $3.1 \times 10^{-3} \mu \mathrm{c}$ plitonium and after excision $2.4 \times 10^{-3} \mathrm{\mu c}$ plutonium remained in the wound. No DTPA treatment was given.

An HL operator received a plutonium contaminated infury at the 308 Building on April 30, 1963, while working with plutonium oxide in a hood. The initial plutonium wound count indicated the presence of $1.9 \times 10^{-3} \mathrm{HC}$ plutonium in the wound. An industrial physician scrubbed the wound in an atr.s.mpt to reduce the contamination. A recount at the plutonium wound counte indicated approximately $1.7 \times 10^{-3} \mathrm{\mu c}$ remained in the wound. No excision was performed.

Several other incidents of significance not involving plutonium include the following:

Six HL employees were exposed to airborne $I^{131}$ while working at the 144-F Building on April 1, 1963. The employees were performing inhalation studies with $I^{13} I$ on four dogs. They were generating the aerosol composed of $100 \mu \mathrm{c}$ of $I^{131}$ and 4 grams of elemental lodine in a chamber. While performing the operation, they noticed lodine vapors escaping from the generator and immediately put on fresh air respiratory equipment. Examination at the whole body counter revealed the presence of $I^{13} \mathrm{I}$ in the thyroids of the six individuals ranging from $8 \times 10^{-5} \mu \mathrm{c}$ to $6 \times 10^{-4} \mu \mathrm{c}$. The MPBB for $I$ l 31 in thyroid is $0.7 \mu \mathrm{C}$.

An IPD fuels maintenance employee who works in the 303 Area discovered four leather gloves in his lunch box when he arrived home Friday evening, April 12, 1963. He placed them in a sack and washed out his lunch box before entering his home. He returned the gloves to security that evening. On Monday, April 15, 1963, the gloves were surveyed by HL monitoring personnel. Contamination of $50,000 \mathrm{~d} / \mathrm{m}$ and $1,000 \mathrm{c} / \mathrm{m}$ (probably uranium) was found on the gloves.

Autoradiographic examination of a contaminated section of a pair of trousers worn by a CPD employee on April 3, 1963, at the 202-A Building indicated a dose of 40 rads beta and $0.3 \mathrm{r}$ gamma to a localized skin area (approximately 5 square centimeters). Apparently some contaminated liquid splattered on the employee's left trouser leg while he was holding the plastic bag containing a process sample.

An HL operator received a localized exposure of 5 rems to the hand when he removed autoradiograph glass and tray from A Cell in the 327 Building on April 19, 1963, without benefit of monitoring. The initial 
TECHNICAL ADMINISTRATION

Employee Relations

Ore hundred and sixty-three Tuition Refund payments were processed.

Thirty nonexempt requisitions were filled during the month; 34 remain to be filled.

Suggestion pian activity showed 52 suggestions received, 55 adopted, 24 rejected and 147 in process at month end. Notable was a 15\% decrease from March in the number of suggestions remaining in process at month end.

\section{Information and Presentations}

The story behind the CSREX process - the recovery of Cesium, Cerium, Stront1um and Rare Earths from waste solutions - wlll be released to the business and technical press early in May.

V1sitors Center activity is surmarized below:
Apr11 attendance
1822
Average attendance per day open
Cumulative attendance since 6-13-62
86
Conducted sroups
19 (totaling 746 people)

Document Information flow during the month was comprised of 1,794 titles (12,375 coples) recelved at Hanford and 58 titles (5,351 copies) sent offsite.

A classification document containing guidance on tritlum was prepared and distributed.

Proposed changes in the classification of relative neutron spectra and relative neutron distribution in Hanford Production Reactors were submitted to the RLOO classification officer.

Plant tour activity:

Mumber Total People

General Public Relations Tours

$\begin{array}{rr}14 & 407 \\ 9 & 148\end{array}$

Special Tours

$9 \quad 148$ 


\section{Professional Placement}

Advanced Degree - Fifteen $\mathrm{Ph} . \mathrm{D}$. appiicants visited HAPO for employment interviews. Six offers were extended; four rejections were recelved. Nine offers are currentiy open.

BS/MS (Direct Placement) - Seventeen offers were extended. Eight acceptances and six rejections were received. Fifteen offers are currentiy open.

BS/MS (Program) - Flfty-nine offers were extended. Thirty-five acceptances and 87 rejections were received. Current open offers total 99.

Technical Graduate Program - Seven Technlcal Graduates were placed on permanent assignment. Six new members were added to the roll. Current Program members total 40 .

\section{FACILITIES ENGINEERING}

\section{Frojects}

At month's end Facilities Engineering Operation was responsible for elght. active projects having total authorized funds in the amount of $\$ 6,260,500$. The total estimated cost of these projects is $\$ 7,595,000$. Expenditures through March 31, 1963 were $\$ 571,000$.

The following summarizes project activity in ApriI:

Number of authorized projects at montr end

Number of new projects authorized

Projects compieted - 1

CAH-936 - Cooliant Systems Development Laboratory, 1706-KE Bullaing Addition

New projects submitted to the AEC CAH-100 - High Temperature Lattice Test Reactor

Projects awalting AEC approval -

CAH-985 - Addition to the 222-U Building

CAH-986 - 300 Area Retention Waste System Expansion

CAH-100 - High Temperature Lattice Test Reactor

Project proposals complete or nearing completion -..........- 3

CAH-999 - Pu Recycie Critical Facility Conversion to Iight Water

PRTR Storage Basin and Experimental Facilities Modifications

Heat Transfer Apparatus for Model Studies 
The current status of projects authorized or awaiting approval is:

CAH-916 - Fuels Recycle P1lot Plant - Construction bids were opened on April 10, 1963. The low bid was $\$ 4,448,000$ by Halvorsen Construction Company. The Government fair cost estimate was $\$ 4,075,000$. The additional required funds have been made available and will be held in reserve by Washington-AEC until needed. It now appears that the construction contract will be awarded early in May.

CAH-922 - Burst Test Facility for Irradiated Zirconium Tubes - The Commission requested the RLOO-AEC construction service contractor to submit on estimate of cost for performance of total construction of this project based on subcontracting as much of the work as is reasonable to a fixed-price contractor. A coffer dam for the wet storage basin is being built by the J.A. Jones shops. Work has been completed on the concrete loading dock, reinstalling the dock roof, backfilling the process sewer line and stainless steel crib waste drain line. Procurement by the General Electric Company is continuing.

CAll-958 - Plutonium Fuels Testing and Evaluation Laboratories - 308 Building A directive was issued on April 9, 1963, extending the directive completion date to October 15, 1963. A revised work authority authorized the Company funds to perform Title III services and to procure the metallograph. J. A. Jones Company is to perform the construction work upon authorization by the Commission.

CAH-962 - Low Level Radiochemistry Building - Commission and Company representatives visited the Architect-Engineer's offices in Seattle to review early preliminary design concepts. Serreral important deslgn features affecting costs were evaluated.

CAH-977 - Facilities for Radioactive Inhalation Studies - Design of this project has been awarded to Gray and Osborne Consuiting Engineers of Yakima, Washington.

CAH-982 - Addition to the Radionuclide Facilities - 141-C Building - The design criteria and scope drawings were transmitted to the Commission on April 24, 1963 for approvel.

CAH-985 - Addition to the 222-U Bullding - The Commission has taken no further action on this project. The date of authorization will depend on the availability of FY 1963 General Plant Project funds later this fiscal year.

CAH-986 - 300 Area Retention Waste System Expansion - No further word has been recelved from the Comission since added information was provided by the Company. 
CGi-0)2 - Additional Fuel Loading Equipment - 308 Building - A modification to the directive authorized the Company total project funds in the amount of $\$ 165,000$. Equipment relocation has been completed, excavation for the pit has been started, and procurement is continuing.

CAH-995 - 309 Building Air Conditioning Modifications - Design is approximately 70 percent complete. Purchase orders for all. major pieces of eng1neered equipment have been placed. Bids on the water chiller are being reviewed.

CAli-999 - Plutonium Recycle Critical Facility Conversion to Light Water The project proposal is awaiting approval by the HAPO General Manager.

CAH-100 - High Temperature Lattice Test Reactor - The project proposal was transmitted to the Commission on April 18, 1963.

\section{Engineering Services}

Engineering service work was provided to research and development personnel as requested. Specific jobs in progress are: (1) design and fabrication assistance on the C-I Loop, (2) preliminary design of PRCF conversion to light water, and (3) design assistance on the 314 bullding pressure bonding autoclave.

\section{Pressure Systems}

Engineering reviews and surveillance of pressure systems continued. The piping systems in 325 and 329 buildings are being audited for code conformance. The breathing air system in 141-C was reviewed and operating procedures recommended. A review was made of the AEC directive for marking of piping for nuclear systems.

\section{Plant Engineering}

Consulting service was provided to maintenance and operating forces. Spec1fic jobs active during the month were: (1) review of alr flow patterns and static pressures in 325-A and consultation with radiation protection personnel, (2) completion of installation and test of double filter boxes at 325-A, (3) completion of design and investigative work for repair of 308 condensate and steam piping, (4) Investigation and start of design for equipment for remote filter handing for 327 bullding, (5) design of a diesel generator unit for third electrical system for emergency operation of one 325 bullding exhaust fan, (6) modification of 326 building electrical equipment to eliminate undercapacity, (7) power usage forecast for FY 1964, and (8) design for repair of Rattlesnake Springs dams. 
Major items of trouble shooting during the month involved: (1) failure of the emergency fan switchgear in 325 building, (2) fallure of a 20-T air conditioning unit in 326 building, (3) review of the process sewer overflow in 306 building, and (4) review of noise problem in 325 building.

\section{Facilities Operation}

Landlord costs for March were $\$ 201,266$, which is 115 percent of the forecast for the month. The total cost to date for the first three quarters is $\$ 1,492,095$, which is 97 percent of the predicted. During this month, improvement maintenance was $\$ 40,893$ as compared with $\$ 15,000$ forecast. Steam cost was $\$ 37,924$ as compared with $\$ 35,000$ predicted. Englneering at $\$ 26,483$ continued well above the anticipated $\$ 14,000$. Improvement maintenance commitments as of mld April were such that no further 1mprovement work was scheduled for this fiscal year. Bxpenditure forecasts indicate budgeted funds probably will be adequate.

The following tabulation sumarizes waste disposal operation:

\begin{tabular}{lrr} 
& February & March \\
\cline { 3 - 3 } & & \\
Concrete barrels disposed & 20 & 12 \\
Crib waste gallons & 220000 & 220000 \\
Loaduggers of dry waste & 29 & 28
\end{tabular}

The \#I trench at 216 BC 1 s almost full and the \#2 trench 1 s about ready for use.

AIl analytical work is performed at PRIR water laboratory. The conflrmatory determinations made by 329 bullding analytical have been discontinued.

Physical testing on waste trailer \#89 reveals it is in good condition.

An unscheduled electrical outage in 325 building on Apr1l 8 revealed weaknesses in the transfer clrcultry which have been corrected.

Preparations have been under way for a complete ventilation outage the weekend of May 3. Access panels have been installed, and utility lines installed to provide steam and emergency power at the exhaust, plenum and fans. Plans have been developed integrating the activities of Safety, Radiation Monitoring, IPD and Hanford Laboratorfes Maintenance, Wiste DIsposal and Decontamination, Bullding Operation and Facilities Englneering personnel as well as those of bullaing occupants. 


\section{Drafting}

The equivalent of 119 drawlings were completed during the month for an average of 28 man-hours per drawing.

Major jobs in progress are: (1) PRIR as-builts, (2) FRIR shim rod control, (3) PRIR cladding cutter assembly, (4) PRIR process tube and fuel handling carriage, (5) 108-F inhalation studies hood, (6) equipment for salt-cycle process - 325-A, (7) as-built drawings - control panel critical mass lab, (8) vacuum welder - 306, (9) fuel element molds - 306, and (10) scope design of fast super critical pressure power reactor.

Bovay Engineers performed 69 man-hours of work during the month and were assigned 149 man-hours. No work was assigned or performed by CE\&UO.

\section{Construction Supervision}

Activity during the month on construction work (J.A. Jones Company) being performed for Hanford Laboratories components is given below:

\begin{tabular}{|c|c|c|}
\hline & $\begin{array}{l}\text { Unexpended } \\
\text { Belance }\end{array}$ & $\begin{array}{l}\text { Waste } \\
\text { Calcination } \\
\text { (Job 7005) }\end{array}$ \\
\hline $\begin{array}{l}\text { Orders outstanding beginning of month } \\
\text { Issued during the month (ine. suppl. } \\
\text { and adj.) }\end{array}$ & $\begin{array}{l}\$ 151100 \\
272350\end{array}$ & $\$ 275400$ \\
\hline $\begin{array}{l}\text { J. A. Jones expenditures during month } \\
\text { (Incl. C.O. costs) } \\
\text { Belance at month's end } \\
\text { Orders closed during month }\end{array}$ & $\begin{array}{l}129800 \\
293650 \\
100000\end{array}$ & $\begin{array}{r}51700 \\
223750\end{array}$ \\
\hline
\end{tabular}

In addition, work on four maintenance work orders having a total face value of $\$ 6,716$, issued to plant forces, was supervised.

Major nonproject jobs in progress are: (1) crane safety inspection, (2) $108-F$ plant growth room, (3) 108-F rooms 402 and 403, (4) $108-F$ room 405 , (5) $216 \mathrm{BC}$ new waste crib, (6) $231-\mathrm{z}$ Intercommunications system, (7) 306 canning line lighting, (8) 306 and 3746 - remove and replace roofs, (9) 309 - Install gas loop heater, (10) 309 radiation shielding, (II) 309 annunciator system, (12) 309 concrete slab and equipment, (13) 309 piping, valves and electrical work, (14) 309 electrical cable to pole \#16, (15) 309 emergency pump low speed controllers, (16) 314 mock-up equipment, (17) 321 hatchway in canyon roof, (18) 321 control room, (19) $325 \mathrm{~s} / \mathrm{s}$ exhaust duct and filter boxes, (20) 325 exterior staimway to roof, (21) 325 rooms 407 and 407-A, (22) 325-A double f1lter boxes, (23) 326 duct work, (24) 327 demineralizer, (25) 329 laboratory ll-B, (26) 340 filter, (27) 3706 partitions and lighting, (28) 325 blower, and (29) 3718-A \& B heavy duty racks and pallets. 
Six purchase requisitions totaling $\$ 19,000$ were issued during the month. Total value of equipment being processed is $\$ 110,000$. New or revised M \& E lists were 1ssued for Waste Calcination, Project CAH-922, CGH-992, and CGH-995.

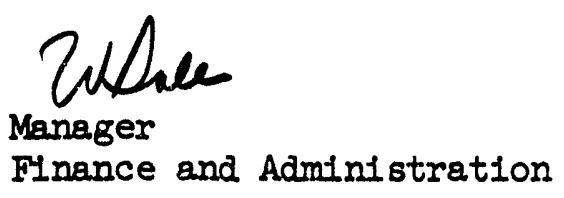

W Sale:whm 
O4 PROGRAM - REACTOR DEVELOPMENT

\section{PLUTONIUM RECYCIE PROGRAM}

Plutonium Recycle Test Reactor

\section{Operation}

Reactor output for April was 545 MWD, for an experimental time efficiency of $49 \%$ and a plant efficiency of $31.3 \%$. There were two operating periods, both of which were terminated manually; one was a scheduled shutdown for fuel transfers and the other was due to "leaker" indication of fuel element 5174 .

The core loading on April 1 consisted of $19 \mathrm{VO}$ elements, $22 \mathrm{Pu}-\mathrm{Al}$ elements and $44 \mathrm{mixed-oxide}$ elements. At the end of the month, the core consisted of $19 \mathrm{UO}_{2}$ elements, $14 \mathrm{Pu}-\mathrm{Al}$ elements and 52 mixed-oxide elements.

Fuel exposure history at month-end was:
Maximum $\mathrm{UO}_{2}$ exposure/element
$3166 \mathrm{MWD} / \mathrm{TU}$
Average $\mathrm{UO}_{2}$ exposure/element
$2162 \mathrm{MWD} / \mathrm{TU}$
Maximum Pu-Al exposure/element
81.5 MWD
Average Pu-Al exposure/element
63.3 MWD
Maximum Moxtyl exposure/element
$55.6 \mathrm{MWD}(\sim 1112 \mathrm{MWD} / \mathrm{TU})$
Average Moxtyl exposure/element
$32.2 \mathrm{MWD}(\sim 6 \mathrm{ik}, \mathrm{MWD} / \mathrm{TU})$

The status of the varlous test elements on April 30, 1963, 1s shown below. Those test elements which had reached their assigned goal exposure or had been permanently discharged for other reasons prior to April 1, 1963, have been deleted from this table. 


\begin{tabular}{|c|c|c|c|c|c|c|}
\hline $\begin{array}{l}\text { PRTR } \\
\text { Test } \\
\text { No. } \\
\end{array}$ & $\begin{array}{l}\text { Channe I } \\
\text { Iocation }\end{array}$ & $\begin{array}{l}\text { Fuel } \\
\text { Element } \\
\text { Number }\end{array}$ & Description & $\begin{array}{l}\text { Date } \\
\text { Initial } \\
\text { Charge } \\
\end{array}$ & $\begin{array}{l}\text { Date Dis - } \\
\text { Charged }\end{array}$ & $\begin{array}{l}\text { Approximate } \\
\text { - Accumliated } \\
\text { MWD } \\
\end{array}$ \\
\hline 10 & Basin & 1082 & $\mathrm{JO}_{2}$-Hot Swage & $11 / 3 / 61$ & $3 / 26 / 63$ & Defer.t. \\
\hline 10 & Basin & 1067 & $\mathrm{UO}_{2}{ }^{2}-\mathrm{Vipac}_{1}$ & $11 / 3 / 61$ & $3 / 26 / 63$ & \\
\hline 13 & Basin & 5094 & Pu-AI Physicis & $12 / 3 / 63$ & $4 / 5 / 63$ & 5 at gos \\
\hline 24 & 1956 & 5097 & Moxtyl-Swaged & $4 / 2 / 62$ & - & repad 27 \\
\hline if & 1356 & 5098 & Moxtyl-VIpac & $5 / 8 / 6$ & .. & repad 5 \\
\hline 14 & 1758 & 5099 & Moxtyl-Vipac & $5 / 8 / 62$ & -- & repad 50 \\
\hline $3 ?$ & $1+49$ & 1096 & $\mathrm{UO}_{2}-\mathrm{Phys} \pm \mathrm{cs}$ & $5 / 12 / 62$ & -- & 60 \\
\hline 37 & 1649 & 1097 & $\mathrm{UO}_{2}$-Physics & $5 / 12 /$ & -- & \\
\hline 37 & 1552 & 1098 & $10_{2}-$ Physics & $5 / 12 /$ & -- & \\
\hline 37 & 1548 & 1099 & $\mathrm{UO}_{2}^{-}$-Physice & $5 / 1$ & - & \\
\hline 37 & 1651 & 1100 & $\mathrm{UO}_{2}$-Physics & $5 / 12 /$ & -- & 49 \\
\hline 48 & 1243 & 5150 & Moxtyl ( $\frac{1}{2} " x \frac{1}{2} "$ pads) & $8 / 1 / 62$ & -- & \\
\hline 54 & 1948 & 5116 & Moxtyl (Elip-on pads) & $5 / 8 / 62$ & & $49.2(33.7 \mathrm{w} / \mathrm{clip})$ \\
\hline 54 & Rasin & 5117 & Moxtyl (clip-on pads & $5 / 8 / 62$ & $4 / 16 / 63$ & $x \in I^{e} \in \mathrm{ct}$ \\
\hline 54 & 1459 & 5118 & Moxtyl (clip-on pads) & $5 / 8 / 62$ & & $53.4(38.4 \mathrm{w} / \mathrm{clip})$ \\
\hline 61 & Basin & 5174 & Moxtyl-Physics & $4 / 5 /$ & $4 / 15 / 63$ & efeet \\
\hline & 1756 & 5176 & Moxtyl-Physics & $4 / 5 / 63$ & -- & .0 \\
\hline
\end{tabular}

A fuel element failure was detected on April 14 and the reactor was shut down. Stagnant water tests determined the defective element to be FE-5174, an Instrumented moxtyl element for physics studies.

The firet element containing recycled plutonium was charged.

$\mathrm{D}_{2} \mathrm{O}$ and indicated helium losses for the month were 1,594 pounds and 103,343 scf, respectively. We shipped 16,556 \# of degraded $D_{2} 0$ to Savannah RIver for upgrading.

\section{Equipment Experience}

A total of 270 hours were charged to repalr work. The containnent bellows on the steam export line was replaced and accounted for 248 hours. Seam welds on the old bellows had falled on several occasions over the past few months makirg ite integrity doubtful. The replacement bellows is a rolled-type with only two seam welds where the old one was an accordion type with welds at each valley and crest.

With the exception of some angle valve packing, the balance of all blue African type material was removed from the primary system and replaced with Canadian white asbestos. The blue African material was not standing up under primary system temperature and pressure and was "washing out" of the flexitallic gaskets. To make the replacements it was necessary to discharge the reactor and drain the primary system. 
Preventive maintenance required 401 hours, or $8 \%$ of the total maintenance effort.

Improvement Work Status (Significant Items)

Work Completed

Enlarge Chemical Feed System

Interlock Between Fuellng Vehicle Shroud Seat and Holst

Fueling Vehicle Modification to Hoist

PSCD Containment Piping for Experimental Cell

Modify Inlet Jumpers on Tubes 1546 and 1548

Work Partially Completed

Inline Gas Sampling

Process Tubes Level Indicator

Primary Loop Drain and Flush Valve Modifications

Independent Criticality Alar:a System of the PRIR Control Room

Shim Rod Rotameter Modification

Recorder Armeter Installation for Primary Pumps

Inlet Gas Sevi Replacement

Design Work Completed

Compressed Air Supply Revision

Effluent Activity Monitor Replacement

Backup Bmergency Pump Low Speed Controllers

E-7 Replacement

Pressurizer to Stack Valve Relocation

Actuator with Hydraulic Snubber for Bottom Blow-Down Line

Deionized Water System

Flash Tank Modification

Gamma Scanner Installation

Design Work Partialiy Completed

Control Wiring for $13.8 \mathrm{kV}$ Motor Operated Switches

Additional Fuel Storage and Bxamination

Vibration Snubbers for Earthquake Protection

PRCF Light Water Conversion

Control Room and Instrument Calibration Shop Alr Conditioning

Process Engineering and Reactor Physics

PRIR Test 62 was prepared to measure the reactivity changes assoclated with changes in the temperature of the moderator plus reflector and the fuel plus coolant. These measurements w1Il be performed during a number of normal cold startups after the fuel loading has been converted to essentially: an all oxide core. 
Four sections wexe tiken from selected process tubes to perform elevated temperature burst tes is at the Radiometallurgy Laboratory. They represented reutron exposures from 7.3 MWD to 76.5 MWD.

The containment valve test was completea and leakage through valves $W-44$ and S.29 was found to be small. There was no water hammer in the second2ry coolant system because of the slow closing of Valve S-29. The final report on the test has been written.

During the April 15, 1963, stagnant water test, bolling around the fuel EI ment forced the coolant out of the tube after forty minutes stagnation time. To prevent the recurrence of bolling during future stagnation test. , worls $i$ is being done to improve the accuracy of calculations for the time to boiling.

The study of the pitting corrosion attack in the deadlegs and intermediate use sections of the ligit water systems continued during the month. Extensive attack was found in the water supply line to the water softener brine tank. This line has since been replaced and an isolation valve. installed to minimize future attack. Provisions were made for radiography of critical deadlegs and low flow sections located in the containment vessel.

An snalysis and report on the secondary coolant activity monitor were completed. Feasibility of the system to locate a 10 gpd leak in the primary coolant heat exchangers depends upon the presence of fission products in the coolart. Without fission products, the instrument would not detect leakage Irom the primary system.

\section{Procedures}

Revised Operating Proseiures Issued

Revised Operatine Standards issued

Temporary Deviations to Operating Standards Issued

Revised Prosess Specif:cations accepted for use

Mainteriance Manuals and Procedures Issued

Drawing As-Built Status:

\begin{tabular}{|c|c|}
\hline ApriI & Total \\
\hline \multirow[t]{10}{*}{17} & 954 \\
\hline & $40^{5}$ \\
\hline & $\frac{79}{078}$ \\
\hline & $\begin{array}{r}1078 \\
382 \\
\end{array}$ \\
\hline & \\
\hline & Manhours \\
\hline & $\begin{array}{l}300 \\
100\end{array}$ \\
\hline & $\begin{array}{r}199 \\
23\end{array}$ \\
\hline & 91 \\
\hline & \\
\hline
\end{tabular}

Approved for As-Built

Ready for Approval

In Drafting

Voİ $\in$ a

Scheduled for Review

Personnel Training:

Qualification Subjects

Specifications, Standards, Procedures

4

2

4

1

Emergency Procedures

Maintenance Procedures 
Status of Qualified Personnel at Month-Find:

Qualified. Reactor Engineers

Qualifled Technicians

Qualified Technologists

Provisionally Qualified Technologists

Plutonium Recycle Critical Facility

Plutonium Recycle Critical Facility startup tests were continued. Twelve days of critical testing and eight days of subcritical testing were realized. Efforts to achieve minimum safety rod worths occupied the major portion of the month.

Repairs were completed to the chemical pump this month. Water had entered the pump (canned type) when the cell was inadvertently flooded. A new stater and bushings were required.

The PRCF Design Scope for Light Water Conversion, HW-76941, was approved and issued:

Reactor kinetic studies of HBWR core: were performed.

One revised Process Specification was accepted.

Fuel Element Rupture Test Fecility (Project CAH-867)

Project Status

Fuel Element Rupture Test Facility Discharge Method, HW-T7117, was issued. Work status of major elements of work follows:

Sampling System - 90\% complete

Leakage Collection System - 60\% complete

Shielding Installation - complete

Revised Rellef Systems - complete

Activation of Spare PSCD line - complete

B Cell Test Section Installation - 30\% complete

Chemical Handling Slab - 75\% complete

Operation

Five ex-reactor operating tests were completed during April. Forty hours were devoted to training. 


\section{GAS COOLED POWER REACTOR PROGRAM}

\section{Pressurized Gas-Cooled Loop Fracility (Project CAH-822)}

\section{Project Status}

The cas 100p was operated at a test section inlet temperature of $1400 \mathrm{~F}$ during the month. The main gas-bearing blower was run continuously for approximately thirty hours at conditions of 150 psig, $450 \mathrm{~F}$, and 6,000 rpin. Calculated flow rate was 4300 pounds per hour of carbon dioxide which agrees closely with the blower curves. Blower performance was stable throughout the run. The heater, which is of unusual design, performed fully within expectations. The annulus helium coolant system performed as designed, the helium blower operating automatically approximately 36 hours with a continuous output of 300 scfm.

Delivery and installation of the main blowers are scheduled for next month.

\section{Operation}

Operational funds for the gas loop were curtailed during April; consequently, s sign testing has been halted, and only those operations of an acceptance

est nature are in progress.

\section{TECHNICAI, SHOPS OPERATION}

Total productive time for the period was 27,033 hours. This includes 15,245 hours performed in Technical Shops, 8,641 hours assigned to Minor Construction, 3,109 hours assigned to off-site vendors, and 38 hours to other project shops. Total shop backlog is 26,978 hours, of which $70 \%$ is required in the current month with the remainder distributed over a three-month period. Overtime worked during the month totaled 1,335 hours or $5.5 \%$ of the total availuble hours.

Distribution of time was as follows:

N-Reactor Department

Irradiation Processing Department

Chemical Processing Department

Hanford Laboratories

Construction Engineering \& Utilities Operation

\section{Man-Hours of Total}

$\begin{array}{rr}2864 & 10.59 \\ 4043 & 14.96 \\ 354 & 1.31 \\ 19772 & 73.14 \\ 0 & 0\end{array} \frac{-}{100.00}$

Requests for emergency service decreased slightly requiring an overtime ratio of $5.5 \%$ versus $6.2 \%$ for the previous month. 


\section{IABORATORY MAINTLENANCE OPERATION}

Total productive time was 17,400 hours of a possible 19,200 hours potentially available. Of the total productive time realized, $87.5 \%$ was expended in support of Hanford Iaboratories comonents with the remaining $12.5 \%$ directed toward providing service for other HAPO organizations. Overtime worked during the month was $1.8 \%$ of total avallable hours.

Manpower utilization for April is summarized below:
A. Shop Work
B. Maintenance
1. Preventive Maintenance
2. Mmergency or Unscheduled Maintenance
3. Normal Scheduled Maintenance
4. Overtime (Inc uded in Figures Above)
C. R\&ed Assistance

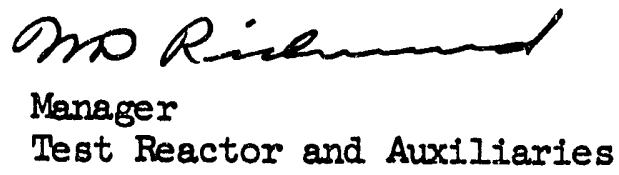

WD Richmond:JGZ :bk 


\section{INVENTIONS OR DISCOVERIES}

All persons engaged in work that might reasonably be expected to result in inventions or discoveries advise that, to the best of their knowledge and belief: no inventions or discoveries were made in the course of their work during the period covered by this report except as listed below. Such persons further advise that, for the period therin covered by this report, notebook records, if any, kept in the course of their work have been examined for possible inventions or discoveries.

INVENTOR

H. J. Anderson

\section{TITLE OF INVENTION OR DISCOVERY}

Method of Preparing High Density Plutonium Dioxide and Plutonium Dioxide-Uranium Dioxide by Arc Melting. HW-77307

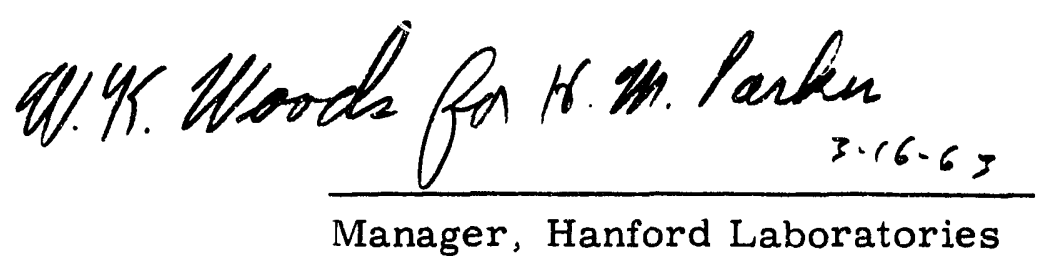



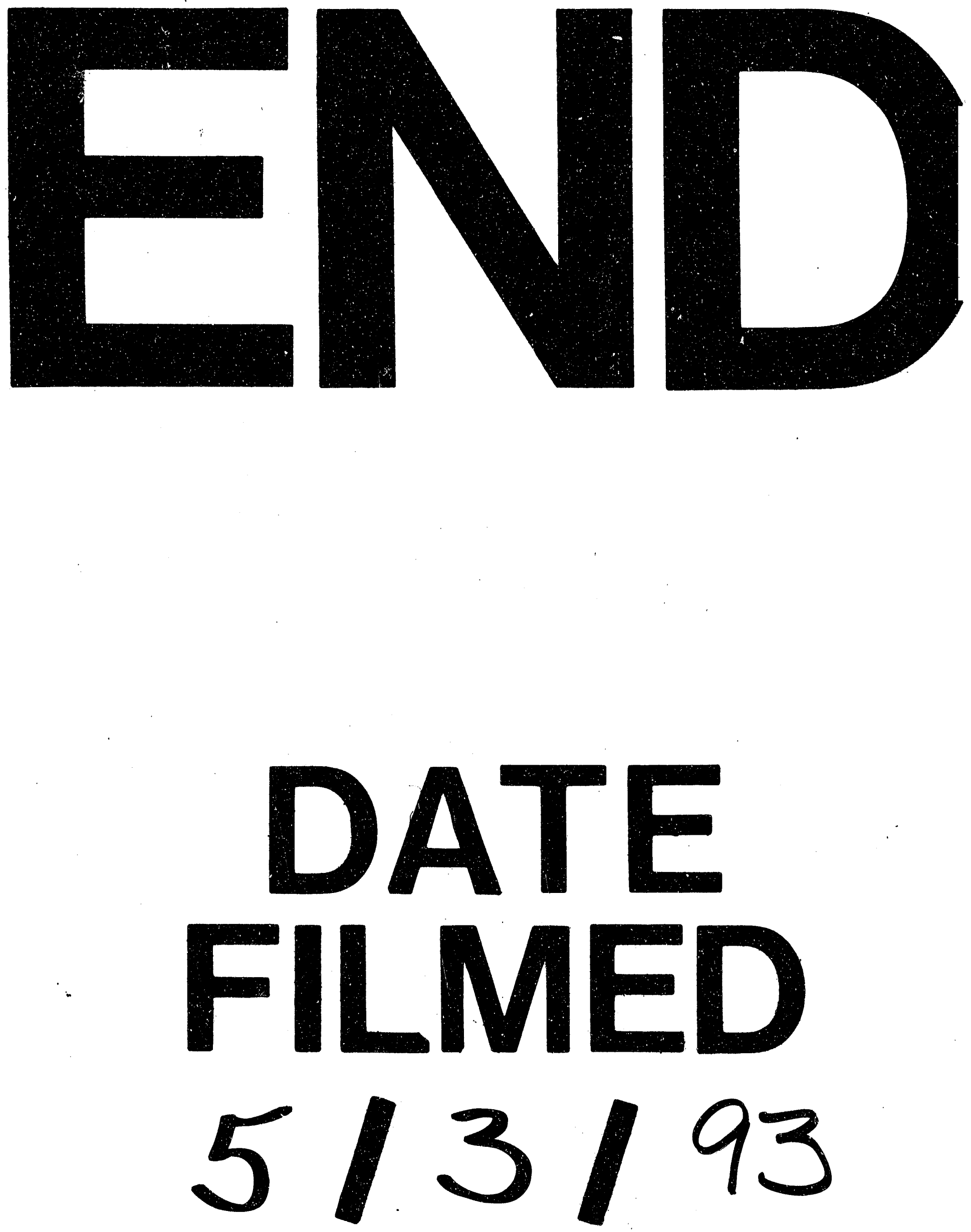
